\title{
WestVirginiaUniversity
}

THE RESEARCH REPOSITORY @ WVU

Graduate Theses, Dissertations, and Problem Reports

2001

\section{Moisture diffusion through vinyl ester/clay nanocomposites}

Apoorva Paresh Shah

West Virginia University

Follow this and additional works at: https://researchrepository.wvu.edu/etd

\section{Recommended Citation}

Shah, Apoorva Paresh, "Moisture diffusion through vinyl ester/clay nanocomposites" (2001). Graduate Theses, Dissertations, and Problem Reports. 1206.

https://researchrepository.wvu.edu/etd/1206

This Thesis is protected by copyright and/or related rights. It has been brought to you by the The Research Repository @ WVU with permission from the rights-holder(s). You are free to use this Thesis in any way that is permitted by the copyright and related rights legislation that applies to your use. For other uses you must obtain permission from the rights-holder(s) directly, unless additional rights are indicated by a Creative Commons license in the record and/ or on the work itself. This Thesis has been accepted for inclusion in WVU Graduate Theses, Dissertations, and Problem Reports collection by an authorized administrator of The Research Repository @ WVU. For more information, please contact researchrepository@mail.wvu.edu. 


\title{
Moisture Diffusion through Vinyl Ester/Clay Nanocomposites
}

\author{
Apoorva P. Shah \\ Thesis submitted to the College of Engineering and Mineral Resources at \\ West Virginia University \\ in partial fulfillment of the requirements \\ for the degree of \\ Master of Science \\ in \\ Chemical Engineering \\ Rakesh K. Gupta, Ph.D., Chair \\ Hota V. S. GangaRao, Ph.D. \\ Joseph A. Shaeiwitz, Ph.D. \\ Department of Chemical Engineering \\ Morgantown, West Virginia \\ 2001 \\ Keywords: Vinyl ester, moisture diffusion, nanocomposites, nanoclays, \\ Montmorillonite, Permeability \\ Copyright 2001 Apoorva P. Shah
}




\title{
ABSTRACT \\ Moisture Diffusion through Vinyl Ester/Clay Nanocomposites
}

\author{
Apoorva P. Shah
}

Moisture diffusion was studied through vinyl ester samples containing up to $5 \mathrm{wt} \%$ montmorillonite clay; two different kinds of clay surface treatments were employed to make the clay compatible with the vinyl ester resin. These nanocomposites were characterized using differential scanning calorimetry (DSC), mechanical property measurements, x-ray diffraction (XRD) and transmission electron microscopy (TEM). TEM pictures showed that the clay platelets were either exfoliated or intercalated, and the two different surface treatments resulted in different dispersion characteristics. All the samples were post cured, and the diffusivity of moisture was measured by soaking the samples in water at $25{ }^{\circ} \mathrm{C}$ and noting the increase in weight with increasing time of immersion. It was found that water diffusivity and resin permeability decreased with increasing clay content. Diffusivity was reduced to half its value in the neat resin when the clay content was only $1 \mathrm{wt} \%$, regardless of the nature of clay surface treatment. However, the equilibrium moisture content, the glass transition temperature, and the elastic modulus all increased with increasing amounts of clay. 


\section{ACKNOWLEDGEMENTS}

I would like to thank first of all, my parents and family for their support and blessing throughout my education. I also express my sincere gratitude to Harakh masa and Anuja masi for all their support and help during my stay in Morgantown.

I'm greatly indebted to my advisor Dr. Rakesh Gupta, for giving me the opportunity to work under him and for all his invaluable guidance and advice, not only in my research, but also my entire graduate education. I am also thankful for the financial assistance he gave me at the end of my study. I am also grateful to Dr. Hota GangaRao and Dr. Joseph Shaeiwitz for their valuable suggestions, recommendations and comments that have gone towards shaping my research. All the advice and suggestions were very much appreciated.

I would like to express my special gratitude to Dr. Clois (Bert) E. Powell, Senior Scientist, Southern Clay Products, Inc, Texas for sharing his valuable insights and experience in nanoclay technology with me, and helping me out in my research. A big thanks to Southern Clay Products Inc., for promptly performing the all XRD tests on my nanocomposite samples. I am thankful to Dr. Eung H. Cho, Dr. John Zondlo and Dr. Edwin Kugler for allowing me to use their facilities for performing my tests. I am particularly grateful to Dr. Cho for helping me out with the ball mill experiments. My heart felt thanks to Ms. Marylin Howton, Dept. of Pathology, WVU for her immense help in promptly doing the TEM work, in spite of all her other commitments. 
I also sincerely thank Jim Hall for patiently listening to all my requests and helping me out with the molds and design of experiments. Jim is truly an exceptional person.

Last but not the least, I thank my friends Mahesh Iyer, Dr. Ruifeng Liang, Dr. Lawrence Norcio, Manish Bhole and Hari Prashanth for all the little things they have done for me during my stay here.

I would also like to thank the US Department of Transportation and the Federal Highway Administration for the funding for this project.

Thank you all! 


\section{DEDICATION}

To my beloved parents and family.... 


\section{TABLE OF CONTENTS}

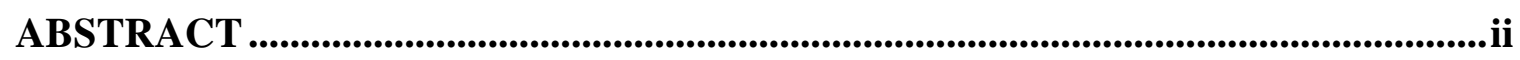

ACKNOWLEDGEMENTS.........................................................................................iii

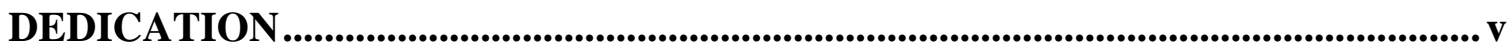

TABLE OF CONTENTS.......................................................................................... vi

LIST OF FIGURES

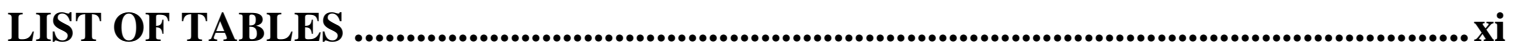

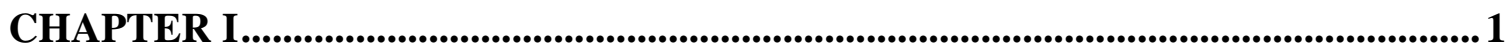

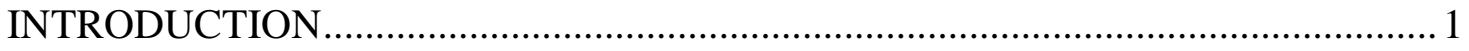

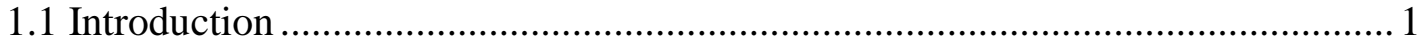

1.2 Objectives and Scope of Research ................................................................ 3

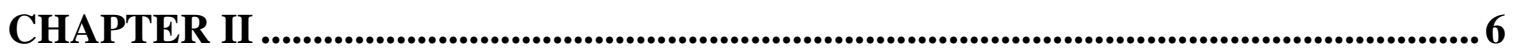

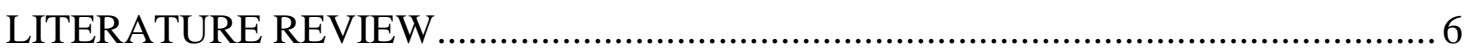

2.1 Moisture Diffusion through Polymers............................................................ 6

2.1.1 Fundamental Equations ........................................................................ 6

2.1.2 Representative Results for Diffusion through Epoxy and Vinyl Ester Resins

2.1 .1 Equilibrium Moisture content and Diffusion Coefficient:

2.1.2.2 Effect of temperature....................................................................... 15

2.1.2.3 Water - Polymer interactions ............................................................... 17

2.1.2.4 Effect of Changes in the physical structure of the resin and the

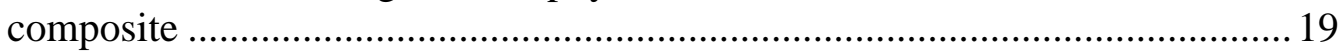

2.1.2.5 Effect of Extent of Cure …………………………………………. 23

2.1.2.6 Effect of Glass Reinforcement ..........................................................25

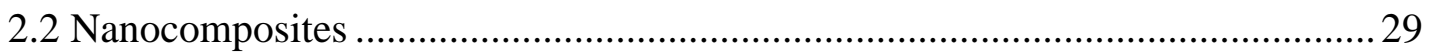

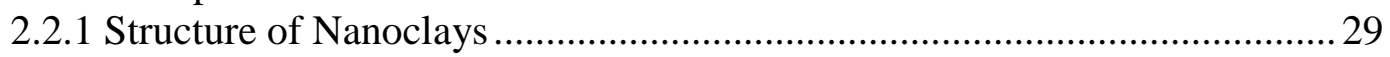

2.2.2 Surface Modification................................................................................... 31

2.2.2.1 Ion Exchange Method ...................................................................... 32

2.2.2.2 Ion Dipole Method ............................................................................. 33

2.2.3 Types of Nanocomposites ............................................................................... 33

2.2.4 Properties of Polymer - Nanocomposites...................................................... 36

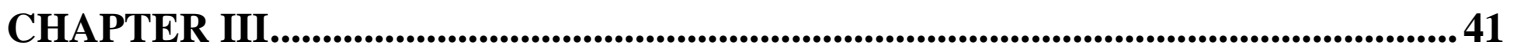

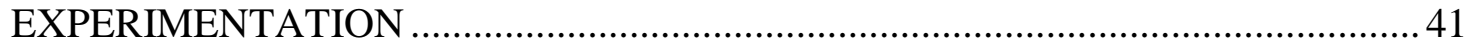

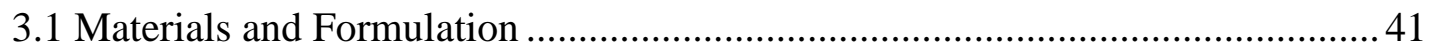

3.1.1 Vinyl ester Chemistry............................................................................... 41

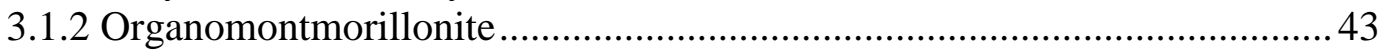

3.2 Sample Preparation ....................................................................................... 44 
3.1.2 Organomontmorillonite .................................................................. 43

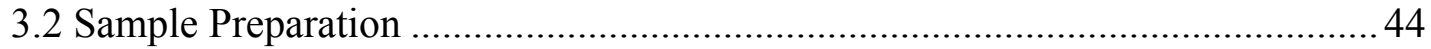

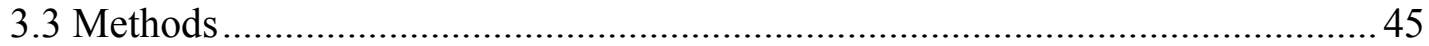

3.3.1 Water Diffusion Experiments.......................................................... 45

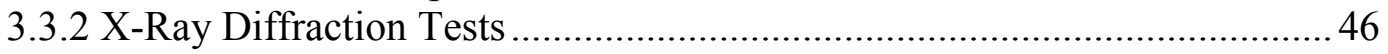

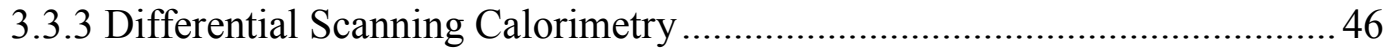

3.3.4 Transmission Electron Microscopy (TEM).......................................... 47

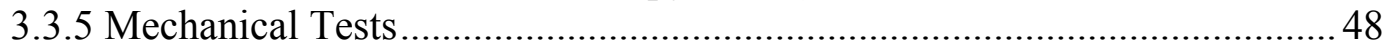

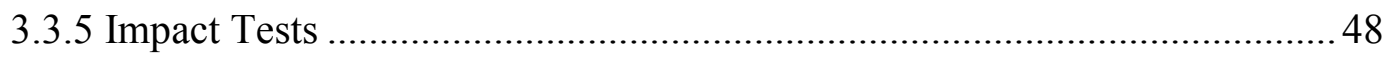

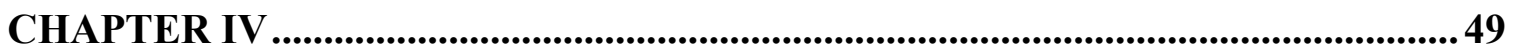

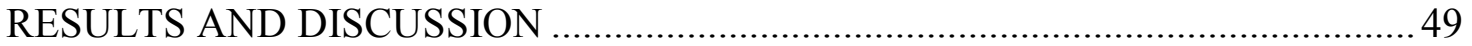

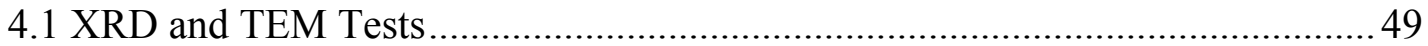

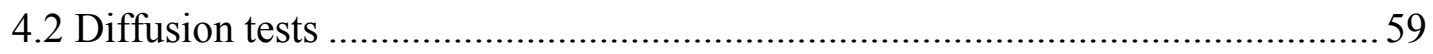

4.2.1 Mechanism of Diffusion through Vinyl ester resin.................................. 76

4.2.2 Proposed Mechanism of Diffusion through Polymer-Clay nanocomposites 79

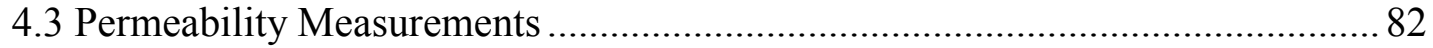

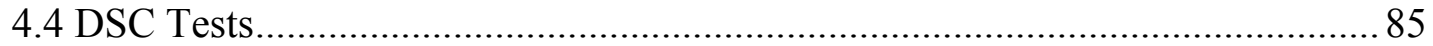

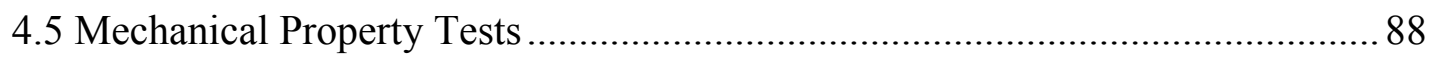

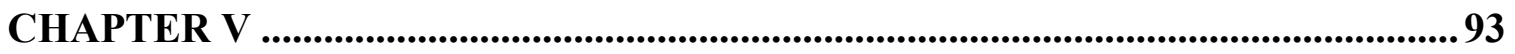

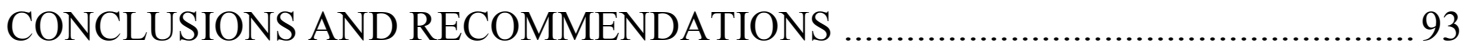

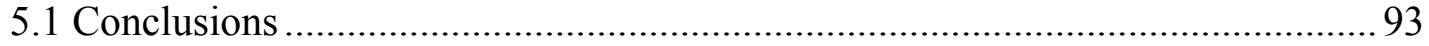

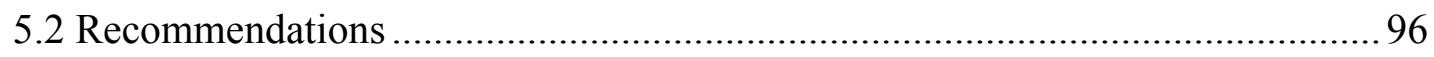

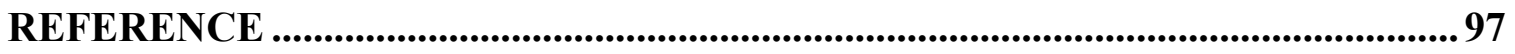

APPENDICES ..................................................................................................................... 101

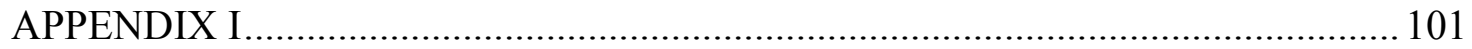

Theories Proposed To Describe the Process of Anomalous Diffusion In Glassy

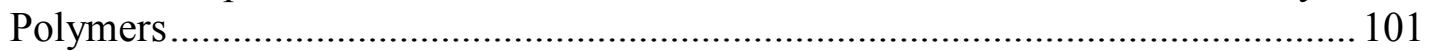

A.1.1 Time - dependent boundary conditions ........................................... 101

A.1.2 Model based on polymer relaxation ...................................................... 103

A.1.3 Model based on Langmuir type of behavior ......................................... 105

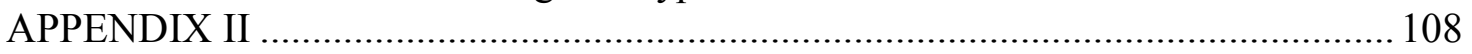

Sample Calculations ..................................................................................... 108

A.2.1 Sample Calculation for Diffusion Coefficient........................................ 108

A.2.2 Langmuir theory Calculations ............................................................ 110

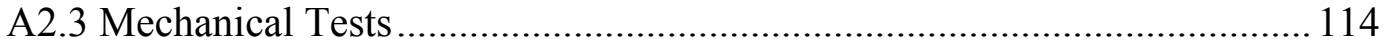

APPENDIX III ............................................................................................ 116

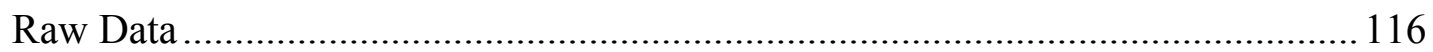

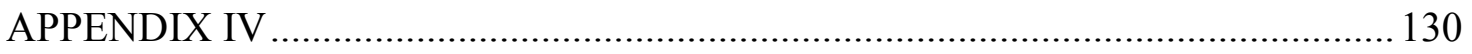

Derivation of exact solution and short times solutions to Fick's Law ................... 130

Derivation of Tortuosity in Polymer Nanocomposites ...................................... 146 


\section{LIST OF FIGURES}

Figure 2.1 Water uptake curves for (a) Epoxy and (b) vinyl ester (c) isopolyester resins at $22^{\circ} \mathrm{C}$. (Chin et al., 1999)

Figure 2.2 Typical structure of a crosslinked epoxy resin (Mallick, 1993).

Figure 2.3. Typical structure of (a) Polyester resin and (b) vinyl ester resin (Ghorbel and Valentin, 1991).

Figure 2.4 Sorption curves for (a) Epoxy and (b) vinyl ester (c) isopolyester resins at 22 ${ }^{\circ} \mathrm{C}$. (Chin et al., 1999).

Figure 2.5 Bonds between glass fiber and coupling agent (Ritter et al., 1998).............. 27

Figure 2.6. Structure of Montmorillonite (MMT) clay (Kornmann et al., 1998).............. 30

Figure 2.7 Types of Nanocomposite morphologies (Kornmann, et al., 1998)................. 34

Figure 2.8 Dependence of permeability of water vapor on montmorillonite content in polyimide - clay hybrids (Yano et al., 1993).

Figure 2.9 Schematic of the flow of a penetrant through a nanocomposite (Yano et al., 1993).

Figure 3.1. Chemistry of vinyl ester resin (Mallick, 1993).....

Figure 3.2 Schematic structure of DERAKNE Vinyl ester resins (Dow Chemical Co.).. 42

Figure 3.3 Schematic of a cross-linked vinyl ester resin (Mallick, 1993).

Figure 3.4. Schematic representation of sample microtoming for TEM analysis. Direction of electron beam incidence is the direction of view. 48

Figure 4.1 XRD scans on Cloisite $10 \mathrm{~A}^{\circledR}$ and Cloisite $10 \mathrm{~A}^{\circledR}$ nanocomposite samples. Wt $\%$ organoclay is indicated on the figure.

Figure 4.2. TEM photograph of 0.5 wt \% Cloisite $10 A^{\circledR}$ - DERAKANE ${ }^{\text {TM }}$ 411-350 vinyl ester nanocomposite sample. (1500x). (MMT content -0.305 wt \%)........................... 51

Figure 4.3. TEM photograph of 5 wt \% Cloisite $10 A^{\circledR}$ - DERAKANETM 411-350 vinyl ester nanocomposite sample (1500x). MMT content $-3.05 \mathrm{wt} \%$.

Figure 4.4. TEM photograph of $0.5 \mathrm{wt} \%$ Cloisite $10 \mathrm{~A}^{\circledR}$ - DERAKANE ${ }^{\mathrm{TM}}$ 411-350 vinyl ester nanocomposite sample $(100,000 x)$. Clay platelets are seen as dark lines. MMT content -0.305 wt $\%$.

Figure 4.5. TEM picture of 5 wt $\%$ Cloisite $10 A^{\circledR}-$ DERAKANETM $^{\text {4 }}$ 411-350 nanocomposite $(200,000 \mathrm{x})$. Clay platelets are seen as dark lines. MMT content $-3.05 \mathrm{wt}$ $\%$.

Figure 4.6. TEM photograph of $1.0 \mathrm{wt} \%$ Cloisite $10 \mathrm{~A}^{\circledR}$ - DERAKANE ${ }^{\mathrm{TM}}$ 411-350 vinyl ester nanocomposite sample (1500x). MMT content $0.78 \mathrm{wt} \%$. .55 
Figure 4.7. TEM photograph of 5.0 wt \% Cloisite $10 A^{\circledR}$ - DERAKANETM 411-350 vinyl ester nanocomposite sample (1500x). MMT content 3.9 wt \% ....................................55

Figure 4.8. TEM photograph of 5.0 wt \% Cloisite $10 A^{\circledR}$ - DERAKANE ${ }^{\text {TM }}$ 411-350 vinyl ester nanocomposite sample (150,000x). MMT content - 3.9 wt \% ...............................56

Figure 4.9 XRD scans on VMC and VMC nanocomposite samples. Wt \% organoclay is indicated on the figure. 56

Figure 4.10. TEM photograph of ultrasonicated 1.0 wt \% VMC - DERAKANE ${ }^{\mathrm{TM}} 411$ 350 vinyl ester nanocomposite sample (1500x). MMT content $-0.78 \mathrm{wt} \%$. 57

Figure 4.11. TEM photograph of ultrasonicated 1.0 wt \% VMC - DERAKANETM 411350 vinyl ester nanocomposite sample (150,000x). MMT content $-0.78 \mathrm{wt} \%$.............57

Figure 4.12. Representative reaction process upon polymerization. .59

Figure 4.13 Water uptake curves of non-post cured DERAKANETM 411-350 vinyl ester resin at $25^{\circ} \mathrm{C}$.

Figure 4.14 Sorption curve of non-post cured DERAKANE ${ }^{\text {TM }}$ 411-350 vinyl ester resin at $25^{\circ} \mathrm{C}$

Figure 4.15 Water uptake curves of post cured DERAKANE ${ }^{\mathrm{TM}}$ 411-350 vinyl ester resin at $25^{\circ} \mathrm{C}$.

Figure 4.16 DSC scan on a non-post cured DERAKANE ${ }^{\text {TM }}$ 411-350 vinyl ester resin.... 64

Figure 4.17. DSC scan on post-cured DERAKANETM 411-350 vinyl ester resin............. 64

Figure 4.18. Curing peak of liquid DERAKANETM 411-350 vinyl ester resin................ 65

Figure 4.19 Water uptake curves of post cured $0.5 \mathrm{wt} \%$ Cloisite $10 \mathrm{~A}^{\circledR}$-DERAKANETM 411-350 vinyl ester resin at $25^{\circ} \mathrm{C}$.

Figure 4.20 Water uptake curves of post cured $1.0 \mathrm{wt} \%$ Cloisite $10 \mathrm{~A}^{\circledR}$-DERAKANETM 411-350 vinyl ester resin at $25^{\circ} \mathrm{C}$.

Figure 4.21 Water uptake curves of post cured $2.5 \mathrm{wt} \%$ Cloisite $10 \mathrm{~A}^{\circledR}$-DERAKANETM 411-350 vinyl ester resin at $25^{\circ} \mathrm{C}$.

Figure 4.22 Water uptake curves of post cured 5 wt \% Cloisite $10 A^{\circledR}$-DERAKANETM 411-350 vinyl ester resin at $25^{\circ} \mathrm{C}$.

Figure 4.23 Water sorption curves of post cured $0.5 \mathrm{wt} \% \mathrm{VMC}^{\mathrm{N}}$-DERAKANETM 411-350 vinyl ester resin at $25^{\circ} \mathrm{C}$.

Figure 4.24 Water sorption curves of post cured $1.0 \mathrm{wt} \% \mathrm{VMC}$-DERAKANE ${ }^{\mathrm{TM}}$ 411-350 vinyl ester resin at $25^{\circ} \mathrm{C}$.

Figure 4.25 Water sorption curves of post cured $2.5 \mathrm{wt} \%$ VMC-DERAKANE $^{\mathrm{TM}}$ 411-350 vinyl ester resin at $25^{\circ} \mathrm{C}$.

Figure 4.26 Water uptake curves of post cured 5.0 wt \% VMC-DERAKANETM 411-350 vinyl ester resin at $25^{\circ} \mathrm{C}$. 
Figure 4.27 Variation of diffusion coefficient of DERAKANE ${ }^{\mathrm{TM}}$ 411-350 vinyl ester

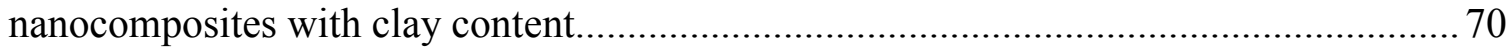

Figure 4.28 Variation of equilibrium moisture content with weight percent clay in the sample.

Figure 4.29. Water sorption curve of $0.66 \mathrm{wt} \%$ Cloisite $\mathrm{Na}^{\circledR}$ - DERAKANETM 411-350 vinyl ester resin at $25^{\circ} \mathrm{C}$.

Figure 4.30. Water sorption curve of 3.25 wt \% Cloisite $\mathrm{Na}^{\circledR}$ - DERAKANETM 411-350 vinyl ester resin at $25^{\circ} \mathrm{C}$. 74

Figure 4.31. Relative Permeability of Cloisite $10 \mathrm{~A}^{\circledR}$ and VMC vinyl ester resin nanocomposites. $(\mathrm{L}=180 \mathrm{~nm}, \mathrm{~W}=1 \mathrm{~nm})$. Volume fraction was calculated using $\boldsymbol{\rho}_{\text {clay }}=$

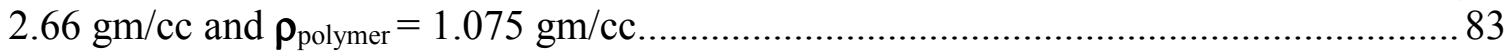

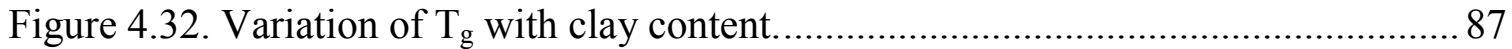

Figure 4.33. Tensile modulus of the nanocomposite as a function of Cloisite $10 \mathrm{~A}^{\circledR}$ and VMC loading. .89

Figure 4.34. Tensile strength of the nanocomposite as a function of Cloisite $10 \mathrm{~A}^{\circledR}$ and

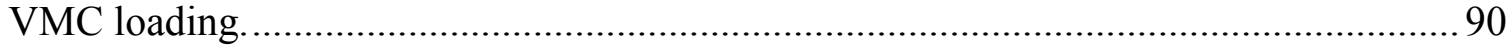

Figure A.1. Graphical Method of determining diffusion parameters, $\mathrm{C}_{0}$ and $\mathrm{C}_{\mathrm{eq}}$. (Weitsman and Tsotsis 1994). 103

Figure A.2 Sorption curve of post-cured neat DERAKANETM 411-350 Vinyl ester resin. 110

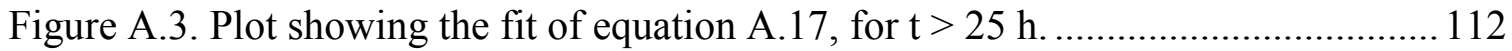

Figure A.4 Calculation of initial slope for Diffusion coefficient, $\mathrm{D}_{\gamma} \ldots \ldots \ldots \ldots \ldots \ldots \ldots \ldots \ldots . . . . . . . . . . .113$

Figure A.5 Stress - Strain curve for 0.5 \% VMC - DERAKANE 411-350 vinyl ester resin 115

Figure A.6 Schematic of polymer film and boundary conditions. 130

Figure A.7 Comparison between Fick's Law Exact solution and Fick's Law solution for short times. Data are for neat vinyl ester resins. 145

Figure A8. Volume element of a polymer nanocomposite film..... 146 


\section{LIST OF TABLES}

Table 1.1 Polymeric Matrix Materials (Mallick, 1993)

Table 2.1. Equilibrium Uptake of Epoxy, Vinyl ester and polyester films. (Chin et al., 1999) 11

Table 2.2. Solubility of Epoxy, Vinyl ester and polyester resins (Chin et al., 1999)........ 12

Table 2.3. Diffusion coefficients of various solutions in Epoxy, Vinyl ester and polyester resins (Chin et al., 1999).

Table 2.4 Variation of equilibrium moisture content and diffusion coefficient with temperature for DERAKANE ${ }^{\text {TM }}$ 441-440 vinyl ester resin. (Verghese, et al., 1999)........ 17

Table 2.5. Equilibrium moisture content and glass transition temperature of Epon 828 with two different cure cycles. (Wong and Broutman 1985a)

Table 2.6 Variation of density, $\mathrm{T}_{\mathrm{g}}$, equilibrium moisture content and diffusion coefficient of Epon 828 with cure time. Data for exposure to $51 \% \mathrm{RH}$ and $25{ }^{\circ} \mathrm{C}$ (Enns and Gillham 1983).

Table 2.7 Diffusion parameters of water through EPON 828 with varying percentages of Aniline at $25^{\circ} \mathrm{C} / 98 \%$ RH (Diamant et al., 1981)

Table 2.8. Threshold-energy release rate for various glasses and glass-epoxy systems (Ritter, et al., 1998)

Table 2.9 Glass Transition Temperature and Flexural Modulus of EPON 862/I.30E nanocomposites (Chen and Curliss, 2001).

Table 2.10 Composition and water vapor permeability in nylon nanocomposite films (Messersmith and Giannelis, 1995). 40

Table 4.1. XRD scan results of Cloisite $10 \mathrm{~A}^{\circledR}$ and VMC nanocomposites. .....................58

Table 4.2. Diffusion Test Results on Post Cured samples

Table 4.3 Water uptake tests on Cloisite $\mathrm{Na}^{\circledR}$, Cloisite $10 \mathrm{~A}^{\circledR}$ and VMC $\left(75 \% \mathrm{RH} / 25{ }^{\circ} \mathrm{C}\right)$.

Table 4.4. Summary of the diffusion model parameters 82

Table 4.5. Permeability of Nanocomposite samples as calculated from diffusion data.... 84

Table 4.6. Variation of Glass Transiton temperature of nanocomposite samples with clay content, before and after equilibrating with distilled water at $25{ }^{\circ} \mathrm{C}$. 86

Table 4.7 Impact Strength (in $\mathrm{J} / \mathrm{m}$ ) of vinyl ester nanocomposite samples. 92

Table A.1 Diffusion data of post-cured neat DERAKANE 411-350 vinyl ester resin... 108

Table A.2. Water uptake data of $5 \mathrm{wt} \%$ Cloisiste $10 \mathrm{~A}^{\circledR}$ nanocomposites 111

Table A.3 Tensile test data 114 
Table A.4a Water Uptake data for Non-Post Cured DERAKANE TM Vinyl ester Resins: 116

Table A.4b Water Uptake data for Non-Post Cured DERAKANE Tм Vinyl ester Resins: 117

Table A.4c Water Uptake data for Non-Post Cured DERAKANE Tм Vinyl ester Resins: 118

Table A.5a Water Uptake data for Post Cured Neat DERAKANE ${ }^{\mathrm{TM}}$ 411-350 vinyl ester resin: 119

Table A.5b Water Uptake data for Post Cured DERAKANE Tм Vinyl ester Resins:..... 119

Table A.6a Water uptake data for $0.5 \mathrm{wt} \%$ VMC nanocomposite samples:.................. 120

Table A.6b Water uptake data for $0.5 \mathrm{wt} \%$ VMC nanocomposite samples: ................. 120

Table A.7a Water uptake data for $1.0 \mathrm{wt} \%$ VMC nanocomposite samples:.................. 121

Table A.7b Water uptake data for $1.0 \mathrm{wt} \%$ VMC nanocomposite samples: ................. 121

Table A.8a Water uptake data for $2.5 \mathrm{wt} \%$ VMC nanocomposites samples: ................ 122

Table A.8b Water uptake data for $2.5 \mathrm{wt} \%$ VMC nanocomposites samples:................ 122

Table 4.9a Water uptake data for 5.0 wt \% VMC nanocomposite samples:.................... 123

Table 4.9b Water uptake data for 5.0 wt\% VMC nanocomposite samples: ................... 123

Table 4.9c Water uptake data for 5.0 wt \% VMC nanocomposite samples:................... 124

Table 4.10a Water uptake data for $0.5 \mathrm{wt} \%$ Cloisite $10 \mathrm{~A}^{\circledR}$ nanocomposite samples: ... 124

Table $4.10 \mathrm{~b}$ Water uptake data for $0.5 \mathrm{wt} \%$ Cloisite $10 \mathrm{~A}^{\circledR}$ nanocomposite samples: ... 125

Table 4.11a Water uptake data for $1.0 \mathrm{wt} \%$ Cloisite $10 \mathrm{~A}^{\circledR}$ nanocomposite samples: .... 125

Table $4.11 \mathrm{~b}$ Water uptake data for $1.0 \mathrm{wt} \%$ Cloisite $10 \mathrm{~A}^{\circledR}$ nanocomposite samples: ... 126

Table 4.12a Water uptake data for $2.5 \mathrm{wt} \%$ Cloisite $10 \mathrm{~A}^{\circledR}$ nanocomposite samples: ... 126

Table $4.12 \mathrm{~b}$ Water uptake data for $2.5 \mathrm{wt} \%$ Cloisite $10 \mathrm{~A}^{\circledR}$ nanocomposite samples: ... 127

Table 4.13a Water uptake data for $5.0 \mathrm{wt} \%$ Cloisite $10 \mathrm{~A}^{\circledR}$ nanocomposite samples: ... 127

Table $4.13 \mathrm{~b}$ Water uptake data for $5.0 \mathrm{wt} \%$ Cloisite $10 \mathrm{~A}^{\circledR}$ nanocomposite samples:... 128

Table 4.14a Water uptake data for $0.66 \mathrm{wt} \%$ Cloisite $\mathrm{Na}^{\circledR}$ nanocomposite samples: ... 128

Table 4.14b Water uptake data for $3.25 \mathrm{wt} \%$ Cloisite $\mathrm{Na}^{\circledR}$ nanocomposite samples: ... 129 


\section{CHAPTER I}

\section{INTRODUCTION}

\subsection{Introduction}

Glass-fiber reinforced polymer (GFRP) composites employing thermosetting polymer matrices - epoxy, vinyl ester and unsaturated polyester - are beginning to be used in the construction and repair of bridges and other civil structures (GangaRao and Craigo, 1999 and Kshirsagar, 2000, for example). The low-density, high-strength, high stiffness-toweight ratio; excellent durability; and design flexibility of fiber-reinforced polymers (FRPs), when compared to conventional materials such as steel and aluminum, are the primary reason for their increasing use in many structural components in aerospace, automotive, marine, electronics, and other industries (Mallick, 1993).

Fiber-reinforced polymer (FRP) composites consist of fibers of high strength and modulus embedded in or bonded to a polymer matrix with distinct interfaces (boundary) between them. In this form, both the fibers and matrix retain their physical and chemical identities but produce a combination of properties that cannot be achieved with either constituent acting alone. In any FRP, the fibers are the load-carrying members, while the surrounding matrix keeps them in the desired location and orientation. The matrix acts as a load-transferring medium between the fibers, and it also helps protect the load-bearing fibers from environmental damage resulting from exposure to elevated temperature or atmospheric moisture. Thus, even though the fibers provide reinforcement, the matrix performs several vital functions in the durability of the composite. The role of the matrix in FRPs can be summarized as (1) to transfer stress equally between the fibers, (2) to 
provide a barrier against an adverse environment such as chemicals and water and, (3) to protect the fibers from mechanical abrasion. The various polymeric matrix materials that have been used in FRPs are listed in Table 1.1. Among these, thermosetting polymers such as epoxies, unsaturated polyesters, and vinyl esters are in greatest commercial use, mainly due to the ease of processing and composite manufacture, higher thermal stability, and chemical resistance.

Table 1.1 Polymeric Matrix Materials (Mallick, 1993)

\section{Thermoset Polymers (resins):}

Epoxies: principally used in aerospace and aircraft applications.

Polyester and Vinyl Esters: commonly used in automotive, marine, chemical and electrical applications.

Phenolics: used in bulk molding compounds.

Polyimides, polybenzimidazoles (PBI), polyphenylquinoxaline (PPQ): for high temperature aerospace applications (temperature range of $250{ }^{\circ} \mathrm{C}-400{ }^{\circ} \mathrm{C}$ ).

\section{Themoplastic Polymers:}

Nylons (such as nylon 6, nylon 6,6), thermoplastic polyesters (such as PET, PBT), polycarbonate (PC), polyacetals: used in injection molded articles.

Polyamide-imide (PAI), polyether-ether ketone (PEEK), polysulfone (PSUL), polyphenylene sulfide (PPS), polyether imide (PEI): suitable for moderately high temperature applications. 


\subsection{Objectives and Scope of Research}

Any application of polymer composites in an outdoor environment inevitably involves exposure to moisture, either in the form of atmospheric water vapor or rain. In addition to water, composite materials may also be exposed to other chemicals and solvents depending on the specific application. Some examples include aviation turbine fuel, deicing liquids and paint strippers in aircraft applications; gasoline or motor oil in automotive applications; and salt water in waterfront or offshore applications. Such environments may have a significant effect on the properties of the matrix resin and the composite as a whole. The durability or the effectiveness of the matrix material to act as a barrier to the diffusion of such chemicals, thereby protecting the fibers, becomes important here.

Widespread utilization of GFRPs in construction has been hindered by the lack of reliable scientific information on long-term durability and performance data to computationally project service life of a composite. This is especially true, when it is realized that GFRP composites used in infrastructure applications are intended to have a service life in excess of 50 years. When exposed to a moist environment or to humid air, the polymeric matrix materials have been known to absorb moisture. This takes place by instantaneous surface adsorption followed by diffusion through the matrix. In this regard, it is found that atmospheric moisture can diffuse to the fiber-matrix interface and cause both delamination and fiber weakening (Kajorncheappunngam et al., 2001). The matrix may also be plasticized and/or degraded resulting in weakening of the matrix material (Chin et al., 1999). These will inevitably cause deterioration in the mechanical properties of the 
polymer and its composites. It is, therefore, of interest to know the amount of moisture that can be contained in a polymer matrix under equilibrium conditions and the rate at which equilibrium is attained. This necessitates determination of diffusivity and water uptake in both the unreinforced and reinforced polymers. This knowledge and, in particular, the mechanism by which moisture is transported through a glassy polymer matrix will allow us to minimize the effects of moisture and other liquids on the durability of fiber-reinforced polymer composites (FRPs). Based on these needs, the following study was proposed on vinyl ester resins, a commercially important polymer.

The proposed study includes the following objectives:

1. Measuring the diffusion coefficients, equilibrium moisture content and establishing the mechanism of water diffusion through neat DERAKANE ${ }^{\text {TM }}$ 411-350 vinyl ester resin, non-post cured and post cured.

2. Reducing the diffusion coefficient through the resin by dispersing nanoclays.

3. Studying the effect of clay loading on the diffusion properties of the resin matrix by varying the amount of clay $(0.5 \%, 1 \%, 2.5 \%$, and $5 \%$ by weight).

4. Using techniques like XRD, TEM and DSC to characterize the structure of polymerclay nanocomposites.

5. Determining the changes in mechanical properties of vinyl ester - clay nanocomposites with varying amounts of nanoclay.

6. Studying the effect of surface treatment of clay on diffusion coefficient, equilibrium moisture content and mechanical properties. 
To summarize, diffusion of water through vinyl ester resins will be studied gravimetrically, by performing transient water uptake experiments. Diffusion coefficient and equilibrium moisture content will be calculated from the data obtained which will provide insight into the rate and amount of water ingress into the sample. Nanoclays will be dispersed or exfoliated into the polymer matrix, to act as a barrier to the diffusion of water. The effect of clay loading on diffusion properties will also be determined from water uptake experiments. Additionally, the organic surface treatment given to the clay will be modified to incorporate a reactive group, such as a vinyl group. The effect of the nature of the surface treatment group (i.e. presence or absence of a reactive group) on exfoliation and clay morphology will be characterized using X-Ray diffraction (XRD) and Transmission Electron Microscopy (TEM). The effect of organoclay, type and clay content, on diffusion of water and mechanical properties such as tensile modulus, strength and glass transition temperature will also be studied. Finally all the results will be correlated with the morphology of the clay within the polymer and a mechanism of water uptake will be proposed.

The sections that follow review the moisture transport through glassy, thermosetting polymer matrix materials, with an emphasis on vinyl ester resins. It also includes a discussion of nanocomposites, a promising method by which we can not only reinforce a polymer, but also reduce the diffusion coefficient of water through the host polymer. Verification of this idea and studying the diffusion of water through vinyl ester resin matrix is the main focus of the present research. 


\section{CHAPTER II}

\section{LITERATURE REVIEW}

\subsection{Moisture Diffusion through Polymers}

\subsubsection{Fundamental Equations}

When a concentration gradient exists in a material, such as a solid polymer, there is a natural tendency for the concentration difference to be reduced and eliminated by the process of mass transfer. The mass flux is generally proportional to the local concentration gradient; this is often known as Fick's first law, and the constant of proportionality is called the diffusivity or the diffusion coefficient. When Fick's first law is used in a mass balance, one obtains Fick's second "law", whose one-dimensional form is:

$$
\frac{\partial c}{\partial t}=D \frac{\partial^{2} c}{\partial x^{2}}
$$

in which, $\mathrm{c}$ is the concentration of the diffusing species (in this case water), $\mathrm{t}$ is time, $\mathrm{x}$ is the position in the diffusing direction, and D is the diffusion coefficient. Here D is taken to be a constant, but its value can depend on temperature and concentration of the diffusing species; it usually increases with increasing temperature.

When a dry sheet of polymer of uniform thickness $(2 \ell)$ is exposed to moisture, the sample mass increases due to water uptake, and upon solving equation 2.1 with constant boundary conditions, we get moisture uptake (or mass gain) $\mathrm{M}_{\mathrm{t}}$ to be,

$$
\frac{M_{t}}{M_{\infty}}=\left[1-\sum \frac{8}{(2 n+1)^{2} \pi^{2}} \exp \left[\frac{-D(2 n+1)^{2} \pi^{2} t}{4 \ell^{2}}\right]\right]
$$


where $\mathrm{M}_{\infty}$ is the equilibrium increase in sample mass and $2 \ell$ is the sample thickness. For the derivation of equation 2.2 refer to Appendix IV.

The corresponding solution of Fick's Law at short times is also derived in Appendix IV, and is:

$$
\frac{\mathrm{M}_{\mathrm{t}}}{\mathrm{M}_{\infty}}=2\left(\frac{\mathrm{Dt}}{\ell^{2}}\right)^{1 / 2}\left\{\pi-1 / 2+\underset{0}{-\infty}(-1)^{\mathrm{n}} \text { ierfc } \frac{\mathrm{n} \ell}{\sqrt{(\mathrm{Dt})}}\right\}
$$

The diffusion coefficient can be calculated by simplifying equation 2.3 (Crank, 1975).

For $\frac{\mathrm{Dt}}{4 \ell^{2}}<0.05$, equation 2.3 can be approximated to (Singh et al., 1991 for example):

$$
\frac{\mathrm{M}_{\mathrm{t}}}{\mathrm{M}_{\infty}}=4\left(\frac{\mathrm{Dt}}{\pi(2 \ell)^{2}}\right)^{1 / 2}
$$

The diffusion coefficient can now be calculated from the initial slope of $\frac{M_{t}}{M_{\infty}}$ versus $\mathrm{t}^{1 / 2} / 2 \ell$ plot. Alternately, the diffusion coefficient can be determined from, (Crank, 1975) $\mathrm{D}=\frac{0.049}{\left(\mathrm{t} / 4 \ell^{2}\right)_{1 / 2}}$

where $\left(\mathrm{t} / 4 \ell^{2}\right)_{1 / 2}$ is the value at $\mathrm{M}_{\mathrm{t}} / \mathrm{M}_{\infty}=0.5$.

If the process of diffusion obeys equation 2.1, the situation is called Case 1 or Fickian diffusion. This typically occurs when the time scale over which molecules rearrange themselves is much shorter than the time scale of diffusion, and the surface concentration reaches the equilibrium value immediately. A different situation that is sometimes observed is Case II diffusion. Here, the diffusion process is accompanied by significant 
swelling of the polymer, transforming it from a glassy state to a partially rubbery state (McMaster and Soane, 1989). Now, the sample mass increases linearly with time rather then the square root of time as predicted by equation 2.4 (Kumar and Gupta, 1998). Case II diffusion is a special case of anomalous or Non-Fickian diffusion, wherein the rate of diffusion is greater than that predicted by the use of Fick's law. This behavior is explained by saying that diffusion through glassy polymers involves time dependent relaxation of polymer chains, and this results in anomalous behavior (Berens and Hopfenberg, 1979). Deviations from Fickian diffusion also arise due to interaction of the penetrant with specific groups on the polymer chains, e.g., hydrogen bonding of water molecules with polar groups on the polymer chain (Carter and Kibler, 1978).

\subsubsection{Representative Results for Diffusion through Epoxy and Vinyl Ester Resins}

\subsubsection{Equilibrium Moisture content and Diffusion Coefficient:}

Diffusion of water through polymers may take place due to absorption and adsorption (Chin et al., 1999). Absorption is a capillary uptake of water by the existing pores in the material. Adsorption, on the other hand, is the process by which a solution is formed and generates heat (in the form of heat of solution). Adsorption of water molecules take place on the surface of the polymer, followed by the penetration of water into the polymer due to random molecular motion. For a polymer free of pores or voids, the process of water uptake is mainly due to adsorption. However in reality, no polymer is free of voids or pores, hence both adsorption and absorption take place simultaneously. Thus the entire process of water uptake is termed as a sorption process. Chin et al., (1999) studied the sorption and diffusion of water, salt water and concrete pore solution in epoxy, vinyl ester 
and polyester matrices. The vinyl ester resin used in the study was the Dow Chemical Co.'s DERAKANE ${ }^{\mathrm{TM}}$ 411-350PA. They observed Fickian diffusion in all the resins for each of the solutions. Shown in Figure 2.1 are their water uptake curves for epoxy, vinyl ester and polyester resins at $22{ }^{\circ} \mathrm{C}$. Sample thicknesses ranged from 230 to $260 \mu \mathrm{m}$. Uptake was rapid for the first $10 \mathrm{~h}$, and then slowed between 10 and 100 hours as equilibrium was attained. Uptake for epoxy was found to be the greatest among the three resin materials as summarized in Table 2.1. This was due to the chemical structure of the individual resins. The epoxy resin has a higher concentration of hydrophilic hydroxyl groups (formed during cure) located along the backbone as well as amine groups from the hardener used in curing epoxies, and these groups attract water molecules. A representation of a crosslinked epoxy is shown in Figure 2.2. The hydrophilic groups are circled. Similarly, typical structures of a crosslinked polyester and vinyl ester resin are shown in Figure 2.3. Again the hydrophilic groups are circled. In terms of the relative hydrophilicity, $\mathrm{O}-\mathrm{C}=\mathrm{O}$ groups are the least hydrophilic, followed by $-\mathrm{OH}$ groups, and the amine groups $(-\mathrm{NH})$ are the most hydrophilic. Note that the polyester resin does not contain any hydrophilic $-\mathrm{OH}$ or $-\mathrm{NH}$ groups on its backbone. The epoxy resin has the greatest affinity for water due to the presence of both $-\mathrm{OH}$ and $-\mathrm{NH}$ groups and hence has the highest equilibrium water content. In general, the greater the number and the larger the polarity of the hydrophilic groups present in the polymer matrix, the higher would be its sorptive affinity towards water. Equilibrium mass uptake can also be expressed in terms of solubility (i.e., the mass of sorbed penetrant per unit volume of specimen) and the calculated values are summarized in Table 2.2. As expected, based on mass uptake data, the solubility was lowest for vinyl ester resins. The sorption curves for 
epoxy, vinyl ester and polyester resin when exposed to the 3 different solutions are shown in Figure 2.4. Superposition of data is observed for all the resins, and the curves also show an initial linear region that extends up to or even beyond $\mathrm{M}_{t} / \mathrm{M}_{\infty}=0.6$. This is followed by a region concave to the abscissa. Both of these indicate Fickian behavior. Diffusion coefficients calculated for all the three resins using plots similar to those shown in Figure 2.4 are summarized in Table 2.3.

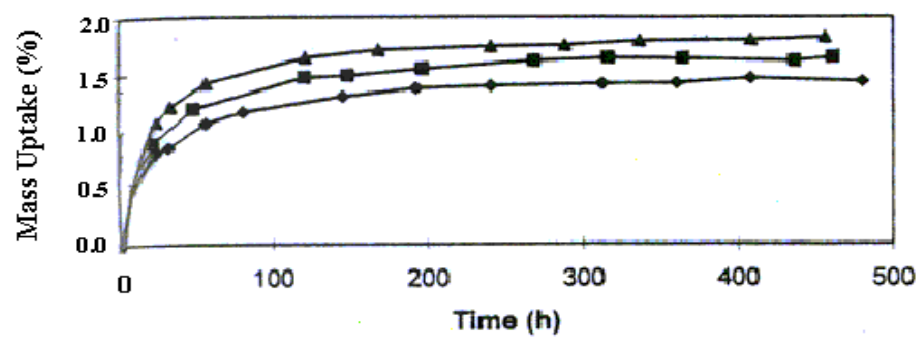

(a)

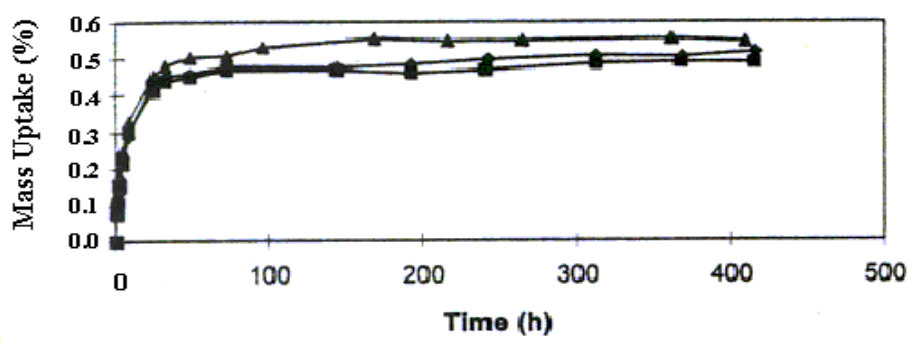

(b)

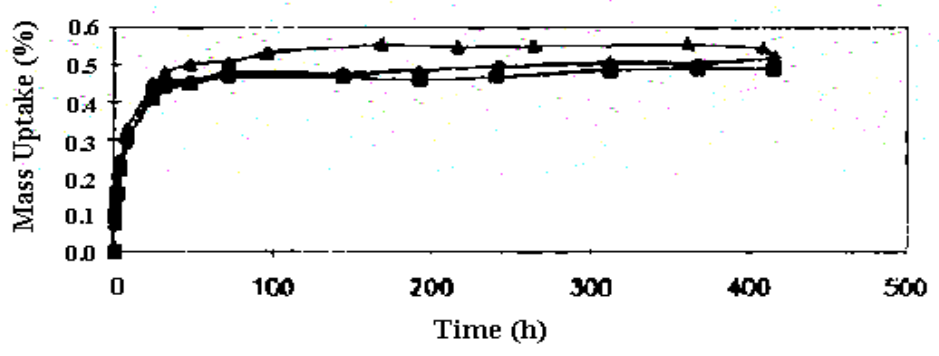

(c)

Figure 2.1 Water uptake curves for (a) Epoxy and (b) vinyl ester (c) isopolyester resins at $22{ }^{\circ} \mathrm{C}$. (Chin et al., 1999) 
Table 2.1. Equilibrium Uptake of Epoxy, Vinyl ester and polyester films. (Chin et al., 1999)

\begin{tabular}{|c|c|c|c|}
\hline \multirow[t]{2}{*}{ Matrix } & \multirow[t]{2}{*}{ Sorbent } & \multicolumn{2}{|c|}{ Equilibrium Mass Uptake ( wt. \%) } \\
\hline & & $22{ }^{\circ} \mathrm{C}$ & $60{ }^{\circ} \mathrm{C}$ \\
\hline Epoxy & $\begin{array}{l}\text { Distilled water } \\
\text { Salt Solution } \\
\text { Pore solution }\end{array}$ & $\begin{array}{l}1.42 \pm 0.03 \\
1.79 \pm 0.04 \\
1.64 \pm 0.04 \\
\end{array}$ & $\begin{array}{c}2.00 \pm 0.1 \\
1.93 \pm 0.08 \\
1.88 \pm 0.06\end{array}$ \\
\hline Vinyl ester & $\begin{array}{l}\text { Distilled water } \\
\text { Salt Solution } \\
\text { Pore solution }\end{array}$ & $\begin{array}{l}0.52 \pm 0.01 \\
0.55 \pm 0.01 \\
0.49 \pm 0.04\end{array}$ & $\begin{array}{l}0.62 \pm 0.05 \\
0.69 \pm 0.04 \\
0.64 \pm 0.03\end{array}$ \\
\hline Polyester & $\begin{array}{l}\text { Distilled water } \\
\text { Salt Solution } \\
\text { Pore solution }\end{array}$ & $\begin{array}{c}0.56 \pm 0.02 \\
0.55 \pm 0.03 \\
0.5 \pm 0.04\end{array}$ & $\begin{array}{c}0.5 \pm 0.08 \\
0.45 \pm 0.1 \\
0.49 \pm 0.05\end{array}$ \\
\hline
\end{tabular}

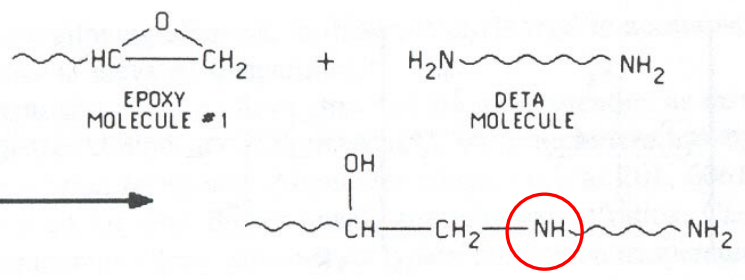

(a)
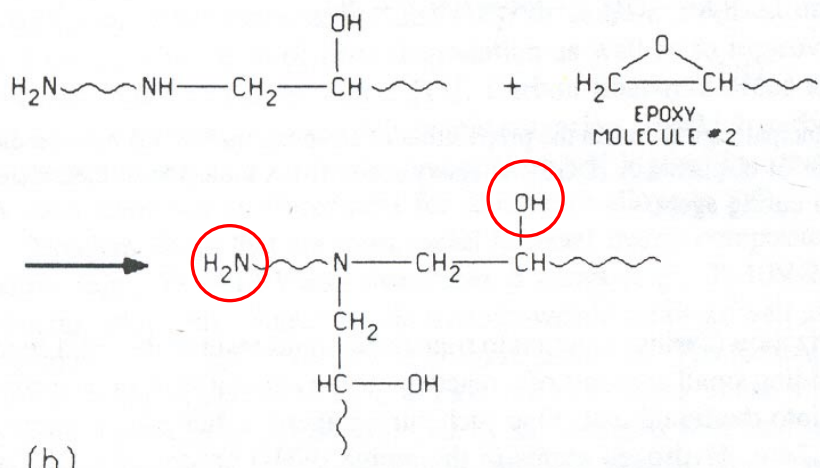

(b)

Figure 2.2 Typical structure of a crosslinked epoxy resin (Mallick, 1993). 


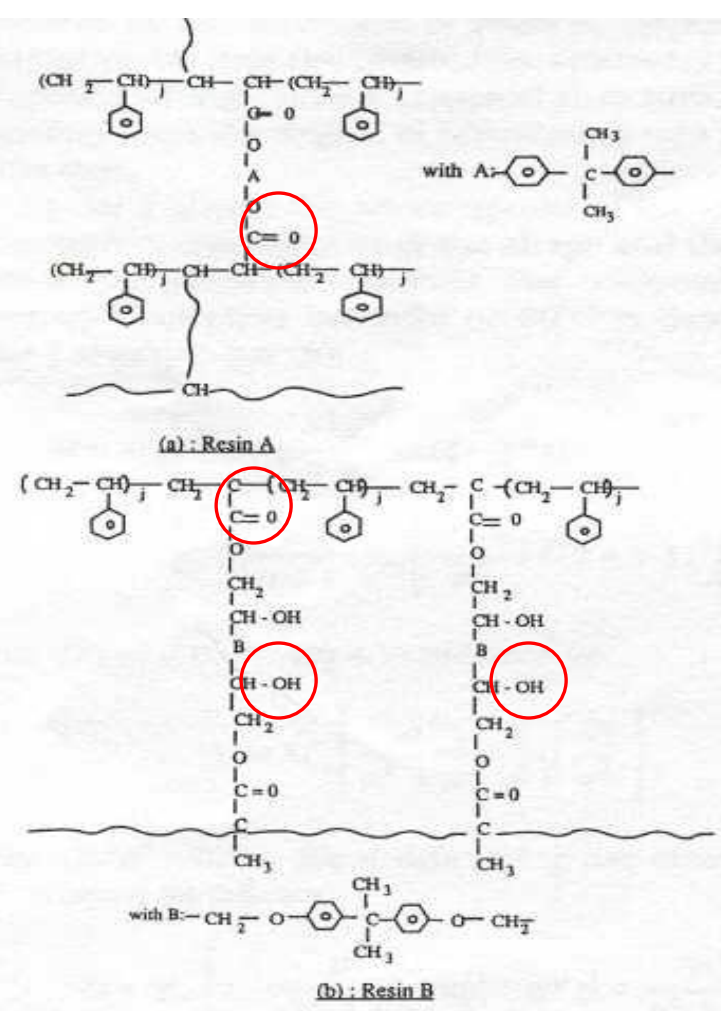

Figure 2.3. Typical structure of (a) Polyester resin and (b) vinyl ester resin (Ghorbel and Valentin, 1991).

Table 2.2. Solubility of Epoxy, Vinyl ester and polyester resins (Chin et al., 1999)

\begin{tabular}{|c|c|c|c|}
\hline \multirow{2}{*}{ Matrix } & Sorbent & \multicolumn{2}{|c|}{ Solubility $\left(\mathrm{mg} \mathrm{cm}^{-3}\right)$} \\
\cline { 2 - 4 } & & $22{ }^{\circ} \mathrm{C}$ & $60{ }^{\circ} \mathrm{C}$ \\
& & & \\
\hline \multirow{2}{*}{ Epoxy } & Distilled water & 16.22 & 22.79 \\
& Salt Solution & 20.45 & 22.03 \\
& Pore solution & 18.66 & 21.49 \\
\hline \multirow{2}{*}{ Vinyl ester } & Distilled water & 5.87 & 7.09 \\
& Salt Solution & 6.3 & 7.85 \\
& Pore solution & 5.56 & 7.25 \\
\hline \multirow{2}{*}{ Polyester } & Distilled water & 6.46 & 6.63 \\
& Salt Solution & 6.4 & 5.73 \\
& Pore solution & 5.8 & 6.11 \\
\hline
\end{tabular}




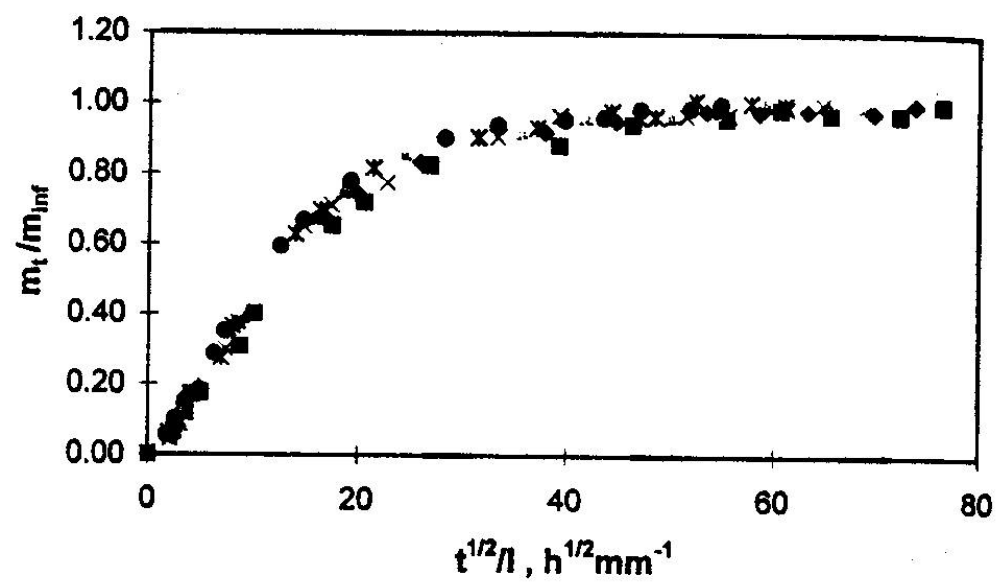

(a)
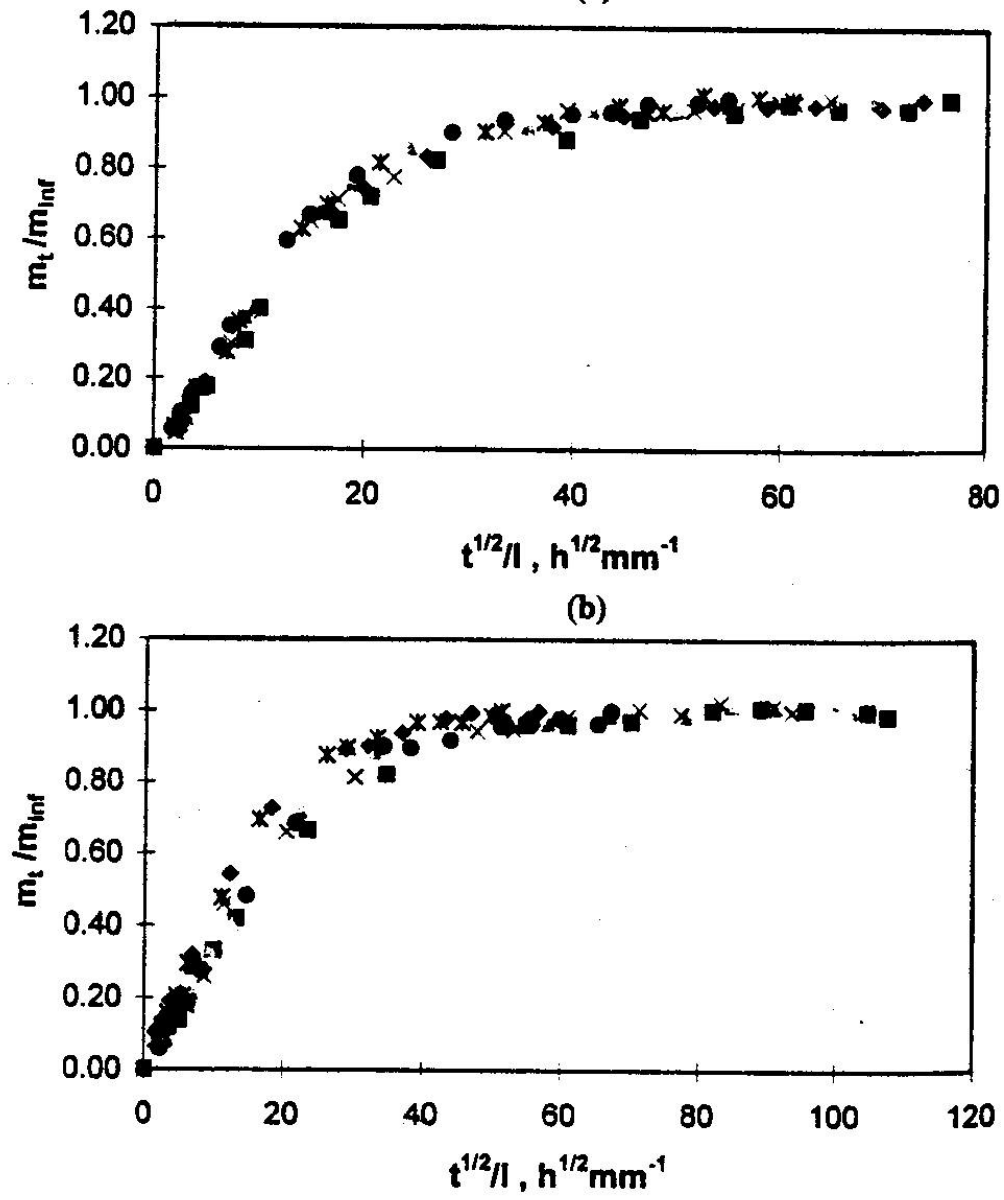

(c)

Figure 2.4 Sorption curves for (a) Epoxy and (b) vinyl ester (c) isopolyester resins at 22 ${ }^{\circ} \mathrm{C}$. (Chin et al., 1999). 
Table 2.3. Diffusion coefficients of various solutions in Epoxy, Vinyl ester and polyester resins (Chin et al., 1999).

\begin{tabular}{|c|c|c|c|}
\hline \multirow{2}{*}{ Matrix } & \multirow{2}{*}{ Sorbent } & \multicolumn{2}{|c|}{ Diffusion Coefficients, D } \\
\cline { 2 - 4 } & & $22{ }^{\circ} \mathrm{C}$ & $60{ }^{\circ} \mathrm{C}$ \\
\cline { 2 - 4 } & Distilled water & 0.53 & 13.6 \\
\multirow{2}{*}{ Epoxy } & Salt solution & 1.04 & 8.54 \\
& Pore solution & 0.67 & 9.82 \\
\hline \multirow{2}{*}{ Vinyl Ester } & Distilled water & 6.88 & 19.0 \\
& Salt solution & 8.75 & 24.5 \\
& Pore solution & 8.72 & 24.3 \\
\hline \multirow{2}{*}{ Polyester } & Distilled water & 8.93 & 41.9 \\
& Salt solution & 11.7 & - \\
\hline & Pore solution & 8.89 & - \\
\hline
\end{tabular}

Note that, although the vinyl ester resin exhibited the lowest equilibrium moisture uptake, water had a higher diffusion coefficient in vinyl ester than in epoxy. This is not surprising since diffusivity and solubility are in general independent quantities.

Similar to the work of Chin et al., (1999), Verghese et al., (1999) also observed Fickian diffusion in their studies using DERAKANE ${ }^{\mathrm{TM}}$ 441-400 vinyl ester resins. The moisture diffusion coefficient at $25{ }^{\circ} \mathrm{C}$ was reported to be $1.18 \times 10^{-8} \mathrm{~cm}^{2} / \mathrm{s}$, and equilibrium moisture content was observed as 0.97 wt \%. Although Ghorbel and Valentin (1993) reported Fickian diffusion of water in neat vinyl ester resins, the sorption in glass fiber composites of the same resin was modeled using the Langmuir theory. In the Langmuir type of model, the diffusion process was described by separating the diffusing molecules into two phases, mobile and bound. The model is further explained in Appendix I. The 
saturation level for composites was also more than that for neat resins, due to greater voidage and possible debonding at the fiber matrix interface, though the process of diffusion was slower. They reported $\mathrm{D}$ for neat vinyl ester resin to be $8.47 \times 10^{-7} \mathrm{~cm}^{2} / \mathrm{s}$, while for composites, it was $2.78 \times 10^{-10} \mathrm{~cm}^{2} / \mathrm{s}$. The equilibrium moisture content was $0.71 \mathrm{wt} \%$ for neat vinyl ester resin and $1.489 \mathrm{wt} \%$ for glass fiber composites. The tests were performed at $60^{\circ} \mathrm{C}$. A possible explanation for different authors reporting different values of diffusion coefficient for vinyl ester resins may be because of the different types of the vinyl ester resins used in each individual study. Chin et al., (1999) performed their study on DERAKANE ${ }^{\text {TM }}$ 411-350PA, while Verghese et al., (1999) used DERAKANE ${ }^{\text {TM }}$ 441-400 vinyl ester resin. It is possible that each vinyl ester resin may have a different chemical structure and the processing conditions may lead to different extents of cure, cross-linking and microstructure. Also note that equilibrium moisture contents differed, indicating these possible differences in the resin system, all of which might be contributing to different diffusion behavior, thus leading to different values of diffusion coefficient and equilibrium moisture content.

\subsubsection{Effect of temperature}

The observed effect of temperature on the sorption of water is that the rate of sorption increases as the temperature increases; this suggests that diffusion of water is a thermally governed process. The variation in diffusion coefficient in glassy polymers below their glass transition temperature $\left(\mathrm{T}_{\mathrm{g}}\right)$ has been modeled by several authors using the Arrhenius relationship (Verghese et al., 1999; Bonniau and Bunsell, 1981; and Marsh et al., 1984):

$$
\mathrm{D}=\mathrm{D}_{0} \exp \left(-\frac{\mathrm{E}}{\mathrm{RT}}\right)
$$


where $\mathrm{D}_{0}$ is a constant coefficient, $\mathrm{E}$ is the activation energy for diffusion, $\mathrm{R}$ is the universal gas constant and $\mathrm{T}$ is the absolute temperature. Bonniau and Bunsell (1981) calculated $\mathrm{E}$ to be of the order of $46 \mathrm{KJ} / \mathrm{mol}(11000 \mathrm{cal} / \mathrm{mol})$ for diglycedyl ether of bisphenol A (DGEBA) epoxy cured with different hardeners. Marsh et al., (1984) in their experiments with epoxy resin and E-glass fiber composites, calculated E for both neat resins and composites as $39.75 \mathrm{KJ} / \mathrm{mol}(9500 \mathrm{cal} / \mathrm{mol})$ and $41.6 \mathrm{KJ} / \mathrm{mol}(9940 \mathrm{cal} / \mathrm{mol})$, respectively. Verghese et al., (1999) found $\mathrm{E} / \mathrm{R}$ to be $4620 \mathrm{~K}$ (i.e., $\mathrm{E}=38.41 \mathrm{KJ} / \mathrm{mol}$ ) for DERAKANE ${ }^{\text {TM }}$ 441-400 vinyl ester resin. The values seem to be comparable among the different resin systems. Also the value of activation energy does not seem to vary too much between neat resins and glass fiber composites. This led Marsh et al., (1984) to conclude that the diffusion of water took place only in the bulk resin part of the composite, with little or no effect of the glass fibers on the kinetics of the diffusion process.

In addition to observing that the diffusion coefficient increased with temperature, Verghese et al., (1999) found that the equilibrium moisture content in the resin was higher at higher temperatures. Their results are tabulated in Table 2.4. 
Table 2.4 Variation of equilibrium moisture content and diffusion coefficient with temperature for DERAKANE ${ }^{\text {TM }}$ 441-440 vinyl ester resin. (Verghese, et al., 1999)

\begin{tabular}{|c|c|c|}
\hline Temperature, ${ }^{\circ} \mathrm{C}$ & $\begin{array}{c}\text { Equilibrium moisture } \\
\text { content, } \mathrm{wt} \%\end{array}$ & $\begin{array}{c}\text { Diffusion Coefficient, D x } \\
10^{8} \mathrm{~cm}^{2} / \mathrm{s}\end{array}$ \\
\hline 25 & 0.97 & 1.18 \\
\hline 45 & 1.17 & 2.5 \\
\hline 66 & 1.37 & 5.37 \\
\hline 84 & 1.60 & 20.3 \\
\hline
\end{tabular}

Chin et al., (1999) suggested that at higher temperatures, hygrothermal aging may also become important, and a part of the measured higher equilibrium moisture content may be due to crazing and microcracking in the polymeric sample.

\subsubsection{Water - Polymer interactions}

FTIR and NMR studies have shown (Antoon and Koenig (1981), Verghese et al., (1999), Koltz et al., (1996)) that the water molecules can interact with specific groups on the polymer chains (e.g., epoxide, $-\mathrm{NH},-\mathrm{OH})$. The peaks of the corresponding groups were altered for samples equilibrated with water, when compared with those for the dry sample. Antoon and Koenig (1981) studied wet samples of diglycidyl ether of bis-phenol A (DEGBA) epoxy resin cured with methyl anhydride. They observed changes in the peaks for $\mathrm{C}=\mathrm{O}$ and also $-\mathrm{NH}$ groups, which indicated the interaction between water with these specific groups, in the aged epoxy samples.

Interactions of water with polar groups within the polymer chain of vinyl ester resins have been confirmed through FTIR studies on saturated samples. Specific interactions 
through hydrogen bonding were observed in DERAKANE ${ }^{\mathrm{TM}}$ 441-400 vinyl ester resin composites. FTIR studies made before and after aging showed a shift in the peak at 3500 $\mathrm{cm}^{-1}$ to lower wave numbers. This was attributed to the influence of the water molecule on the $-\mathrm{OH}$ group on the vinyl ester chain (Verghese et al., 1999). A model resin was also studied, in which the $-\mathrm{OH}$ groups were replaced by $-\mathrm{CH}_{3}$ groups. FTIR gave no evidence of water interacting with the polymer. There was only a vertical shift in the spectra, with no change in peak intensities, due to the existence of water that does not interact with the polymer. The model resin also did not exhibit the thermal-spiking phenomenon, and the saturation level of the resin was lower compared to DERAKANE ${ }^{\mathrm{TM}}$ 441-400 vinyl ester resin. Thermal spiking or Reverse Thermal Effect (RTE) is essentially the inverse dependence of moisture absorption on temperature near equilibrium saturation. Contrary to the observed phenomenon of equilibrium moisture content increasing with temperature, it was observed that some polymers absorbed additional moisture, reaching a higher equilibrium moisture content, when placed in a cooler temperature water bath, after they had been saturated at a relatively higher temperature. Verghese et al., (1999) concluded that the reverse thermal effect was due to hydrogen bonding of water with the polymer. The hydrogen bonding tends to become stronger as temperature decreases, which led to the polymer absorbing more water when placed in water bath at a lower temperature. This phenomenon was not observed in the model resin, where the equilibrium moisture content reduced when the sample was transferred to a bath at a lower temperature. Also, the new equilibrium content corresponded to the equilibrium moisture content of a sample equilibrated at $25{ }^{\circ} \mathrm{C}$. The model resin lacked the $-\mathrm{OH}$ groups on its backbone and hence lacked the ability to 
hydrogen bond with the diffusing water. This study showed the existence of hydrogen bonding within the polymer system and its effect on equilibrium moisture content.

It is also proposed (Klotz et al., 1996) that these interactions may lead to some water becoming bound, and hence, a cause for anomalous behavior. This is evident due to residual moisture remaining in the resin, which can only be removed by heating the polymer to above its $\mathrm{T}_{\mathrm{g}}$. This would lead to water existing as either "bound" or "unbound" water within the system. Existence of water in these two states was confirmed by ${ }^{2} \mathrm{H}$ - NMR studies by Klotz, et al., (1996) on diglycidyl ether bisphenol A resin cured with dicyandiamide, and/or diamino-diphenyl sulfone. The exact nature of the bound sites is not definitely determined. They found the diffusing heavy water to exist in two different states, bound and free. It is proposed that the water molecules form hydrogen bonds with the polar groups present and become bound. The unbound water resides in cracks/voids and interface region and hence, is more mobile. It is also believed that water might cluster within the polymer. However, the absence of the endothermic peak in the DSC at $0{ }^{\circ} \mathrm{C}$ (denoting the melting of ice) is a sign that clustering may not take place (Netravali, et al., 1984).

\subsubsection{Effect of Changes in the physical structure of the resin and the composite}

Changes can take place within the polymer and polymer composites due to the sorption of water, and these may be reversible or irreversible. Wong and Broutman (1985a) showed that slow rearrangement of the polymer chains takes place due to ingress of the water molecule. This causes changes in the free volume and hence, the second and 
subsequent sorption, was found to be comparatively faster than the first sorption experiment. Wong and Broutman (1985a-b) studied the sorption of water into EPON 828 resin (DGEBA) cured with m-phenyldiamine/aniline and concluded that Fickian sorption was taking place, although the diffusion coefficient was concentration dependent. The experiments were conducted at 70 and $90{ }^{\circ} \mathrm{C}$ and by immersion in distilled water. Desorption as well as resorption proceeded faster than the first sorption. However, the amount of water taken in was the same as that of the original sample. This led them to propose that the rearrangement of polymer chains did not cause any damage to the epoxy resin. Also, this rearrangement was not permanent and the polymer reverted to its original form when annealed or heated to temperatures greater than its $T_{g}$. When this sample was subjected to the sorption experiment after annealing, the behavior was found to be the same as that of the original sample.

McMaster and Soane (1989) also found that the $2^{\text {nd }}$ and $3^{\text {rd }}$ sorptions were faster than the first. The diffusion coefficient for one such result was, first sorption, $3.5 \times 10^{-9} \mathrm{~cm}^{2} / \mathrm{sec}$ and second sorption $4.2 \times 10^{-9} \mathrm{~cm}^{2} / \mathrm{sec}$. Hence, the history of the polymer can have a definite bearing on subsequent sorption.

Moisture sorption into a polymeric material lowers the glass transition temperature $\left(\mathrm{T}_{\mathrm{g}}\right)$ and hence reduces the maximum working temperature of the material. Reduction of $\mathrm{T}_{\mathrm{g}}$ is due to plasticization effect of water on the polymer. The water disrupts the inter-chain hydrogen bonding between the $-\mathrm{OH}$ groups on the polymer backbone. This induces higher molecular mobility and hence lowers glass transition temperature. Hilts and 
Keough (20) studied the influence of absorbed water on the $T_{g}$ of a poly amideimide using dynamic mechanical analysis (DMA) and differential scanning calorimeter (DSC). The results indicated a decrease in $\mathrm{T}_{\mathrm{g}}$ from $568 \mathrm{~K}$ to $477 \mathrm{~K}$ as the weight of absorbed water increased from $0 \%$ to $4.25 \%$. This established a clear correlation between $\mathrm{T}_{\mathrm{g}}$ and amount of water absorbed. The reduction in $\mathrm{T}_{\mathrm{g}}$ is solely due to plasticization of the resin, and the chemical structure is not affected; a decrease in $T_{g}$ is observed due to increase in the chain mobility. Ghorbel and Valentin (1993) correlated the decrease in $T_{g}$ as a function of exposure time in vinyl ester resins. They found that for nearly completely cured samples, $\mathrm{T}_{\mathrm{g}}$ decreased with time as an exponential function modeled as $\mathrm{T}_{\mathrm{g}}=\mathrm{A} \exp (-\mathrm{Bt})+\mathrm{C}$

where $\mathrm{A}, \mathrm{B}$ and $\mathrm{C}$ are constants. For partially cured samples, $\mathrm{T}_{\mathrm{g}}$ increased after a while probably due to additional curing of the sample.

Concerning vinyl ester reins, hydrolysis of the matrix is observed for long periods of time ( $>4000$ h) (Buck et al., 1998). Water causes the ester linkages to break into acid and alcohol groups. Vinyl ester resins are generally considered more stable to such hydrolysis than polyester resins. This is because the ester linkages in vinyl ester resins are terminal and are shielded by the methyl functional groups. The results of Chin et al., (1999) emphasized this fact as they observed weight loss, attributed to leaching of hydrolysis products, in polyester resin samples in salt water and concrete pore solution at $60{ }^{\circ} \mathrm{C}$. This was not observed in vinyl ester resins. However, Ghorbel and Valentin (1993) studied the changes in structure with time of aging using FTIR and concluded that the 
above reaction was contributing to hydrolysis of the vinyl ester resin at long exposure duration.

Additional irreversible changes that may take place in the composite are cracking/crazing and degradation of the matrix/fiber interface. Under extreme conditions, (i.e., temperatures close to boiling point of water) Ishai (1975) found significant damage to the resin as well as the reinforcing fibers (shown by SEM studies of sectioned samples). Among the different kinds of damage, he found extensive cracking, debonding at the matrix-fiber interface, and also degradation of the glass fibers. Dewimille and Bunsell (1983) studied sorption in DGEBA composites and also found similar results. Significant damage was found to lower fiber regions, attributed to imbalance of stress distribution. However, damage at lower temperatures was negligible. Samples that were immersed in distilled water at room temperature for over 3 years showed no damage to the composite structure. An important conclusion of their study was that long-term aging cannot be simulated by subjecting the resin or composite to higher temperatures, since under these conditions, other phenomena such as permanent damage to resin takes place that dominate over the sorption of water. Thus, at higher temperatures, there were other factors that controlled the sorption process. Cracking/crazing of the resin and degradation of the interfacial layer and damage to fibers at higher temperatures dominated the sorption process, and these phenomena were found to be increasingly important as the temperature was increased. 


\subsubsection{Effect of Extent of Cure}

The effect of curing temperature and time of cure has been reported by a number of researchers. Though, post-cured samples have greater crosslinking and are expected to absorb less water, exactly the opposite has been observed in epoxy resins. In all cases, the amount of water sorbed has been found to increase with the extent of curing. Wong \& Broutman (1985a) found this in their study of DGEBA/ m-phenyldiamine/aniline epoxy resin. Shalin and Peppas (1991) found the post cured TGDDM/DDS resin to consistently sorb more water than the one without the post cure.

Wong and Broutman (1985a) also observed that the post-cured sample did absorb more water. One sample (E-1) was given an additional cure for $2 \mathrm{hrs}$ at $175{ }^{\circ} \mathrm{C}$. The equilibrium moisture contents of the two samples are summarized in Table 2.5.

Table 2.5. Equilibrium moisture content and glass transition temperature of Epon 828 with two different cure cycles. (Wong and Broutman 1985a)

\begin{tabular}{|c|c|c|c|}
\hline Sample & Cure & $\mathrm{M}_{\infty} \%$ & $\mathrm{~T}_{\mathrm{g}}{ }^{\circ} \mathrm{C}$ \\
\hline \multirow{3}{*}{$\mathrm{E}-1$} & $85^{\circ} \mathrm{C}, 2 \mathrm{~h}$ & 3.42 & 146 \\
& $150^{\circ} \mathrm{C}, 2 \mathrm{~h}$ & & \\
& $175^{\circ} \mathrm{C}, 2 \mathrm{~h}$ & & 144 \\
\hline $\mathrm{E}-2$ & $85^{\circ} \mathrm{C}, 2 \mathrm{~h}$ & Approx. 3.0 & \\
& $150^{\circ} \mathrm{C}, 2 \mathrm{~h}$ & & \\
\hline
\end{tabular}

Enns and Gillham (1983) cured DGEBA with a stoichiometric amount of DDS at $175^{\circ} \mathrm{C}$ for 4 different times, 50, 100, 180 and 600 minutes. 600 minutes was not enough to cure the sample fully, as the $\mathrm{T}_{\mathrm{g}}$ was below the $\mathrm{T}_{\mathrm{g} \infty}$ (approx. $215^{\circ} \mathrm{C}$ ) of the fully cured sample. 
The samples were then subjected to a humid environment at $25{ }^{\circ} \mathrm{C}$. Four different humidities were used, $31 \%, 51 \%, 79.3 \%$ and $93 \%$. The sorption experiments showed that the more cured sample absorbed more water at all the conditions. Typical results are shown in Table 2.6. Although a definite explanation was not given, it is possible that greater cure in epoxy resins leads to the formation of more $-\mathrm{OH}$ groups, making the epoxy resin more susceptible to water absorption. However this phenomenon can be offset by the fact that longer cure cycles lead to greater cross-linking (indicated by increase in $\mathrm{T}_{\mathrm{g}}$ ) which sterically shields some $-\mathrm{OH}$ groups.

Table 2.6 Variation of density, $T_{g}$, equilibrium moisture content and diffusion coefficient of Epon 828 with cure time. Data for exposure to $51 \% \mathrm{RH}$ and $25{ }^{\circ} \mathrm{C}$ (Enns and Gillham 1983).

\begin{tabular}{|c|c|c|c|c|}
\hline Cure time, min & $\mathrm{T}_{\mathrm{g}}{ }^{\circ} \mathrm{C}$ & Density $(\mathrm{g} / \mathrm{ml})$ & $\mathrm{M}_{\infty}, \mathrm{wt} \%$ & $\mathrm{D} \times 10^{9} \mathrm{~cm}^{2} / \mathrm{s}$ \\
\hline 50 & 135 & 1.237 & 1.074 & 1.69 \\
\hline 100 & 160 & 1.2357 & 1.136 & 1.7707 \\
\hline 180 & 185 & 1.2339 & 1.65 & 1.58885 \\
\hline 600 & 195 & 1.2334 & 1.737 & 1.7170 \\
\hline
\end{tabular}

The effect of resin morphology and polarity on diffusion properties was shown by Diamant et al., (1981). They varied the crosslink density of DGEBA epoxy resin by replacing stoichiometic amounts of the original diamine hardener (m-phenylene diamine) by monoamine hardener (aniline). The cross-link density decreased as more m-phenylene diamine was substituted by aniline. Contrary to expectations, $M_{\infty}$ and diffusivity decreased as the amount of aniline was increased, i.e., with a decrease in cross-link density. Samples with aniline showed a two-phase morphology, where regions of low 
cross-link density were surrounded by regions of higher cross-link density. It was proposed that the high cross-link density regions slowed or prevented water from entering the encapsulated low cross-link density regions. Another possible explanation given was based on the relative polarities of the hardener used. m-phenylene diamine being more polar was expected to attract more moisture than aniline, leading to higher moisture contents. Some of the results are tabulated in Table 2.7.

Table 2.7 Diffusion parameters of water through EPON 828 with varying percentages of Aniline at $25^{\circ} \mathrm{C} / 98 \%$ RH (Diamant et al., 1981)

\begin{tabular}{|c|c|c|c|c|c|}
\hline Sample & $\begin{array}{c}\text { Wt \% } \\
\text { aniline }\end{array}$ & $\mathrm{M}_{\mathrm{c}}$ & $\mathrm{T}_{\mathrm{g}},{ }^{\circ} \mathrm{C}$ & $\mathrm{M}_{\infty}$, wt. \% & $\begin{array}{c}\mathrm{D}, \mathrm{x} 10^{9} \\
\mathrm{~cm}^{2} / \mathrm{s}\end{array}$ \\
\hline E-1 & 0 & 446 & 150 & 3.1 & 0.83 \\
\hline E-2 & 7.6 & 605 & 127 & 2.7 & 0.66 \\
\hline E-3 & 10.2 & 874 & 113 & 2.5 & 0.6 \\
\hline
\end{tabular}

$\mathrm{M}_{\mathrm{c}}$ is the average chain molecular weight between adjacent crosslinks.

\subsubsection{Effect of Glass Reinforcement}

Marsh, et al., (1984) studied the sorption of water into a bisphenol A and cresol novolac epoxy cured with dicyandiamide. Neat resins as well as composites with $40 \%$ E-type glass were studied at $75{ }^{\circ} \mathrm{C} / 100 \% \mathrm{RH}$. The sorption by the composite was the same as that of the neat resin if the volume of glass was corrected for. Also, both the neat resin as well as the composite showed an intermediate saturation before the onset of residual moisture. These similarities led them to the conclusion that the water did not enter the interface between the matrix and the fiber, and hence there was no difference in the sorption of neat resin and composites. On the other hand, Ishai (1975) showed that the 
behavior of neat resins was quite different from composites. In the case of diffusion of moisture into Epon 828 resin with E-type glass fibers, significant damage was found not only to the interface but also to the glass fiber (confirmed by SEM pictures). The degradation was signaled by a drastic change in the sorption curve. Plotting the Relative Weight Change (RWC) versus Relative Length Changes (RLC) also showed the onset of degradation. The extent of degradation was more for samples exposed to extreme environments, i.e., temperatures of $80{ }^{\circ} \mathrm{C}$. Also, the degradation of the interface was considerably lesser at lower temperatures, i.e., $20{ }^{\circ} \mathrm{C}$. Similar results were obtained by Dewimille and Bunsell (1983) who also found the composite (DGEBA/Anhydride with E-Glass) to degrade when exposed to water at high temperatures $\left(80^{\circ} \mathrm{C}\right.$ and above).

Similar sorption studies were made on glass fiber reinforced vinyl ester composites. The effect of lay-up sequencing of glass fibers in various acidic environments was studied by Pai, et al., (1997 a-b) on 6 different types of resins, including vinyl esters. Composite samples were made with three different lay-up sequences using chopped strand mat (CSM) and woven roving of E-glass laminate layers. They found that the composite with chopped strand matrix in outer layers exhibited the least resistance to all liquids (water, $15 \%, 25 \%$ and $35 \%$ sulfuric acid). It was believed that the loosely bound fibers of chopped strand mat layers facilitated an easy path for the diffusing molecule. On the other hand, the more compact woven roving mat presented a smaller diffusing path, which led to the lower diffusion coefficient values in these composites. Although the diffusion process became sluggish as the concentration of sulfuric acid increased, the saturation levels were also much higher. They also studied the extent of degradation of 
the composite. They assessed the fiber/matrix interface by performing an Interlaminar Shear Strength Test. The loss of the shear strength increased as the concentration of sulfuric acid increased, showing an increased rate of degradation with increasing $\mathrm{pH}$.

In order for the composite to function properly, it is desirable that there be a chemical bond between the matrix and the reinforcing fibers so that the applied load (applied to the matrix) can be transferred to the fibers. In 'fiber glass', the fiber is inorganic while the matrix is organic, and the two do not bond readily unless the fibers are treated to modify their surface. Silica $\left(\mathrm{SiO}_{2}\right)$ is hygroscopic, i.e., it absorbs water onto its surface where the water breaks down into hydroxyl (-OH) groups. The coupling agent takes the form of a silane $\left(\mathrm{R}-\mathrm{SiX}_{3}\right)$ where $\mathrm{R}$ is an organic radical that is compatible with the polymer matrix and $\mathrm{X}$ is a hydrolizable organic group such as an alcohol. The most common silane coupling agent is tri-ethoxy-silane. Heat will force the elimination of water between the $\mathrm{OH}$ pairs at the hydrated silica surface and the silane, as well as between the adjacent silane molecules forming a strong bond between the matrix and the fibers. (Figure 2.5)

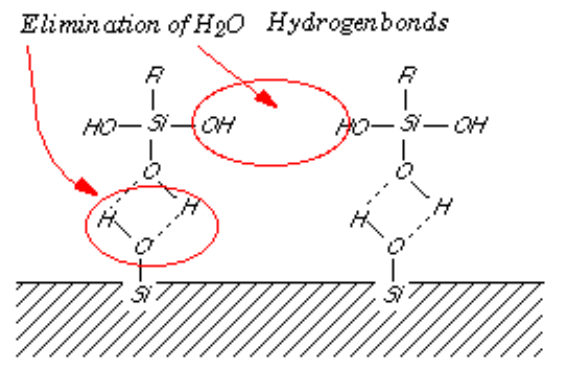

Figure 2.5 Bonds between glass fiber and coupling agent (Ritter et al., 1998). 
If the bonds are chemical, then the presence of the glass will have a negligible effect. If, however, the bonds are weak and can be displaced by the hydrogen bonding due to water, debonding and degradation of the glass fiber can be pronounced. Ritter et al., (1998) studied the propagation of a crack in monolithic glass (soda-lime and fused silica), untreated glass-epoxy interface, and glass-epoxy interface sized with 2-amino propyl triethoxy silane (3-AMPS) using a double cleavage drilled compression test. All samples were subjected to a $95 \%$ humid atmosphere for 1 hour before testing. The adhesive strength was the strongest for the glass-epoxy interface, which was sized with 3-AMPS. It also had the highest threshold-energy release rate $\mathrm{G}_{\text {th }}$ (below which no measurable crack growth occurred). The propagation of the crack in the untreated epoxy-glass interface takes place due to the displacement of the physically adhered epoxy molecules, starting from the crack tip.

The increase in resistance of the silane bonded epoxy interface is due to the fact that the epoxy is chemically bonded to the glass via the coupling agent. The rupture or debonding will take place only by breaking of the Si-O-Si bonds formed between the glass and the silane-coupling agent. However, the $\mathrm{G}_{\mathrm{th}}$ for the soda-lime glass is lowered as the alkali molecules can bond with water and hence prevent the silane molecules from properly bonding to the glass surface. The $\mathrm{G}_{\mathrm{th}}$ calculated is given in the Table 2.8 . 
Table 2.8. Threshold-energy release rate for various glasses and glass-epoxy systems (Ritter, et al., 1998)

\begin{tabular}{|l|c|}
\hline Specimen & $\mathrm{G}_{\mathrm{th}}, \mathrm{Jm}^{-2}$ \\
\hline Soda-Lime glass (SLG) & 1.69 \\
\hline Fused Silica (FS) & 2.76 \\
\hline Untreated SLG-Epoxy & 0.25 \\
\hline Untreated FS-Epoxy & 0.25 \\
\hline Silane treated SLG-Epoxy & 1.32 \\
\hline Silane treated FS-Epoxy & 3.31 \\
\hline
\end{tabular}

\subsection{Nanocomposites}

The field of nanocomposites has attracted considerable attention as a method of enhancing polymer properties and extending the utility of polymers, both thermoplastics and thermosets, by using nanoscale reinforcements like clays. Nanocomposites, similar to all composites, are a combination of 2 or more phases containing different compositions or structures. Here, however, at least one dimension of one of the phases is in the nanometer regime. The nanofiller has a large aspect ratio, is orientable and has a large surface area per unit volume.

\subsubsection{Structure of Nanoclays}

Clay is the most common reinforcement used in polymer nanocomposites. The principal building blocks of nanoclay minerals are 2-D arrays of silicon - oxygen tetrahedra and 2D arrays of Al-, or Mg - oxygen - hydroxyl octahedra (van Olphen, 1977). In the Sioxygen sheets, the Si atoms are coordinated with 4 oxygen atoms, each located at the 4 corners of a tetrahedron. This is called the tetrahedral sheet or the silica sheet. In the Al-, 
$\mathrm{Mg}-\mathrm{O}-\mathrm{OH}$ sheets, the $\mathrm{Al}$ or $\mathrm{Mg}$ atoms are coordinated with six oxygen or hydroxyl groups located at the 6 corners of a regular octahedron. This is called the octahedral sheet or the alumina or magnesia sheet. The apex oxygen atom in the silica sheet is shared with the adjacent octahedral sheet. Sharing may take place between one tetrahedral sheet and one octahedral sheet or between 2 tetrahedral sheets and one octahedral sheet. This gives rise to 2 or 3 layered clays. Such a combination is called a unit layer. Clays are composed of many such layers stacked parallel to each other and held together by van der Waals forces of attraction. Within each layer a certain unit of structure repeats itself. This is called a unit cell. A typical unit cell of a Montmorillonite (MMT) type of clay is shown in Figure 2.6.

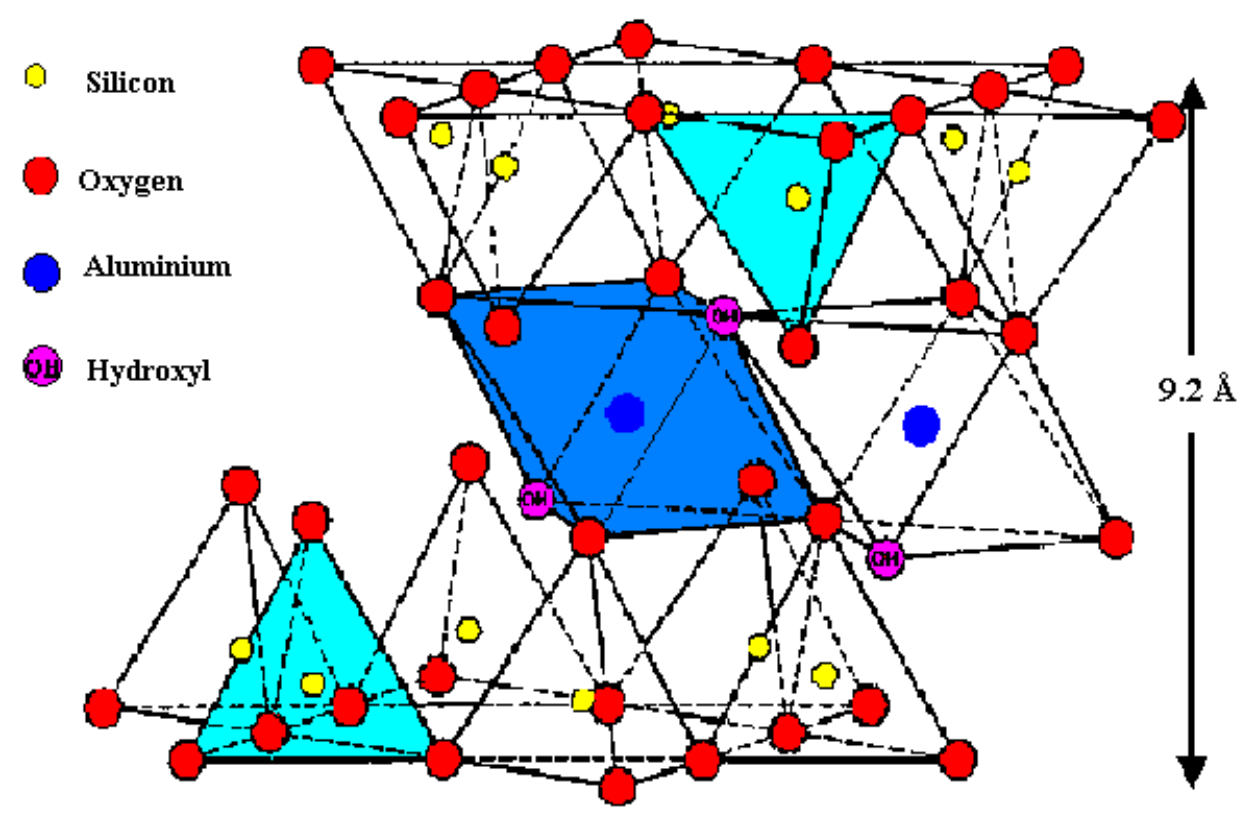

Figure 2.6. Structure of Montmorillonite (MMT) clay (Kornmann et al., 1998) 
The distance between a certain plane in the unit layer, to the corresponding plane in an adjoining layer is called the 001 basal spacing or the d-spacing. For 2-layered clays it is between 7.1-7.2 $\AA$, and for 3-layered clays it is $9.2 \AA$.

In many types of clay, (e.g., Montmorillonite) some tetravalent Si atoms in the tetrahedral sheet are partly replaced by trivalent atoms like Al. Also, in the octahedral sheet, some trivalent $\mathrm{Al}$ atoms may be replaced by divalent atoms like $\mathrm{Mg}, \mathrm{Fe}, \mathrm{Cr}, \mathrm{Zn}$ etc. This results in a deficit of positive charge or an excess of negative charge being imparted to the clay platelet. This negative charge is compensated by adsorption, on the clay surface, of cations such as $\mathrm{Na}^{+}$and $\mathrm{Ca}^{2+}$. In the presence of water, these cations can be exchanged for others that are present in the solution. This property of clays is used to treat the surface of the clay with organic cations, to make it compatible with an organic phase, such as a polymer. The swelling in water causes an increase in the basal spacing allowing easy insertion of bulky organic groups and it also serves as a medium in which the exchange takes place. This is explained in the section 2.2.2.1. The amount of cations that can be exchanged is expressed in milli-equivalents per 100 grams of dry clay and is called Cation Exchange Capacity (CEC).

\subsubsection{Surface Modification}

Clay by nature is hydrophilic and swells upon adsorption of moisture. To make it compatible with an organic material such as a polymer, it is given a surface treatment involving a compatibilizer. One may, for example, adsorb on the surface of the clay, organic cation molecules, thus changing the hydrophilic character to organophilic, and 
thereby improving wetting of the clay with an organic polymer. In addition to this, surface treatment serves two other purposes, (1) it reduces the layer-to-layer interaction, and (2) it causes expansion of the gallery spacing to as much as $20 \AA$, allowing greater intercalation of polymer molecules between the clay platelets. Intercalation is the term given to the process by which monomer or polymer molecules enter into the gallery spacing during the preparation of the nanocomposite. This not only swells the clay by pushing the clay platelets apart, but also serves to reduce the forces of attraction between them. The individual clay particles can then be separated and dispersed into the polymer matrix. This is called exfoliation. For thermoplastic materials, exfoliation is done either during polymerization or by the application of shear forces in an extruder (Dennis et al, 2001). For thermosetting resins, on the other hand, exfoliation is achieved by dispersing the clay in the liquid resin by the application of shear forces. Surface modification can be done by:

1. Ion Exchange Method

2. Ion Dipole Method

\subsubsection{Ion Exchange Method}

This is the simplest technique used to treat the clay. Ion-exchange treatment involves replacing the adsorbed cations (such as $\mathrm{Na}^{+}, \mathrm{Ca}^{2+}$ ) by an organic cation, typically an onium ion or an amine salt. The organic molecule replaces the cation making the clay surface organophilic. The organic molecules also enter the gallery spacing and cause the clay to swell. This technique was first developed at the Toyota Central R\&D 
Laboratories, Japan (Lan et al., www.nanocor.com) where montmorillonite was compatibalized with Caprolactum (Nylon) using amino dodecanoic acid.

\subsubsection{Ion Dipole Method}

Ion Dipole surface treatment is a relatively new approach where the sodium atoms are left on the surface of the clay. The induced positive charge on the sodium atoms can interact with partially negative charges on functional monomers or polymer groups. The functional groups having negative dipole moments include alcohols, carbonyls, esters, amines and ethers. This process was developed by Nanocor, Inc., of Chicago. (Lan et al., Www.nanocor.com)

\subsubsection{Types of Nanocomposites}

Based on their morphology, clay filled nanocomposites maybe be of three types (Kornmann et al., 1998):

1. Conventional Composite

2. Intercalated Composite

3. Delaminated Composite or exfoliated.

In a conventional composite, the silicate tactoids exist in their original aggregated state with no intercalation. The basal spacing of the clay within the nanocomposite remains the same as in the pristine clay. An intercalated composite has polymer molecules between the silicate platelets, but the individual platelets have not completely separated. Consequently, the XRD peak would be shifted towards higher basal spacing. A 
delaminated composite has individual clay platelets uniformly dispersed in the matrix. A schematic representation of this is shown in Figure 2.7. The full potential of nanoclay fillers is only realized in the exfoliated form. Note that montmorillonite has a high surface area, of the order of $750 \mathrm{~m}^{2} / \mathrm{g}$ (Dennis et al., 2001). Property enhancements are obtained due to molecular scale interactions between the polymer and the clay surface. These interactions are greater in exfoliated morphology, where the clay particles present the largest surface area, when they exist as individual platelets. Also, since during exfoliation clay aggregates break up into several nanometer sized individual platelets, very small clay loading can lead to significant property enhancements.

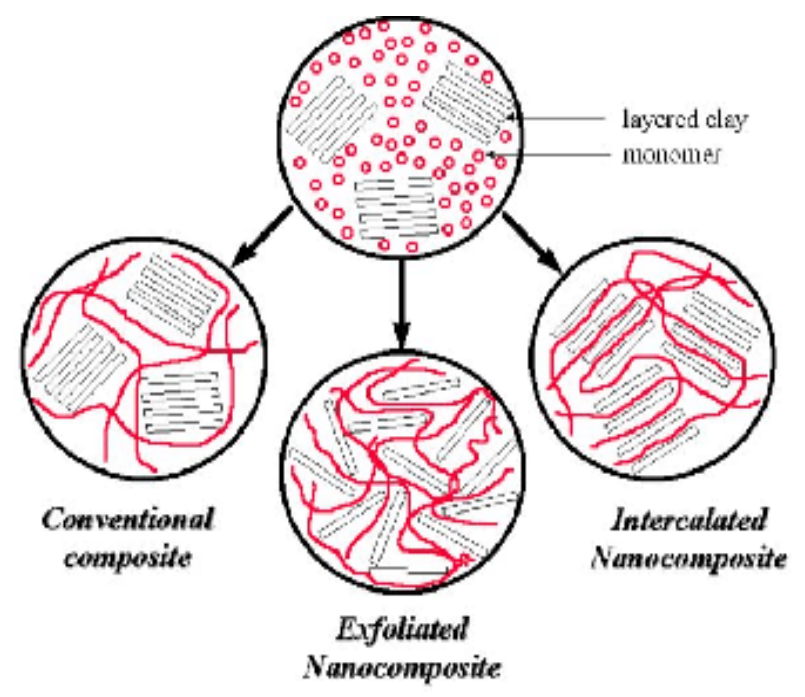

Figure 2.7 Types of Nanocomposite morphologies (Kornmann, et al., 1998)

The various types of clay minerals are Montmorillonite, Illite, Kaolinite and Attapulgite. Of these, the illinite clays are non-swelling and hence do not offer the required qualities for use in composites. The Kaolinite and Attapulgite clays have low CEC's compared to Montmorillonite clays. Kaolin also has a small basal spacing, and so the penetration of 
intercalant into the space between the individual layers is limited. By far, the most popular clay used for nanocomposites is Montmorillonite (MMT).

Montmorillonite clays have a flat plate-like structure with a large aspect ratio in the range of 200-1500. Each platelet has length and width in the range of microns but thickness of only one nanometer. MMT has a high CEC in the range of 70 to 140 milligrams per 100 grams of dry clay. Montmorillonite clays are popular in making nanocomposites because of the following reasons:

1. Bentonite is the most abundantly available clay, and it contains over $50 \%$ montmorillonite.

2. Montmorillonite belongs to the smectite (Swelling clay) family of clays. They also have high CEC that allows easy surface treatment and intercalation by organic molecules when compared to other clays like Kaolin that have CEC of $1-10$ and do not swell as much.

3. Particle shape is known to affect barrier properties. Montmorillonite is a nanoparticle with a plate-like shape with a high aspect ratio. Hence, at the same loading, it leads to a better permeation barrier when compared to Attapulgite clay, which has a needle like shape.

4. Montmorillonite develops similar increase in modulus and tensile strength at loading of $3-5 \%$ as compared to $20-60 \%$ loading of other fillers like Kaolin and carbon black. 


\subsubsection{Properties of Polymer - Nanocomposites}

In addition to their space filling properties, nanoclays also increase flexural modulus, tensile strength, fire retardation properties, and improve barrier properties to gases and liquids (Kornmann et al., 1998, Yano et al., 1993, Chen and Curliss, 2001), even at low loading of $2-10 \mathrm{wt} \%$. Yano et al., (1993) prepared polyimide - montmorillonite nanocomposites using montmorillonite that was treated with an ammonium salt of dodecylamine. An exfoliated morphology was observed. They found permeability coefficients of polyimide nanocomposites to be reduced by half with only $2 \mathrm{wt} \%$ loading of clay, compared to ordinary polyimide samples. This is illustrated in Figure 2.8. The exfoliated clay improves barrier properties by physically impeding the movement of the penetrant through the matrix. The mechanism is termed "Tortuous Path" impedance. The clay nano platelets orient themselves in layers as shown in the schematic representation in Figure 2.9. Due to the nanoclay particles dispersed through out the resin, the effective path of the diffusing molecule is longer, leading to a decrease in the diffusion coefficient and permeability. 


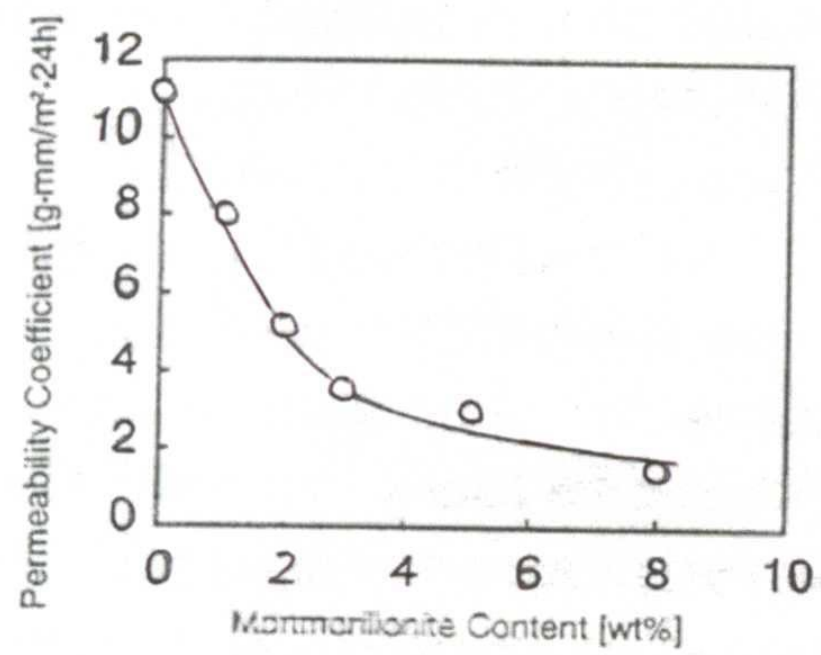

Figure 2.8 Dependence of permeability of water vapor on montmorillonite content in polyimide - clay hybrids (Yano et al., 1993).

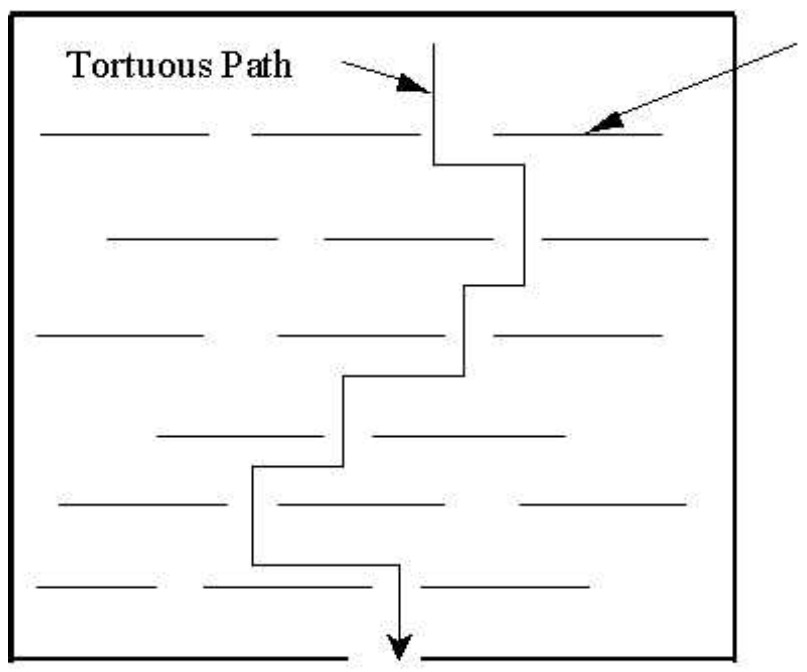

Dispersed Nanoclay

Figure 2.9 Schematic of the flow of a penetrant through a nanocomposite (Yano et al., 1993). 
The reduction in permeability can be explained by the tortuous path theory as explained by Yano et al., (1993). Permeability is the amount of material (in this case weight of water) passing through unit area of a membrane or film per unit time. In the ideal case the clay is assumed to completely exfoliate and orient themselves perpendicular to the direction of the diffusing molecule as shown in Figure 2.9. The effective path that the molecule has to traverse is then increased by $\mathrm{L} / 2$ for each clay platelet. The tortuousity $(\tau)$ is then given by the relation,

$$
\tau=\frac{1}{1+\left(\frac{\mathrm{L}}{2 \mathrm{~W}}\right) \mathrm{V}_{\mathrm{f}}}
$$

Hence the relative permeability is then written in terms of the clay platelet dimensions and content as,

$$
\frac{\mathrm{P}_{\mathrm{c}}}{\mathrm{P}_{\mathrm{p}}}=\frac{1}{1+\left(\frac{\mathrm{L}}{2 \mathrm{~W}}\right) \mathrm{V}_{\mathrm{f}}}
$$

where,

$\mathrm{P}_{\mathrm{c}}$ is the permeability of the nanocomposite

$\mathrm{P}_{\mathrm{p}}$ is the permeability of the neat resin (polymer).

$\mathrm{L}$ is the length of the clay plates.

$\mathrm{W}$ is the thickness

$\mathrm{V}_{\mathrm{f}}$ is the volume fraction of clay in the sample.

Kornmann et al., (1998) found that the tensile modulus of unsaturated polyester containing exfoliated montmorillonite increased linearly with clay content. The tensile strength, though, was observed to decrease only slightly at high clay contents. The 
fracture energy was also found to increase from $70 \mathrm{~J} / \mathrm{m}^{2}$ to $138 \mathrm{~J} / \mathrm{m}^{2}$ with montmorillonite content of only $1.5 \mathrm{vol} \%$. Chen and Curliss (2001) prepared exfoliated as well as partly exfoliated epoxy-montmorillonite nanocomposites, and these showed reduced thermal expansion coefficients, higher dynamic mechanical modulus, somewhat reduced fracture toughness and higher solvent resistance. Mass uptake of acetone of 6 wt.\% nanocomposite, after 38 days of immersion, was found to be half that of the unfilled polymer. The higher solvent resistance was ascribed to the barrier effect of the nanosheets. The flexural modulus and glass transition temperature changes with I.30E (Nanocor Inc.) nanoclay as reported by Chen and Curliss (2001) are listed in Table 2.9. Similar to Kornmann et al., (1998), they also concluded that the platelet-matrix interface was critical in improving mechanical properties such as toughness and strength.

Table 2.9 Glass Transition Temperature and Flexural Modulus of EPON 862/I.30E nanocomposites (Chen and Curliss, 2001).

\begin{tabular}{|c|c|c|c|}
\hline Sample & $\begin{array}{c}\text { Weight percent clay } \\
(\mathrm{I} .30 \mathrm{E})\end{array}$ & $\begin{array}{c}\text { Glass Transition } \\
\text { temperature, }{ }^{\circ} \mathrm{C}\end{array}$ & $\begin{array}{c}\text { Flexural modulus, } \\
\text { Ksi }\end{array}$ \\
\hline EPON 862 & 0 & 154 & 0.387 \\
\hline EPON 862 & 1.0 & 153 & 0.455 \\
\hline EPON 862 & 2.0 & & 0.435 \\
\hline EPON 862 & 4.3 & 158 & 0.436 \\
\hline
\end{tabular}

Messersmith and Giannelis (1995) found increased barrier properties in poly ( $\varepsilon$ caprolactone) nanocomposites. Transient water uptake of nylon nanocomposite films when exposed to $75 \% \mathrm{RH}$ was found to decrease with an increase in clay content. After $240 \mathrm{~h}$ of exposure, $4.8 \mathrm{vol} \%$ nanocomposites were found to have a $75 \%$ lower water 
uptake than neat resin samples. Weight gain after $240 \mathrm{~h}$ for neat nylon sample was approximately $0.42 \mathrm{~g}$, while for the $4.8 \mathrm{vol} \%$ nanocomposite was $0.1 \mathrm{~g}$. However, these are not equilibrium water uptake values. Similarly, they found a nearly linear decrease in nylon permeability with increase in montmorillonite content. The values are listed in Table 2.10.

Table 2.10 Composition and water vapor permeability in nylon nanocomposite films (Messersmith and Giannelis, 1995).

\begin{tabular}{|c|c|}
\hline Vol \% Silicate & Permeability $\times 10^{3} \mathrm{~g}-\mathrm{m} /\left(\mathrm{h}-\mathrm{m}^{2}\right)$ \\
\hline 0 & $0.185 \pm 0.023$ \\
\hline 1.1 & $0.164 \pm 0.011$ \\
\hline 2.5 & $0.113 \pm 0.017$ \\
\hline 3.6 & $0.076 \pm 0.003$ \\
\hline 4.8 & $0.038 \pm 0.006$ \\
\hline
\end{tabular}

Gilman, et al., (2000) in their flammability study with polystyrene and Nylon-6 nanocomposite systems found the peak heat release rate to be $50-75 \%$ lower for the nanocomposites. They also proposed that the enhanced flame-retardant properties were due to the clay consolidating the char, which then acted as a protective layer for the unburned polymer. In another study on epoxy and vinyl ester nanocomposites, Gilman at al., (1999) reported $25 \%$ and $39 \%$ reduction in peak heat release rate for DERAKANE ${ }^{\text {TM }}$ 8084 and DERAKANE ${ }^{\text {TM }} 441$ vinyl ester resins containing 6 wt \% Cloisite $15 \mathrm{~A}^{\circledR}$ nanoclay. However, heat of combustion, soot and carbon monoxide yields were found to be unchanged. Also, large uncertainties were observed in ignition times of the samples. 


\section{CHAPTER III}

\section{EXPERIMENTATION}

\subsection{Materials and Formulation}

The resin used in this study was DERAKANE ${ }^{\mathrm{TM}}$ 411-350 epoxy vinyl ester resin obtained from Dow Chemical Co., and it contained 45 wt.\% dissolved styrene. The resin was cured at room temperature, as recommended in the fabrication guidelines of Dow Chemical Co. The resin was cured at room temperature with $0.5 \%$ by weight of $6 \%$ Cobalt Naphthenate catalyst and 1.5 wt \% of Methyl Ethyl Ketone Peroxide (9\% active oxygen) initiator, both obtained from Sigma Aldrich Co. Additionally, $0.05 \%$ of $99 \% \mathrm{~N}$, N Dimethyl Aniline (Lancaster Synthesis, Pelham, NH) was used as an accelerator.

\subsubsection{Vinyl ester Chemistry}

Vinyl ester resins are produced by reacting an epoxy resin with an unsaturated monocarboxylic acid, in most cases Methacrylic acid, which produces a molecule with unsaturated polymeric reaction end groups (double bonds) and ester groups. A typical reaction is shown in Figure 3.1.

Vinyl esters have several advantages. The epoxy resin backbone gives the resin good toughness, while the hydroxyl groups provide improved wetting and adhesion. On a molecular basis, vinyl ester resins also have better chemical resistance due to the presence of the methyl groups that shield the ester groups. The presence of the unsaturated reactive end groups (double bonds) enables ease in processing of the resin. 
The vinyl ester resin used in the present work was DERAKANE ${ }^{\mathrm{TM}}$ 411-350 supplied by the Dow Chemical Co. Its structure is shown in Figure 3.2

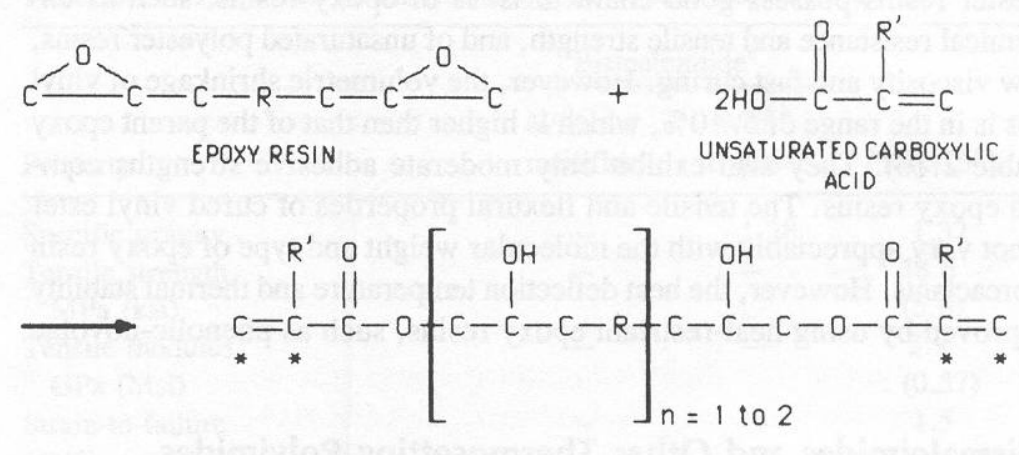

VINYL ESTER RESIN

where

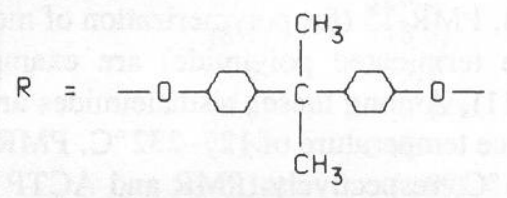

and

$$
R^{\prime}=-H \text { or }-\mathrm{CH}_{3}
$$

Figure 3.1. Chemistry of vinyl ester resin (Mallick, 1993)

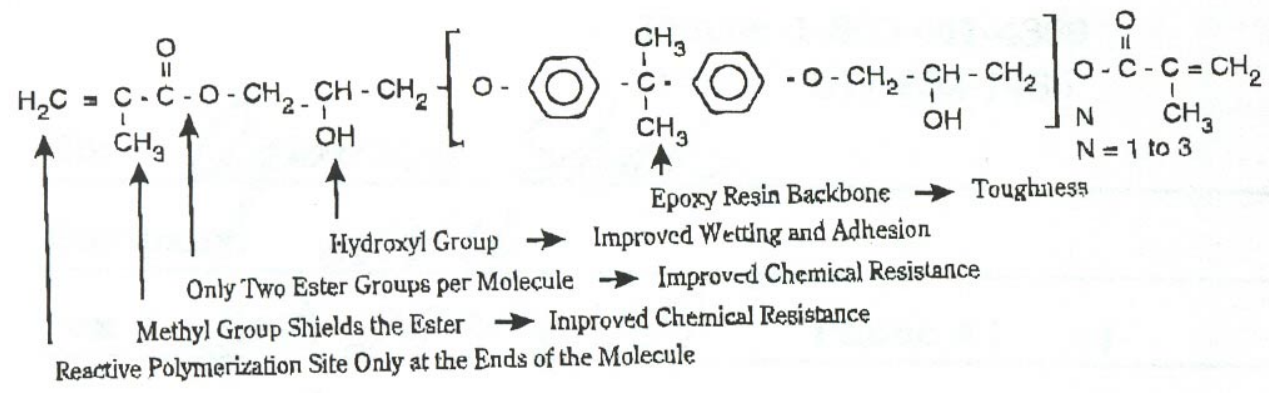

Figure 3.2 Schematic structure of DERAKNE Vinyl ester resins (Dow Chemical Co.)

Vinyl ester resins cure by chemical cross-linking reactions between the vinyl ester oligomers and styrene, in which they are dissolved. Most vinyl ester resin formulations contain about $35 \%$ or less of styrene. Vinyl esters may be cured at room temperature with 
initiator/promoter/accelerator systems. The most common source of free radicals, which are needed to initiate the curing reaction, are peroxides such as methyl ethyl ketone peroxide (MEKP) and benzoyl peroxide; these are called initiators. The function of the promoter or catalyst, usually cobalt naphthenate, is to decompose the initiator rapidly at room temperature. An accelerator commonly used with benzoyl peroxide is dimethyl aniline (DMA). The degree of cure will increase with time at room temperature, but if maximum corrosion resistance or heat distortion is required, then a postcuring step might be necessary. A schematic of a cross-linked vinyl ester resin is shown in Figure 3.3.

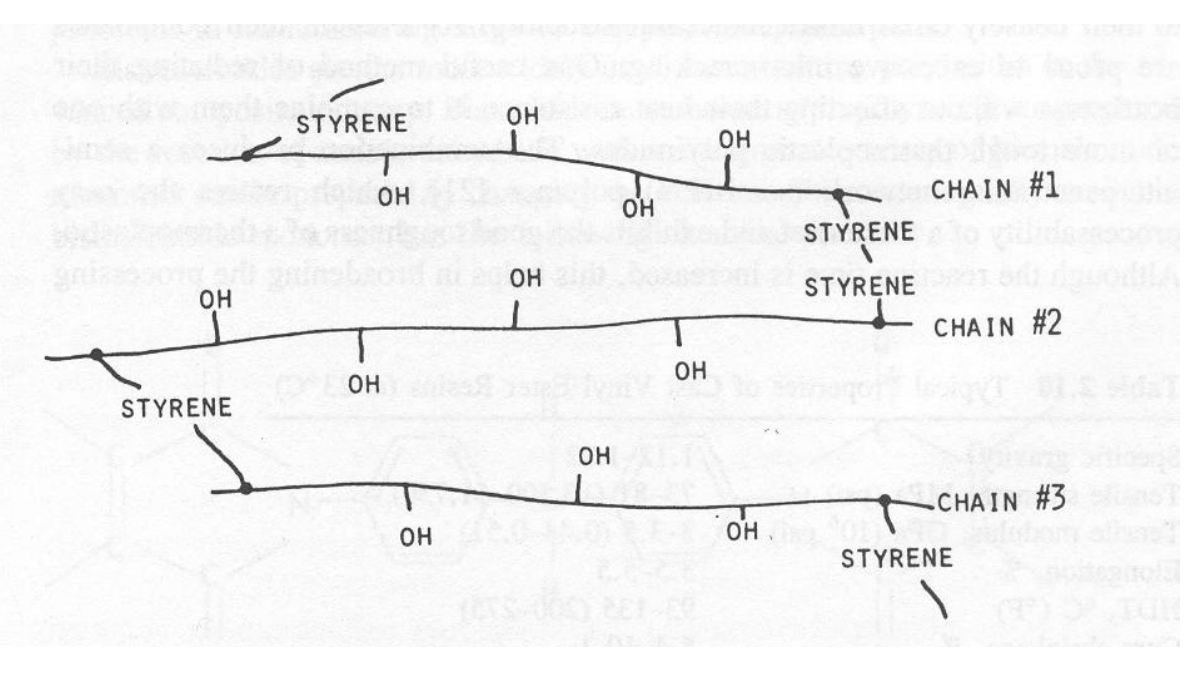

Figure 3.3 Schematic of a cross-linked vinyl ester resin (Mallick, 1993).

\subsubsection{Organomontmorillonite}

Two different clay samples were used in this study, Cloisite $10 \mathrm{~A}^{\circledR}$ and Vinyl Monomer Clay (VMC). The two clays differed only in the surface treatment group present on the clay. Cloisite $10 \mathrm{~A}^{\circledR}$ was used as obtained from Southern Clay Products, Inc, Gonzales, TX. This was Sodium Montmorillonite that had been treated with benzyl (hydrogenated 
tallow alkyl) dimethyl quaternary ammonium chloride. The organic content of Cloisite $10 \mathrm{~A}^{\circledR}$ is $\approx 39 \mathrm{wt} \%$, as determined by loss of weight on ignition.

VMC was prepared in the laboratory by treating sodium montmorillonite (Cloisite $\mathrm{NA}^{\circledR}$, Southern Clay Products, Inc, TX) with vinyl benzyl trimethyl ammonium chloride (Akelah and Moet, 1996), obtained from Sigma Aldrich Co. 30 grams of Cloisite $\mathrm{Na}^{\circledR}$ was dispersed in $800 \mathrm{ml}$ of distilled water with constant stirring with a mechanical stirrer for 5 hours. Separately, 6.35 grams of vinyl benzyl trimethyl ammonium chloride (VBTMAC) obtained from Sigma Aldrich Co., and corresponding to $100 \mathrm{meq} / 100 \mathrm{~g}$ of clay, was dissolved in $80 \mathrm{ml}$ of distilled water. At the end of $5 \mathrm{~h}$, the VBTMAC solution was added drop by drop to the clay dispersion, while stirring was continued. The result was the formation of a white precipitate of the organically treated clay. The mixture was stirred for another 3 hours, and the organomontmorillonite was then filtered using a vacuum filter and dried in an oven at $100{ }^{\circ} \mathrm{C}$. It was later ground in a ball mill. The organic content of $\mathrm{VMC}$ was $22 \%$ by weight.

\subsection{Sample Preparation}

Transparent, neat resin coupons of vinyl ester resin were cast by pouring the resin reaction mixture into Teflon ${ }^{\circledR}$ molds, and allowing the mixture to cure. For the diffusion experiments, mold dimensions were $50 \mathrm{~mm} \times 12.5 \mathrm{~mm}$, with the thickness ranging from $0.2 \mathrm{~mm}$ to $0.6 \mathrm{~mm}$. The polymer was allowed to cure at room temperature for 24 hours, and it was subsequently post cured in an oven for 3 hours at $90{ }^{\circ} \mathrm{C}$. In the case of vinyl ester resin-clay nanocomposites, the organically treated clay was added to the liquid resin 
and manually stirred. The mixture was then degassed in a vacuum oven to remove air bubbles. The catalyst, initiator and accelerator were then added, and the resin was poured into the molds and subjected to the same cure cycle as the neat resin. Nanocomposite samples were prepared using both Cloisite $10 \mathrm{~A}^{\circledR}$ and vinyl monomer clay; the samples were transparent at low concentrations of clay, while at higher concentrations $(5 \mathrm{wt} \%)$ they became slightly translucent. To examine the influence of mixing procedure, some of the samples containing VMC clay were not manually stirred. Instead, they were ultrasonically mixed for $30 \mathrm{~min}$.

Additionally, tensile test samples were prepared in dog-bone shaped Teflon ${ }^{\circledR}$ molds. The molds were made to conform to ASTM D638 Type I specifications. Impact tests were performed on a Instron/Satec BLI Impact testing machine equipped with a $2.71 \mathrm{~J} / \mathrm{m}(2 \mathrm{ft}-$ lb) IZOD pendulum. Samples were made as per ASTM D4812 specifications. Samples had a thickness of $5.7 \mathrm{~mm}$ as against the recommended $3.17 \mathrm{~mm}$ due to the brittleness of the vinyl ester resin. The procedure of making the samples was the same as for diffusion test samples, and all the samples were taken through the same cure cycle.

\subsection{Methods}

\subsubsection{Water Diffusion Experiments}

Diffusion coefficient and equilibrium moisture content in all samples was determined gravimetrically. The post-cured samples were immersed in distilled water at $25{ }^{\circ} \mathrm{C}$ (room temperature). The samples contained $0.05 \pm 0.005$ wt $\%$ water when diffusion experiments were started. The samples were periodically removed, blotted dry with a lint- 
free tissue, weighed, and re-immersed in the water. The process was repeated until equilibrium was attained. The sample was assumed to have attained equilibrium when the weight became a constant. A typical experiment lasted ten days, and, on the first day, readings were taken as frequently as every $15 \mathrm{~min}$. A Mettler electronic balance was used, and this had an accuracy of $1 \mu \mathrm{g} ; 3$ to 5 replicate runs were carried out for a given set of conditions. Plots of weight change versus reduced time were then prepared. The equilibrium moisture content and the diffusion coefficient were then calculated from the sorption curve as explained in section 2.1.1.

\subsubsection{X-Ray Diffraction Tests}

X-Ray diffraction was used to determine the basal spacing of the montmorillonite clay. These tests were performed on both clay and clay-polymer nanocomposites. The tests were performed at Southern Clay Products, Inc., Gonzales, TX, using a Scintag XDS2000 Diffractometer with a $\mathrm{CuK} \alpha$ source $(\lambda=1.5405 \AA)$. The samples were scanned from $2 \theta$ of $1^{\circ}$ to $11.98^{\circ}$. The slit settings on the tube side were $4 \mathrm{~mm}$ for scatter and 2 $\mathrm{mm}$ for divergence. The slit settings on the detector side were $0.5 \mathrm{~mm}$ for scatter and 0.2 $\mathrm{mm}$ for receiving. Intercalation of the clay by the polymer chains would lead to an increase in the basal spacing, while exfoliation would cause the peak in the XRD graph to disappear.

\subsubsection{Differential Scanning Calorimetry}

Differential scanning calorimeter (DSC) is a thermal analysis instrument that is used to characterize the properties of polymeric material. A TA Instruments DSC with a $910 \mathrm{~S}$ 
cell was used to obtain thermograms on the various samples and, to measure the glass transition temperature of the completely cured material; samples were scanned from 30 ${ }^{\circ} \mathrm{C}$ to $180{ }^{\circ} \mathrm{C}$ at a rate of $10^{\circ} \mathrm{C} / \mathrm{min}$. To ensure that the samples were completely cured, each sample was scanned twice, and the $T_{g}$ was determined from the second scan. The DSC was also used to determine the extent of cure of liquid samples. For liquid samples, the heat of reaction was obtained by performing a dynamic scan from $35{ }^{\circ} \mathrm{C}$ to $200{ }^{\circ} \mathrm{C}$ at a heating rate of $2{ }^{\circ} \mathrm{C} / \mathrm{min}$. The area under the peak gave the total heat evolved during the curing process.

\subsubsection{Transmission Electron Microscopy (TEM)}

Exfoliation of nanoclay within the polymer can be confirmed from pictures obtained using a transmission electron microscope, in which individual clay platelets can be clearly seen. TEM work was done on relatively thick nanocomposite samples in the Department of Pathology at West Virginia University, employing a JEOL 1010 Transmission Electron Microscope with an accelerating voltage of $80 \mathrm{kV}$. Micrographs were taken on $100 \mathrm{~nm}$ thick microtomed sections, cut parallel to the face of the sample. A representative diagram of the sectioning is shown in Figure 3.4. No staining of the sample was required to see the clay platelets. 


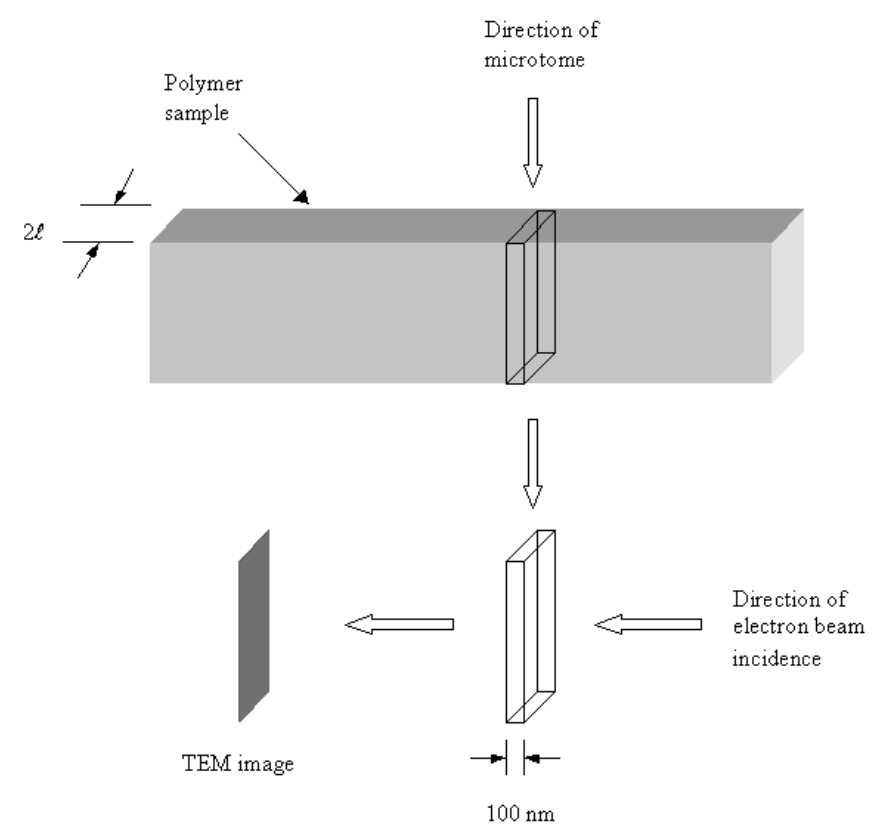

Figure 3.4. Schematic representation of sample microtoming for TEM analysis. Direction of electron beam incidence is the direction of view.

\subsubsection{Mechanical Tests}

Mechanical tests, to measure stiffness and strength, were performed using a $100 \mathrm{kN}$ Instron machine, model 8501 , at a displacement rate of $0.254 \mathrm{~mm} / \mathrm{min}$. The strain was measured independently using a strain gauge affixed to the mid-point of the specimen. The strain gauge used was obtained from Micromeasurements Inc., Raliegh, NC.

\subsubsection{Impact Tests}

Impact tests on un-notched samples were conducted on a Instron/Satec BLI Impact testing machine equipped with a $2.71 \mathrm{~J}(2 \mathrm{ft}-1 \mathrm{~b})$ IZOD pendulum at room temperature. 


\section{CHAPTER IV}

\section{RESULTS AND DISCUSSION}

\subsection{XRD and TEM Tests}

Figure 4.1 shows XRD scans on Cloisite $10 \mathrm{~A}^{\circledR}$ and also on nanocomposite samples containing different amounts of the organoclay. The XRD scans on $0.5,1,2.5$ and 5 wt \% Cloisite $10 \mathrm{~A}^{\circledR}$ nanocomposite samples do not show the characteristic basal reflection (peak) of Cloisite $10 \mathrm{~A}^{\circledR}$ at $1.9 \mathrm{~nm}$. The absence of such a peak is indicative of either exfoliation or breakdown of the ordered structure of the clay. Analysis of the TEM micrographs of the corresponding samples sheds further light on the morphology of the nanocomposite samples. TEM pictures of the samples at low magnification (1500x) show that the clay particles are reasonably uniformity distributed and are randomly oriented. This is what is expected, given the manner in which the samples were made. Representative TEM pictures of 0.5 and 5 wt \% Cloisite $10 \mathrm{~A}^{\circledR}$ are shown in Figures 4.2 and 4.3. The same trend was observed at 1 and $2.5 \mathrm{wt} \%$ samples also. Upon closer examination of the clay particles, at magnifications of $>100,000 x$, it was found that the clay did not exist as individual platelets. Figures 4.4 and 4.5 reveal the presence of aggregates, but the micrographs also show individual platelets in the form of dark lines. The aggregates were made up of 2 to 10 expanded silicate sheets. The size of these aggregates and the number of platelets in them were also found to increase with the percentage of clay within the sample. The distance between adjacent platelets in these aggregates was measured from the TEM pictures. The distance turned out to be in the range of $4.4-5.0 \mathrm{~nm}$, corresponding to a d-spacing of $5.4-6.0 \mathrm{~nm}$. Peaks corresponding 
to this $d$-spacing are then expected to appear at $2 \theta$ around $1-2^{\circ}$ in the XRD scan. These peaks are not likely to be visible in the XRD graph as the diffractometer looses its sensitivity at very small incident angles. This may explain the absence of any peak in the $\mathrm{XRD}$ in spite of the presence of aggregates or stacks of silicate plates as seen from the TEM. Also, from the TEM pictures it was seen that although aggregates of clay intercalates did exist, several had in fact peeled away from the stacks or exfoliated and are clearly visible as individual dark lines in high magnification $(>100,000 x)$ TEM pictures shown in Figures 4.4 and 4.5.

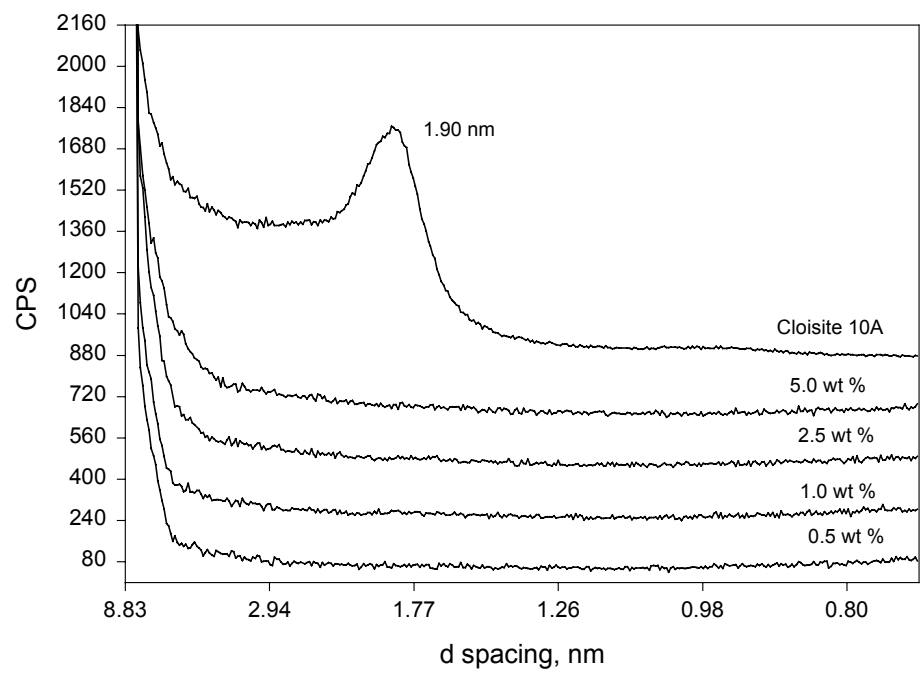

Figure 4.1 XRD scans on Cloisite $10 \mathrm{~A}^{\circledR}$ and Cloisite $10 \mathrm{~A}^{\circledR}$ nanocomposite samples. Wt $\%$ organoclay is indicated on the figure. 


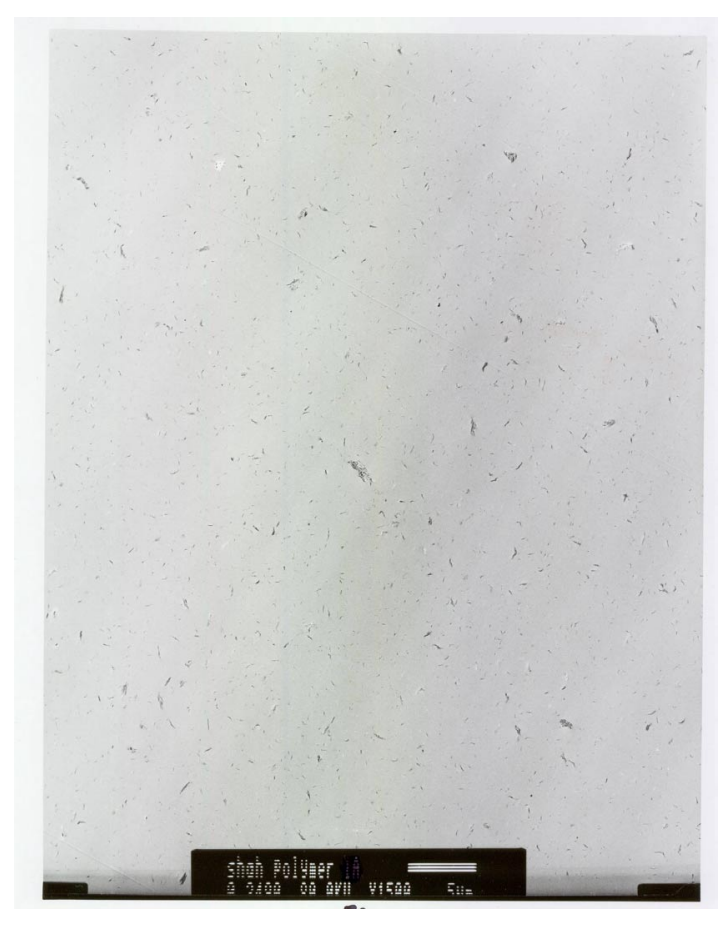

Figure 4.2. TEM photograph of $0.5 \mathrm{wt} \%$ Cloisite $10 \mathrm{~A}^{\circledR}$ - DERAKANE ${ }^{\mathrm{TM}}$ 411-350 vinyl ester nanocomposite sample. (1500x). (MMT content -0.305 wt \%).

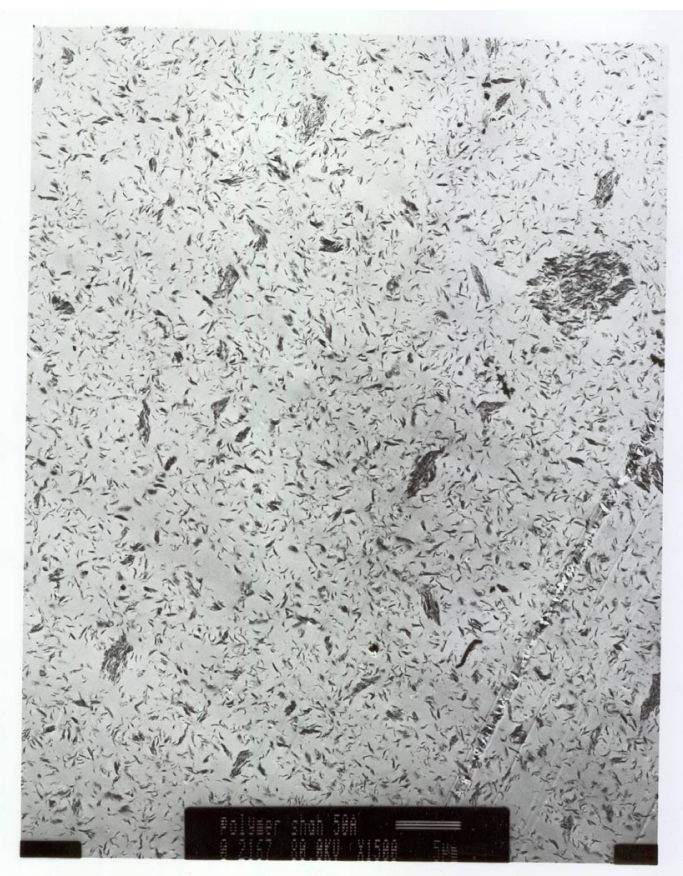

Figure 4.3. TEM photograph of $5 \mathrm{wt} \%$ Cloisite $10 \mathrm{~A}^{\circledR}$ - DERAKANE ${ }^{\mathrm{TM}}$ 411-350 vinyl ester nanocomposite sample (1500x). MMT content $-3.05 \mathrm{wt} \%$. 


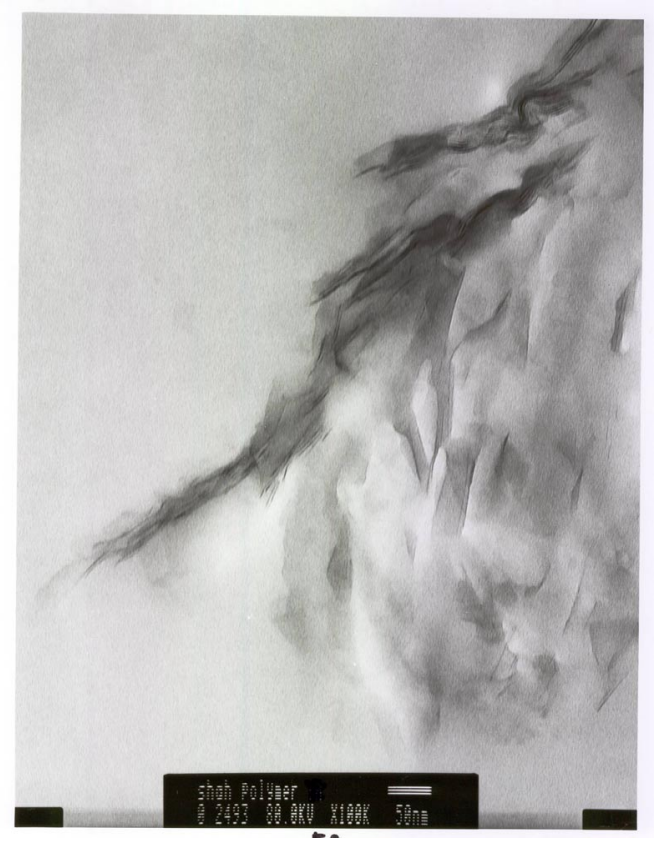

Figure 4.4. TEM photograph of 0.5 wt \% Cloisite $10 A^{\circledR}$ - DERAKANE ${ }^{\text {TM }}$ 411-350 vinyl ester nanocomposite sample $(100,000 x)$. Clay platelets are seen as dark lines. MMT content -0.305 wt $\%$.

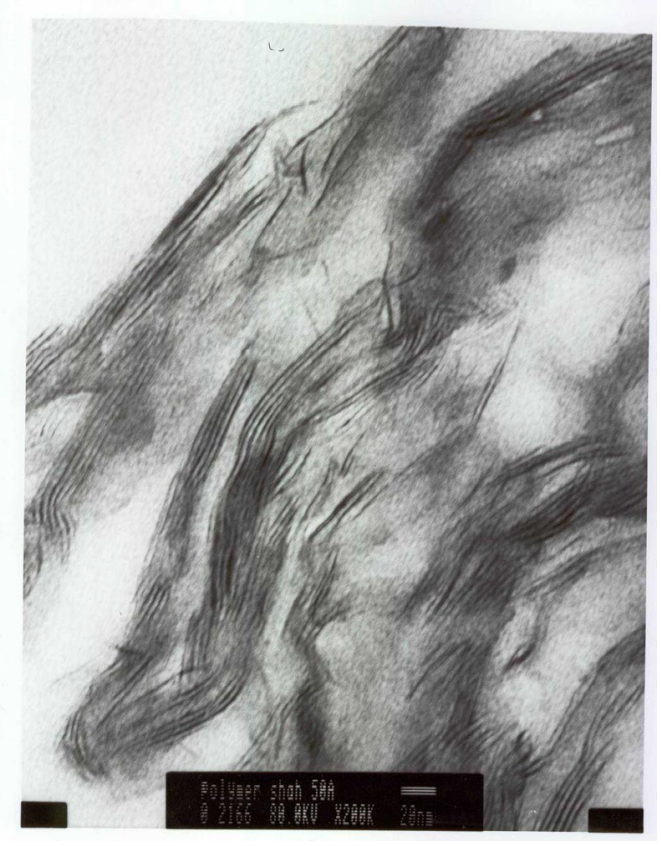

Figure 4.5. TEM picture of $5 \mathrm{wt} \%$ Cloisite $10 \mathrm{~A}^{\circledR}-$ DERAKANE $^{\mathrm{TM}}$ 411-350 nanocomposite $(200,000 \mathrm{x})$. Clay platelets are seen as dark lines. MMT content $-3.05 \mathrm{wt}$ $\%$. 
The Cloisite $10 \mathrm{~A}^{\circledR}$ nanocomposite samples are not completely exfoliated and a better distribution of the clay can be definitely obtained though more vigorous mixing techniques. A possible explanation for the observed morphology may be due to the method of mixing/dispersing the clay used. In this study, the clay was stirred manually into the liquid resin at room temperature. It is possible that in regions where the clay platelets started to expand and peel away, the local viscosity greatly increased. There was no possibility of lowering of this viscosity as the mixing was performed at room temperature, for fear of losing styrene at higher temperatures. This may have caused regions of high concentrations of clay and others with a lower concentration. As the mixing was not very intense, the clay platelets in these high concentration regions were not effectively dispersed to the lower concentration zones. The lack of dispersion might have caused the apparent clay concentration to increase significantly, thereby stopping further expansion of clay platelets, and hence we see regions of high clay concentration with d-spacing of around $6 \mathrm{~nm}$. This phenomenon is seen at all clay percentages and is more pronounced at higher contents. Thus, the problem could be possibly solved by, (1) increasing the shear to better disperse the clay platelets and (2) raising the temperature of the mixture while mixing the clay to reduce the local viscosity and prevent the excessive clay local concentration build up.

Although Cloisite $10 \mathrm{~A}^{\circledR}$ is not completely exfoliated, the available information suggests more than just intercalation, as the d-spacing is greater than 2-3 nm (Dennis et al., 2001). The TEM pictures show that a full range of morphology namely, exfoliated, intercalated and stacked structure exist within the sample. It must be noted that significant expansion 
of clay platelets has been observed even at such mild mixing when in-situ polymerization is carried out (Messersmith and Giannelis, 1995). This suggests that the monomer wets the clay easily, and, in the present case, there is very good compatibility of the surface treatment of Cloisite $10 \mathrm{~A}^{\circledR}$ with vinyl ester resin systems.

The XRD graphs and TEM pictures of VMC nanocomposites present a completely different picture from that presented for Cloisite $10 \mathrm{~A}^{\circledR}$. Low magnification (1500x) TEM pictures of 1 and $5 \mathrm{wt} \% \mathrm{VMC}$ samples (Figures 4.6 and 4.7) show that the clay exists in large tactoids and stacks, the size of some being as much as $6-8 \mu \mathrm{m}$. This suggests that the mixing might not have been very effective in shearing the clay particles apart as in the case with Cloisite $10 \mathrm{~A}^{\circledR}$. Upon examining the tactoids more closely at higher magnifications of $150,000 \mathrm{x}$, no individual platelets could be discerned suggesting that the spacing between them is very small. A representative TEM picture of $5.0 \mathrm{wt} \% \mathrm{VMC}$ is shown in Figure 4.8. This was confirmed through XRD scans (Figure 4.9) that showed peaks at spacing of around $1.5 \mathrm{~nm}$, which is a slight increase from the d-spacing of the clay of $1.486 \mathrm{~nm}$. From this information, it was concluded that the clay platelets are, at best, intercalated, and that the clay exists as tactoids. We expected that violent mechanical stirring or ultrasonication would help in better dispersing the clay. But, even with ultrasonic mixing, XRD data (summarized in Table 4.1) revealed that the spacing of VMC was only marginally increased from $1.486 \mathrm{~nm}$ for the clay to $1.51 \mathrm{~nm}$ in the nanocomposites. The TEM pictures also did not show any difference when compared to samples that were not ultrasonicated. A TEM photograph of a $1.0 \mathrm{wt} \%$ ultrasonicated sample is shown in Figures 4.10 and 4.11. 


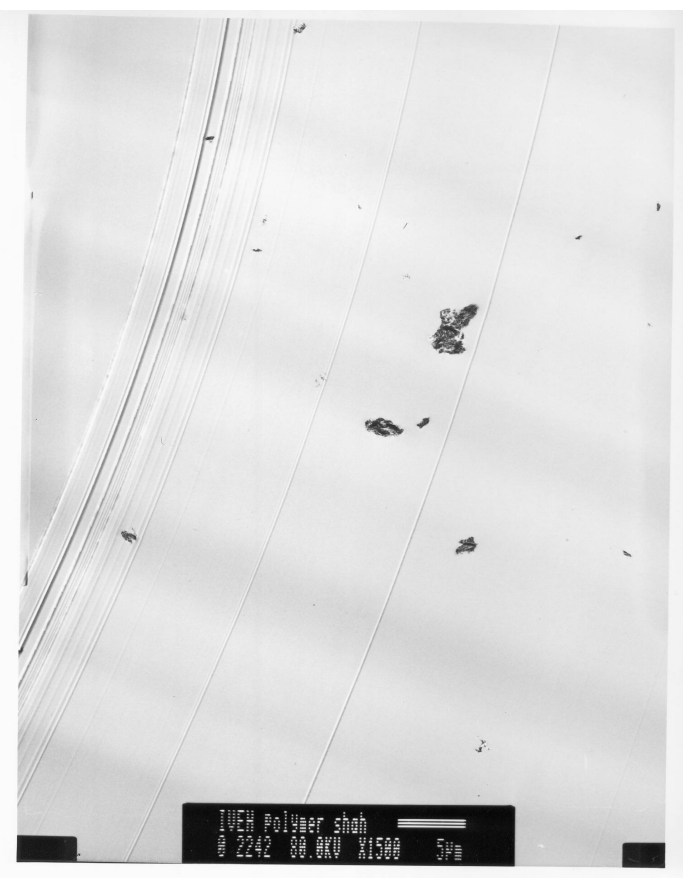

Figure 4.6. TEM photograph of $1.0 \mathrm{wt} \%$ Cloisite $10 \mathrm{~A}^{\circledR}$ - DERAKANE ${ }^{\mathrm{TM}}$ 411-350 vinyl ester nanocomposite sample (1500x). MMT content $0.78 \mathrm{wt} \%$.

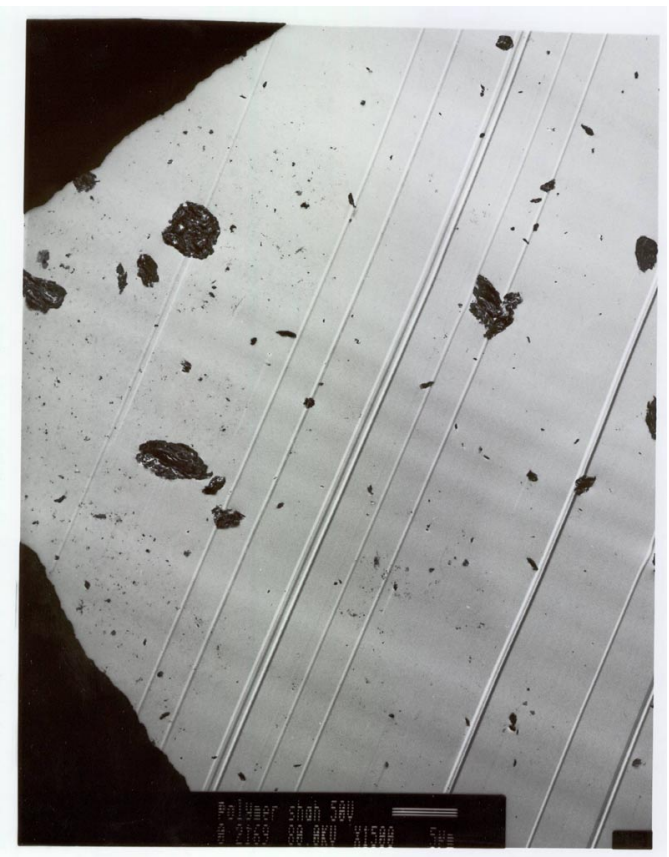

Figure 4.7. TEM photograph of 5.0 wt \% Cloisite $10 A^{\circledR}$ - DERAKANE ${ }^{\text {TM }}$ 411-350 vinyl ester nanocomposite sample (1500x). MMT content $3.9 \mathrm{wt} \%$. 


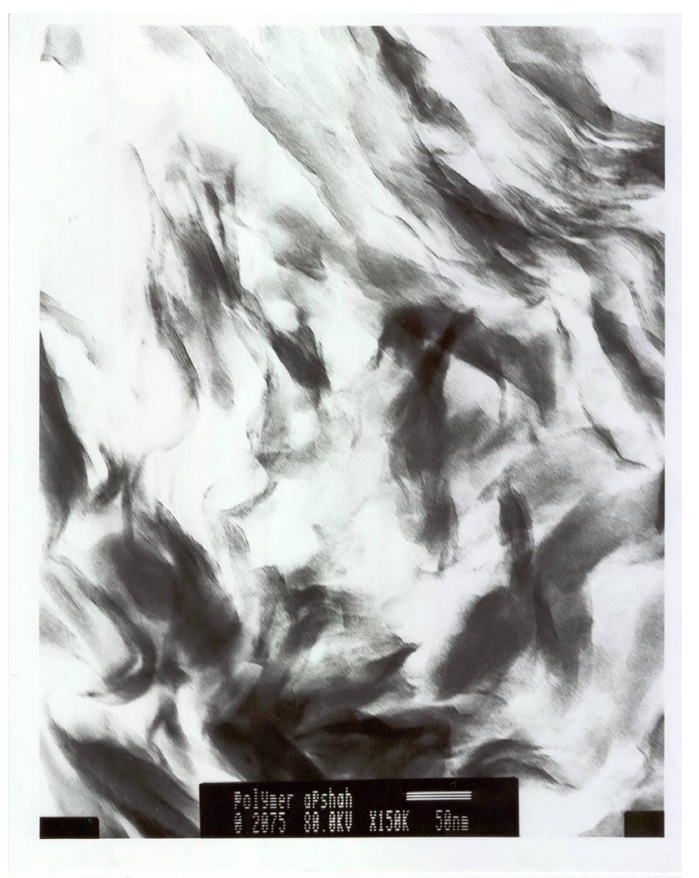

Figure 4.8. TEM photograph of 5.0 wt \% Cloisite $10 \mathrm{~A}^{\circledR}$ - DERAKANE ${ }^{\mathrm{TM}}$ 411-350 vinyl ester nanocomposite sample (150,000x). MMT content - $3.9 \mathrm{wt} \%$.

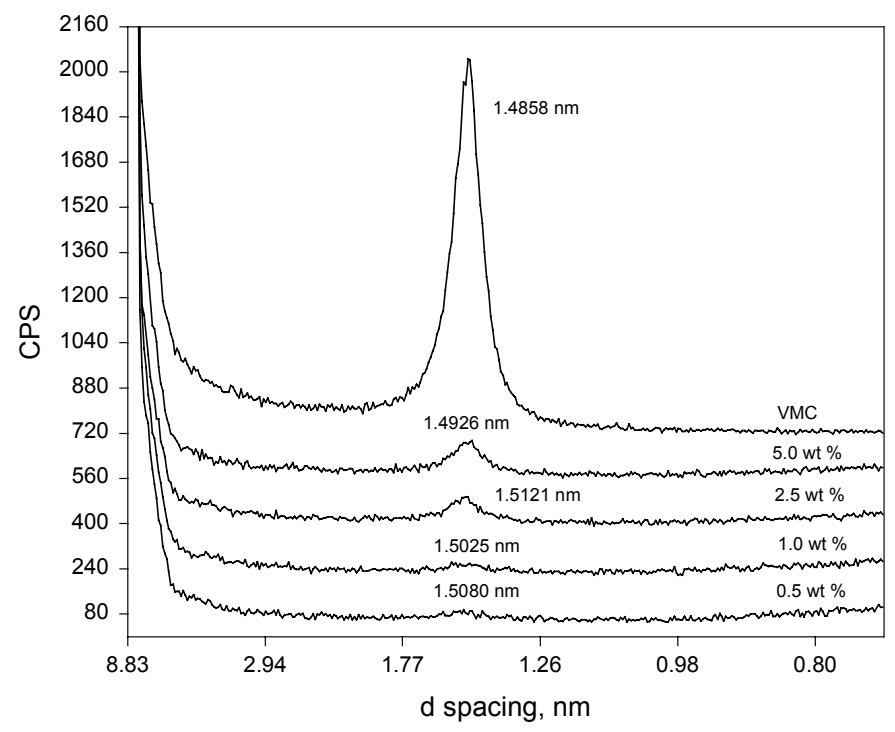

Figure 4.9 XRD scans on VMC and VMC nanocomposite samples. Wt \% organoclay is indicated on the figure. 


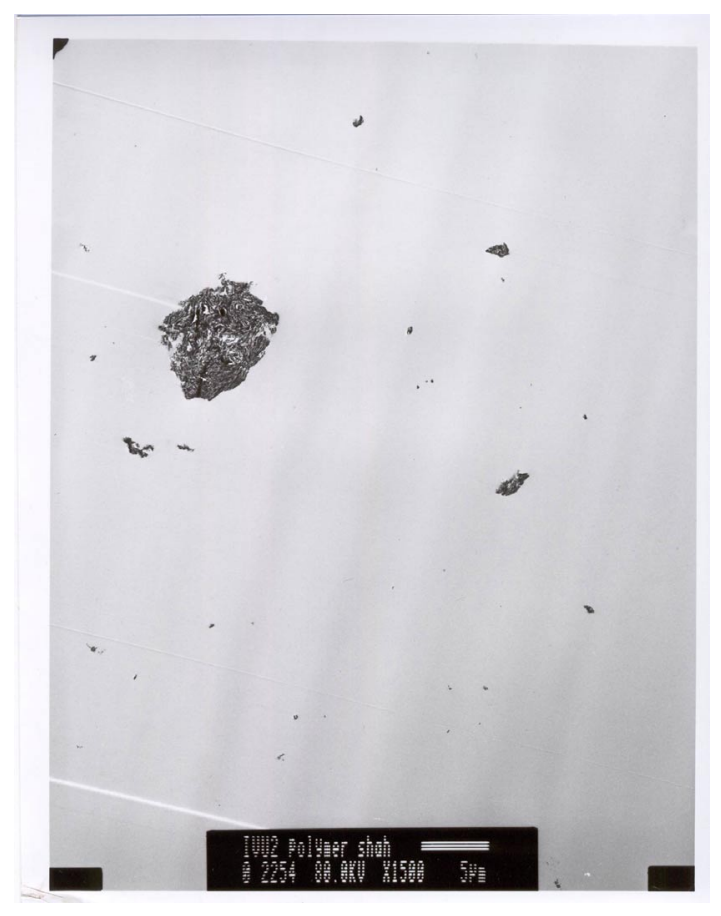

Figure 4.10. TEM photograph of ultrasonicated $1.0 \mathrm{wt} \% \mathrm{VMC}$ - DERAKANE ${ }^{\mathrm{TM}} 411$ 350 vinyl ester nanocomposite sample (1500x). MMT content $-0.78 \mathrm{wt} \%$.

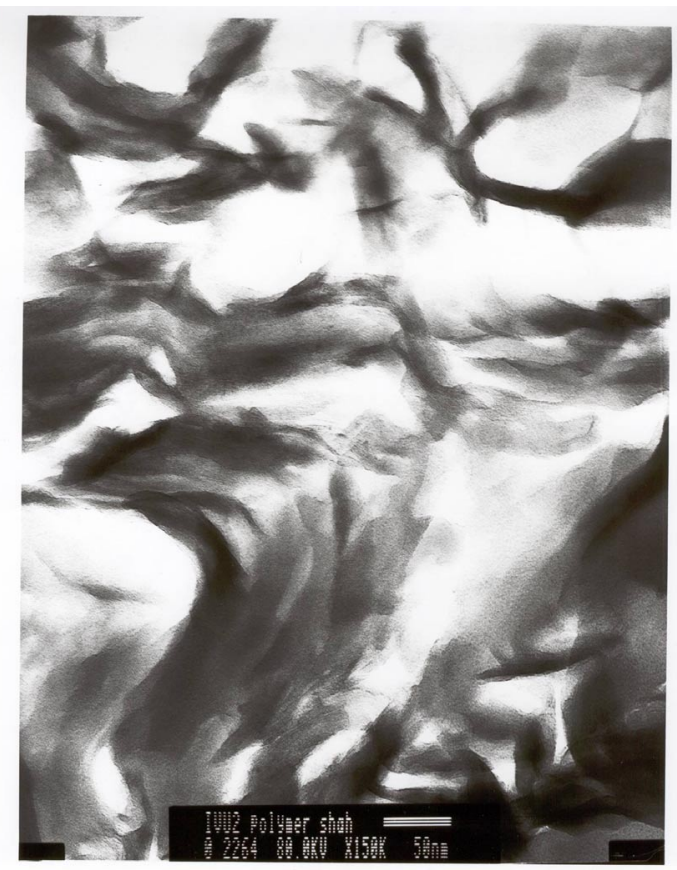

Figure 4.11. TEM photograph of ultrasonicated $1.0 \mathrm{wt} \%$ VMC - DERAKANETM 411350 vinyl ester nanocomposite sample (150,000x). MMT content $-0.78 \mathrm{wt} \%$. 
Table 4.1. XRD scan results of Cloisite $10 \mathrm{~A}^{\circledR}$ and VMC nanocomposites.

\begin{tabular}{|l|c|c|l|}
\hline Sample & ${\text { Cloisite } 10 \mathrm{~A}^{\circledR}}^{\circledR}$ & $\begin{array}{l}\text { Vinyl Monomer } \\
\text { Clay (VMC) }\end{array}$ & $\begin{array}{l}\text { VMC } \\
\text { (Ultrasonically } \\
\text { mixed) }\end{array}$ \\
\hline Clay & 1.9 & 1.486 & 1.486 \\
\hline $0.5 \mathrm{wt} \%$ & No Peak & 1.508 & 1.519 \\
\hline $1.0 \mathrm{wt} \%$ & No Peak & 1.503 & 1.502 \\
\hline $2.5 \mathrm{wt} \%$ & No Peak & 1.511 & 1.512 \\
\hline $5.0 \mathrm{wt} \%$ & No Peak & 1.493 & 1.514 \\
\hline
\end{tabular}

An initial d-spacing of $1.7 \mathrm{~nm}$ is essential for expansion of clay in the polymer (Beall G. W., www.nanocor.com, Nanocor Inc., Chicago) prior to exfoliation during polymerization or cross-linking reaction. The initial swelling of VMC in the vinyl ester resin was not much due to small initial d-spacing and consequently strong attractive forces between the platelets. This allowed for possible cross-linking reaction between the unsaturated bonds on the surface treatment molecules on adjacent plates, with a vinyl group of an intercalated polymer chain. This would then lead to a covalent bond connecting two adjacent clay platelets, through the intercalated polymer chain, thus preventing them from expanding any further. A schematic of this process is represented in Figure 4.12. Messersmith and Giannelis (1994) reported a similar phenomenon in epoxy nanocomposites. Little or no change in basal spacing was observed, for many of the bifunctional primary and secondary amine curing agents they were used to cure the epoxy resin. This was thought to be due to "bridging" of the silicate sheets by the bifunctional amine curing agents, thus preventing any further expansion of the layers. 


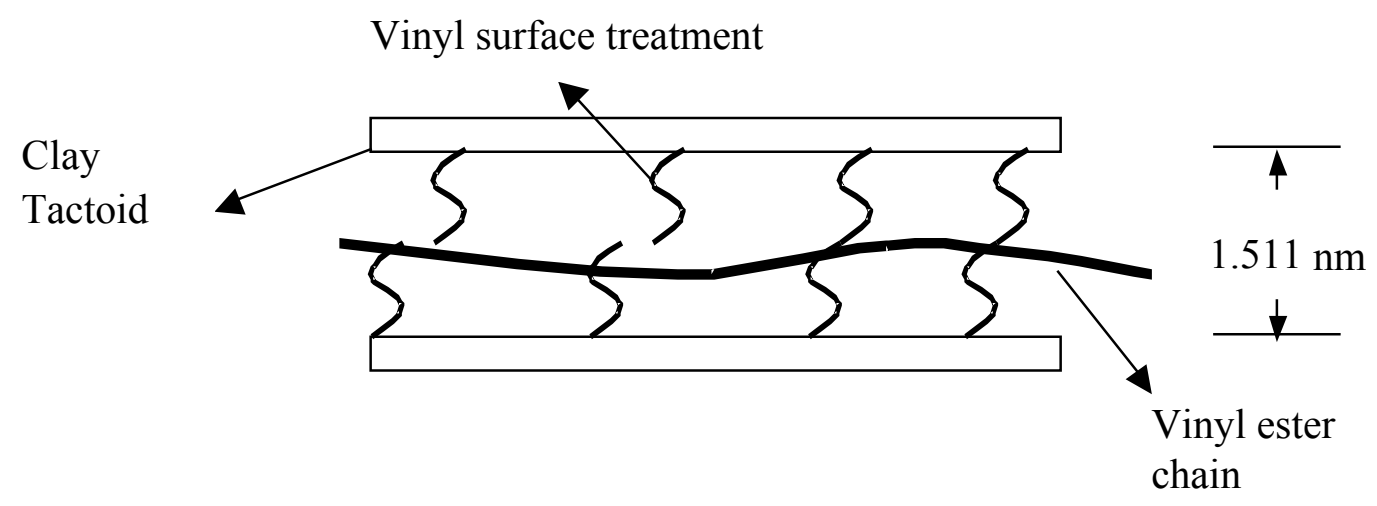

Figure 4.12. Representative reaction process upon polymerization.

\subsection{Diffusion tests}

Neat resin samples showed Fickian diffusion with a linear initial water uptake. Superposition of data for various thicknesses was also observed. This is shown in the diffusion curves in Figures 4.13-4.15. An excellent fit of equation 2.2 to all the data was obtained as shown by the solid line in Figures 4.14 and 4.15. The solid line was drawn using equation 2.2 using D values as computed from the data as outlined in section 2.1.1. The results are also tabulated in Table 4.2. The diffusivity of water in neat resin is $9.19 \mathrm{x}$ $10^{-7} \mathrm{~mm}^{2} / \mathrm{s}$, and this is comparable to the value reported by others (Chin et al., 1999, Verghese et al., 1999). It should be noted here that the samples were not completely dry when the diffusion experiments were started. Hence the "actual" moisture content when equilibrium was attained will be higher than the values reported in Table 4.2 by $0.05 \pm$ $0.005 \mathrm{wt} \%$ for all samples. However this is not expected to change the diffusion behavior of the sample or the results of the experiments, as long as the initial weight used in the calculations is the weight of the sample at the start of the experiment. The Fickian theory can be applied to a system irrespective of the initial boundary conditions. Also, 
since a constant diffusion coefficient is able to predict the water uptake, no change in the initial slope, and hence, the diffusion coefficient is expected, even if the sample were completely dry when the experiments were started.

The diffusion coefficient and equilibrium moisture content of post-cured neat vinyl ester resins was found to be less than that for non-post cured resins. The decrease in diffusion coefficient and equilibrium moisture content is due to greater cross-linking in the postcured resin. The non-post cured resin samples showed a $\mathrm{T}_{\mathrm{g}}$ of around $59{ }^{\circ} \mathrm{C}$ and were about $84.29 \%$ cured. The post cured resins on the other hand showed at $\mathrm{T}_{\mathrm{g}}$ of around $97.65{ }^{\circ} \mathrm{C}$. The absence of an exothermic curing peak in the DSC scan after the glass transition temperature was crossed suggests that the post cured samples are completely cured. DSC scans on both post-cured and non-post cured resins are shown in Figures 4.16 and 4.17. Partially cured non-post cured samples showed an exothermic peak once the $T_{g}$ was crossed. This indicates further curing of the sample. The extent of cure was calculated from the heat released per gram, obtained from the DSC scan and the heat released for complete cure of liquid resin, $345.1 \mathrm{~J} / \mathrm{g}$. The DSC scan of a liquid resin sample is shown in Figure 4.18. 


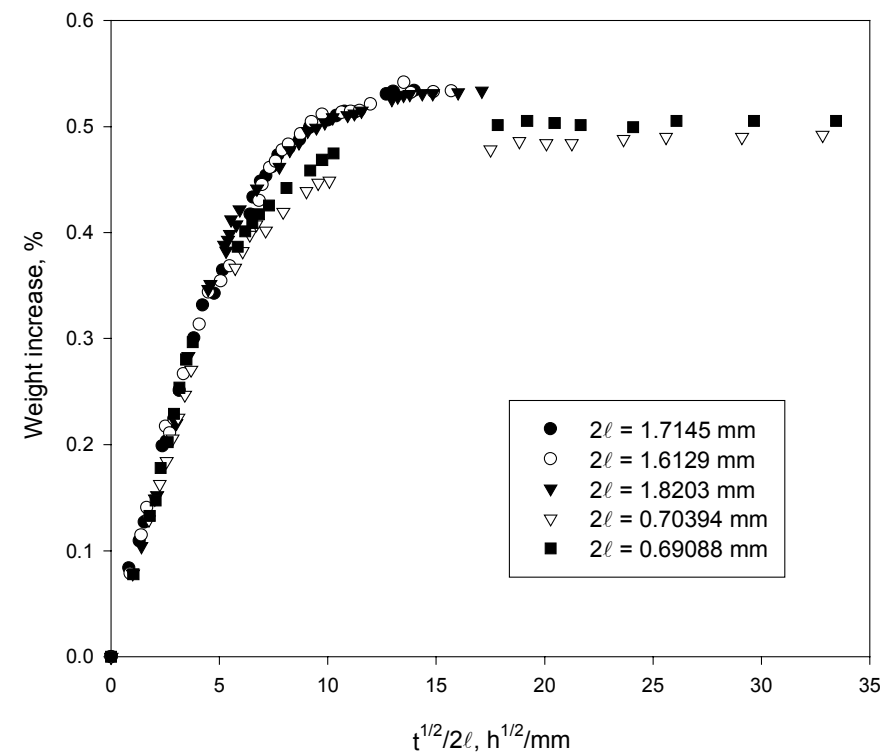

Figure 4.13 Water uptake curves of non-post cured DERAKANETM 411-350 vinyl ester resin at $25^{\circ} \mathrm{C}$.

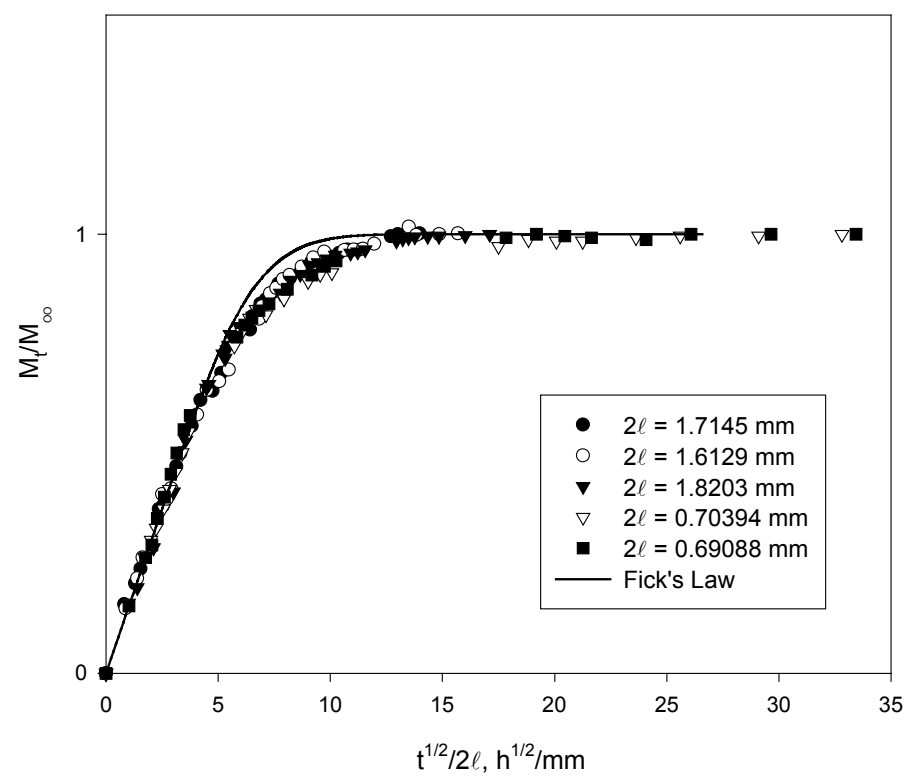

Figure 4.14 Sorption curve of non-post cured DERAKANE ${ }^{\text {TM }}$ 411-350 vinyl ester resin at $25^{\circ} \mathrm{C}$. 


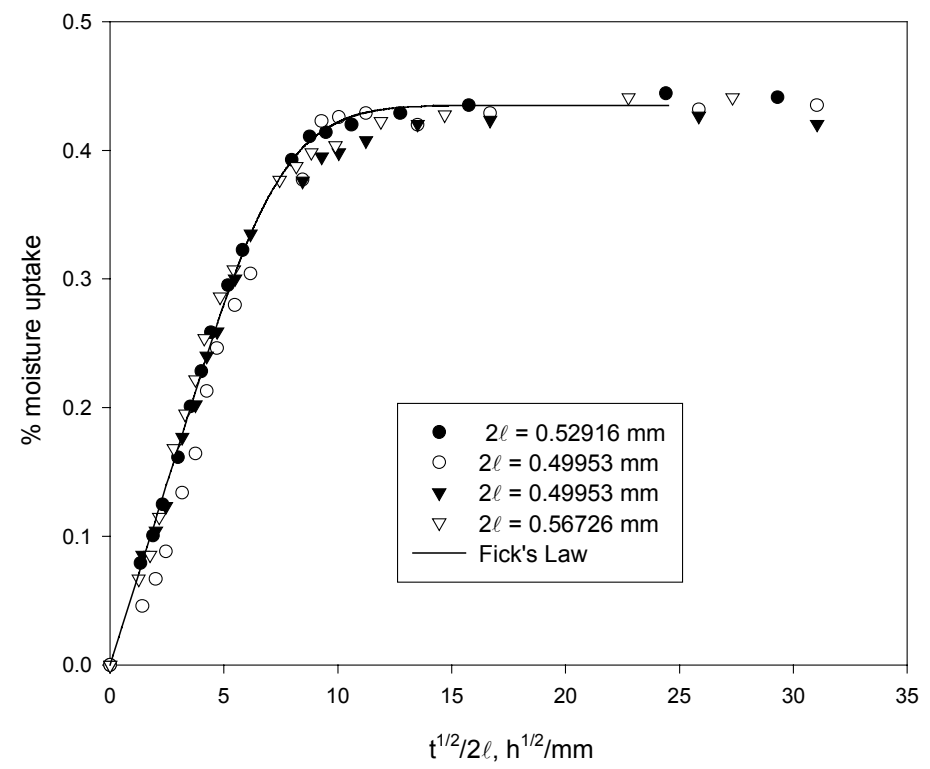

Figure 4.15 Water uptake curves of post cured DERAKANE ${ }^{\text {TM }}$ 411-350 vinyl ester resin at $25{ }^{\circ} \mathrm{C}$. 
Table 4.2. Diffusion Test Results on Post Cured samples

\begin{tabular}{|c|c|c|}
\hline System & $\begin{array}{l}\text { Diffusion coefficient, } \\
\qquad \times 10^{+6} \mathrm{~mm}^{2} / \mathrm{s}\end{array}$ & $\begin{array}{c}\text { Equilibrium Moisture Content, } \\
\text { weight percent (\%) }\end{array}$ \\
\hline $\begin{array}{l}\text { Neat Resin (Non-post } \\
\text { cured) }\end{array}$ & $1.226(0.082)$ & $0.512(0.025)$ \\
\hline Neat Resin & $0.919(0.030)$ & $0.434(0.012)$ \\
\hline $0.5 \mathrm{wt} \% \mathrm{VMC}$ & $0.534(0.025)$ & $0.691(0.004)$ \\
\hline $1 \mathrm{wt} \% \mathrm{VMC}$ & $0.368(0.041)$ & $0.862(0.005)$ \\
\hline $2.5 \mathrm{wt} \% \mathrm{VMC}$ & $0.238(0.019)$ & $1.056(0.021)$ \\
\hline $5 \mathrm{wt} \% \mathrm{VMC}$ & $0.198(0.008)$ & $1.166(0.021)$ \\
\hline $0.5 \mathrm{wt} \%$ Cloisite $10 \mathrm{~A}^{\circledR}$ & $0.452(0.025)$ & $0.828(0.007)$ \\
\hline $1 \mathrm{wt} \%$ Cloisite $10 \mathrm{~A}^{\circledR}$ & $0.337(0.026)$ & $0.927(0.011)$ \\
\hline $2.5 \mathrm{wt} \%$ Cloisite $10 \mathrm{~A}^{\circledR}$ & $0.239(0.021)$ & $1.109(0.005)$ \\
\hline $5 \mathrm{wt} \%$ Cloisite $10 \mathrm{~A}^{\circledR}$ & $0.125(0.015)$ & $1.484(0.011)$ \\
\hline 0.66 wt $\%$ Cloisite $\mathrm{Na}^{\circledR}$ & $0.654(0.253)$ & $0.901(0.01)$ \\
\hline 3.25 wt $\%$ Cloisite $\mathrm{Na}^{\circledR}$ & $0.513(0.195)$ & $1.126(0.026)$ \\
\hline
\end{tabular}

Note: Numbers in brackets are Standard Deviations. 


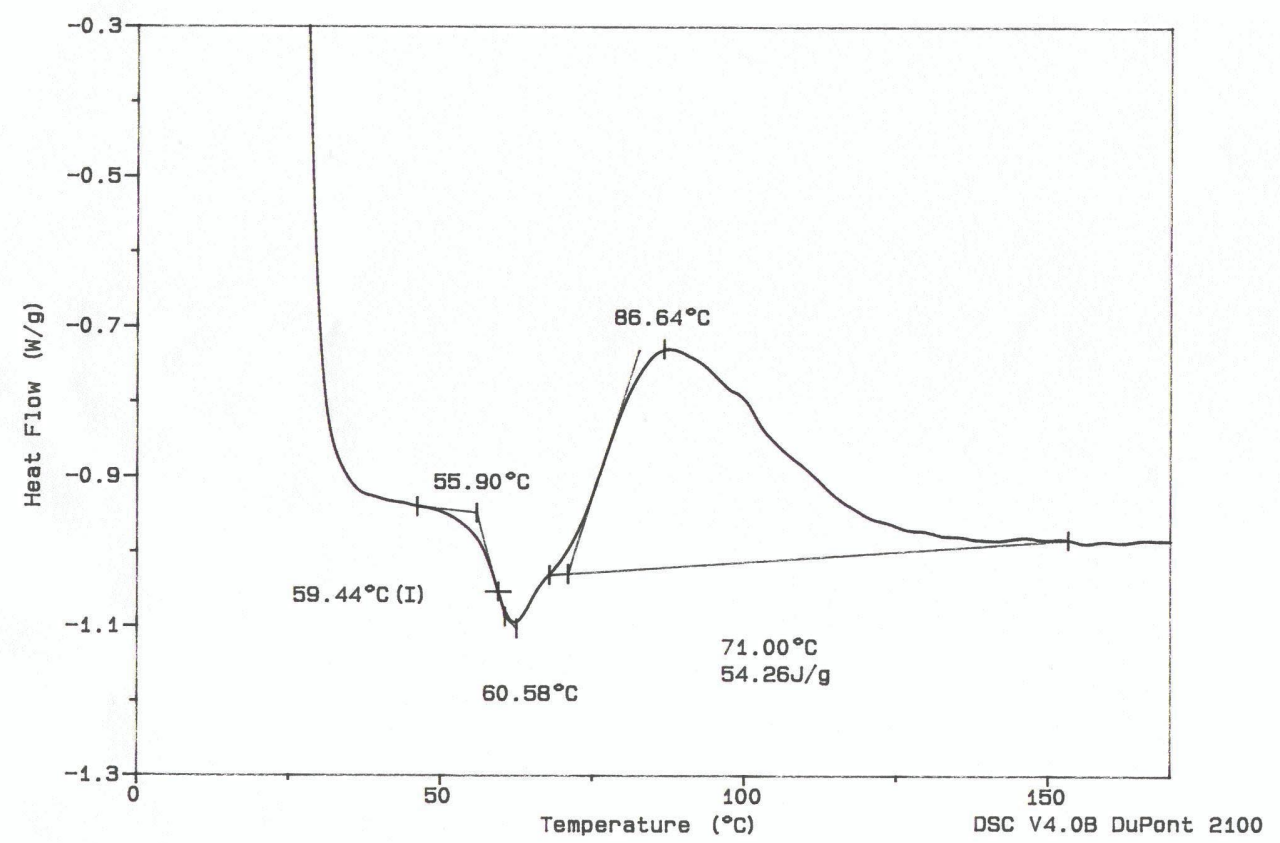

Figure 4.16 DSC scan on a non-post cured DERAKANE ${ }^{\mathrm{TM}}$ 411-350 vinyl ester resin.

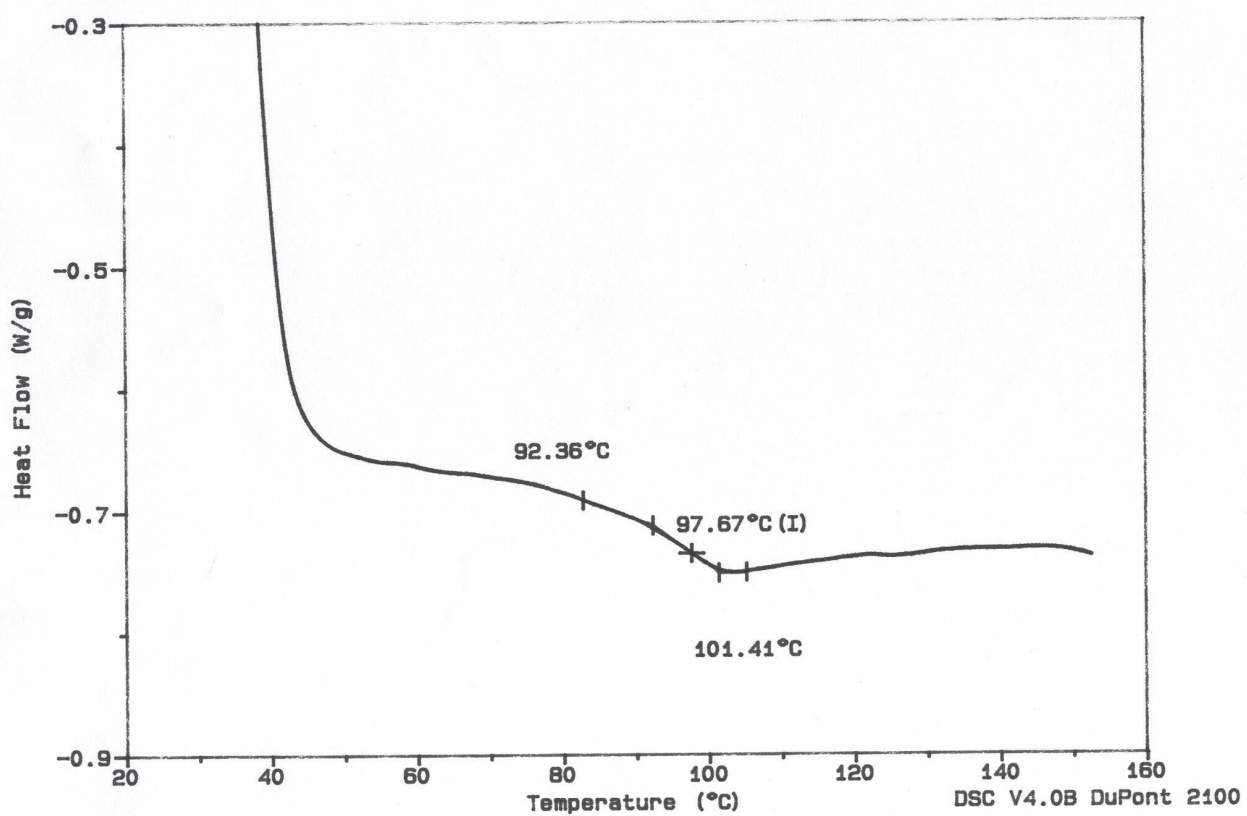

Figure 4.17. DSC scan on post-cured DERAKANETM 411-350 vinyl ester resin. 


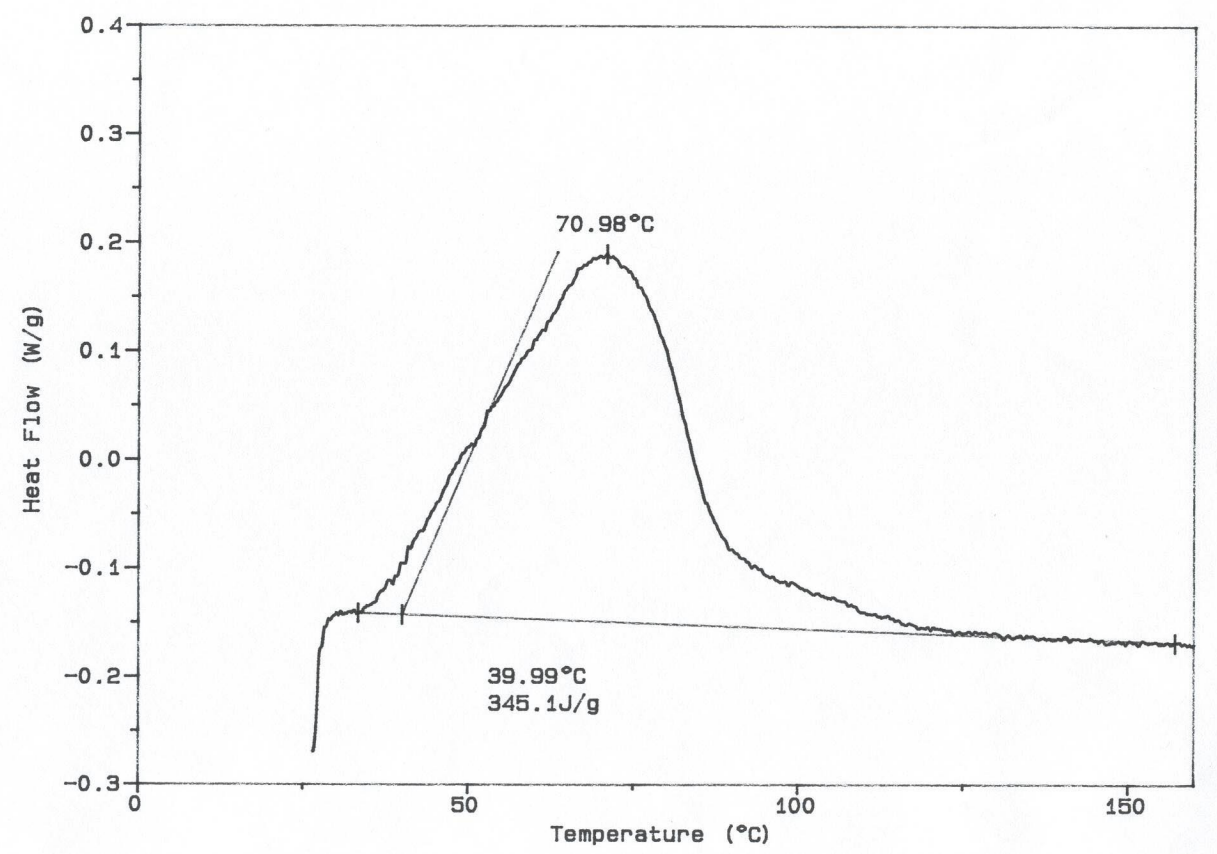

Figure 4.18. Curing peak of liquid DERAKANETM 411-350 vinyl ester resin.

The behavior of the nanocomposites containing low loading of clay was found to be Fickian, and this is demonstrated in Figure 4.19 for samples containing $0.5 \mathrm{wt} \%$ Cloisite $10 \mathrm{~A}^{\circledR}$. At higher percentages of clay namely 1, 2.5 and $5 \mathrm{wt} \%$ organoclay (Figures $4.20-$ 4.22), all the samples still showed a linear initial uptake, but the time to reach equilibrium was longer than what was theoretically expected (for e.g. see $5 \mathrm{wt} \%$ oragnoclay data in Figure 4.22). A similar trend was seen in VMC nanocomposites. VMC nanocomposites also showed Fickian behavior at low clay contents $(0.5$ and $1 \mathrm{wt} \%)$ as can be seen from Figures $4.23-4.24$. But again, just as in Cloisite $10 \mathrm{~A}^{\circledR}$ nanocomposites, at high organoclay contents of 2.5 and $5 \mathrm{wt} \%$ (Figures $4.25-4.26$ ), the process appeared to slow down and the time taken to reach equilibrium was longer than that predicted by ideal Fickian behavior. 


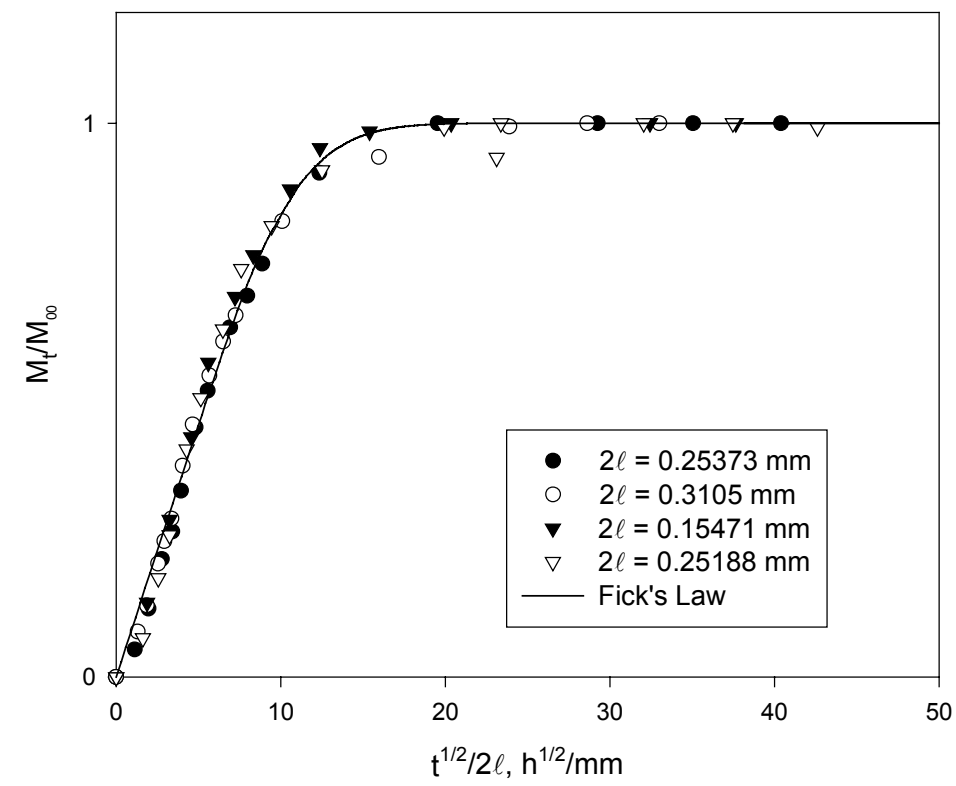

Figure 4.19 Water uptake curves of post cured $0.5 \mathrm{wt} \%$ Cloisite $10 \mathrm{~A}^{\circledR}$-DERAKANETM 411-350 vinyl ester resin at $25^{\circ} \mathrm{C}$.

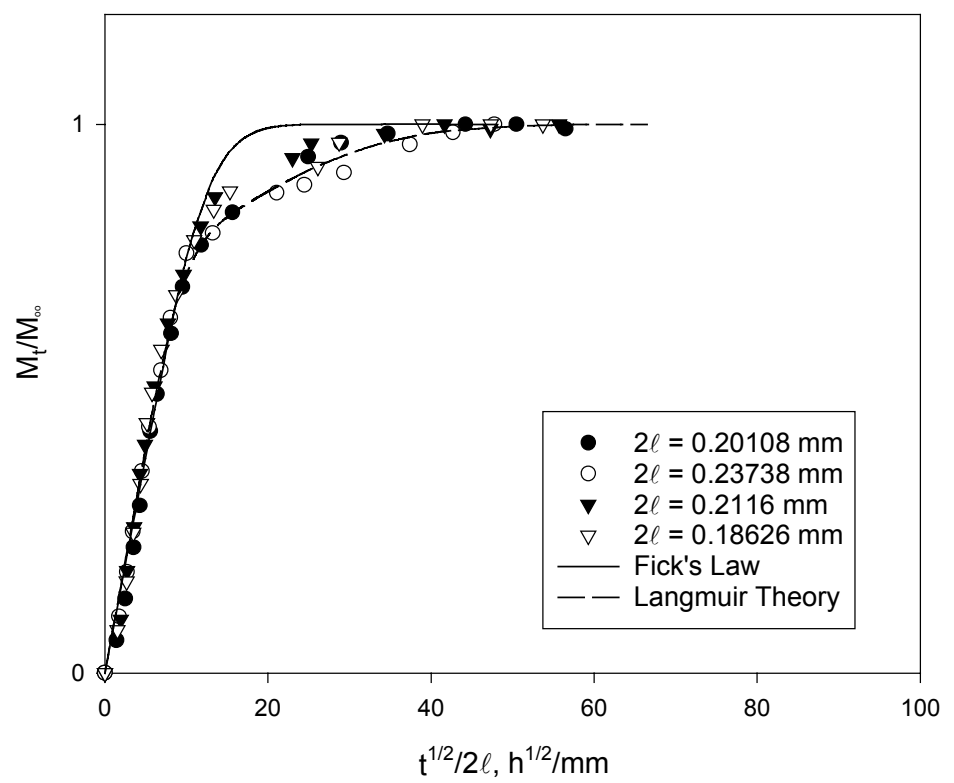

Figure 4.20 Water uptake curves of post cured $1.0 \mathrm{wt} \%$ Cloisite $10 \mathrm{~A}^{\circledR}$-DERAKANE ${ }^{\mathrm{TM}}$ 411-350 vinyl ester resin at $25^{\circ} \mathrm{C}$. 


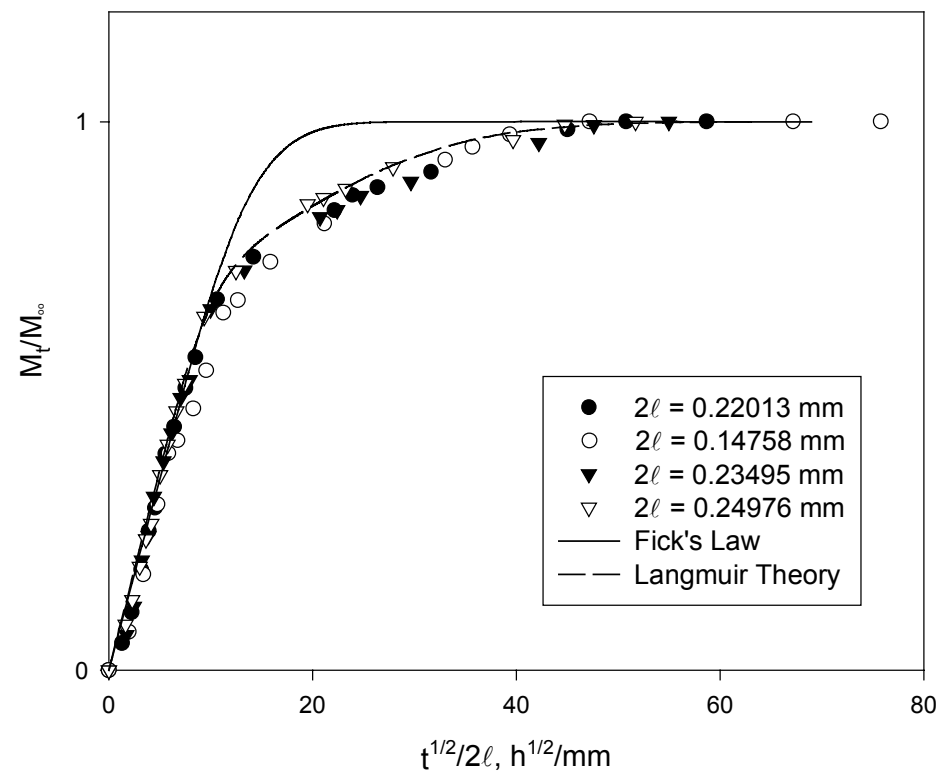

Figure 4.21 Water uptake curves of post cured $2.5 \mathrm{wt} \%$ Cloisite $10 \mathrm{~A}^{\circledR}$-DERAKANE ${ }^{\mathrm{TM}}$ 411-350 vinyl ester resin at $25^{\circ} \mathrm{C}$.

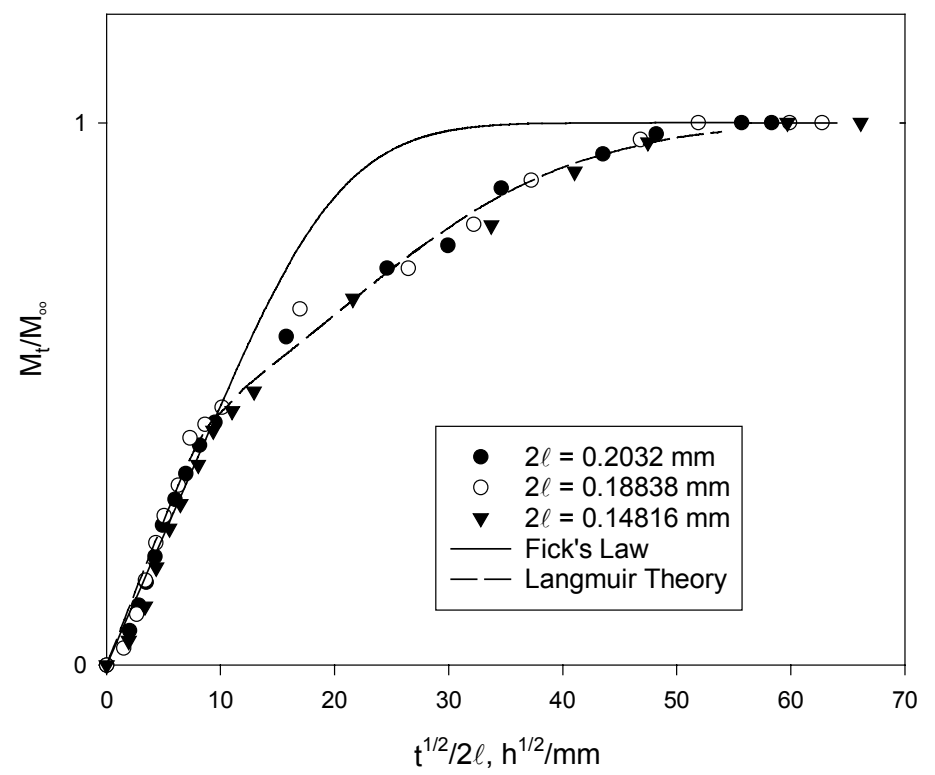

Figure 4.22 Water uptake curves of post cured $5 \mathrm{wt} \%$ Cloisite $10 \mathrm{~A}^{\circledR}$-DERAKANE ${ }^{\mathrm{TM}}$ 411-350 vinyl ester resin at $25^{\circ} \mathrm{C}$. 


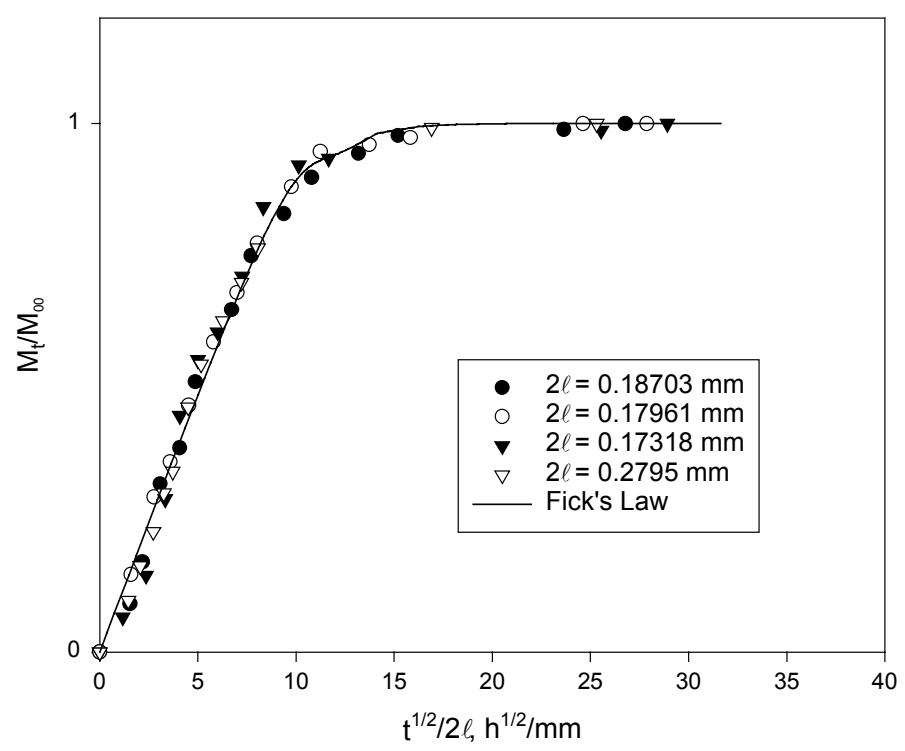

Figure 4.23 Water sorption curves of post cured 0.5 wt \% VMC-DERAKANETM 411-350 vinyl ester resin at $25^{\circ} \mathrm{C}$.

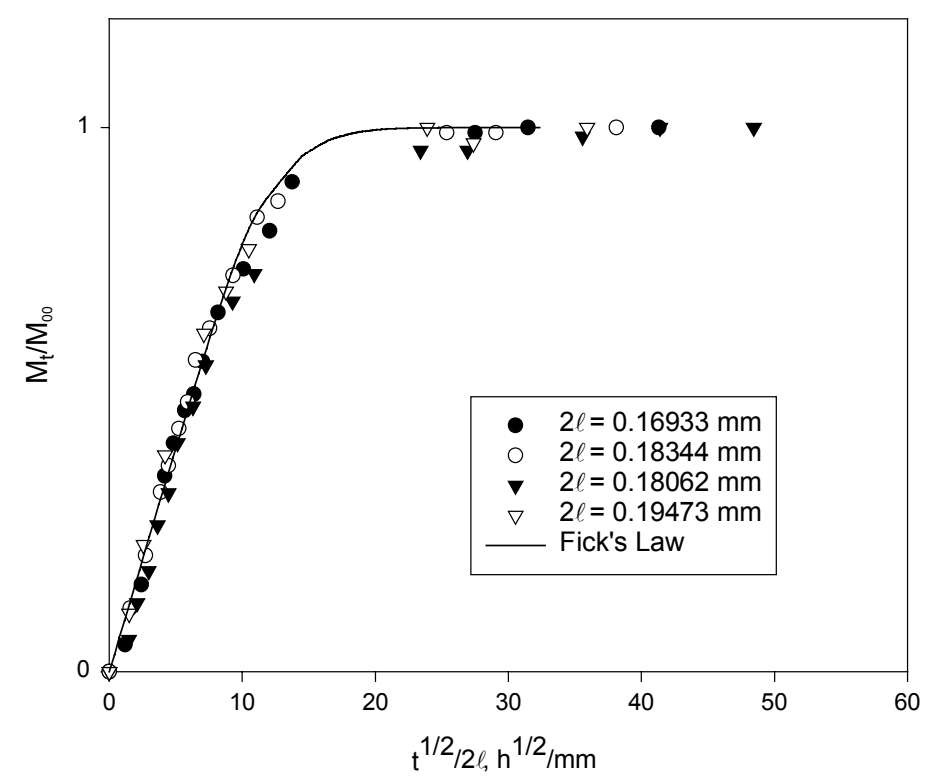

Figure 4.24 Water sorption curves of post cured $1.0 \mathrm{wt} \%$ VMC-DERAKANETM 411-350 vinyl ester resin at $25^{\circ} \mathrm{C}$. 


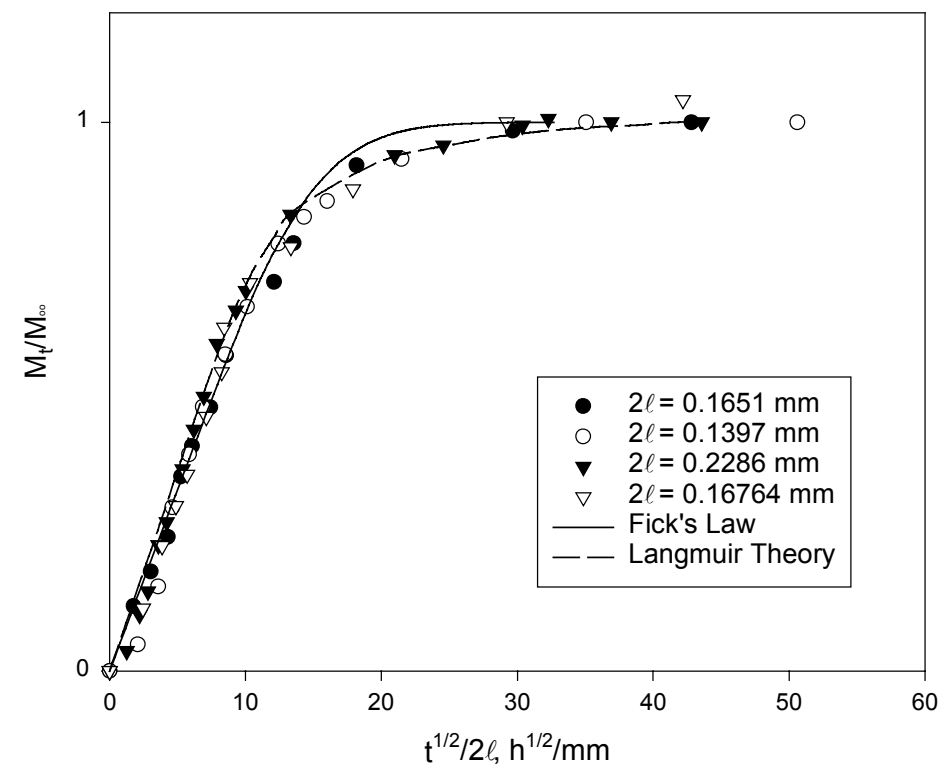

Figure 4.25 Water sorption curves of post cured $2.5 \mathrm{wt} \% \mathrm{VMC}^{\mathrm{V}}$-DERAKANE ${ }^{\mathrm{TM}}$ 411-350 vinyl ester resin at $25^{\circ} \mathrm{C}$.

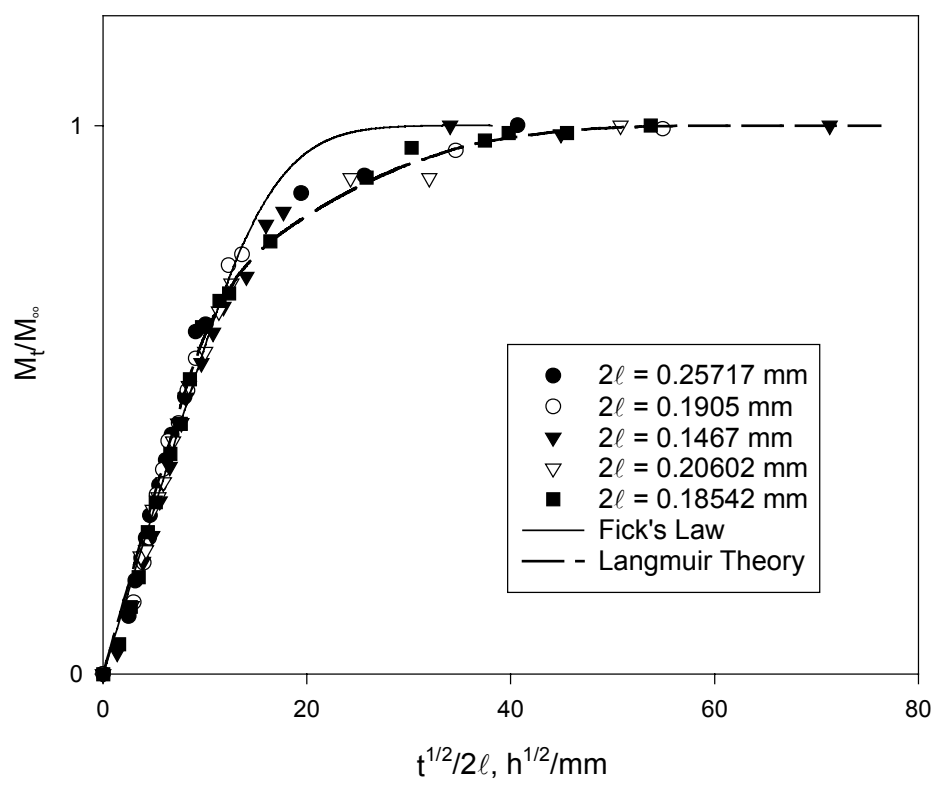

Figure 4.26 Water uptake curves of post cured 5.0 wt \% VMC-DERAKANE ${ }^{\mathrm{TM}}$ 411-350 vinyl ester resin at $25^{\circ} \mathrm{C}$. 
It is seen that the addition of montmorillonite clay has a very significant effect on moisture diffusivity that reduces to about a fourth of its value in samples containing 2.5 wt $\%$ organoclay; this is true for both kinds of surface treatment. Although the diffusion coefficient reduces rapidly and progressively, there are diminishing returns, and a plateau appears to be reached at about $5 \mathrm{wt} \%$ organoclay. Figure 4.27 shows the variation of diffusion coefficient with clay content. Yano et al., (1993), observed a similar trend with permeability of oxygen and water vapor through polyimide-clay nanocomposites.

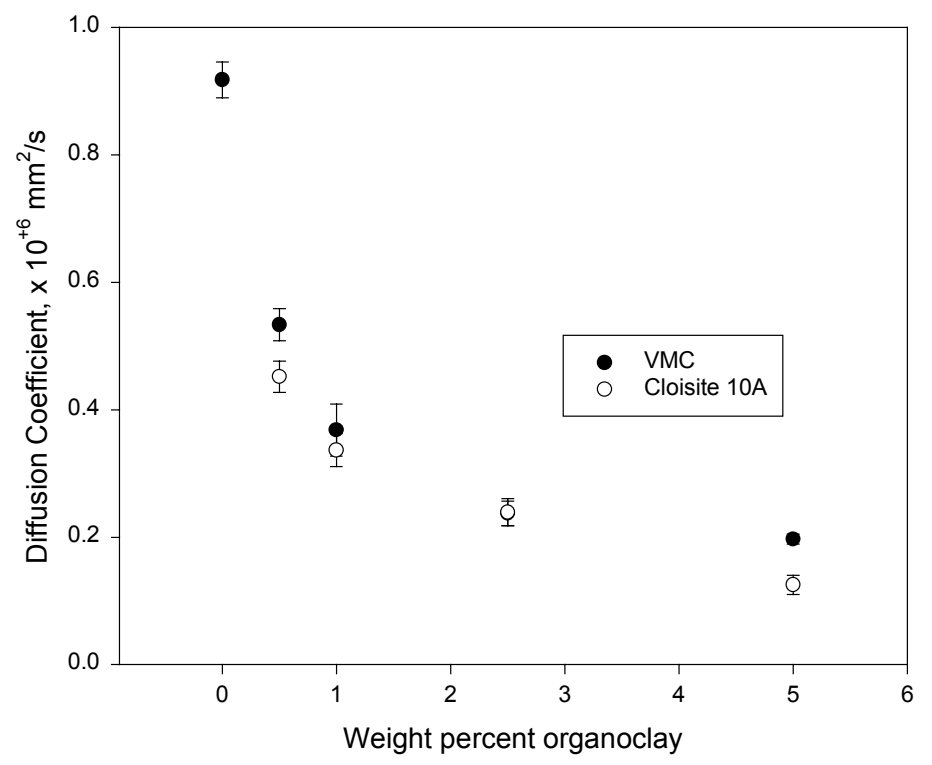

Figure 4.27 Variation of diffusion coefficient of DERAKANE ${ }^{\text {TM }}$ 411-350 vinyl ester nanocomposites with clay content.

As opposed to the decrease in diffusivity with clay addition, the equilibrium moisture content of the nanocomposite sample was found to increase with the amount of clay added. At low concentrations of organoclay, i.e., $<1 \mathrm{wt} \%$ the increase in the equilibrium 
moisture content was fairly linear, but it tapered off at higher concentrations of clay. These results are also listed in Table 4.2 and also plotted against organoclay content in Figure 4.28. The equilibrium moisture content appears to depend slightly on the type of clay surface treatment. Yano et al., (1993) found equilibrium moisture content to be relatively unchanged between neat polyimide and polyimide clay nanocomposites.

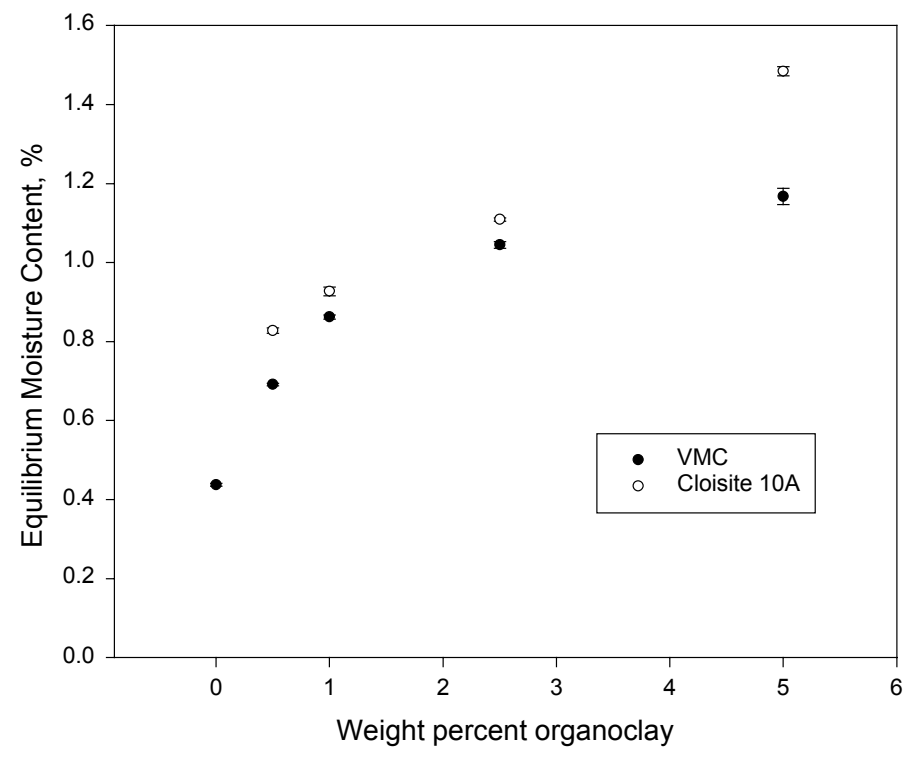

Figure 4.28 Variation of equilibrium moisture content with weight percent clay in the sample.

The reason for the higher equilibrium water content with increasing amounts of clay is due to the natural tendency of the clay to adsorb water (Van Olphen, 1977). Although the clay was treated with the organic quaternary compound, the clay still retained some of its hydrophilicity. This was observed with the clays used, Cloisite $10 \mathrm{~A}^{\circledR}$ and vinyl monomer clay. This is shown in Table 4.3 which summarizes water uptake by Cloisite NA ${ }^{\circledR}$, 
Cloisite $10 \mathrm{~A}^{\circledR}$ and $\mathrm{VMC}$ in a humid environment of $75 \% \mathrm{RH}$ at $25^{\circ} \mathrm{C}$. The untreated clay absorbs more than three times as much moisture as the treated clay.

Table 4.3 Water uptake tests on Cloisite $\mathrm{Na}^{\circledR}$, Cloisite $10 \mathrm{~A}^{\circledR}$ and VMC (75 \% RH/25 $\left.{ }^{\circ} \mathbf{C}\right)$.

\begin{tabular}{|c|c|c|c|}
\hline \multirow{2}{*}{ Time, $\mathrm{h}$} & \multicolumn{3}{|c|}{ Water Content (weight percent increase) } \\
\hline & ${\text { Cloisite } \mathrm{Na}^{\circledR}}^{\circledR}$ & ${\text { Cloisite } 10 \mathrm{~A}^{\circledR}}^{\circledR}$ & VMC \\
\hline 0 & 0 & 0 & 0 \\
\hline 24 & 26.02 & 7.08 & 9.06 \\
\hline 48 & 31.62 & 9.16 & 11.56 \\
\hline 264 & 46.87 & 15.15 & 17.04 \\
\hline 720 & 59.68 & 18.94 & 19.36 \\
\hline
\end{tabular}

The amount of water adsorbed by the clay is then believed to be dependent on the exposed surface area of the clay platelets. At higher concentrations of clay, multi-layer stacks and clay aggregates are seen. It is the existence of multi-layer stacks and aggregates at higher clay concentrations, which have an effective exposed surface area that is less than the total area of the exfoliated clay that leads to the negative deviation from a linear relationship between the equilibrium water content and amount of added clay. In addition, it appeared that Cloisite $10 \mathrm{~A}^{\circledR}$ nanocomposites adsorbed more water than the VMC nanocomposite samples, although from Table 4.3 Cloisite $10 \mathrm{~A}^{\circledR}$ by itself seemed to adsorb the same amount as VMC. The consequence of water adsorbing onto the clay particles in the nanocomposite sample is that the otherwise transparent samples became whitish and lost their transparency. Cloisite $10 \mathrm{~A}^{\circledR}$ nanocomposite samples started to become opaque and lose their transparency at high clay concentrations. This was not 
the case with VMC nanocomposites as they retained their transparency even days after they had reached equilibrium. The lower equilibrium moisture content and the above phenomenon are believed to be due to the presence of greater cross link density around the clay particles by virtue of the reactive unsaturated group in VMC taking part in the cross linking reaction. This greater crosslink density hindered the passage of water molecules, thereby preventing them from reaching the clay surface and adsorbing onto them in VMC nanocomposites.

Diffusion tests on untreated clay or sodium montmorillonite (Cloisite $\mathrm{Na}^{\circledR}$ ) yielded diffusion coefficients, which, under comparable conditions, were about twice as large as both VMC and Cloisite $10 \mathrm{~A}^{\circledR}$ nanocomposites. This was not surprising due to the expected poor distribution of Cloisite $\mathrm{Na}^{\circledR}$ in the vinyl ester, simply because of incompatibility of the hydrophilic clay and the organic resin. The results are tabulated in Table 4.2. Diffusion curves for 0.66 and $3.25 \mathrm{wt} \%$ Cloisite $\mathrm{Na}^{\circledR}$ (which corresponds to 1 and 5 wt $\%$ organoclay respectively) in DERAKANE ${ }^{\text {TM }} 411-350$ vinyl ester resin are shown in Figs. 4.29 and 4.30. 


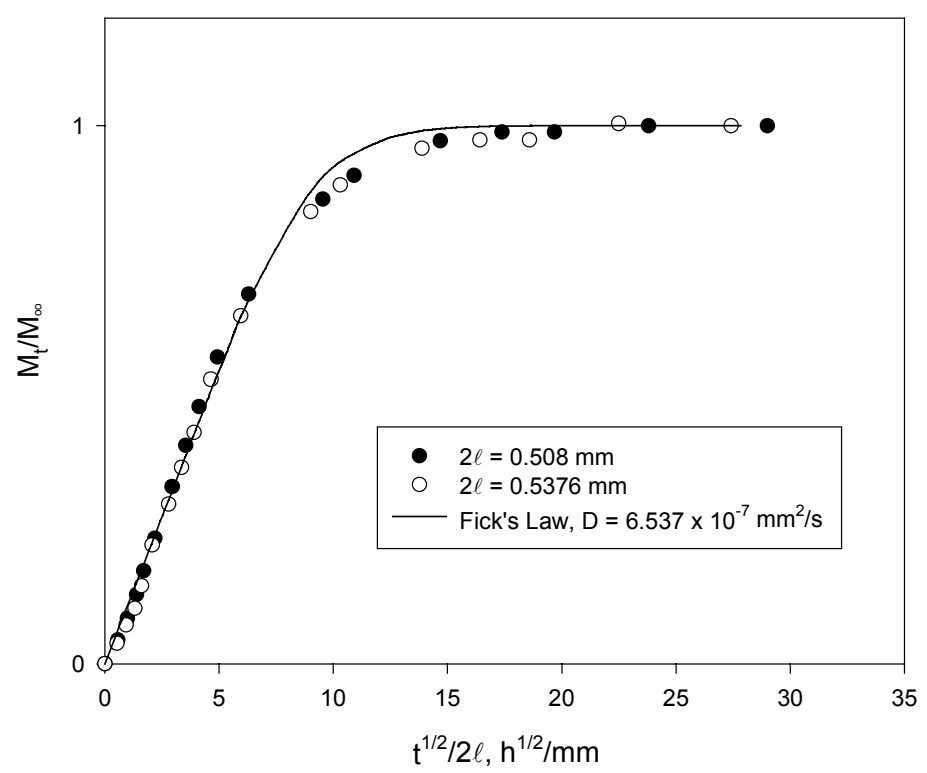

Figure 4.29. Water sorption curve of $0.66 \mathrm{wt} \%$ Cloisite $\mathrm{Na}^{\circledR}$ - DERAKANE ${ }^{\mathrm{TM}}$ 411-350 vinyl ester resin at $25^{\circ} \mathrm{C}$.

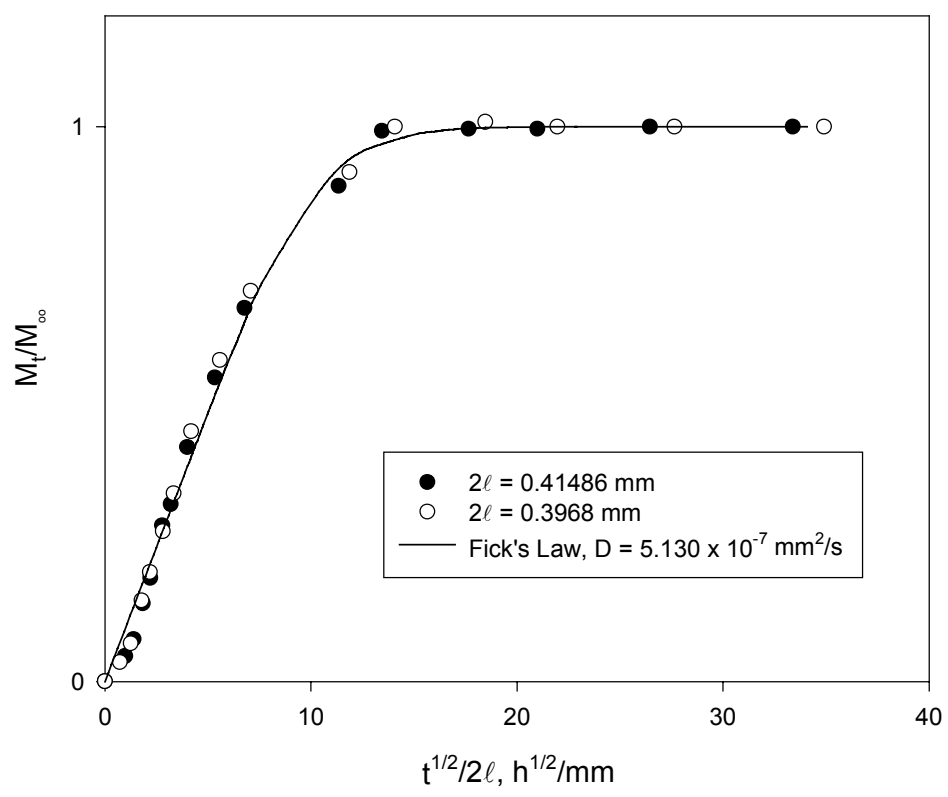

Figure 4.30. Water sorption curve of $3.25 \mathrm{wt} \%$ Cloisite $\mathrm{Na}^{\circledR}$ - DERAKANE ${ }^{\mathrm{TM}}$ 411-350 vinyl ester resin at $25^{\circ} \mathrm{C}$. 
It was however, surprising that the diffusion coefficient did not differ significantly between Cloisite $10 \mathrm{~A}^{\circledR}$ and vinyl monomer clay nanocomposites. Upon comparing the low magnification TEM pictures (Figures 4.2 and 4.3, 4.6 and 4.7) of Cloisite $10 \mathrm{~A}^{\circledR}$ and VMC nanocomposites, it can be seen that the clay platelets in Closite $10 \mathrm{~A}^{\circledR}$ nanocoposites is much better separated and distributed than in VMC nanocomposites. Due to this, the area covered by the clay in Cloisite $10 \mathrm{~A}^{\circledR}$ nanocomposites is much more that in the VMC nanocomposites. The presence of VMC as large tactoids leaves large "voids" or spaces, through which water molecules can easily diffuse unhindered. Thus it is expected that Cloisite $10 \mathrm{~A}^{\circledR}$ nanocomposites should show far larger decreases in diffusion coefficient than VMC nanocomposites. Thus, it must be true that the increased barrier property resulting from clay addition is not just due to the presence of a "tortuous path" created by the clay platelets that are locally oriented; it must also be a function of some other structural variable. We speculate that this additional variable is the relaxation behavior of the polymer chains. The motion of the polymer chains is restricted around the nanometer sized clay platelets (Kornmann et al., 1998). Moisture diffusion necessitates a rearrangement of polymer chains to allow for the creation of a diffusion path, and the diffusion coefficient becomes a function of the relaxation time of the polymer (Berens and Hopfenberg, 1979). In the case of the vinyl monomer clay nanocomposite samples, in spite of poor distribution and presence of tactoids, the movement of the polymer chains is further restricted than in Cloisite $10 \mathrm{~A}^{\circledR}$ samples because of the cross-linking reaction with the clay. This would in turn lead to longer relaxation times, hindering the movement of water molecules. The higher glass transition temperatures observed, which is a function of chain mobility, in VMC nanocomposites shows that the chains are infact restricted in 
their motion. Indeed, it is the slow polymer rearrangement of polymer chains in the presence of clay that is most likely responsible for the longer than anticipated time needed to reach diffusion equilibrium as seen in Figure 4.22.

Another theory that can be applied to explain the diffusion of water through the nanocomposite samples is the Langmuir adsorption theory. Carter and Kibler (1978) applied this theory to explain the slow uptake of water in epoxy resins. It is hypothesized that the diffusing water molecules that adsorb onto the clay platelets get bound creating the "bound" phase. This adsorption of water molecules on the clay surface would then cause a reduction in diffusion coefficient by impeding the advance of the diffusing molecules. An explanation of the mechanism of diffusion of water through neat resin as well a nanocomposite samples is presented in section 4.2.1.

\subsubsection{Mechanism of Diffusion through Vinyl ester resin}

Diffusion of a penetrant like water in glassy polymers takes place in two essential steps. The first is adsorption or dissolution of water molecules onto the surface of the polymer. This creates a concentration gradient within the polymer. Water molecules then diffuse through the polymer due to this concentration gradient until equilibrium is reached.

Mensitieri et al., (1995), explained sorption of water in glassy epoxy resin by the sorption-diffusion process. The water molecules first dissolved in the bulk polymer by Langmuir adsorption and Flory-Huggins dissolution. They were then free to diffuse, or were partially immobilized at certain sites. In the absence of significant polymer 
relaxation, the sorption was then modeled using the Dual Sorption theory. Fick's law was combined with the relation for the Flory-Huggins dissolved species and an equivalent Langmuir adsorbed species. The differential equation was written in terms of $C_{d}$ and $C_{h}$, concentration of dissolved and Langmuir adsorbed species, and $D_{d}$ and $D_{h}$, the respective diffusion coefficients. Re-writing Fick's Law in terms of the concentration of the dissolved species,

$\frac{\partial}{\partial x}\left(D_{d} \frac{\partial C_{d}}{\partial x}+D_{h} \frac{\partial C_{h}}{\partial x}\right)=\frac{\partial\left(C_{h}+C_{d}\right)}{\partial t}$

where $\mathrm{C}_{\mathrm{h}}$ is written in terms of the hole capacity constant, $\mathrm{C}_{\mathrm{h}}$, , affinity constant, $\mathrm{b}$ and the Henry's constant, $\mathrm{k}_{\mathrm{d}}$ as,

$$
\mathrm{C}_{\mathrm{h}}=\frac{\frac{\mathrm{C}_{\mathrm{h}}{ }^{\mathrm{b}} \mathrm{bC}_{\mathrm{d}}}{\mathrm{k}_{\mathrm{d}}}}{1+\frac{\mathrm{bC}_{\mathrm{d}}}{\mathrm{k}_{\mathrm{d}}}}
$$

If, $\mathrm{C}_{\mathrm{T}}=\mathrm{C}_{\mathrm{d}}+\mathrm{C}_{\mathrm{h}}$, then equation 4.1 can be re-arranged as,

$\frac{\partial}{\partial x}\left(D_{\text {eff }} \frac{\partial C_{T}}{\partial x}\right)=\frac{\partial C_{T}}{\partial t}$

where, $\mathrm{D}_{\text {eff }}=\mathrm{D}_{\mathrm{d}} \frac{1+\frac{\mathrm{FK}}{\left(1+\mathrm{aC}_{\mathrm{d}}\right)^{2}}}{1+\frac{\mathrm{K}}{\left(1+\mathrm{aC}_{\mathrm{d}}\right)^{2}}}$

Here, $\mathrm{a}=\frac{\mathrm{b}}{\mathrm{k}_{\mathrm{d}}}, \mathrm{F}=\frac{\mathrm{D}_{\mathrm{h}}}{\mathrm{D}_{\mathrm{d}}}$ and $\mathrm{K}=\frac{\mathrm{C}_{\mathrm{h}}^{\prime} \mathrm{b}}{\mathrm{k}_{\mathrm{d}}}$

In many cases, the Langmuir adsorbed penetrant molecule can be assumed to be completely immobilized, i.e., $\mathrm{D}_{\mathrm{h}}=0$, which then reduces the diffusion equation 4.3 to 
Fick's Law and hence, the sorption behavior follows equation 2.1, though the diffusion coefficient $\left(\mathrm{D}_{\text {eff }}\right)$ assumes a different expression,

$D_{\text {eff }}=D_{d} \frac{k_{d}}{k_{d}+C_{h}^{\prime} b}$, for low penetrant activity

and

$\mathrm{D}_{\mathrm{eff}}=\mathrm{D}_{\mathrm{d}}$, for high penetrant activity.

Vinyl ester resins contain - $\mathrm{OH}$ groups in their chain as seen from Figures 2.2 and 2.3. Typically, there exists significant hydrogen bonding between -OH groups of adjacent chains that give the vinyl ester resin its high $\mathrm{T}_{\mathrm{g}}$. However, diffusing water molecules have been known to interact with these hydrophilic groups. Verghese et al., (1999) proposed that water molecules in the vinyl ester resin system could be immobilized by weak hydrogen bonding with the hydrophilic $-\mathrm{OH}$ groups on the vinyl ester chain, and this interaction is reduced as temperature is increased. The affinity towards such hydrophilic groups may also increase the capacity of the resin to retain water, or its equilibrium moisture content. This phenomenon was seen with respect to non-post cured and postcured DERAKANE ${ }^{\mathrm{TM}}$ 411-350 resins. The non-post cured resins not only had higher moisture content, but also a higher diffusivity. The lower cross-link density presented a lesser hindrance to the diffusion of water molecules. Also, due to lower cross-link density, the hydrophilic groups were more accessible, making the resin more hydrophilic. In the post-cured resins, some hydrophilic $-\mathrm{OH}$ groups were sterically shielded by the cross-linked polymer chains (Soles and Yee, 2000). This reduced the number of $-\mathrm{OH}$ groups accessible to water molecules, thereby reducing the moisture uptake to $0.44 \%$. In 
the case of epoxy resins, researchers found an opposite trend, where equilibrium moisture uptake increased with cure. This is because $-\mathrm{OH}$ groups are created with cure in the case of epoxies. Also, the presence of unreacted amine hardener in epoxies adds to the hydrophilic nature. Unlike epoxies, in vinyl ester resins, the $-\mathrm{OH}$ groups are present on the polymer chains, and not created during cure. Moreover, no amine hardener is added, and cross-linking takes place due to bond formation with styrene. Thus the number of $\mathrm{OH}$ groups are the same in the non-post cured resin and post cured resin.

If the immobilized water molecules are assumed to contribute only to the equilibrium moisture content and not towards the diffusion process, only the mobile molecules govern the diffusion through the resin. Thus by the discussion above, the diffusion process would be Fickian as explained earlier, and this is as observed from the data.

\subsubsection{Proposed Mechanism of Diffusion through Polymer-Clay nanocomposites}

Diffusion through polymer clay nanocomposites showed certain deviations from Fickian behavior, especially at high clay contents. Yano et al., (1993) explained reduction of diffusion of water vapor and gases through polymer-clay nanocomposites by the tortuous path theory, using which they were able to explain the reduction in permeability of gases and water vapor through polyimide clay nanocomposites. The transient diffusion of water through polymer nanocomposites studied here seems to follow a slightly different behavior. It was observed that the equilibrium moisture content of the samples increased with the amount of clay, though not linearly. Also, as expected, the diffusion coefficient decreased with increase in clay content. 
This increase in moisture content was due to have occurred due to water adsorbing on the clay surface (van Olphen, 1977). Since the clay is much more hydrophilic than hydrogen bonded interactions of water with $-\mathrm{OH}$ groups, it was assumed that this has a more profound effect on the diffusion characteristics. The water molecules are believed to adsorb onto the clay surface, thereby rendering them immobile. Thus the diffusion behavior was modeled using the Langmuir theory (Carter and Kibler, 1978). Following this theory, it is also assumed that the immobilized water molecules can become mobile and vice versa. See Appendix I for model details. The model fitted the data well, especially at high clay contents. The values of the parameters of the model for VMC as well as Cloisite $10 \mathrm{~A}^{\circledR}$ are tabulated in Table 4.4. Some conclusions of the values of the parameters in the Langmuir model were drawn from the data obtained. If the assumption of clay adsorbing water were true, more molecules would become bound as the amount of clay in the sample increases. According to the Langmuir theory, at equilibrium $\gamma \mathrm{n}=\beta \mathrm{N}$

where $\gamma$ is the probability per unit time that molecules become bound, $\beta$ is the probability at unit time with which they become mobile. $\mathrm{n}$ is the number of mobile molecules per unit volume and $\mathrm{N}$ is the number of bound molecules per unit volume. Re-arranging equation 4.4 we get,

$\frac{\mathrm{n}}{\mathrm{N}}=\frac{\beta}{\gamma}$

which is a ratio of the number of mobile molecules to bound molecules within the sample, at equilibrium. This ratio, for the calculated values of $\gamma, \beta$ for the polymer clay systems is tabulated in Table 4.4. This ratio decreases as the clay content increases, meaning that there are lesser mobile molecules in samples with higher clay contents. This 
is what was expected from the earlier assumption. Also, $\mathrm{D}_{\gamma}$, or the diffusion coefficient of the mobile molecules in the polymer is the same for a particular polymer-clay system. This is not unexpected, as the resin chemistry is not changed and the reduction in diffusion coefficient is only due to the immobilization of water on the clay surfaces, which stops its advance.

There was a slight variation of $\mathrm{D}_{\gamma}$ between VMC and Cloisite $10 \mathrm{~A}^{\circledR}$ samples. This may be due to the different clay surface chemistries. The VMC samples absorbed lesser amount of water, assumed to be due to the cross-linking around the clay surface by the reactive surface treatment group. This meant shielding of the clay surfaces, leading to not only lower sorption, but also higher $\frac{n}{N}$ ratios. Also, $\mathrm{D}_{\gamma}$ was found to be slightly lower for this system. The reason for almost similar overall diffusivities between VMC and Cloisite $10 \mathrm{~A}^{\circledR}$ samples could be explained by this phenomenon. The reactive clay created greater cross-linking within the polymer, causing greater hindrance to the movement of the water molecules. Also, as mentioned earlier, the chains in VMC samples are more restricted in their motion than in Cloisite $10 \mathrm{~A}^{\circledR}$ nanocomposites. Both these combined might be the reason for the lower $\mathrm{D}_{\gamma}$ observed in VMC samples. The only behavior that cannot be convincingly explained is the apparent Fickian behavior shown by polymer nanocomposite samples containing very low clay concentrations. It is therefore concluded that in cases of very low concentrations of clay, Fickian mode of diffusion may be dominating, as the number of adsorption sites will be smaller at low clay concentrations. 
Table 4.4. Summary of the diffusion model parameters

\begin{tabular}{|c|c|c|c|c|c|c|c|c|}
\hline Sample & $0.5 \%$ & $1 \%$ & $2.5 \%$ & $5 \%$ & $0.5 \%$ & $1 \%$ & $2.5 \%$ & $5 \%$ \\
VMC & VMC & VMC & VMC & $10 \mathrm{~A}$ & $10 \mathrm{~A}$ & $10 \mathrm{~A}$ & $10 \mathrm{~A}$ \\
\hline $\begin{array}{c}\mathrm{D}_{\mathrm{F}} \\
\mathrm{x} 10^{+6} \mathrm{~mm}^{2} / \mathrm{s}\end{array}$ & 0.5339 & 0.3683 & 0.2381 & 0.1976 & 0.4519 & 0.3365 & 0.2393 & 0.1254 \\
\hline $\mathrm{E}_{\mathrm{F}}^{2}$ & 0.0024 & 0.012 & 0.0218 & 0.0261 & 0.0081 & 0.0491 & 0.0766 & 0.1271 \\
\hline$\gamma, \mathrm{h}^{-1}$ & - & - & 0.0098 & 0.0232 & - & 0.0093 & 0.0125 & 0.0324 \\
\hline$\beta, \mathrm{h}^{-1}$ & - & - & 0.0452 & 0.049 & - & 0.0295 & 0.0279 & 0.0279 \\
\hline $\begin{array}{c}\mathrm{D} \gamma \\
\mathrm{x} 10^{+6} \mathrm{~mm}^{2} / \mathrm{s}\end{array}$ & - & - & 0.394 & 0.4234 & - & 0.5184 & 0.5371 & 0.5975 \\
\hline $\mathrm{E}_{\mathrm{L}}^{2}$ & - & - & 0.0122 & 0.0098 & - & 0.0183 & 0.0055 & 0.0067 \\
\hline$\frac{n}{N}$ & - & - & 4.612 & 2.112 & & 3.172 & 2.232 & 0.8611 \\
\hline
\end{tabular}

Note: E refer to $\left(\mathrm{E}_{\text {exp }}-\mathrm{E}_{\mathrm{cal}}\right)^{2}$.

L refers to Langmuir adsorption theory

F refers to Fick's.

\subsection{Permeability Measurements}

Permeability $(P)$ of DERAKANE ${ }^{\text {TM }}$ 411-350 vinyl ester resin and nanocomposite samples were calculated as a product of diffusion coefficient and solubility: $P=D S$

where, $\mathrm{D}$ is the diffusion coefficient and $\mathrm{S}$ is the solubility of water in the resin, $\mathrm{g} / \mathrm{m}^{3}$. Solubility of water was calculated by multiplying the equilibrium moisture content of the samples with the density of the dry sample. Density was measured by the water displacement method. The samples were accurately weighed and the volume measured by immersing them in a measuring jar with an least count of $0.2 \mathrm{ml}$. Reported values are 
averages of 4 samples. The results of the calculation are tabulated in Table 4.5 and the corresponding permeabilities are plotted in Figure 4.29.

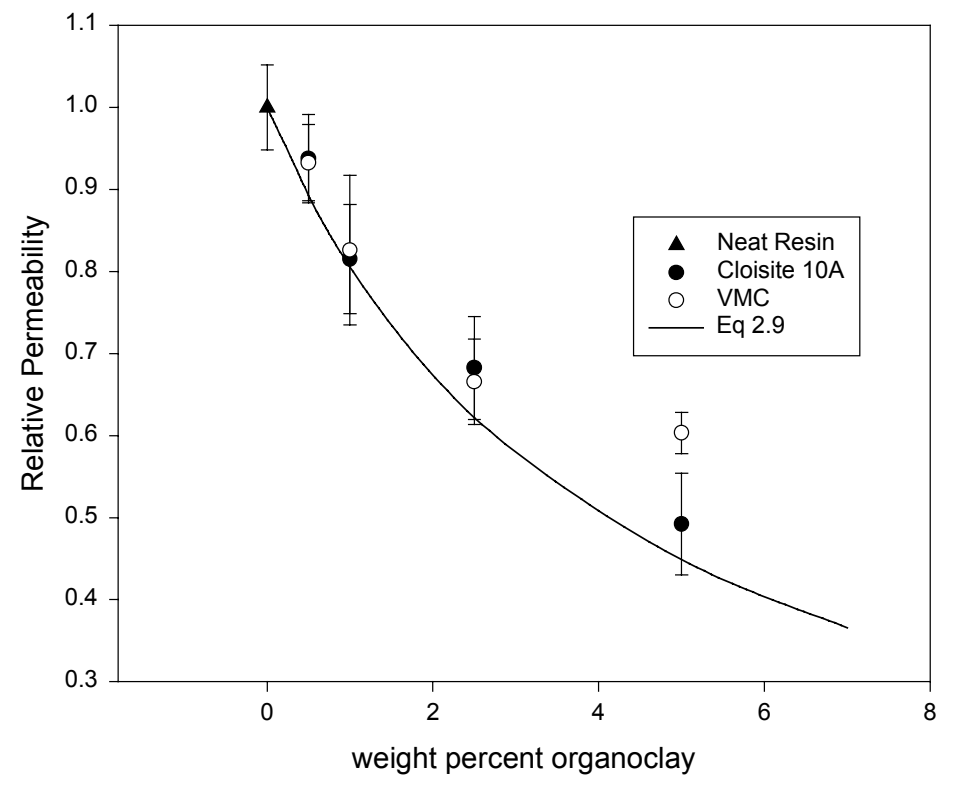

Figure 4.31. Relative Permeability of Cloisite $10 \mathrm{~A}^{\circledR}$ and VMC vinyl ester resin nanocomposites. $(\mathrm{L}=180 \mathrm{~nm}, \mathrm{~W}=1 \mathrm{~nm})$. Volume fraction was calculated using $\rho_{\text {clay }}=$ $2.66 \mathrm{gm} / \mathrm{cc}$ and $\rho_{\text {polymer }}=1.075 \mathrm{gm} / \mathrm{cc}$.

The solubility increases as the amount of clay in the sample increases. This is because of the water molecules adsorbing onto the clay surface. The permeability coefficient mirrors the diffusion coefficient change, and reduces as the amount of clay is increased in the sample. However, unlike diffusivity, which was found to reduce by about $85 \%$ with 5 wt. $\%$ of Cloisite $10 \mathrm{~A}^{\circledR}$, permeability is found to decrease only by $50 \%$ for the same loading of clay. Messersmith and Giannelis (1995) reported a $40 \%$ reduction in water vapor permeability through nylon nanocomposites containing about 2.5 vol \% (5 wt \%) of silicate. Their values are given in Table 2.10 in Section 2.2.4. 
Table 4.5. Permeability of Nanocomposite samples as calculated from diffusion data.

\begin{tabular}{|c|c|c|c|c|c|c|}
\hline Sample & $\mathrm{M}_{\infty}$ & $\begin{array}{c}\mathrm{D}, \mathrm{x} 10^{6} \\
\mathrm{~mm}^{2} / \mathrm{s}\end{array}$ & $\begin{array}{c}\text { Density, } \\
\mathrm{gm} / \mathrm{cc}\end{array}$ & $\begin{array}{c}\text { Solubility, } \\
\mathrm{mg} / \mathrm{cc}\end{array}$ & $\begin{array}{c}\text { Permeability, } \\
\text { x } 10^{9} \\
\text { g- } \mathrm{m}^{2} / \mathrm{m}^{3}-\mathrm{s}\end{array}$ & $\begin{array}{c}\text { Relative } \\
\text { Permeability }\end{array}$ \\
\hline $\begin{array}{l}\text { Neat } \\
\text { Resin }\end{array}$ & 0.4337 & 0.9191 & 1.0715 & 4.647 & 4.271 & 1 \\
\hline $\begin{array}{l}0.5 \% \\
\text { VMC }\end{array}$ & 0.6912 & 0.5339 & 1.0804 & 7.468 & 3.987 & 0.9334 \\
\hline $\begin{array}{c}1 \% \\
\text { VMC }\end{array}$ & 0.8623 & 0.3683 & 1.1126 & 9.594 & 3.533 & 0.8272 \\
\hline $\begin{array}{l}2.5 \% \\
\text { VMC }\end{array}$ & 1.056 & 0.2381 & 1.1324 & 11.96 & 2.847 & 0.6666 \\
\hline $\begin{array}{c}5 \% \\
\text { VMC }\end{array}$ & 1.1658 & 0.1976 & 1.1198 & 13.05 & 2.579 & 0.6039 \\
\hline $\begin{array}{c}0.5 \% \\
\text { Cloisite } \\
10 \mathrm{~A}^{\circledR} \\
\end{array}$ & 0.8275 & 0.4519 & 1.0721 & 8.872 & 4.009 & 0.9386 \\
\hline $\begin{array}{c}1 \% \\
\text { Cloisite } \\
10 \mathrm{~A}^{\circledR} \\
\end{array}$ & 0.9270 & 0.3365 & 1.1171 & 10.36 & 3.484 & 0.8158 \\
\hline $\begin{array}{c}2.5 \% \\
\text { Cloisite } \\
10 \mathrm{~A}^{\circledR} \\
\end{array}$ & 1.1085 & 0.2393 & 1.1002 & 12.2 & 2.918 & 0.6832 \\
\hline $\begin{array}{c}5 \% \\
\text { Cloisite } \\
10 \mathrm{~A}^{\circledR} \\
\end{array}$ & 1.4839 & 0.1254 & 1.1300 & 16.77 & 2.102 & 0.4923 \\
\hline
\end{tabular}

The solid line in Figure 4.29 was drawn using equation 2.9, which relates the relative permeability of a nanocomposite with the linear dimensions of the clay platelets and the clay content for the ideal case. $\mathrm{L}$ and $\mathrm{W}$ were measured from the TEM pictures and were 80-180 $\mathrm{nm}$ and $1 \mathrm{~nm}$ respectively for all Cloisite $10 \mathrm{~A}^{\circledR}$ nanocomposite samples. The same calculations could not be done for $\mathrm{VMC}$ as $\mathrm{L}$ and $\mathrm{W}$ could not be calculated from the TEM pictures obtained. However, the data are shown in Figure 4.29 for the sake of comparison. 
It is found that the reduction in permeability follows the same trend as predicted by equation 2.9. However some deviation is seen between the predicted and observed values, i.e. the values are less than predicted by equation 2.9 . This might be due to the lack of complete exfoliation and existence of aggregates in the Cloisite $10 \mathrm{~A}^{\circledR}$ and VMC samples. Such deviations are more for VMC because of no exfoliation.

\subsection{DSC Tests}

The polymer molecules at the surface of the nanoscale particles are completely immobilized (Kornmann et al., 1998). This would lead to restriction in the mobility of the polymer chains, leading to an increase in the glass transition temperature of the samples. Also, the smaller the individual clay particles or in other words the greater the exfoliation, the more the interaction between the clay and polymer and hence higher would be the $\mathrm{T}_{\mathrm{g}}$. This phenomenon is observed in the results obtained with $0.5,1,2.5$ and 5 weight $\%$ Cloisite $10 \mathrm{~A}^{\circledR}$ samples. The results are tabulated in Table 4.6 and Figure 4.32. It was found that glass transition temperature increased as the percentage of clay in the sample increased. The glass transition temperature appeared to level off as the loading of clay was increased. This may be due to the presence of greater amount of multilayer tactoids in such samples. This is confirmed by comparison of the TEM pictures of the samples as shown in Figures 4.2 and 4.3.

DSC scans were also made on $0.5,1,2.5$ and 5 weight \% Vinyl monomer clay (VMC) samples to determine the $\mathrm{T}_{\mathrm{g}}$. Glass transition temperature of 0.5 and $1 \% \mathrm{VMC}$ samples were around 109.59 and $112.61{ }^{\circ} \mathrm{C}$, respectively, and did not seem to vary much with 
clay content. This was contrary to the reasoning above, as the TEM pictures showed intercalated samples with a spacing of around $1.511 \mathrm{~nm}$ with the clay existing as large tactoids. The significantly higher $T_{g}$ is attributed to the reaction between the clay and the polymer chains, which leads to greater restriction in the motion of the chains thereby leading to higher $T_{g}$. The drop in $T_{g}$ at higher percentages of clay is again similar to what was seen with Cloisite $10 \mathrm{~A}^{\circledR}$ samples and due to poorer distribution of clay samples through out the samples. The test results are tabulated in Table 4.6 and Figure 4.32.

Table 4.6. Variation of Glass Transiton temperature of nanocomposite samples with clay content, before and after equilibrating with distilled water at $25^{\circ} \mathrm{C}$.

\begin{tabular}{|c|c|c|c|c|c|}
\hline \multirow[t]{2}{*}{ Sample } & \multirow{2}{*}{$\begin{array}{l}\text { Clay } \\
\text { Percentage, wt } \\
\%\end{array}$} & \multicolumn{4}{|c|}{ Sample Glass Transiton temperature, ${ }^{\circ} \mathrm{C}$} \\
\hline & & Dry Sample & $\begin{array}{c}\text { Equilibrated } \\
\text { Sample }\end{array}$ & $\Delta \mathrm{T}_{\mathrm{g},} \%$ & $\begin{array}{c}\text { Re-Dried } \\
\text { (One } \\
\text { sample) }\end{array}$ \\
\hline & Neat & $97.97(0.35)$ & $91.11(0.43)$ & 7.00 & 97.62 \\
\hline \multirow{4}{*}{$\begin{array}{l}\text { Cloisite } \\
10 \mathrm{~A}^{\circledR}\end{array}$} & 0.5 & $101.51(0.55)$ & $97.09(0.38)$ & 4.35 & 101.66 \\
\hline & 1.0 & $104.7(0.32)$ & $98.22(0.18)$ & 6.19 & 103.22 \\
\hline & 2.5 & $112.73(0.18)$ & $103.32(0.45)$ & 8.35 & 112.15 \\
\hline & 5.0 & $117.34(0.34)$ & $106.33(0.16)$ & 9.38 & 117.11 \\
\hline \multirow{4}{*}{ VMC } & 0.5 & $109.59(0.05)$ & $101.57(0.39)$ & 7.32 & 109.00 \\
\hline & 1.0 & $112.61(0.12)$ & $103.09(0.19)$ & 8.45 & 112.05 \\
\hline & 2.5 & $110.1(0.19)$ & $101.44(0.47)$ & 7.86 & 109.38 \\
\hline & 5.0 & $108.69(0.31)$ & $101.14(0.63)$ & 6.95 & 108.26 \\
\hline
\end{tabular}

Note: Numbers in brackets are standard deviations. 


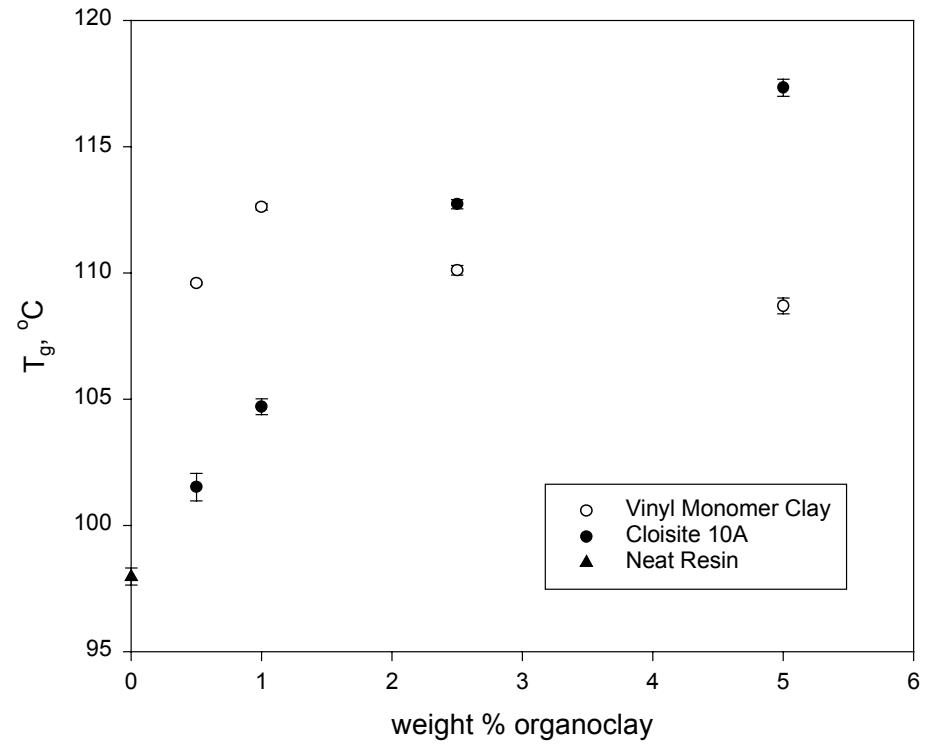

Figure 4.32. Variation of $\mathrm{T}_{\mathrm{g}}$ with clay content.

Tsagaropoulos and Eisenberg (1995) studied glass transition temperature changes in polyvinyl acetate and poly (styrene - vinyl pyridine) - silica composites. The size of the silica particles as measured from TEM pictures were $7 \mathrm{~nm}$ existing as aggregates of approx. 50nm in diameter. They found the samples to have two glass transition temperatures, one that coincided with that of the unfilled polymer and another, which was $40-110{ }^{\circ} \mathrm{C}$ higher. This increase in $\mathrm{T}_{\mathrm{g}}$ was believed to be because of the interaction between the silica particles and the polymer chains. The polymer chains adjacent to the particles are believed to be completely or partially immobilized. The increase in glass transition temperature was believed to be due to the partially immobilized polymer chains. The increase in glass transition temperature was found to decrease at silica content increased to $20 \%$. At higher percentages of silica, aggregates were observed. It was postulated that there was a critical distance between the silica particles below which 
more polymer chains existed as completely immobilized, and hence the observed decrease in the higher $T_{g}$. Similarly, Messersmith and Giannelis (1994) observed a shift and broadening of the $\tan \delta$ peak to higher temperatures in their DMA experiments on epoxy nanocomposites, indicating an increase in $T_{g}$. However, 4 vol $\%$ of montmorillonite showed only a $4{ }^{\circ} \mathrm{C}$ increase in $\mathrm{T}_{\mathrm{g}}$ over neat resin samples.

Samples were then equilibrated in distilled water at $25{ }^{\circ} \mathrm{C}$ for a month. Upon reaching equilibrium, DSC scans were run on them to measure the glass transition temperature of wet samples. A scan was also made on the re-dried samples to determine if there was any change in the $T_{g}$ of the samples. The results are tabulated in Table 4.6. The $T_{g}$ of all equilibrated samples was lower due to plasticizing effect of water. Though the $T_{g}$ of equilibrated samples was still higher than the $\mathrm{T}_{\mathrm{g}}$ of dry neat resin sample. Also, for Cloisite $10 \mathrm{~A}^{\circledR}$ nanocomposites, the extent of plasticization seemed to increase with moisture content. On the other hand, the reduction in $\mathrm{T}_{\mathrm{g}}$ for $\mathrm{VMC}$ samples seemed independent of clay content. However the process of plasticization was reversible as the $\mathrm{T}_{\mathrm{g}}$ of re-dried samples were almost the same as the original dry samples, for neat resin as well as for VMC and Cloisite $10 \mathrm{~A}^{\circledR}$ nanocomposite samples. Hence, it is possible that the water adsorbed onto the clay surface does not cause any real adverse effect to the matrix polymer.

\subsection{Mechanical Property Tests}

Figure 4.33 shows the measured Young's modulus for nanocomposites made with both Cloisite $10 \mathrm{~A}^{\circledR}$ and VMC. Tensile modulus of neat DERAKANE 411-350 vinyl ester resin 
was found to be $3.11 \pm 0.2 \mathrm{GPa}$, which agrees well with the $3.2 \mathrm{GPa}$ as reported by Dow Chemical Co. (www.dow.com/derakane/specific/product $/ \mathrm{m} 411350 . \mathrm{htm}$ ). The stiffness has increased by about $25 \%$ with organoclay addition. However, as in the case of moisture diffusivity and glass transition temperature, the rate of property improvement decreases with increasing clay content. This again may be due to the clay existing as larger particles at higher clay contents as seen in from the TEM pictures. This expectedly reduces the beneficial effect of each individual platelet. Note that Cloisite $10 \mathrm{~A}^{\circledR}$ appears to be more effective in raising the Young's modulus at low clay concentrations, while, at the higher clay loading, both clays appear to perform nearly equally well. A similar increase in tensile modulus of DGEBA epoxy resin required addition of $10 \mathrm{vol} \%$ of glass beads with an average diameter of $10 \mu \mathrm{m}$ (Zhang and Berglund, 1993).

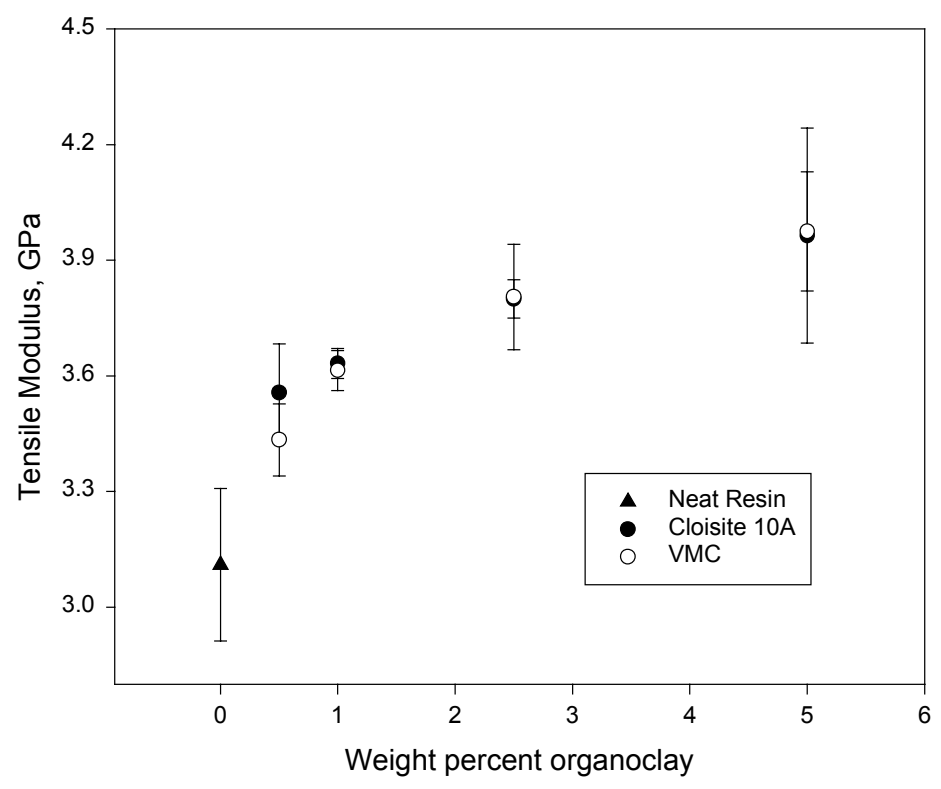

Figure 4.33. Tensile modulus of the nanocomposite as a function of Cloisite $10 \mathrm{~A}^{\circledR}$ and VMC loading. 
Corresponding results for the tensile strength are given in Figure 4.34. There is greater variability in these results, and this is not surprising since strength is a failure property. Although strength appears to reduce marginally with clay content for Cloisite $10 \mathrm{~A}^{\circledR}$ nanocomposite samples, VMC nanocomposites show a slightly different trend. At low concentrations of VMC, the tensile strength appears to increase. We postulate that this increase in strength is due to the chemical bond formed between VMC's surface treatment and the vinyl ester chains during curing, which is more effective in transferring stress to the clay platelets than in the case of an unreactive clay like Cloisite $10 \mathrm{~A}^{\circledR}$. The subsequent slight drop in tensile strength at $1 \mathrm{wt} \%$ and $2.5 \mathrm{wt} \%$ clay contents maybe due to lack of proper distribution of clay. The increase seen in tensile strength at higher percentages of clay maybe due to the properties of clay starting to influence the overall property of the nanocomposite.

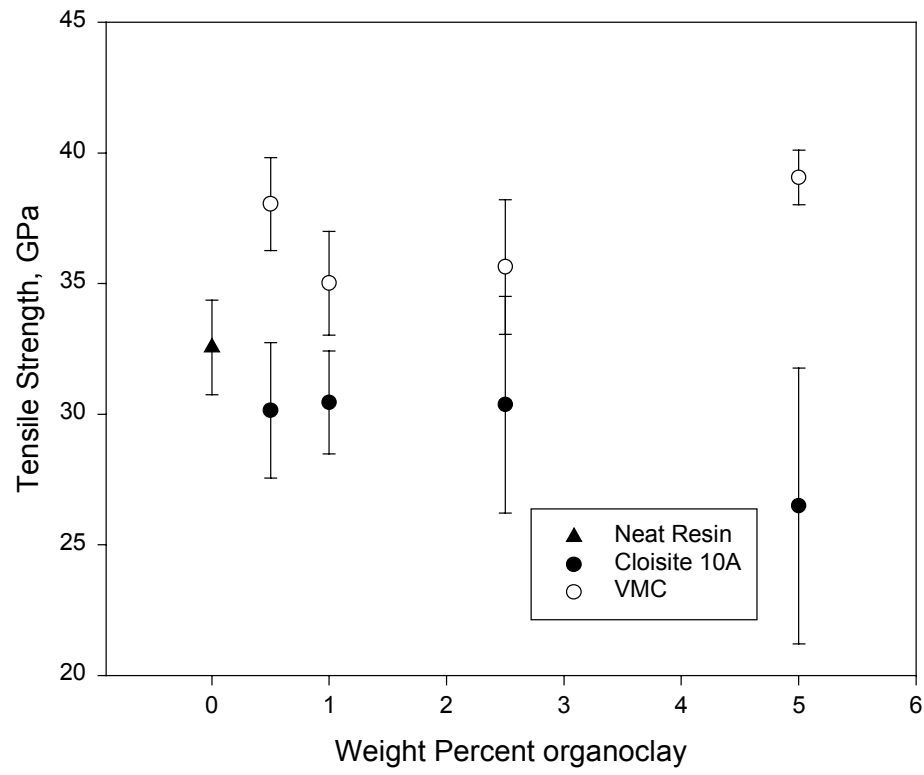

Figure 4.34. Tensile strength of the nanocomposite as a function of Cloisite $10 \mathrm{~A}^{\circledR}$ and VMC loading. 
The above results are similar to those reported by other researchers. Kornmann et al. (1998) in their study on unsaturated polyester-MMT nanocomposites reported a linear increase in tensile modulus with MMT content. They found an increase in modulus of as much as $23 \%$ for $5 \mathrm{wt} \%$ of MMT. On the other hand tensile strength was found to be relatively unchanged, but decreased slightly at high clay contents of $10 \mathrm{wt} \%$. Lan et al., (1995) have reported a $35 \%$ increase in tensile modulus with 1 wt \% exfoliated montmorrilonite in EPON 828 epoxy resin. They also found that d-spacing of the clay in the nanocomposite affected the level of property increase in the epoxy nanocomposites. For nanocomposite containing approximately $2 \mathrm{wt} \%$ montmorillonite with a d-spacing of $1.66 \mathrm{~nm}$, the tensile modulus and strength was found to be slightly lower than that of the neat resin. Also Okada and Usuki (1995) in their study on Nylon 6 nanocomposites, reported no change in tensile strength and modulus for nanocomposites where the dspacing did not change after incorporation of the clay. While for exfoliated nanocomposites the modulus increased from $1.1 \mathrm{GPa}$ to $2.1 \mathrm{GPa}$ for $4.2 \mathrm{wt} \% \mathrm{MMT}$. Based on the above-referred work and from the TEM pictures in Figure 2-8, the authors expected Cloisite $10 \mathrm{~A}^{\circledR}$ nanocomposites to out perform VMC nanocomposites. However the results obtained suggest that in spite of the morphological differences between Cloisite $10 \mathrm{~A}^{\circledR}$ and VMC nanocomposites, both organoclays seem to perform equally well. This again is possibly due to the reactive group in the surface treatment of VMC that might have taken part in the crosslinking reaction.

Impact strength data for un-notched samples presented in Table 4.7 show large standard deviation. Hence no definite conclusion could be obtained from the data, though it seems 
that the addition of clay does not adversely affect the impact strength of the vinyl ester resin. The unusually large standard deviations may be due to certain defects in some samples. The exact reason needs to be investigated further in future work. For comparison, IZOD Impact strength data for notched samples of thermosetting resins like epoxy and polyester as reported in literature (Harper, 1975) are in the range of 0.2-1 ftlb/in (10.67-53.4 J/m) and, 0.2-0.4 ft-lb/in (10.67-21.37 J/m) respectively.

Table 4.7 Impact Strength (in $\mathrm{J} / \mathrm{m}$ ) of vinyl ester nanocomposite (un-notched) samples.

\begin{tabular}{|l|c|c|}
\hline Weight percent organoclay & ${\text { Cloisite } 10 \mathrm{~A}^{\circledR}}^{{ }^{\circledR}}$ & VMC \\
\hline Neat Resin $(0 \%)$ & $58.07(7.75)$ & $58.07(7.75)$ \\
\hline 0.5 & $69.95(20.19)$ & $57.42(27.38)$ \\
\hline 1.0 & $64.39(22.46)$ & $89.77(30.38)$ \\
\hline 2.5 & $67.44(9.29)$ & $56.33(13.8)$ \\
\hline 5.0 & $40.3(6.82)$ & $61.18(22.51)$ \\
\hline
\end{tabular}




\section{CHAPTER V}

\section{CONCLUSIONS AND RECOMMENDATIONS}

\subsection{Conclusions}

The use of montmorillonite clay having two different surface treatments resulted in two nanocomposites with different morphologies. VMC led to an intercalated structure with the clay existing as large tactoids with a small increase in d-spacing, while Cloisite $10 \mathrm{~A}^{\circledR}$ gave a mixed morphology containing intercalated and partially exfoliated platelets. Exfoliation was not observed in VMC nanocomposites due to the smaller surface treatment on the clay (which imparted a smaller initial basal spacing to the clay). We believe the smaller surface treatment molecule may have led to bridging of adjacent clay platelets by a chemical bond. Cloisite $10 \mathrm{~A}^{\circledR}$ was found to partially exfoliate within the vinyl ester resin with only mild mixing. This suggests that the surface treatment given to Cloisite $10 \mathrm{~A}^{\circledR}$, namely benzyl (hydrogenated tallow alkyl) dimethyl quarternary ammonium chlorides, is compatible with vinyl ester resin systems. Greater exfoliation is expected with higher shear, like ultrasonication, which would lead to better than observed properties.

Diffusion tests conducted by immersing the nanocomposites in water showed that montmorillonite clay was effective in reducing the diffusion coefficient of water through the vinyl ester resin. Surprisingly, the reduction in the diffusion coefficient was only marginally more for Cloisite $10 \mathrm{~A}^{\circledR}$ than for $\mathrm{VMC}$, which did not seem to disperse well according to TEM evidence. However, the reduction in diffusion coefficient was found to 
level off at higher clay loading. The solubility of water in the nanocomposites appeared to increase with the amount of clay, as evidenced by the increase in equilibrium moisture content. This was due to water getting adsorbed onto the clay. It is hypothized that in this way the clay would act as a moisture scavenger by trapping water and preventing it from reaching the glass matrix interface in FRPs. However, it remains to be seen that whether this will help or hurt the durability of GRFP composites made with a clay-containing vinyl ester matrix. Reductions seen in permeability of water through the resin inspite of an increase in equilibrium moisture content is however encouraging.

The nature of the surface treatment group was found to affect the diffusion characteristics. The presence of a reactive group in the surface treatment, as in VMC, is expected to protect the clay surface from the diffusing water by forming crosslinks around the clay platelets.

As expected, the addition of nanoclay was accompanied by an increase in the polymer glass transition temperature and an increase in the elastic modulus. Both of these property increases are due to interaction between the polymer chains and clay platelets. Tensile strength on the other hand did not show much change for Cloisite $10 \mathrm{~A}^{\circledR}$ nanocomposite samples. The mechanical property increases for VMC nanocomposites were comparable and even more than the better-dispersed Cloisite $10 \mathrm{~A}^{\circledR}$ nanocomposites. This points towards the importance of a good interface between clay and the matrix polymer. This interface was indeed better in VMC due to the presence of the reactive surface treatment group. It is inferred from the data that the increase in properties is due to better 
interfacing that overcomes the adequacy of exfoliation. It can be expected that exfoliated VMC would enhance the properties even more than those seen with exfoliated nonreactive clay nanocomposites.

The Langmuir-Adsoprtion model used to explain the mechanism of diffusion of water through polymer nanocomposites seemed to fit the data well. The model was also able to predict the deviation from Fickian behavior and the slow reach to equilibrium at high organoclay contents. This could mean that water molecules exist in two phases, namely, "free" water and "bound" water which is adsorbed onto the clay. This would then not only slow down the diffusion of water molecules, but also prevent the water from reaching the glass fibers; thereby improving the durability of a glass fiber reinforced polymer composite. However, Fickian diffusion was still observed at low organoclay contents, for which case the model parameters became insignificant. Hence the diffusion process may not be explained by any one mode of diffusion alone. There might be regions when one mode influences the diffusion more than another does. For e.g., in cases of very low concentrations of clay, Fickian mode of diffusion may be dominating, as the number of adsorption sites will be smaller at low clay concentrations.

Finally, addition of nanoclay to matrix polymeric resins does show potential for improving barrier properties. Reduction of diffusion coefficient is evidently observed. In addition, mechanical and physical property enhancements are seen even at low clay contents. This would help in extending the utility and application of the composite in more severe environments. 


\subsection{Recommendations}

Although use of nanoclays to enhance barrier properties of polymeric matrices has shown promising results, the following lists out some of the possible areas that may need to be addressed in future studies.

1. Verification of the proposed theory of protective effect of nanoclays in the matrix of glass-fiber reinforced polymeric composites. This can be investigated further by performing diffusion tests on GFRP samples as well as steady state permeability tests.

2. Further enhance barrier and mechanical properties of the matrix by improving the exfoliation of clay platelets using higher shear mixing techniques like Cowles Dissolver or ultrasonication.

3. Having a reactive group on the surface treatment of the clay was found to give satisfactory property enhancements even in the intercalated form. It is proposed that exfoliation of such a nanoclay would yield better than observed results. Lack of exfoliation in VMC was partly due to the small surface treatment group. It is recommended that investigations can be made using a nanoclay with a larger unsaturated surface treatment group to confirm this theory. 


\section{REFERENCE}

Akelah A. and Moet A., "Polymer-clay nanocomposites: Free radical gratfting of polystyrene on to organphilic montmorillonite interlayers", J. Mat. Sci.., 31, 3589 - 3596 (1996).

Antoon M.K. and Koenig J.L., "FTIR study of the reversible interactions of water and a cross-linked epoxy matrix”, J. Polym. Sci. Polym. Phys., 19, 1567 -1575 (1981).

Berens A.R. and Hopfenberg H.B., "Induction and Measurement of glassy sate relaxation by vapor sorption techniques”, J. Polym. Sci.: Polym. Phys. Ed., 17, 1757 - 1770 (1979).

Bonniau P. and Bunsell A.R., "A comparative study if water absorption theories applied to glass-epoxy composites”, J. Comp. Mat., 15, 272 - 293 (1981).

Buck E, Lischer D.W. and Nemat-Nasser S., "The Durability of E-Glass/Vinyl Ester Composite Materials subjected to Environmental Conditioning and Sustained Load", J. Comp. Mat., 32, 874 - 891 (1998).

Carter H.G. and Kibler K.G., "Langmuir-Type model for Anomalous Moisutre Diffusion in Composite Resins”, J. Comp. Mat., 12, 118 - 131 (1978).

Chen C. and Curliss D., " Organoclay-Aerospace Epoxy Nanocomposites", Proc. Int. SAMPE Symposium and Exhibition, 46, 362 - 374 (2001).

Chin J.W., Nguyen T., Aouadi K., "Sorption and Diffusion of water, salt water and concrete pore solution in composite matrices", J Appl. Polym Sci., 71, 483 - 492 (1999).

Crank J., Mathematics of Diffusion, $2^{\text {nd }}$ ed., Oxford University Press, London 1975.

Dennis H. R., Hunter D. L., Chang D., Kim S., White J. L., Cho J. W., Paul D. R., "Effect of melt processing condition on the extent of exfoliation in organoclay-based nanocomposites", Polymer, 42, 9513 - 9522 (2001).

Dennis R.H., Hunter D.L., Chang D., Kim S., White J.L., Cho J.W., Paul D.R., "Nanocomposites: The Importance of Processing", Plastics Engineering, LVII (Vol. 57) no. $1,56-60$ (2001).

Dewimille B. and Bunsell A.R., "Accelerated Aging of a glass fiber-reinforced epoxy resin in water", Composites, 14, 35 - 40 (1983).

Diamant Y., Marom G., Broutman L.J., "The Effect of Network Structure on Moisture Absorption of Epoxy Resins", J Appl. Polm Sci., 26, 3015 - 3025 (1981).

Enns B. and Gillham J.K., "Effect of the extent of cure on the modulus, Glass Transition temperature, water absorption and density of an amine cured epoxy", J. Appl. Polym. Sci., 28, $2831-2846$ (1983).

GangaRao H.V.S. and Craigo C., IABSE-Structural Engineering International, 9, 286 (1999). 
Ghorbel I. and Valentin D., "Hydrothermal effect on the physico-chenical properties of pure and glass fiber reinforced polyester and vinyl ester resins", Polym. Comp., 14, 324 334 (1993).

Gilman J.W., Jackson C.L., Morgan A.B., Harris Jr. R., Manias E., Giannelis E.P., Wuthenow M., Hilton D., Phillips S.H., "Flammibility Properties of Polymer-Layered Silicate Nanocomposites. Polypropylene and Polystyrene Nanocomposites", $\underline{\text { Chem. }}$ Mater., 12, 1866 - 1873 (2000).

Harper, Charles A., Handbook of Plastics and Elastomers, McGraw-Hill Inc., New York, 1975 Chapter 3.

Hiltz J.A and Keogh I.A, "A study of the effect of absorbed water on the $\mathrm{T}_{\mathrm{g}}$ of a Poly amideimide using DMA and DSC", Thermochimica Acta, 212, 151 - 162 (1992)

Ishai O., "Environmental Effects on Deformation, Strength and degradation of unidirectional glass-fiber reinforced plastics II. Experimental study", Polym. Eng. Sci., 15, 491 - 499 (1975).

Kajorncheappunngam S., Gupta R.K., and GangaRao H.V.S., "The effect of aging environment on the degradation of glass-reinforced epoxy", ASCE J. Composites for Construction, (accepted 2001).

Klotz J., Brostow W., Hess M. and Veeman W.S., "Epoxy and glass composites in water studied with ${ }^{2}$ H-NMR", Polm. Eng. Sci., 36, 1129 - 1133 (1996).

Kornmann X., Berglund L. A., Sterte J., Giannelis E. P., "Nanocomposites Based on Montmorillonite and Unsaturated Polyester”, Polym. Eng. Sci., 38, 1351 - 1358 (1998).

Kshirsagar S., Lopez-Anido R.A., and Gupta R.K., "Environmental Aging of FiberReinforced Polymer-Wrapped Concrete Cylinders" ACI Materials J., 97, 703 - 712 (2000).

Lan T., Kaviratna P. D., Pinnavaia T. J., "Mechanism of Clay Tactoid Exfoliation in Epoxy-Clay Nanocomposites”, Chem. Mater.,7, 2144 - 2150 (1995).

Lan T., Liang Y., Beall G.W. and Kamena K., "Advances in Nanomer Additives for Clay/Polymer Nanocomposites”, Nanocor, Inc, Chicago, USA (www.nanocor.com).

Long F.A. and Richman D., "Concentration gradients for diffusion of vapors in glassy polymer and their relation to time dependent diffusion phenomena". J. Am. Chem. Soc., 82, $513-519$ (1960).

Mallick P.K., Fiber-Reinforced Composites: Materials, Manufacturing and Design, $2^{\text {nd }}$ ed., Marcel Dekker, Inc., New York, 1993 pp. 41 - 64.

Marsh L.L., Lasky R., Seraphim D. P., Springer G.S., "Moisture solubility and diffusion in epoxy and glass epoxy composites”, IBM J. Res. Develop., 28, 655 - 661 (1984). 
McMaster M.G. and Soane D.S., "Water sorption in epoxy thin films", IEEE Transactions on components, hybrids and manufacturing technology, 12, $373-386$ (1989).

Mensitieri G., Del Nobile M. A., Apicella A., Nicolais L., "Moisture-Matrix Interactions in Polymer based Composite Materials", Revue De L'Institut Francais Du Petrole, 50, $551-571(1995)$.

Messersmith P. B. and Giannelis E. P., "Synthesis and Barrier Properties of Poly ( $\varepsilon$ Caprolactome) - Layered Silicate Nanocomposites", J. Polym. Sci.,: Part A, Polym Chem.., 33, 1047 - 1057 (1995).

Messersmith P. B. and Giannelis E. P., "Synthesis and Characterization of Layered Silicate-Epoxy Nanocomposites”, Chem. Mater., 6, 1719 - 1725 (1994)

Netravalli A.N., Fornes R.E., Gilbert R.D. and Memory J.D., "Investigations of water \& high Energy Radiation interactions in an epoxy", J. Appl. Polym. Sci., 29, 311 - 318 (1984).

Okada A. and Usuki A, "The chemistry of polymer-clay hybrids", Mat. Sci. Eng., C3, $109-115$ (1995).

Pai R., Kamath M.S. and Rao R.M.V.G.K., "Acid Resistance of Glass fiber Composites with Different Lay-up Sequencing: Part I - Diffusion Studies", J. Reinforced Plastics Comp., 16, 1002 - 1012 (1997a).

Pai R., Kamath M.S. and Rao R.M.V.G.K., "Acid Resistance of Glass fiber Composites with Different Lay-up Sequencing: Part II - Degradation Studies”, J. Reinforced Plastics Comp., 16, 1013 - 1019 (1997b).

Ritter J.E., Fox J.R., Hutko D.I. and Lardner J., "Moisture Assisted Crack Growth at Epoxy-Glass Interfaces”, J. Mat. Sci., 33, 4581 - 4588 (1998).

Sahlin J. and Peppas N.A., Ind. Eng. Chem. Res., 30, 211 - 217 (1991).

Singh K. S., Singh P. N. and Rao R.M.V.G.K., "Hygrothermal effects on chopped fibre/woven fabric reinforced epoxy composites. Part A. Moisture absorption characteristics", J. Reinforced Plastics and Comp., 10, 446 - 456 (1991).

Soles C. L., Yee A. F., “A Discussion of Molecular Mechanisms of Moisutre Transport in Epoxy Resins”, J. Polym. Sci.: Part B: Polym Phys., 38, 792 -802 (2000).

Tsagaropoulos G. and Eisenberg A., "Dynamic Mechanical Study of the Factors Affecting the Two Glass Transition Behavior of Filler Polymers. Similarities and Differences with Random Ionomers", Macromolecules, 28, 6067 - 6077 (1995).

Tsotsis T.K. and Weitsman Y., "A simple graphical method for determining different parameters for 2-stage sorption in composites", J. Mat Sci. Let., 13, 1635 - 1636 (1994). 
Van Olphen H., An introduction to clay colloid chemistry, $2^{\text {nd }}$ ed., John Wiley \& Sons, New York, (1977).

Verghese K.N.E., Hayes M.D., Garcia K., Carrier C., Wood J., Riffle J.R. and Lesko J.J., "Influence of Matrix Chemistry on the Short Term, Hydrothermal Aging of Vinyl Ester Matrix Composites under Both Isothermal and Thermal Spiking Conditions", J. Comp. Mat., 33, 1918 - 1938 (1999).

Wong T.C. and Broutman L.J., "Moisture diffusion in epoxy resins: Part 1- Non-fickian sorption processes", Polym. Eng. Sci., 25, 521 - 528 (1985a).

Wong T.C. and Broutman L.J., "Water in epoxy resins: Part-II-Diffusion mechanism", Polym. Eng. Sci., 25, 529 - 534 (1985b).

Yano K., Usuki A., Okada A., Kurauchi T., Kamigaito O., "Synthesis and Properties of Polyimide-Clay Hybrid”, J. Polym. Sci. Part A: Polym Chem, 31, 2493 - 2498 (1993).

Zang H. and Berlund L.A., "Deformation and Fracture of Glass Beads/CTBNRubber/Epoxy Composites", Polym. Eng. Sci., 33, 100 - 107 (1993). 


\section{APPENDICES}

\section{APPENDIX I}

Theories Proposed To Describe the Process of Anomalous Diffusion In Glassy

\section{Polymers}

\section{A.1.1 Time - dependent boundary conditions}

The surface concentration in glassy polymers may not reach the equilibrium value immediately. Hence, there is deviation from Fickian diffusion. Time-varying boundary concentration of the penetrant in glassy polymers was first observed by Long and Richman (1960) during their study of penetration of methyl iodide vapors through glassy poly vinyl acetate at $20{ }^{\circ} \mathrm{C}$ and cellulose acetate at $40{ }^{\circ} \mathrm{C}$. On plotting the penetrant concentration against sample thickness, they found the surface concentration to increase with time and initially be well below the final equilibrium concentration. Also, even after 1275 minutes of exposure, the surface concentration reached only $30 \%$ of the final value. This led them to propose a boundary condition of the form:

$\mathrm{C}_{\mathrm{s}}=\mathrm{C}_{\mathrm{o}}+\left(\mathrm{C}_{\mathrm{eq}}-\mathrm{C}_{\mathrm{o}}\right)\left(1-\mathrm{e}^{-\beta \mathrm{t}}\right)$

Where,

$\mathrm{C}_{\mathrm{s}}-$ surface concentration at time $\mathrm{t}$.

$\mathrm{C}_{0}-$ initial surface concentration

$\mathrm{C}_{\mathrm{eq}}-$ equilibrium concentration

$\beta$ - inverse of relaxation time

$\mathrm{t}$ - time.

This satisfies the conditions, 
$\mathrm{C}_{\mathrm{s}}=\mathrm{C}_{\mathrm{o}}$ at $\mathrm{t}=0$, and

$\mathrm{C}_{\mathrm{s}}=\mathrm{C}_{\mathrm{eq}}$ at $\mathrm{t}=\infty$

The diffusion coefficient, which was assumed to remain constant during the diffusion process, was modified as (Tsotsis and Weitsman, 1994) to fit the data correctly.

$\mathrm{D}=\mathrm{D}_{\mathrm{F}}\left(\mathrm{C}_{\mathrm{eq}} / \mathrm{C}_{\mathrm{o}}\right)^{2}$

Where,

$\mathrm{D}_{\mathrm{F}}-$ diffusivity for the Fickian diffusion.

The resulting diffusion expression is given in as:

$$
\begin{aligned}
& \frac{\mathrm{M}_{\mathrm{t}}}{2 \ell}=\mathrm{C}_{0}-\frac{8 \mathrm{C}_{0}}{\pi^{2}} \sum_{0}^{\infty} \frac{\exp \left[\frac{-\mathrm{D}(2 \mathrm{n}+1)^{2} \pi^{2} \mathrm{t}}{4 \ell^{2}}\right]}{(2 \mathrm{n}+1)^{2}}+\left(\mathrm{C}_{\mathrm{eq}}-\mathrm{C}_{0}\right)-\left(\mathrm{C}_{\mathrm{eq}}-\mathrm{C}_{0}\right) \exp \left[-\beta \mathrm{t}\left(\mathrm{D} / \beta \ell^{2}\right)^{1 / 2} \tan \left(\beta \ell^{2} / \mathrm{D}\right)^{1 / 2}\right. \\
& -8 \frac{\left(\mathrm{C}_{\mathrm{eq}}-\mathrm{C}_{0}\right)}{\pi^{2}} \sum_{0}^{\infty} \frac{\exp \left[-\mathrm{D}(2 \mathrm{n}+1)^{2} \pi^{2} \mathrm{t} / 4 \ell^{2}\right]}{(2 \mathrm{n}+1)^{2}\left[1-(2 \mathrm{n}+1)^{2}\left(\frac{\mathrm{D} \pi^{2}}{4 \beta \ell^{2}}\right)\right]}
\end{aligned}
$$

Weitsman and Tsotsis (1994) developed a simple graphical method for determining the diffusivity parameters. If tangents are drawn to the moisture weight gain versus $\sqrt{\mathrm{t}}$ curve, at its initial region and leveling off region, then, the point of intersection of the two tangents gives the value of $\mathrm{C}_{0} . \mathrm{C}_{\mathrm{eq}}$ is the equilibrium moisture content of the sample. This is represented graphically in Figure A.1. 


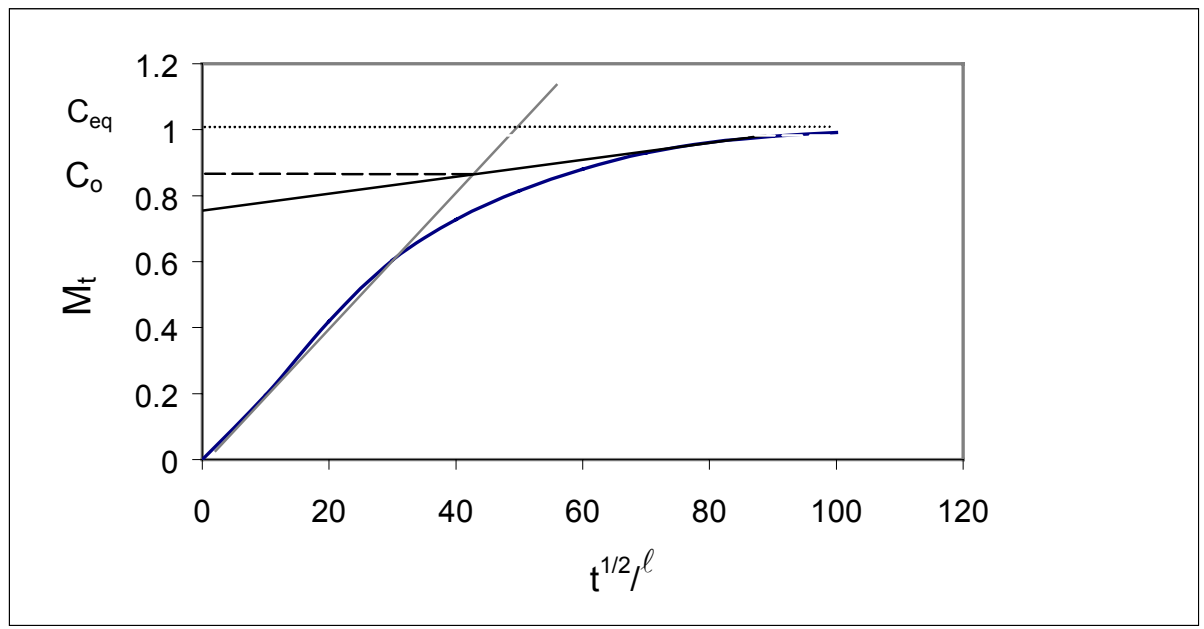

Figure A.1. Graphical Method of determining diffusion parameters, $\mathrm{C}_{0}$ and $\mathrm{C}_{\mathrm{eq}}$. (Weitsman and Tsotsis 1994)

The value of $\mathrm{C}_{0}, \mathrm{C}_{\mathrm{eq}}$ and $\mathrm{D}$ are calculated from the weight gain curve. Equation A.3 was then fitted to the data for an optimum value of $\beta$. The equation fit the data for epoxy resins well. Also the $\beta$ values obtained were of the order of $1 / 4928 \mathrm{~h}^{-1}$, which lay in the middle of the mechanical relaxation times of epoxies.

\section{A.1.2 Model based on polymer relaxation}

This model was put forward by Berens and Hopfenberg (1979) during their sorption/desorption studies on PVC and polystyrene and organic vapors. They found that at low penetrant pressures, the diffusion process followed Fick's law. But at appreciable pressures, anomalies such as slow reach to equilibrium, developed in the sorption process. They suggested that both rapid Fickian sorption as well as slower relaxation controlled sorption was taking place simultaneously. The experimental observations led them to model the process as a sum of two independent mechanisms, Fickian and Non- 
Fickian (due to polymer relaxation). The total amount of water sorbed $\left(\mathrm{M}_{\mathrm{t}}\right)$ at time $t$ per unit weight of the polymer was given as,

$\mathrm{M}_{\mathrm{t}}=\mathrm{M}_{\mathrm{tF}}+\mathrm{M}_{\mathrm{tR}}$

where,

$\mathrm{M}_{\mathrm{t}}$ - total amount sorbed

$\mathrm{M}_{\mathrm{tF}-}$ contribution due to the Fickian part.

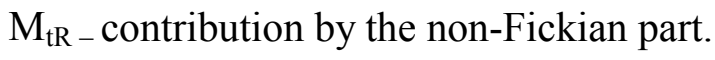

$\mathrm{M}_{\mathrm{tF}}$ is given by equation A.5, which is proportional to the usual Fick's solution by a fraction, $\phi_{\mathrm{F}}$,

$\mathrm{M}_{\mathrm{tF}}=\Phi_{\mathrm{F}}\left[1-\sum \frac{8}{(2 \mathrm{n}+1)^{2} \pi^{2}} \exp \left[\frac{-\mathrm{D}(2 \mathrm{n}+1)^{2} \pi^{2} \mathrm{t}}{4 \ell^{2}}\right]\right]$

An expression for $\mathrm{M}_{\mathrm{tR}}$ was found assuming a first-order rate proportional to the difference between $\mathrm{M}_{\mathrm{tF}}$ and $\mathrm{M}_{\odot, \mathrm{R}}$, the equilibrium amount of sorption due to relaxation.

Thus

$$
\frac{\mathrm{dM}_{\mathrm{t}, \mathrm{R}}}{\mathrm{dt}}=\mathrm{k}\left(\mathrm{M}_{\infty, \mathrm{R}}-\mathrm{M}_{\mathrm{t}, \mathrm{R}}\right)
$$

Upon integration this gives,

$$
M_{t R}=\sum_{i} M_{\infty i}\left(1-e^{-k_{i} t}\right)
$$

The summation is for taking into account a spectrum of relaxation times. In many cases it is adequate to use only one term (Sahlin and Peppas, 1991).

Peppas and Sahlin (1991) applied the above model in their study of TGDDM-DDS epoxy resin. They used the equation, 


$$
\frac{\mathrm{M}_{\mathrm{t}}}{\mathrm{M}_{\infty}}=\Phi_{\mathrm{F}}\left[1-\sum \frac{8}{(2 \mathrm{n}+1)^{2} \pi^{2}} \exp \left[\frac{-\mathrm{D}(2 \mathrm{n}+1)^{2} \pi^{2} \mathrm{t}}{4 \ell^{2}}\right]\right]+\Phi_{\mathrm{R}}\left(1-\mathrm{e}^{-\mathrm{k}_{\mathrm{i}} \mathrm{t}}\right)
$$

where $\Phi_{\mathrm{f}}, \Phi_{\mathrm{r}}$ are the fractions of Fickian and relaxation behavior.

The first term dominates at fast relaxation times (i.e.. $\mathrm{k}_{\mathrm{i}}<<1$ ), because the term that represents the non-Fickian part becomes small. On the other hand when the relaxation time of the polymer chains is large, the influence of the second term cannot be neglected.

\section{A.1.3 Model based on Langmuir type of behavior}

Carter and Kibler (1978) based their theory on Langmuir type of adsorption. They proposed that the absorbed moisture is divided into two phases, a mobile phase and a bound phase. Molecules of the mobile phase are assumed to diffuse through the material with a constant diffusion coefficient, $\mathrm{D}_{\gamma}$. The diffusion coefficient, $\mathrm{D}_{\gamma}$, is assumed to be independent of concentration and stress. Also, water molecules may become bound with a probability per unit time of $\gamma$ at certain unspecified sites whose chemical nature is not known. Additionally, bound molecules are emitted from the bound sites, thereby becoming mobile, with a probability per unit time, $\beta$. The local weight fraction reaches an equilibrium, $\mathrm{M}_{\infty}$ when the number of mobile molecules per unit volume, $\mathrm{n}$ and the number of bound molecules per unit volume, $\mathrm{N}$ approach values such that,

$\gamma \mathrm{n}=\beta \mathrm{N}$

When $\gamma, \beta$ are small compared to the parameters that determines the rate of saturation for a one dimensional specimen of thickness $2 \delta,\left[\mathrm{K}=\pi^{2} \mathrm{D}_{\gamma} /(2 \delta)^{2}\right]$ the moisture uptake is given by, 
$M_{t}=M_{\infty}\left[\frac{\beta}{\gamma+\beta} e^{-\gamma t}\left[1-\frac{8}{\pi^{2}} \sum_{0}^{\infty} \frac{1}{(2 n+1)^{2}} e^{-K(2 n+1)^{2} t}\right]+\frac{\beta}{\gamma+\beta}\left(e^{-\beta t}-e^{-\gamma t}\right)+\left(1-e^{-\beta t}\right)\right]$

$$
2 \gamma, 2 \beta<1 / \mathrm{K}
$$

Note, when $\gamma=0$, the equation reduces to the simple diffusion equation obtained from Fick's second law.

At small exposure times, i.e., $\mathrm{Kt}<0.7$, the following approximation holds,

$$
\mathrm{M}_{\mathrm{t}} \approx \frac{4}{\pi^{3 / 2}}\left(1-\frac{\beta}{\gamma+\beta} \mathrm{M}_{\infty}\right) \sqrt{\mathrm{Kt}}
$$

While at larger times, when $\mathrm{t}>>1 / \mathrm{K}$

$$
\mathrm{M}_{\mathrm{t}} \approx \mathrm{M}_{\infty}\left[1-\frac{\gamma}{\gamma+\beta} \mathrm{e}^{-\beta \mathrm{t}}\right]
$$

Bonniau \& Bunsell (1981) used the above model and fitted the data obtained for the sorption experiments on Bisphenol A epoxy resin woven with EC 9.68 glass fiber. The resin was cured with Dicyandiamide, Diamine and Anhydride hardeners. Humidity range was from $12 \%-100 \% \mathrm{RH}$ and temperatures of study varied from $25{ }^{\circ} \mathrm{C}$ to $90{ }^{\circ} \mathrm{C}$.

Marsh, et al., (1984) extended the theory and fitted the diffusion data of brominated bisphenol A and cresol Novolac epoxy resin - E-glass composite. They, however, reported $\gamma$ and $\beta$ to be dependent of partial pressure of the penetrant and temperature. The relations developed were, 
$\gamma=(251.3 / \mathrm{p}) \exp (-4817 / \mathrm{T})$

$\beta=(314.7 / \mathrm{p}) \exp (-5198 / \mathrm{T})$

where $\mathrm{p}$ - partial pressure $[\mathrm{mmHg}]$

and $\quad \mathrm{T}$ - temperature of the system $[\mathrm{K}]$ 


\section{APPENDIX II}

\section{Sample Calculations}

\section{A.2.1 Sample Calculation for Diffusion Coefficient}

Table A.1 Diffusion data of post-cured neat DERAKANE 411-350 vinyl ester resin.

Neat Resin Post cured sample

$$
2 \ell=0.56726 \mathrm{~mm}
$$

Time, $h \quad t^{1 / 2} / 2 \ell, h^{1 / 2} / m m$ Sample weight, mg Water uptake, $\% \quad M_{t} / M_{\circ}$

$\begin{array}{ccccc}0 & 0.000 & 374.17 & 0.0000 & 0.0000 \\ 0.5 & 1.247 & 374.42 & 0.0668 & 0.1515 \\ 1 & 1.763 & 374.49 & 0.0855 & 0.1939 \\ 1.5 & 2.159 & 374.6 & 0.1149 & 0.2606 \\ 2.5 & 2.787 & 374.8 & 0.1684 & 0.3818 \\ 3.5 & 3.298 & 374.9 & 0.1951 & 0.4424 \\ 4.5 & 3.740 & 375 & 0.2218 & 0.5030 \\ 5.5 & 4.134 & 375.12 & 0.2539 & 0.5758 \\ 7.5 & 4.828 & 375.24 & 0.2860 & 0.6485 \\ 9.5 & 5.433 & 375.32 & 0.3073 & 0.6970 \\ 17.83 & 7.444 & 375.58 & 0.3768 & 0.8545 \\ 21.5 & 8.174 & 375.62 & 0.3875 & 0.8788 \\ 25.167 & 8.844 & 375.66 & 0.3982 & 0.9030 \\ 31.5 & 9.894 & 375.68 & 0.4036 & 0.9152 \\ 45.5 & 11.891 & 375.75 & 0.4223 & 0.9576 \\ 69.5 & 14.696 & 375.77 & 0.4276 & 0.9697 \\ 166.83 & 22.770 & 375.82 & 0.4410 & 1.0000 \\ 240.5 & 27.339 & 375.8 & 0.4356 & 0.9879\end{array}$

Water Upta ke $=\frac{\mathrm{W}_{\mathrm{t}}-\mathrm{W}_{0}}{\mathrm{~W}_{0}} \times 100$ 


$$
\begin{gathered}
=\frac{375.24-374.17}{374.17} \times 100 \\
=0.2860 \\
\frac{\mathrm{M}_{\mathrm{t}}}{\mathrm{M}_{\infty}}=\frac{\mathrm{W}_{\mathrm{t}}-\mathrm{W}_{0}}{\mathrm{~W}_{\infty}-\mathrm{W}_{0}} \\
=\frac{375.24-374.17}{375.82-374.17} \\
=0.6485
\end{gathered}
$$

The diffusion coefficient was then calculated using equation 2.4,

$$
\begin{aligned}
& \frac{\mathrm{M}_{\mathrm{t}}}{\mathrm{M}_{\infty}}=4\left(\frac{\mathrm{Dt}}{\pi 2 \ell^{2}}\right)^{1 / 2} \\
& \mathrm{D}=\frac{\pi}{16}\left(\frac{\mathrm{M}_{\mathrm{t}} / \mathrm{M}_{\infty}}{\sqrt{\mathrm{t}} / 2 \ell}\right)^{2}
\end{aligned}
$$

where $\left(\frac{M_{t} / M_{\infty}}{\sqrt{t} / 2 \ell}\right)$ is the slope of the straight line (see Figure A.2) from the plot of $\frac{M_{t}}{M_{\infty}}$

$$
\begin{aligned}
& \text { versus } \mathrm{t}^{1 / 2} / 2 \ell \text { drawn upto } \frac{\mathrm{M}_{\mathrm{t}}}{\mathrm{M}_{\infty}}<0.5 \\
& \therefore \mathrm{D}=\frac{\pi}{16}(0.131)^{2} / 3600=9.359 \times 10^{-7} \mathrm{~mm}^{2} / \mathrm{s}
\end{aligned}
$$




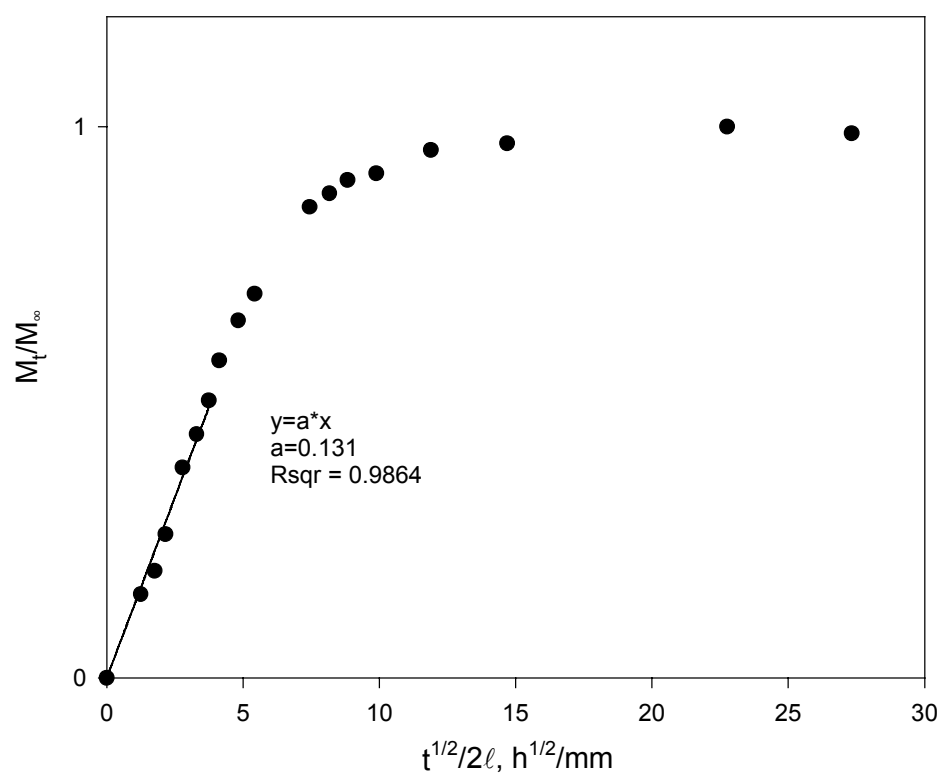

Figure A.2 Sorption curve of post-cured neat DERAKANE ${ }^{\text {TM }}$ 411-350 Vinyl ester resin.

An average diffusion coefficient was calculated from the values obtained for four runs.

This value was used in equation 2.2 to simulate the uptake.

\section{A.2.2 Langmuir theory Calculations}

The data were fitted to the Langmuir theory as described in Section A.1.3. The parameters $\gamma$ and $\beta$ were determined as explained by Carter and Kibler (1978). The procedure is explained below. Data of water uptake of 5 wt $\%$ Cloisiste $10 \mathrm{~A}^{\circledR}$ nanocomposites is shown in Table A.2. 
Table A.2. Water uptake data of $5 \mathrm{wt} \%$ Cloisiste $10 \mathrm{~A}^{\circledR}$ nanocomposites $5 \mathrm{wt} \%$ Cloisite 10A in DERAKANE 411-350 vinyl ester resin $21=0.2032 \mathrm{~mm}$

Time, $\mathrm{h} \mathrm{t}^{1 / 2} / 2 \ell, \mathrm{h}^{1 / 2} / \mathrm{mm}$ Sample weight, mg Water uptake, $\% \quad \mathrm{M}_{\mathrm{t}} / \mathrm{M}_{\circ}$

$\begin{array}{ccccc}0 & 0.000 & 127.49 & 0.0000 & 0.0000 \\ 0.1667 & 2.009 & 127.61 & 0.0941 & 0.0632 \\ 0.333 & 2.841 & 127.7 & 0.1647 & 0.1105 \\ 0.5 & 3.480 & 127.78 & 0.2275 & 0.1526 \\ 0.75 & 4.262 & 127.87 & 0.2981 & 0.2000 \\ 1 & 4.921 & 127.98 & 0.3843 & 0.2579 \\ 1.5 & 6.027 & 128.07 & 0.4549 & 0.3053 \\ 2 & 6.960 & 128.16 & 0.5255 & 0.3526 \\ 2.75 & 8.161 & 128.26 & 0.6040 & 0.4053 \\ 3.75 & 9.530 & 128.34 & 0.6667 & 0.4474 \\ 10.25 & 15.756 & 128.64 & 0.9020 & 0.6053 \\ 25 & 24.606 & 128.88 & 1.0903 & 0.7316 \\ 37 & 29.935 & 128.96 & 1.1530 & 0.7737 \\ 49.5 & 34.624 & 129.16 & 1.3099 & 0.8789 \\ 78.25 & 43.533 & 129.28 & 1.4040 & 0.9421 \\ 96 & 48.218 & 129.35 & 1.4589 & 0.9789 \\ 128 & 55.678 & 129.39 & 1.4903 & 1.0000 \\ 140.5 & 58.333 & 129.39 & 1.4903 & 1.0000\end{array}$

For $\mathrm{t}>>1 / \mathrm{k}$, the data was fitted to equation,

$\mathrm{y}=\left(1-\mathrm{ae}^{-\mathrm{bt}}\right)$

This is analogous to equation A.12 where $a=\frac{\gamma}{\gamma+\beta}$ and $b=\beta$ 


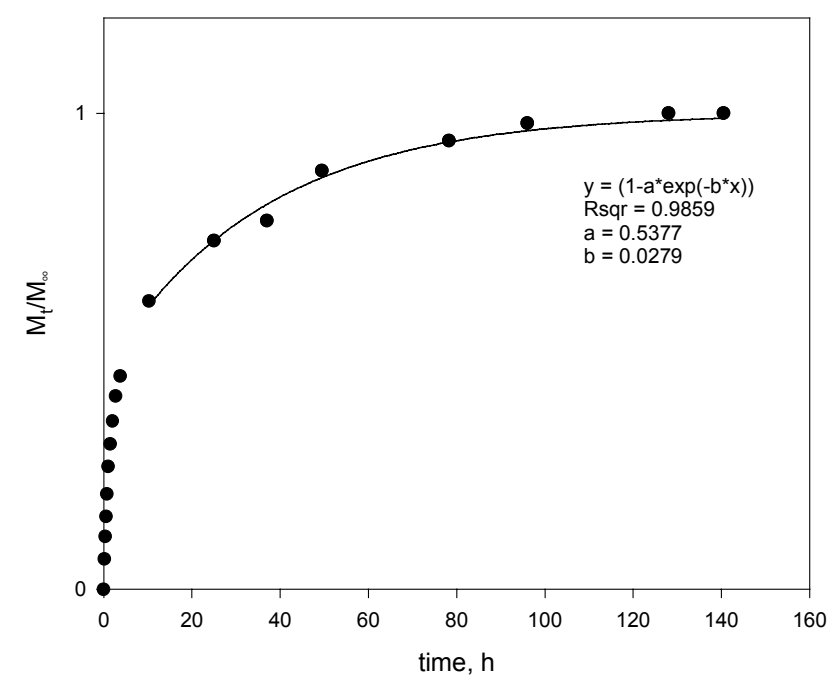

Figure A.3. Plot showing the fit of equation A.17, for $\mathrm{t}>25 \mathrm{~h}$.

From the fit, we get,

$\mathrm{a}=0.5377$ and

$\mathrm{b}=0.0279$

Thus we get, $\gamma=0.0324, \mathrm{~h}^{-1}$ and $\beta=0.0279 \mathrm{~h}^{-1}$

These values were used in equation A.11 to obtain the value of $\mathrm{D}_{\gamma}$ from the initial slope.

The solution is shown in Figure A.4 


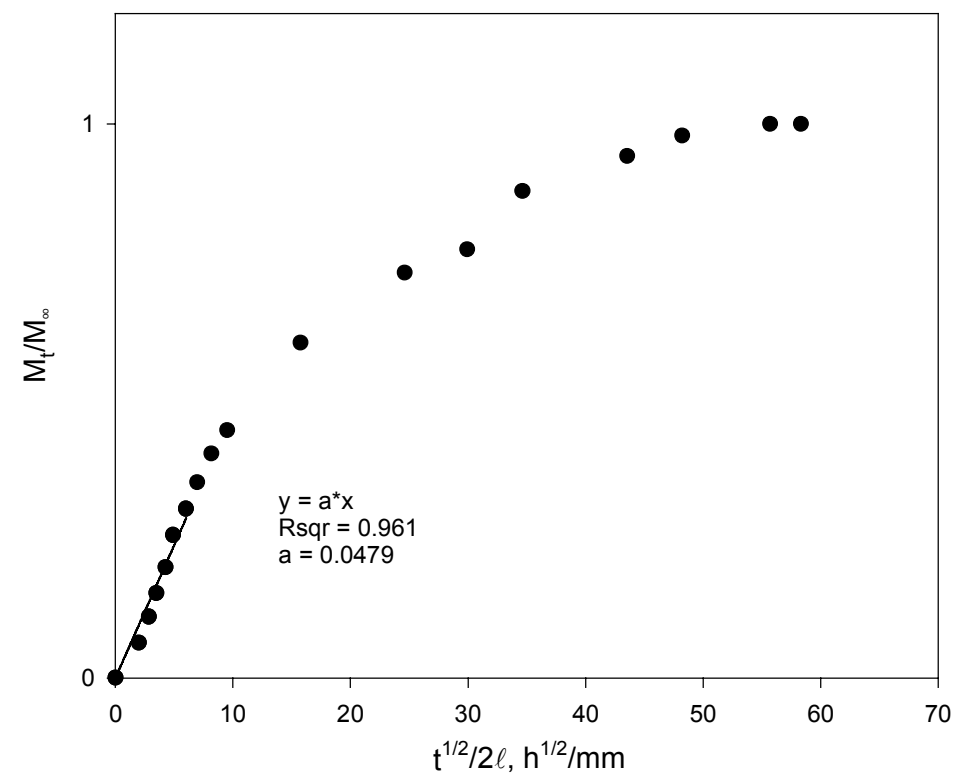

Figure A.4 Calculation of initial slope for Diffusion coefficient, $\mathrm{D}_{\gamma}$.

Diffusion coefficient is then calculated by re-arranging equation A.11 to,

$\mathrm{D}_{\gamma}=\frac{\pi}{16}\left(\frac{\gamma+\beta}{\beta}\right)^{2}\left(\frac{\mathrm{M}_{\mathrm{t}} / \mathrm{M}_{\infty}}{\sqrt{\mathrm{t}} / 2 \ell}\right)^{2}$

where $\frac{M_{t} / M_{\infty}}{\sqrt{t} / 2 \ell}$ is the slope of the straight line (shown in Figure A.4)

$\therefore \mathrm{D}_{\gamma}=\frac{\pi}{16}\left(\frac{0.03245+0.0279}{0.0279}\right)^{2}(0.0479)^{2} / 3600=5.852 \times 10^{-7} \mathrm{~mm}^{2} / \mathrm{s}$

To verify the constraints of the theory, we compare the values of $\mathrm{k}$ and $2 \gamma$ and $2 \beta$,

$\mathrm{k}=\frac{\pi^{2} 5.85 \times 10^{-7}}{(0.2032)^{2}} \times 3600=0.5034, \mathrm{~h}^{-1}$

$2 \gamma=0.0648$

$2 \beta=0.0558$ 
Thus the condition of $2 \gamma, 2 \beta<\mathrm{k}$ is satisfied.

\section{A2.3 Mechanical Tests}

Table A.3 Tensile test data

\begin{tabular}{|c|c|c|c|c|}
\hline \multirow[b]{2}{*}{ Load, lb. } & \multicolumn{4}{|c|}{ Cross Section $=10.1346 \mathrm{~mm} \times 2.0805 \mathrm{~mm}$} \\
\hline & $\begin{array}{c}\text { Corrected } \\
\text { load, lb. }\end{array}$ & $\begin{array}{c}\text { Stress, } \\
\mathrm{kg} / \mathrm{mm}^{2}\end{array}$ & Strain & Percentage Strain \\
\hline 20 & 11.34 & 0.244465 & 0.000614 & 0.0614 \\
\hline 30 & 21.34 & 0.460042 & 0.001207 & 0.1207 \\
\hline 40 & 31.34 & 0.675619 & 0.001799 & 0.1799 \\
\hline 50 & 41.34 & 0.891196 & 0.002449 & 0.2449 \\
\hline 60 & 51.34 & 1.106774 & 0.003064 & 0.3064 \\
\hline 70 & 61.34 & 1.322351 & 0.003731 & 0.3731 \\
\hline 80 & 71.34 & 1.537928 & 0.004352 & 0.4352 \\
\hline 90 & 81.34 & 1.753506 & 0.005019 & 0.5019 \\
\hline 100 & 91.34 & 1.969083 & 0.005734 & 0.5734 \\
\hline 110 & 101.34 & 2.18466 & 0.006411 & 0.6411 \\
\hline 120 & 111.34 & 2.400237 & 0.00713 & 0.713 \\
\hline
\end{tabular}




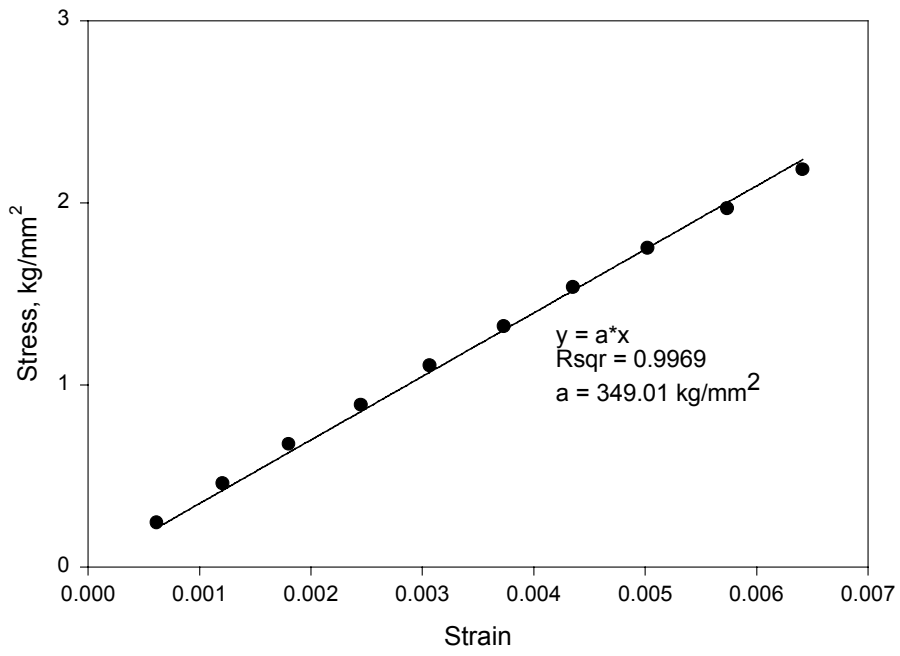

Figure A.5 Stress - Strain curve for 0.5 \% VMC - DERAKANE 411-350 vinyl ester resin

Tensile Modulus $=349.01 \mathrm{~kg} / \mathrm{mm}^{2}=3.424 \times 10^{9} \mathrm{~Pa}$. 


\section{APPENDIX III}

\section{Raw Data}

Table A.4a Water Uptake data for Non-Post Cured DERAKANE TM Vinyl ester Resins:

\begin{tabular}{|c|c|c|c|c|c|c|}
\hline Time, $\mathrm{h}$ & Weight, mg & $\begin{array}{c}\text { Water } \\
\text { content, } \\
\text { Wt \% }\end{array}$ & $M_{t} / M_{i n f}$ & Weight, mg & $\begin{array}{c}\text { Water } \\
\text { content, } \\
\text { Wt\% }\end{array}$ & $M_{t} / M_{i n f}$ \\
\hline \multicolumn{4}{|c|}{$2 \ell=0.70394 \mathrm{~mm}$} & \multicolumn{3}{|c|}{$2 \ell=0.69088 \mathrm{~mm}$} \\
\hline 0 & 510.26 & 0.0000 & 0.0000 & 488.75 & 0.0000 & 0.0000 \\
\hline 0.5 & 510.66 & 0.0784 & 0.1594 & 489.13 & 0.0777 & 0.1538 \\
\hline 1.5 & 510.92 & 0.1293 & 0.2629 & 489.4 & 0.1330 & 0.2632 \\
\hline 2 & 511.02 & 0.1489 & 0.3028 & 489.47 & 0.1473 & 0.2915 \\
\hline 2.5 & 511.09 & 0.1627 & 0.3307 & 489.62 & 0.1780 & 0.3522 \\
\hline 3.25 & 511.2 & 0.1842 & 0.3745 & 489.74 & 0.2026 & 0.4008 \\
\hline 4 & 511.31 & 0.2058 & 0.4183 & 489.87 & 0.2292 & 0.4534 \\
\hline 4.75 & 511.41 & 0.2254 & 0.4582 & 489.99 & 0.2537 & 0.5020 \\
\hline 5.75 & 511.52 & 0.2469 & 0.5020 & 490.12 & 0.2803 & 0.5547 \\
\hline 6.75 & 511.64 & 0.2705 & 0.5498 & 490.2 & 0.2967 & 0.5870 \\
\hline 16.25 & 512.13 & 0.3665 & 0.7450 & 490.64 & 0.3867 & 0.7652 \\
\hline 18.25 & 512.21 & 0.3822 & 0.7769 & 490.71 & 0.4010 & 0.7935 \\
\hline 20.25 & 512.29 & 0.3978 & 0.8088 & 490.75 & 0.4092 & 0.8097 \\
\hline 22.25 & 512.34 & 0.4076 & 0.8287 & 490.79 & 0.4174 & 0.8259 \\
\hline 25.25 & 512.31 & 0.4018 & 0.8167 & 490.83 & 0.4256 & 0.8421 \\
\hline 31.25 & 512.4 & 0.4194 & 0.8526 & 490.91 & 0.4419 & 0.8745 \\
\hline 40.25 & 512.5 & 0.4390 & 0.8924 & 490.99 & 0.4583 & 0.9069 \\
\hline 45.25 & 512.54 & 0.4468 & 0.9084 & 491.04 & 0.4685 & 0.9271 \\
\hline 50.25 & 512.55 & 0.4488 & 0.9124 & 491.07 & 0.4747 & 0.9393 \\
\hline 151.75 & 512.7 & 0.4782 & 0.9721 & 491.2 & 0.5013 & 0.9919 \\
\hline 175.75 & 512.74 & 0.4860 & 0.9880 & 491.22 & 0.5054 & 1.0000 \\
\hline 199.75 & 512.73 & 0.4841 & 0.9841 & 491.21 & 0.5033 & 0.9960 \\
\hline 223.75 & 512.73 & 0.4841 & 0.9841 & 491.2 & 0.5013 & 0.9919 \\
\hline 276.75 & 512.75 & 0.4880 & 0.9920 & 491.19 & 0.4992 & 0.9879 \\
\hline 324.75 & 512.76 & 0.4899 & 0.9960 & 491.22 & 0.5054 & 1.0000 \\
\hline 419.75 & 512.76 & 0.4899 & 0.9960 & 491.21 & 0.5033 & 0.9960 \\
\hline 485.75 & 512.77 & 0.4919 & 1.0000 & 491.22 & 0.5054 & 1.0000 \\
\hline 485.78 & 512.77 & 0.4919 & 1.0000 & 491.23 & 0.5074 & 1.0040 \\
\hline
\end{tabular}


Table A.4b Water Uptake data for Non-Post Cured DERAKANE TM Vinyl ester Resins:

\begin{tabular}{|c|c|c|c|c|c|c|}
\hline Time, $\mathrm{h}$ & Weight, $g$ & $\begin{array}{c}\text { Water } \\
\text { content, } \\
\text { wt } \%\end{array}$ & $M_{t} / M_{\text {inf }}$ & Weight, g & $\begin{array}{c}\text { Water } \\
\text { content, } \\
\text { wt\% }\end{array}$ & $M_{t} / M_{i n f}$ \\
\hline & \multicolumn{3}{|c|}{$2 \ell=1.7145$} & \multicolumn{3}{|c|}{$2 \ell=1.6129 \mathrm{~mm}$} \\
\hline 0 & 1.18205 & 0.0000 & 0.0000 & 1.13218 & 0.0000 & 0.0000 \\
\hline 2 & 1.18304 & 0.0838 & 0.1571 & 1.13307 & 0.0786 & 0.1476 \\
\hline 5 & 1.18334 & 0.1091 & 0.2048 & 1.13348 & 0.1148 & 0.2156 \\
\hline 7 & 1.18355 & 0.1269 & 0.2381 & 1.13377 & 0.1404 & 0.2637 \\
\hline 16.5 & 1.1844 & 0.1988 & 0.3730 & 1.13464 & 0.2173 & 0.4080 \\
\hline 19 & 1.18445 & 0.2030 & 0.3810 & 1.13457 & 0.2111 & 0.3964 \\
\hline 22 & 1.1846 & 0.2157 & 0.4048 & 1.13472 & 0.2243 & 0.4212 \\
\hline 29 & 1.18502 & 0.2513 & 0.4714 & 1.1352 & 0.2667 & 0.5008 \\
\hline 43 & 1.1856 & 0.3003 & 0.5635 & 1.13573 & 0.3136 & 0.5887 \\
\hline 52.5 & 1.18597 & 0.3316 & 0.6222 & 1.13607 & 0.3436 & 0.6451 \\
\hline 66.5 & 1.1861 & 0.3426 & 0.6429 & 1.13619 & 0.3542 & 0.6650 \\
\hline 78 & 1.18636 & 0.3646 & 0.6841 & 1.13635 & 0.3683 & 0.6915 \\
\hline 121.25 & 1.18698 & 0.4171 & 0.7825 & 1.13705 & 0.4301 & 0.8076 \\
\hline 126 & 1.18717 & 0.4331 & 0.8127 & 1.13722 & 0.4452 & 0.8358 \\
\hline 139.5 & 1.18735 & 0.4484 & 0.8413 & 1.1374 & 0.4611 & 0.8657 \\
\hline 150 & 1.18741 & 0.4534 & 0.8508 & 1.13747 & 0.4672 & 0.8773 \\
\hline 162.25 & 1.18751 & 0.4619 & 0.8667 & 1.13759 & 0.4778 & 0.8972 \\
\hline 174.25 & 1.18764 & 0.4729 & 0.8873 & 1.13765 & 0.4831 & 0.9071 \\
\hline 198.25 & 1.18772 & 0.4797 & 0.9000 & 1.13776 & 0.4929 & 0.9254 \\
\hline 222.5 & 1.18781 & 0.4873 & 0.9143 & 1.13789 & 0.5043 & 0.9469 \\
\hline 246.5 & 1.18795 & 0.4991 & 0.9365 & 1.13797 & 0.5114 & 0.9602 \\
\hline 294.5 & 1.18803 & 0.5059 & 0.9492 & 1.13799 & 0.5132 & 0.9635 \\
\hline 318 & 1.18808 & 0.5101 & 0.9571 & 1.138 & 0.5141 & 0.9652 \\
\hline 342 & 1.18813 & 0.5144 & 0.9651 & 1.13801 & 0.5149 & 0.9668 \\
\hline 372.5 & 1.18812 & 0.5135 & 0.9635 & 1.13808 & 0.5211 & 0.9784 \\
\hline 474 & 1.18832 & 0.5304 & 0.9952 & 1.13831 & 0.5414 & 1.0166 \\
\hline 498 & 1.18835 & 0.5330 & 1.0000 & 1.1382 & 0.5317 & 0.9983 \\
\hline 575.5 & 1.18836 & 0.5338 & 1.0016 & 1.13821 & 0.5326 & 1.0000 \\
\hline
\end{tabular}


Table A.4c Water Uptake data for Non-Post Cured DERAKANE ${ }^{\text {TM }}$ Vinyl ester Resins:

\begin{tabular}{cccc} 
Time, h & Weight, g & $\begin{array}{c}\text { Water } \\
\text { content, } \\
\text { wt } \%\end{array} \mathrm{M}_{\mathrm{t}} / \mathrm{M}_{\text {inf }}$ \\
\multicolumn{4}{c}{} \\
\multicolumn{4}{c}{$2 \ell=1.8203 \mathrm{~mm}$} \\
0 & 1.26691 & 0.0000 & 0.0000 \\
6.5 & 1.26823 & 0.1042 & 0.1961 \\
15 & 1.26884 & 0.1523 & 0.2868 \\
30 & 1.2697 & 0.2202 & 0.4146 \\
42 & 1.2705 & 0.2834 & 0.5334 \\
66.5 & 1.2713 & 0.3465 & 0.6523 \\
69.5 & 1.27136 & 0.3512 & 0.6612 \\
90 & 1.27183 & 0.3883 & 0.7311 \\
93.5 & 1.27176 & 0.3828 & 0.7207 \\
96.5 & 1.27189 & 0.3931 & 0.7400 \\
99.5 & 1.27196 & 0.3986 & 0.7504 \\
101.5 & 1.27213 & 0.4120 & 0.7756 \\
111 & 1.27207 & 0.4073 & 0.7667 \\
116.5 & 1.27225 & 0.4215 & 0.7935 \\
150 & 1.2725 & 0.4412 & 0.8306 \\
200 & 1.27276 & 0.4618 & 0.8692 \\
225 & 1.27296 & 0.4775 & 0.8990 \\
249 & 1.27305 & 0.4846 & 0.9123 \\
273 & 1.27319 & 0.4957 & 0.9331 \\
297 & 1.27323 & 0.4989 & 0.9391 \\
322.25 & 1.27329 & 0.5036 & 0.9480 \\
346.25 & 1.27335 & 0.5083 & 0.9569 \\
394.25 & 1.27338 & 0.5107 & 0.9614 \\
417.75 & 1.2734 & 0.5123 & 0.9643 \\
442.25 & 1.27343 & 0.5146 & 0.9688 \\
555.75 & 1.27357 & 0.5257 & 0.9896 \\
579.75 & 1.2736 & 0.5281 & 0.9941 \\
603.75 & 1.27362 & 0.5296 & 0.9970 \\
628.25 & 1.27363 & 0.5304 & 0.9985 \\
681.75 & 1.27364 & 0.5312 & 1.0000 \\
729.75 & 1.27364 & 0.5312 & 1.0000 \\
849.75 & 1.27365 & 0.5320 & 1.0015 \\
& & &
\end{tabular}




\section{Table A.5a Water Uptake data for Post Cured Neat DERAKANE ${ }^{\mathrm{T} M}$ 411-350 vinyl ester resin:}

\begin{tabular}{|c|c|c|c|}
\hline Time, $h$ & $\begin{array}{c}\text { Weight, } \\
\text { mg }\end{array}$ & $\begin{array}{c}\text { Water } \\
\text { content } \\
\text { wt } \% \\
0.52916\end{array}$ & $M_{t} / M_{i n f}$ \\
\hline 0 & 328.74 & 0.0000 & 0.0000 \\
\hline 0.5 & 329 & 0.0791 & 0.1793 \\
\hline 1 & 329.07 & 0.1004 & 0.2276 \\
\hline 1.5 & 329.15 & 0.1247 & 0.2828 \\
\hline 2.5 & 329.27 & 0.1612 & 0.3655 \\
\hline 3.5 & 329.4 & 0.2008 & 0.4552 \\
\hline 4.5 & 329.49 & 0.2281 & 0.5172 \\
\hline 5.5 & 329.59 & 0.2586 & 0.5862 \\
\hline 7.5 & 329.71 & 0.2951 & 0.6690 \\
\hline 9.5 & 329.8 & 0.3224 & 0.7310 \\
\hline 17.83 & 330.03 & 0.3924 & 0.8897 \\
\hline 21.5 & 330.09 & 0.4107 & 0.9310 \\
\hline 25.167 & 330.1 & 0.4137 & 0.9379 \\
\hline 31.5 & 330.12 & 0.4198 & 0.9517 \\
\hline 45.5 & 330.15 & 0.4289 & 0.9724 \\
\hline 69.5 & 330.17 & 0.4350 & 0.9862 \\
\hline 166.8 & 330.2 & 0.4441 & 1.0069 \\
\hline & 30.1 & 0.2 & 1.0000 \\
\hline
\end{tabular}

\begin{tabular}{|c|c|c|}
\hline $\begin{array}{c}\text { Weight, } \\
\text { mg }\end{array}$ & $\begin{array}{c}\text { Water } \\
\text { content, } \\
\text { wt } \% \\
0.49953\end{array}$ & $\mathrm{M}_{\mathrm{t}} / \mathrm{M}_{\mathrm{inf}}$ \\
\hline 328.8 & 0.0000 & 0.0000 \\
\hline 329. & 0.04 & 0.1049 \\
\hline 32 & 0.06 & 0. \\
\hline 329. & 0.08 & 0.2 \\
\hline 329.3 & 0.13 & 0.3077 \\
\hline 329.42 & 0.1642 & 0.3776 \\
\hline 329.5 & 0.21 & 0.4895 \\
\hline 329.69 & 0.2463 & 0.5664 \\
\hline 98 & 0.27 & 0.6434 \\
\hline 329.88 & 0.30 & 93 \\
\hline & 0. & 0. \\
\hline 33 & 0.42 & 0.9720 \\
\hline 330.28 & 0.4257 & 0.9790 \\
\hline 330.29 & 0.4287 & 0.9860 \\
\hline 330.26 & 0.4196 & 0.9650 \\
\hline 330.29 & 0.4287 & 0.9860 \\
\hline & 0.4318 & 0.9930 \\
\hline 00.0 & 0.4348 & 1.0000 \\
\hline
\end{tabular}

Table A.5b Water Uptake data for Post Cured DERAKANE TM Vinyl ester Resins:

\begin{tabular}{|c|c|c|c|c|c|c|}
\hline Time, $\mathrm{h}$ & $\begin{array}{c}\text { Weight, } \\
\text { mg }\end{array}$ & $\begin{array}{c}\text { Water } \\
\text { content, } \\
\text { wt } \% \\
0.56726\end{array}$ & $M_{t} / M_{\text {inf }}$ & $\begin{array}{c}\text { Weight, } \\
\text { mg }\end{array}$ & $\begin{array}{c}\text { Water } \\
\text { content } \\
\text { wt } \% \\
0.49953\end{array}$ & $M_{t} / M_{i n f}$ \\
\hline 0 & 374.17 & 0.0000 & 0.0000 & 316.48 & 0.0000 & 0.0000 \\
\hline 0.5 & 374.42 & 0.0668 & 0.1515 & 316.75 & 0.0853 & 0.2000 \\
\hline 1 & 374.49 & 0.0855 & 0.1939 & 316.81 & 0.1043 & 0.2444 \\
\hline 1.5 & 374.6 & 0.1149 & 0.2606 & 316.87 & 0.1232 & 0.2889 \\
\hline 2.5 & 374.8 & 0.1684 & 0.3818 & 317.04 & 0.1769 & 0.4148 \\
\hline 3.5 & 374.9 & 0.1951 & 0.4424 & 317.12 & 0.2022 & 0.4741 \\
\hline 4.5 & 375 & 0.2218 & 0.5030 & 317.24 & 0.2401 & 0.5630 \\
\hline 5.5 & 375.12 & 0.2539 & 0.5758 & 317.3 & 0.2591 & 0.6074 \\
\hline 7.5 & 375.24 & 0.2860 & 0.6485 & 317.43 & 0.3002 & 0.7037 \\
\hline 9.5 & 375.32 & 0.3073 & 0.6970 & 317.54 & 0.3349 & 0.7852 \\
\hline 17.83 & 375.58 & 0.3768 & 0.8545 & 317.67 & 0.3760 & 0.8815 \\
\hline 21.5 & 375.62 & 0.3875 & 0.8788 & 317.73 & 0.3950 & 0.9259 \\
\hline 25.167 & 375.66 & 0.3982 & 0.9030 & 317.74 & 0.3981 & 0.9333 \\
\hline 31.5 & 375.68 & 0.4036 & 0.9152 & 317.77 & 0.4076 & 0.9556 \\
\hline 45.5 & 375.75 & 0.4223 & 0.9576 & 317.81 & 0.4202 & 0.9852 \\
\hline 69.5 & 375.77 & 0.4276 & 0.9697 & 317.82 & 0.4234 & 0.9926 \\
\hline 166.83 & 375.82 & 0.4410 & 1.0000 & 317.83 & 0.4266 & 1.0000 \\
\hline 240.5 & 375.8 & 0.4356 & 0.9879 & 317.81 & 0.4202 & 0.9852 \\
\hline
\end{tabular}


Table A.6a Water uptake data for $0.5 \mathrm{wt} \%$ VMC nanocomposite samples:

\begin{tabular}{|c|c|c|c|c|c|c|c|}
\hline Time, $\mathrm{h}$ & $\begin{array}{c}\text { Weight, } \\
\text { mg }\end{array}$ & $\begin{array}{c}\text { Water } \\
\text { content, } \\
\text { wt } \% \\
0.17318\end{array}$ & $\mathrm{M}_{\mathrm{t}} / \mathrm{M}_{\mathrm{inf}}$ & Time, $\mathrm{h}$ & $\begin{array}{c}\text { Weight, } \\
\text { mg }\end{array}$ & $\begin{array}{c}\text { Water } \\
\text { content, } \\
\text { wt\% } \\
0.18703\end{array}$ & $M_{t} / M_{\text {inf }}$ \\
\hline 0.000 & 109.79 & 0.0000 & 0.0000 & 0.0000 & 126.67 & 0.0000 & 0.0000 \\
\hline 0.042 & 109.84 & 0.0455 & 0.0658 & 0.0833 & 126.75 & 0.0 & 0.0909 \\
\hline 0.167 & 109.9 & 0.1002 & 0.1447 & 0.1667 & 126.82 & 0.1184 & 0.1705 \\
\hline 0.333 & 110.01 & 0.2004 & 0.2895 & 0.3333 & 126.95 & 0.2210 & 0.3182 \\
\hline 0.500 & 110.13 & 0.3097 & 0.4474 & 0.5833 & 127.01 & 0.2684 & 0.3864 \\
\hline 0.750 & 110.21 & 0.3825 & 0.5526 & 0.8 & 127.12 & 0.3 & 0.5114 \\
\hline 1.083 & 110 & 0.4190 & 0.60 & 1.5 & 127.24 & & 0.6477 \\
\hline 1.583 & 3 & 0.4918 & 0.7 & 2.0 & 127.33 & 0.5 & 0.7500 \\
\hline 2.083 & 110 & 0.5829 & 0.8 & & 127.4 & & 0.8295 \\
\hline 3.083 & 110.49 & 0.6376 & 0.9 & 4.0 & 127.46 & 0.6237 & 0.8977 \\
\hline 4.083 & 110.5 & 0.6467 & 0.9342 & $6.0 \varepsilon$ & 127.5 & 0.6552 & 0.9432 \\
\hline 19.583 & 110.54 & 0.6831 & 0.9868 & 8.0 & 127.53 & 0.6789 & 0.9773 \\
\hline 25.083 & 110.55 & 0.6922 & 1.0000 & 19.5833 & 127.54 & 0.6868 & 0.9886 \\
\hline 083 & 110.55 & 0.6922 & 1.0000 & 25.0833 & 127.55 & 0.6947 & 1.0000 \\
\hline & & & & & 12 & & . \\
\hline
\end{tabular}

Table A.6b Water uptake data for $0.5 \mathrm{wt} \%$ VMC nanocomposite samples:

\begin{tabular}{|c|c|c|c|c|c|c|c|}
\hline Time, $\mathrm{h}$ & $\begin{array}{l}\text { Weight, } \\
\text { mg }\end{array}$ & $\begin{array}{c}\text { Water } \\
\text { content, } \\
\text { wt } \%\end{array}$ & $M_{t} / M_{\text {inf }}$ & Time, $\mathrm{h}$ & $\begin{array}{c}\text { Weight, } \\
\text { mg }\end{array}$ & $\begin{array}{c}\text { Water } \\
\text { content, } \\
\text { wt } \%\end{array}$ & $M_{t} / M_{i n f}$ \\
\hline & & 0.17961 & & & & $=0.2795$ & \\
\hline 0.0000 & 108.12 & 0.0000 & 0.0000 & 0.0000 & 179.08 & 0.0000 & 0.0000 \\
\hline 0.0833 & 108.23 & 0.1017 & 0.1467 & 0.1667 & 179.2 & 0.0670 & 0.0976 \\
\hline 0.2500 & 108.34 & 0.2035 & 0.2933 & 0.3333 & 179.28 & 0.1117 & 0.1626 \\
\hline 0.4167 & 108.39 & 0.2497 & 0.3600 & 0.5833 & 179.36 & 0.1564 & 0.2276 \\
\hline 0.6667 & 108.47 & 0.3237 & 0.4667 & 0.8333 & 179.45 & 0.2066 & 0.3008 \\
\hline 1.0833 & 108.56 & 0.4070 & 0.5 & 1.0 & 179.5 & 0.2 & 0.3415 \\
\hline 1.58 & 108.63 & 0.4717 & 0.6800 & 1.5 & 179.65 & 83 & 0.4634 \\
\hline 2.0 & 10 & 64 & 0.7 & 2. & 75 & & 0.5447 \\
\hline 3.08 & 108.78 & 0.6104 & 0.8 & 3.0 & 179.85 & 0.4300 & 0.6260 \\
\hline 1.0833 & 108.83 & 0.6567 & 0.9467 & 4.0833 & 179.94 & 0.4802 & 0.6992 \\
\hline 0833 & 108.84 & 0.6659 & 0.9600 & 5.0833 & 180.02 & 0.5249 & 0.7642 \\
\hline 08 & 108.85 & 0.6752 & 0.9733 & 22.3333 & 180.3 & 0.6813 & 0.9919 \\
\hline & 108.87 & 0.6937 & 1.0000 & 50.0833 & 180.31 & 0.6868 & 1.0000 \\
\hline & & & 1.0000 & & & & \\
\hline
\end{tabular}


Table A.7a Water uptake data for $1.0 \mathrm{wt} \%$ VMC nanocomposite samples:

\begin{tabular}{|c|c|c|c|c|c|c|c|}
\hline Time, $\mathrm{h}$ & $\begin{array}{c}\text { Weight, } \\
\text { mg }\end{array}$ & $\begin{array}{c}\text { Water } \\
\text { content, } \\
\text { wt } \% \\
0.18062\end{array}$ & $M_{t} / M_{\text {inf }}$ & Time, $\mathrm{h}$ & $\begin{array}{c}\text { Weight, } \\
\text { mg }\end{array}$ & $\begin{array}{c}\text { Water } \\
\text { content, } \\
\text { wt } \% \\
0.16933\end{array}$ & $M_{t} / M_{i n f}$ \\
\hline 0.0000 & 120.13 & 0.0000 & 0.0000 & 0.0000 & 116.18 & 0.0000 & 0.00 \\
\hline 0.0833 & 120.24 & 0.0916 & 0.1068 & 0.0417 & 116.23 & 0.0430 & 0.05 \\
\hline 0.2500 & 120.37 & 0.1998 & 0.2330 & 0.1667 & 116.34 & 0.1377 & 0.16 \\
\hline 0.6667 & 120.54 & 0.3413 & 0.3981 & 0.5000 & 116.54 & 0.3099 & 0.36 \\
\hline 1.9167 & 120.77 & 0.5328 & 0.6214 & 0.6667 & 116.6 & 0.3615 & 0.42 \\
\hline 2.9167 & 120.85 & 0.5994 & 0.6990 & 0.9167 & 116.66 & 0.4132 & 0.48 \\
\hline 4.1667 & 120.93 & 0.6659 & 0.7767 & 1.1667 & 116.69 & 0.4390 & 0.51 \\
\hline 21.6667 & 121.16 & 0.8574 & 1.0000 & 1.4167 & 116.75 & 0.4906 & 0.57 \\
\hline 28.4167 & 121.13 & 0.8324 & 0.9709 & 1.9167 & 116.84 & 0.5681 & 0.66 \\
\hline 48.9167 & 121.16 & 0.8574 & 1.0000 & 2.9167 & 116.92 & 0.6369 & 0.74 \\
\hline & & & & 4.1667 & 116.99 & 0.6972 & 0.81 \\
\hline & & & & 5.4167 & 117.08 & 0.7747 & 0.90 \\
\hline & & & & 21.6667 & 117.17 & 0.8521 & 0.99 \\
\hline & & & & 28.4167 & 117.18 & 0.8607 & 1.00 \\
\hline & & & & 7 & 117.18 & 07 & 1.00 \\
\hline
\end{tabular}

Table A.7b Water uptake data for $1.0 \mathrm{wt} \%$ VMC nanocomposite samples:

\begin{tabular}{|c|c|c|c|c|c|c|c|}
\hline Time, $\mathrm{h}$ & $\begin{array}{c}\text { Weight, } \\
\text { Mg }\end{array}$ & $\begin{array}{c}\text { Water } \\
\text { content, } \\
\text { wt\% } \\
0.18344\end{array}$ & $M_{t} / M_{\text {inf }}$ & Time, $\mathrm{h}$ & $\begin{array}{c}\text { Weight, } \\
\text { Mg }\end{array}$ & $\begin{array}{c}\text { Water } \\
\text { content, } \\
\text { wt\% } \\
=0.19473\end{array}$ & $M_{t} / M_{\text {inf }}$ \\
\hline 0.0000 & 118.51 & 0.0000 & 0.0000 & 0.0000 & 137.85 & 0 & 0 \\
\hline 0.083 & $11 \varepsilon$ & 0.1013 & 0.1 & 3 & 13 & 0.05078 & 0.05882 \\
\hline 0.2500 & 118.73 & 0.1856 & 0.2136 & 0.1 & 13 & 0.108814 & 0.12605 \\
\hline 0.5000 & 118.85 & 0.2869 & 0.3301 & 0.3 & 138.07 & 0.159594 & 0.184874 \\
\hline 0.6667 & 118.9 & 0.3291 & 0.3786 & 0.5000 & 138.17 & 0.232136 & 0.268908 \\
\hline 0.9167 & 118.97 & 0.3882 & 0.4466 & 0.7 & 138.24 & 0.282916 & 0.327731 \\
\hline 1.1667 & 119.02 & 0.4303 & $0.4 \mathrm{~s}$ & & 138 & 0.362713 & 0.420168 \\
\hline 1.4167 & 1 & 0 & 0.5 & & 3 & 0.420747 & 0.487395 \\
\hline 1.9167 & $11 s$ & 5 & & & & 0.4 & 3025 \\
\hline 2.91 & 11 & 0.63 & 0.7 & & 138 & 0.587595 & 0.680672 \\
\hline 4.1667 & 119.37 & 0.7257 & 0.8350 & 4.5 & 138.72 & 0.631121 & 0.731092 \\
\hline 5.416 & 119. & 0.7510 & 0.8641 & 20. & 138.99 & 0.826986 & 0.957983 \\
\hline 166 & 119.53 & 0.8607 & 0.9903 & 27 & 138.99 & 0.826986 & 0.957983 \\
\hline 28.41 & 119.53 & 0.8607 & 0.9903 & 480 & 139.02 & 0.848749 & 0.983193 \\
\hline 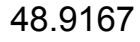 & 119.54 & 0.8691 & 1.0000 & 65 & 139.04 & 0.863257 & 1 \\
\hline & & & & & & 0.863257 & 1 \\
\hline
\end{tabular}


Table A.8a Water uptake data for $2.5 \mathrm{wt} \%$ VMC nanocomposites samples:

\begin{tabular}{|c|c|c|c|c|c|c|c|}
\hline Time, $\mathrm{h}$ & $\begin{array}{c}\text { Weight, } \\
\text { mg }\end{array}$ & $\begin{array}{c}\text { Water } \\
\text { content, } \\
\text { wt } \% \\
0.16764\end{array}$ & $\mathrm{M}_{\mathrm{t}} / \mathrm{M}_{\mathrm{inf}}$ & Time, $\mathrm{h}$ & $\begin{array}{c}\text { Weight, } \\
\text { mg }\end{array}$ & $\begin{array}{c}\text { Water } \\
\text { content, } \\
\text { wt\% } \\
=0.1651\end{array}$ & $M_{t} / M_{i n f}$ \\
\hline 0.0000 & 117.97 & 0.0000 & 0.0000 & 0.0000 & 122.15 & 0.0000 & 0.0000 \\
\hline 0.1667 & 118.11 & 0.1187 & 0.1138 & 0.0833 & 122.3 & 0.1228 & 0.1181 \\
\hline 0.4167 & 118.25 & 0.2373 & 0.2276 & 0.2500 & 122.38 & 0.1883 & 0.1811 \\
\hline 0.6667 & 118.34 & 0.3136 & 0.3008 & 0.5000 & 122.46 & 0.2538 & 0.2441 \\
\hline 0.9167 & 118.41 & 0.3730 & 0.3577 & 0.7500 & 122.6 & 0.3684 & 0.3543 \\
\hline 1.4167 & 118.54 & 0.4832 & 0.4634 & 1.0000 & 122.67 & 0.4257 & 0.4094 \\
\hline 1.9167 & 118.64 & 0.5679 & 0.5447 & 1.5000 & 122.76 & 0.4994 & 0.4803 \\
\hline 2.0000 & 118.74 & 0.6527 & 0.6260 & 2.0 & 122.88 & 0.5976 & 0.5748 \\
\hline 3.0000 & 118.84 & 0.7375 & 0.7073 & 4.0 & 123.05 & 0.7368 & 0.7087 \\
\hline 5.0000 & 118.92 & 0.8053 & 0.7724 & 5.0 & 123.14 & 0.8105 & 0.7795 \\
\hline 9.0000 & 119.05 & 0.9155 & 0.8780 & 9.0000 & 123.32 & 0.9578 & 0.9213 \\
\hline مחمח & 119.2 & & 1.0000 & 24.0000 & 123.4 & 1.0233 & 0.9843 \\
\hline 50.0000 & 119.25 & 1.0850 & 1.0407 & 50.0000 & 123.42 & 1.0397 & 1.0000 \\
\hline
\end{tabular}

Table A.8b Water uptake data for $2.5 \mathrm{wt} \%$ VMC nanocomposites samples:

\begin{tabular}{|c|c|c|c|c|c|c|c|}
\hline Time, $\mathrm{h}$ & $\begin{array}{c}\text { Weight, } \\
\text { mg }\end{array}$ & $\begin{array}{c}\text { Water } \\
\text { content } \\
\text { wt\% } \\
0.1397\end{array}$ & $M_{t} / M_{i n f}$ & Time, $\mathrm{h}$ & $\begin{array}{c}\text { Weight, } \\
\text { mg }\end{array}$ & $\begin{array}{c}\text { Water } \\
\text { content } \\
\text { wt } \% \\
=0.2286\end{array}$ & $M_{t} / M_{i n f}$ \\
\hline 0.0000 & 99.7 & 0.0000 & 0.0000 & 0.0000 & 156.91 & 0.0000 & 0.0000 \\
\hline 0.0833 & 99.75 & 0.0502 & 0.0481 & 0.0833 & 156.97 & 0.0382 & 0.0361 \\
\hline 0.2500 & 99.86 & 0.1605 & 0.1538 & 0.2500 & 157.08 & 0.1083 & 0.1024 \\
\hline 0.4167 & 100.01 & 0.3109 & 0.2981 & 0.4167 & 157.15 & 0.1530 & 0.1446 \\
\hline 0.6667 & 100.11 & 0.4112 & 0.3942 & 0.6667 & 157.29 & 0.2422 & 0.2289 \\
\hline 0.9167 & 100.2 & 0.5015 & 0.4808 & 0.9167 & 157.36 & 0.2868 & 0.2711 \\
\hline 1.4167 & 100.3 & 0.6018 & 0.5769 & 1.5000 & 157.52 & 0.3888 & 0.3675 \\
\hline 2.0000 & 100.39 & 0.6921 & 0.6635 & 2.0000 & 157.64 & 0.4652 & 0.4398 \\
\hline 3.0000 & 100.51 & 0.8124 & 0.7788 & 2.5000 & 157.74 & 0.5290 & 0.5000 \\
\hline 4.0000 & 100.56 & 0.8626 & 0.8269 & 3.2500 & 157.9 & 0.6309 & 0.5964 \\
\hline 5.0000 & 100.59 & 0.8927 & 0.8558 & 4.5000 & 158 & 0.6947 & 0.6566 \\
\hline 9.0000 & 100.67 & 0.9729 & 0.9327 & 5.2500 & 158.06 & 0.7329 & 0.6928 \\
\hline 24.0000 & 100.74 & 1.0431 & 1.0000 & 9.2500 & 158.29 & 0.8795 & 0.8313 \\
\hline 50.0000 & 100.74 & 1.0431 & 1.0000 & 23.0000 & 158.47 & 0.9942 & 0.9398 \\
\hline & & & & 31.5000 & 158.5 & 1.0133 & 0.9578 \\
\hline & & & & 48.2500 & 158.56 & & 0. \\
\hline & & & & 54.5000 & 158.58 & 1.0643 & 1.0060 \\
\hline & & & & 71.2 & 158.57 & 1.0579 & 1.0000 \\
\hline & & & & 99.2500 & 158.57 & 1.0579 & 1.0000 \\
\hline
\end{tabular}


Table 4.9a Water uptake data for $5.0 \mathrm{wt} \% \mathrm{VMC}$ nanocomposite samples:

\begin{tabular}{|c|c|c|c|c|c|c|c|}
\hline Time, h & $\begin{array}{c}\text { Weight, } \\
\text { mg }\end{array}$ & $\begin{array}{c}\text { Water } \\
\text { content, } \\
\text { wt\% } \\
=0.25717\end{array}$ & $M_{t} / M_{i n f}$ & Time, $\mathrm{h}$ & $\begin{array}{c}\text { Weight } \\
\text { Mg }\end{array}$ & $\begin{array}{c}\text { Water } \\
\text { content } \\
\text { wt } \% \\
=0.1905\end{array}$ & $M_{t} / M_{i n t}$ \\
\hline 0 & 186.68 & 0 & 0 & 0.0000 & 132.3 & 0.0000 & 0.0000 \\
\hline 116667 & 186.91 & 0.123205 & 0.105505 & 0. & 132.5 & 0.1512 & 0.1316 \\
\hline 666667 & 187.05 & 0.1982 & 0.169725 & 0.5833 & 132.61 & 0.2343 & 0.2039 \\
\hline 916667 & 187.14 & 0.246411 & 0.211009 & 0.7500 & 132.68 & 0.2872 & 0.2500 \\
\hline 6667 & 187.22 & 0.289265 & 0.247706 & 1.0 & 132.8 & 0.3779 & 0.3289 \\
\hline+16667 & 187.31 & 0.337476 & 0.288991 & 1.2 & 13 & 0.4 & 0. \\
\hline 2 & 18 & 0.401757 & 0.3 & & 132.95 & 0. & 0.4276 \\
\hline 2.5 & 187.53 & 0.455325 & 0.3 & & 133 & 91 & 0.4605 \\
\hline 3 & 187.63 & 0.508892 & 0.4 & 2.5 & 133.09 & 0.5971 & 0.5197 \\
\hline 4.25 & 187.78 & 0.589244 & 0.504587 & 3.0 & 133.18 & 0.6652 & 0.5789 \\
\hline 5 & 188.04 & 0.728519 & 0.623853 & 5.5 & 133.44 & 0.8617 & 0.7500 \\
\hline 6.7 & 188.07 & 0.74459 & 0.637615 & 6.7 & 133.47 & 0.8844 & 0.7697 \\
\hline 2 & 1 & 1.023141 & 0.876147 & 43.5 & 133.76 & 1.1036 & 0.9605 \\
\hline 43.5 & 188.66 & 1.060639 & 0.908257 & 109.5000 & 133.82 & 1.1489 & 1.0000 \\
\hline 109.5 & 188.86 & 1.1 & 1 & & & & \\
\hline
\end{tabular}

Table 4.9b Water uptake data for $5.0 \mathrm{wt} \%$ VMC nanocomposite samples:

\begin{tabular}{|c|c|c|c|c|c|c|c|}
\hline Time, $\mathrm{h}$ & $\begin{array}{c}\text { Weight, } \\
\text { Mg }\end{array}$ & $\begin{array}{c}\text { Water } \\
\text { content, } \\
\text { wt } \% \\
0.20602\end{array}$ & $M_{t} / M_{\text {inf }}$ & Time, $\mathrm{h}$ & $\begin{array}{c}\text { Weight, } \\
\text { mg }\end{array}$ & $\begin{array}{c}\text { Water } \\
\text { content, } \\
\text { wt } \% \\
=0.1467\end{array}$ & $M_{t} / M_{i n f}$ \\
\hline 0.0000 & 145.81 & 0.0000 & 0.0000 & 0.0000 & 106.83 & 0.0000 & 0.0000 \\
\hline 0.3333 & 146.03 & 0.1509 & 0.1243 & 0.0417 & 106.88 & 0.0460 & 0.0394 \\
\hline 0.5833 & 146.19 & 0.2606 & 0.2147 & 0.3333 & 107.09 & 0.2393 & 0.2047 \\
\hline 0.7500 & 146.21 & 0.2743 & 0.2260 & 0.5000 & 107.15 & 0.2946 & 0.2520 \\
\hline 1.0000 & 146.34 & 0.3635 & 0.2994 & 0.6667 & 107.23 & 0.3682 & 0.3150 \\
\hline 1.2500 & 146.38 & 0.3909 & 0.3220 & 0.9167 & 107.31 & 0.4419 & 0.3780 \\
\hline 1.5000 & 146.43 & 0.4252 & 0.3503 & 1.1667 & 107.41 & 0.5339 & 0.4567 \\
\hline 2.0000 & 146.56 & 0.5144 & 0.4237 & 1.4167 & 107.47 & 0.5892 & 0.5039 \\
\hline 2.5000 & 146.62 & 0.5555 & 0.4576 & $2.0 c$ & 107.55 & 0.6628 & 0.5669 \\
\hline 3.0000 & 146.74 & 0.6378 & 0.5254 & 2.5000 & 107.62 & 0.7272 & 0.6220 \\
\hline 4.2500 & 146.85 & 0.7133 & 0.5876 & 3.0 & 107.68 & 0.7825 & 0.6693 \\
\hline 5.5000 & 146.98 & 0.8024 & 0.6610 & 4.2500 & 107.75 & 0.8469 & 0.7244 \\
\hline 6.7500 & 147.07 & 0.8641 & 0.7119 & 5.5000 & 107.87 & 0.9574 & 0.8189 \\
\hline 25.0000 & 147.41 & 1.0973 & 0.9040 & 6.7500 & 107.9 & 0.9850 & 0.8425 \\
\hline 43.5000 & 147.41 & 1.0973 & 0.9040 & 25.0000 & 108.1 & 1.1691 & 1.0000 \\
\hline 00 & 147.58 & 1.2139 & 1.0000 & 43.5000 & 108.08 & 1.1507 & 0.9843 \\
\hline & & & & & 10 & 1.1691 & \\
\hline
\end{tabular}


Table 4.9c Water uptake data for 5.0 wt \% VMC nanocomposite samples:

\begin{tabular}{cccc} 
Time, h & $\begin{array}{c}\text { Weight, } \\
\text { mg }\end{array}$ & $\begin{array}{c}\text { Water } \\
\text { content, } \\
\text { wt\% }\end{array}$ & $\mathrm{M}_{\mathrm{t}} / \mathrm{M}_{\text {inf }}$ \\
& \multicolumn{3}{c}{$2 \ell=0.18452 \mathrm{~mm}$} \\
0.0000 & 128.35 & 0.0000 & 0.0000 \\
0.0833 & 128.43 & 0.0623 & 0.0544 \\
0.2500 & 128.53 & 0.1402 & 0.1224 \\
0.4167 & 128.61 & 0.2026 & 0.1769 \\
0.6667 & 128.73 & 0.2961 & 0.2585 \\
0.9167 & 128.81 & 0.3584 & 0.3129 \\
1.5000 & 128.94 & 0.4597 & 0.4014 \\
2.0000 & 129.02 & 0.5220 & 0.4558 \\
2.5000 & 129.14 & 0.6155 & 0.5374 \\
3.2500 & 129.28 & 0.7246 & 0.6327 \\
4.5000 & 129.35 & 0.7791 & 0.6803 \\
5.2500 & 129.37 & 0.7947 & 0.6939 \\
9.2500 & 129.51 & 0.9038 & 0.7891 \\
23.0000 & 129.68 & 1.0362 & 0.9048 \\
31.5000 & 129.76 & 1.0986 & 0.9592 \\
48.2500 & 129.78 & 1.1141 & 0.9728 \\
54.5000 & 129.8 & 1.1297 & 0.9864 \\
71.2500 & 129.8 & 1.1297 & 0.9864 \\
99.2500 & 129.82 & 1.1453 & 1.0000
\end{tabular}

Table 4.10a Water uptake data for $0.5 \mathrm{wt} \%$ Cloisite $10 \mathrm{~A}^{\circledR}$ nanocomposite samples:

\begin{tabular}{|c|c|c|c|c|c|c|c|}
\hline Time, $\mathrm{h}$ & $\begin{array}{l}\text { Weight, } \\
\text { Mg }\end{array}$ & $\begin{array}{c}\text { Water } \\
\text { content, } \\
\text { wt } \% \\
0.25373\end{array}$ & $M_{t} / M_{i n f}$ & Time, $\mathrm{h}$ & $\begin{array}{c}\text { Weight, } \\
\text { mg }\end{array}$ & $\begin{array}{c}\text { Water } \\
\text { content, } \\
\text { wt\% } \\
=0.3105\end{array}$ & $M_{t} / M_{i n f}$ \\
\hline 0.0000 & 148.59 & 0.0000 & 0.0000 & 0.0000 & 175.77 & 0.000 & 0.0000 \\
\hline 0.0833 & 148. & 0.0404 & 0.0 & 7 & 17 & 0.0 & 0.0816 \\
\hline 0.2500 & 148.74 & 0.1009 & 0.1230 & 0.3333 & 175.96 & 0.1081 & 0.1293 \\
\hline 0.5000 & 148.85 & 0.1750 & 0.2131 & 0.6333 & 176.07 & 0.1707 & 0.2041 \\
\hline 0.7500 & 148.91 & 0.2154 & 0.2623 & 0.8333 & 176.13 & 0.2048 & 0.2449 \\
\hline 1.0000 & 149 & 0.2759 & 0.3 & 1.0 & 176.19 & 0.2389 & 0.2857 \\
\hline $1.50 c$ & 149.14 & 0.37 & 0.4 & & & & 0.3810 \\
\hline 2.00 & 14 & 0.4 & 0.5 & & & 0. & 558 \\
\hline 3.0 & 149 & 0.5 & & & & & 0.5 \\
\hline 4.08 & 149.43 & 0.5653 & 0.6 & 4.0 & 176.66 & 0.5063 & 0.6054 \\
\hline 5.0833 & 149.5 & 0.6124 & 0.7459 & 5.0833 & 176.73 & 0.5462 & 0.6531 \\
\hline 98333 & 149. & 0.7470 & 0.90 & 9.8 & 176.98 & 0.6884 & 0.8231 \\
\hline 15 & 149.81 & 0.8211 & 1.00 & 24.5 & 177.15 & 0.7851 & 0.9388 \\
\hline 2 & 149.81 & 0.8211 & 1.0000 & 55.0833 & 177.23 & 0.8306 & 0.9932 \\
\hline & 149.81 & 0.8211 & 1.0000 & 79.0833 & 177.24 & & 1.0000 \\
\hline 5.08 & 149.81 & 0.8211 & 1.0000 & 105.0833 & 177.24 & 0.8363 & 1.0000 \\
\hline
\end{tabular}


Table 4.10b Water uptake data for $0.5 \mathrm{wt} \%$ Cloisite $10 \mathrm{~A}^{\circledR}$ nanocomposite samples:

\begin{tabular}{|c|c|c|c|c|c|c|c|}
\hline Time, $\mathrm{h}$ & $\begin{array}{c}\text { Weight, } \\
\text { mg }\end{array}$ & $\begin{array}{c}\text { Water } \\
\text { content, } \\
\text { wt } \% \\
0.15471\end{array}$ & $M_{t} / M_{i n f}$ & Time, h & $\begin{array}{c}\text { Weight, } \\
\text { mg }\end{array}$ & $\begin{array}{c}\text { Water } \\
\text { content } \\
\text { wt\% } \\
0.25188\end{array}$ & $M_{t} / M_{i n f}$ \\
\hline 0.0000 & 80.79 & 0.0000 & 0.0000 & 0.0000 & 155.42 & 0.0000 & 0.0000 \\
\hline 0.0833 & 80.88 & 0.1114 & 0.1343 & 0.1667 & 155.51 & 0.0579 & 0.0698 \\
\hline 0.2500 & 80.98 & 0.2352 & 0.2836 & 0.4167 & 155.65 & 0.1480 & 0.1783 \\
\hline 0.5000 & 81.08 & 0.3590 & 0.4328 & 0.6667 & 155.75 & 0.2123 & 0.2558 \\
\hline 0.7500 & 81.17 & 0.4704 & 0.5672 & 1.1667 & 155.95 & 0.3410 & 0.4109 \\
\hline 1.2500 & 81.25 & 0.5694 & 0.6866 & 1.6667 & 156.07 & 0.4182 & 0.5039 \\
\hline 1.6667 & 81.3 & 0.6313 & 0.7612 & 2.6667 & 156.23 & 0.5212 & 0.6279 \\
\hline 2.6667 & 81.38 & 0.7303 & 0.8806 & 3.6667 & 156.37 & 0.6112 & 0.7364 \\
\hline 3.6667 & 81.43 & 0.7922 & 0.9 & 5.6 & 156.47 & 0.6756 & 0.8140 \\
\hline 5.6667 & 81.45 & 0.8169 & 0.9851 & 9.9 & 156.6 & 0.7592 & 0.9147 \\
\hline 9.9167 & 81.46 & 0.8293 & 1.0000 & 25.1667 & 156.7 & 0.8236 & 0.9922 \\
\hline 25.1667 & 81.46 & 0.8293 & 1.0000 & 33.9167 & 156.63 & 0.7785 & 0.9380 \\
\hline \multirow[t]{4}{*}{33.9167} & 81.46 & 0.8293 & 1.0000 & 34.6683 & 156.71 & 0.8300 & 1.0000 \\
\hline & & & & 65.1683 & 156.71 & 0.8300 & 1.0000 \\
\hline & & & & 89.1683 & 156.71 & 0.8300 & 1.0000 \\
\hline & & & & 117. & 156.7 & 0.8236 & 0.9922 \\
\hline
\end{tabular}

Table 4.11a Water uptake data for $1.0 \mathrm{wt}^{\circ}$ Cloisite $10 \mathrm{~A}^{\circledR}$ nanocomposite samples:

\begin{tabular}{|c|c|c|c|c|c|c|c|}
\hline Time, $\mathrm{h}$ & $\begin{array}{c}\text { Weight, } \\
\text { mg }\end{array}$ & $\begin{array}{c}\text { Water } \\
\text { content, } \\
\text { wt } \% \\
0.20108\end{array}$ & $\mathrm{M}_{\mathrm{t}} / \mathrm{M}_{\mathrm{inf}}$ & Time, $\mathrm{h}$ & $\begin{array}{c}\text { Weight, } \\
\text { mg }\end{array}$ & $\begin{array}{c}\text { Water } \\
\text { content, } \\
\text { wt } \% \\
0.23738\end{array}$ & $\mathrm{M}_{\mathrm{t}} / \mathrm{M}_{\mathrm{inf}}$ \\
\hline 0.0000 & 127.76 & 0.0000 & 0.0000 & 0.0000 & 148.96 & 0.0000 & 0.0000 \\
\hline 0.0833 & 127.83 & 0.0548 & 0.0593 & 0.1667 & 149.1 & 0.0940 & 0.1029 \\
\hline 0.2500 & 127.92 & 0.1252 & 0.1356 & 0.4167 & 149.21 & 0.1678 & 0.1838 \\
\hline 0.5000 & 128.03 & 0.2113 & 0.2288 & 0.6667 & 149.31 & 0.2350 & 0.2574 \\
\hline 0.7500 & 128.12 & 0.2818 & 0.3051 & 1.1667 & 149.46 & 0.3357 & 0.3676 \\
\hline 1.2500 & 128.28 & 0.4070 & 0.4407 & 1.6667 & 149.57 & 0.4095 & 0.4485 \\
\hline 1.6667 & 128.36 & 0.4696 & 0.5085 & 2.6667 & 149.71 & 0.5035 & 0.5515 \\
\hline 2.6667 & 128.49 & 0.5714 & 0.6186 & 3.6667 & 149.84 & 0.5908 & 0.6471 \\
\hline 3.6667 & 128.59 & 0.6497 & 0.7034 & 5.6667 & 150 & 0.6982 & 0.7647 \\
\hline 5.6667 & 128.68 & 0.7201 & 0.7797 & 9.9167 & 150.05 & 0.7317 & 0.8015 \\
\hline 9.9167 & 128.75 & 0.7749 & 0.8390 & 25.1667 & 150.15 & 0.7989 & 0.8750 \\
\hline 25.1667 & 128.87 & 0.8688 & 0.9407 & 33.9167 & 150.17 & 0.8123 & 0.8897 \\
\hline 33.9167 & 128.9 & 0.8923 & 0.9661 & 48.6667 & 150.2 & 0.8324 & 0.9118 \\
\hline 48.6667 & 128.92 & 0.9080 & 0.9831 & 79.1667 & 150.27 & 0.8794 & 0.9632 \\
\hline 79.1667 & 128.94 & 0.9236 & 1.0000 & 103.1667 & 150.3 & 0.8996 & 0.9853 \\
\hline 103.1667 & 128.94 & 0.9236 & 1.0000 & 129.1667 & 150.32 & 0.9130 & 1.0000 \\
\hline 129.1667 & 128.93 & 0.9158 & 0.9915 & & & & \\
\hline
\end{tabular}


Table 4.11b Water uptake data for $1.0 \mathrm{wt} \%$ Cloisite $10 \mathrm{~A}^{\circledR}$ nanocomposite samples:

\begin{tabular}{|c|c|c|c|c|c|c|c|}
\hline Time, $\mathrm{h}$ & $\begin{array}{c}\text { Weight, } \\
\text { mg }\end{array}$ & $\begin{array}{c}\text { Water } \\
\text { content } \\
\text { wt } \% \\
=0.2116\end{array}$ & $\mathrm{M}_{\mathrm{t}} / \mathrm{M}_{\mathrm{inf}}$ & Time, $\mathrm{h}$ & $\begin{array}{c}\text { Weight, } \\
\text { mg }\end{array}$ & $\begin{array}{c}\text { Water } \\
\text { content, } \\
\text { wt\% } \\
0.18626\end{array}$ & $M_{t} / M_{\text {inf }}$ \\
\hline 0.0000 & 120.59 & 0.0000 & 0.0000 & 0.0000 & 6.3 & 0.0000 & 0.0000 \\
\hline 0.1667 & 120.7 & 0.0912 & 0.0973 & 0.0833 & 96.37 & 0.0727 & 0.0778 \\
\hline 0.3333 & 120.8 & 0.1741 & 0.1858 & 0.2500 & 96.45 & 0.1558 & 0.1667 \\
\hline 0.5833 & 120.89 & 0.2488 & 0.2655 & 0.4167 & 96.53 & 0.2388 & 0.2556 \\
\hline 0.8333 & 121 & 0.3400 & 0.3628 & 0.6667 & 96.61 & 0.3219 & 0.3444 \\
\hline 1.0833 & 121.06 & 0.3898 & 0.4159 & 0.9167 & 96.71 & 0.4258 & 0.4556 \\
\hline 1.6667 & 121.18 & 0.4893 & 0.5221 & 1.1667 & 96.76 & 0.4777 & 0.5111 \\
\hline 2.6667 & 121.31 & 0.5971 & 0.6372 & 1.66 & 96.83 & 0.5504 & 0.5889 \\
\hline 4.1667 & 121.41 & 0.6800 & 0.7257 & 2.6667 & 96.92 & 0.6438 & 0.6889 \\
\hline 6.1667 & 121.51 & 0.7629 & 0.8 & 4. & 97.01 & 0.7373 & 0.7889 \\
\hline 8.1667 & 121.57 & 0.8127 & 0.8673 & 6.1 & 97.06 & 0.7892 & 0.8444 \\
\hline 23.6667 & 121.65 & 0.8790 & 0.9381 & 8.1667 & 97.09 & 0.8204 & 0.8778 \\
\hline 28.6667 & 121.68 & 0.9039 & 0.9646 & 23.6667 & 97.13 & 0.8619 & 0.9222 \\
\hline 52.6667 & 121.7 & 0.9205 & 0.9823 & 28.6667 & 97.17 & 0.9034 & 0.9667 \\
\hline 77.6667 & 121.72 & 0.9371 & 1.0000 & 52.6667 & 97.2 & 0.9346 & 1.0000 \\
\hline 100.1667 & 121.71 & 0.9288 & 0.9912 & 77.6667 & 97.2 & 0.9346 & 1.0000 \\
\hline 12 & 121.72 & 0.9371 & 1.0000 & 100.1667 & 97.2 & 0.9346 & 1.0000 \\
\hline
\end{tabular}

Table 4.12a Water uptake data for $2.5 \mathrm{wt} \%$ Cloisite $10 \mathrm{~A}^{\circledR}$ nanocomposite samples:

\begin{tabular}{|c|c|c|c|c|c|c|c|}
\hline Time, $\mathrm{h}$ & $\begin{array}{c}\text { Weight, } \\
\text { mg }\end{array}$ & $\begin{array}{c}\text { Water } \\
\text { content, } \\
\text { wt } \% \\
0.22013\end{array}$ & $\mathrm{M}_{\mathrm{t}} / \mathrm{M}_{\mathrm{inf}}$ & Time, h & $\begin{array}{c}\text { Weight, } \\
\text { mg }\end{array}$ & $\begin{array}{c}\text { Water } \\
\text { content, } \\
\text { wt } \% \\
0.14758\end{array}$ & $M_{t} / M_{i n f}$ \\
\hline 0.0000 & 128.06 & 0.0000 & 0.0000 & 0.0000 & 77.81 & 0.0000 & 0.0000 \\
\hline 0.0833 & 128. & 0.0547 & 0.0493 & 0.0 & 77.87 & 0.0771 & 0.0698 \\
\hline 0.2500 & 128.21 & 0.1171 & 0.1056 & 0.2500 & 77.96 & 0.1928 & 0.1744 \\
\hline 0.5000 & 128.32 & 0.2030 & 0.1831 & 0.5000 & 78.07 & 0.3341 & 0.3023 \\
\hline 0.7500 & 128.42 & 0.2811 & 0.2535 & 0.7500 & 78.15 & 0.4370 & 0.3953 \\
\hline 1.0000 & 128.48 & 0.3280 & 0.2958 & 1.0000 & 78.17 & 0.4627 & 0.4186 \\
\hline 1.5000 & 128.62 & 0.4373 & 0.3944 & 1.50 & 78.22 & 0.5269 & 0.4767 \\
\hline 2.0000 & 128.69 & 0.4920 & 0.4 & & 78.28 & 0.6 & 0.5465 \\
\hline 2.75 & 128.79 & 0.5700 & 0.5 & 2.7 & 78.37 & 0.7197 & 0.6512 \\
\hline 3.5000 & 128.87 & 0.6325 & 0.5704 & 3.5000 & 78.39 & 0.7454 & 0.6744 \\
\hline 5.5000 & 129.02 & 0.7496 & 0.6761 & 5.5000 & 78.45 & 0.8225 & 0.7442 \\
\hline 9.750 & 129.13 & 0.8355 & 0.7535 & 9.75 & 78.51 & 0.8996 & 0.8140 \\
\hline 23.7500 & 129.25 & 0.9293 & 0.8380 & 23.7 & 78.61 & 1.0281 & 0.9302 \\
\hline 27.7500 & 129.29 & 0.9605 & 0.8662 & 27.7 & 78.63 & 1.0538 & 0.9535 \\
\hline & 12 & 0.9761 & & & 78.65 & 1.0796 & 0.9767 \\
\hline 48.50 & 129.35 & 1.00 & & 48. & 78.67 & & 1.0000 \\
\hline & & 1.0 & & & 78.67 & & 1.0000 \\
\hline & & 1.1 & 1.00 & 125.0000 & 78.67 & 1.1053 & 1.0000 \\
\hline 7 & 129.48 & 1.1089 & 1.0000 & & & & \\
\hline
\end{tabular}


Table 4.12b Water uptake data for $2.5 \mathrm{wt} \%$ Cloisite $10 \mathrm{~A}^{\circledR}$ nanocomposite samples:

\begin{tabular}{|c|c|c|c|c|c|c|c|}
\hline Time, h & $\begin{array}{c}\text { Weight, } \\
\text { mg }\end{array}$ & $\begin{array}{c}\text { Water } \\
\text { content } \\
\text { wt } \% \\
0.23495\end{array}$ & $\mathrm{M}_{\mathrm{t}} / \mathrm{M}_{\mathrm{inf}}$ & Time, $\mathrm{h}$ & $\begin{array}{c}\text { Weight, } \\
\text { mg }\end{array}$ & $\begin{array}{c}\text { Water } \\
\text { content, } \\
\text { wt } \% \\
0.24976\end{array}$ & $M_{t} / M_{i n f}$ \\
\hline 0.0000 & 140.16 & 0.0000 & 0.0000 & 0.0000 & 161.39 & 0.0000 & 0.0000 \\
\hline 0.1667 & $14 C$ & 0.0713 & 0.0 & 7 & 4 & 0.0 & 0.0833 \\
\hline 0.3333 & 140. & 0.1284 & 0.1 & 0.3 & 2 & 0.1 & 0.1278 \\
\hline 0.5833 & 140.47 & 0.2212 & 0.2000 & 0.5 & 161.73 & 0.2107 & 0.1889 \\
\hline 0.8333 & 140.54 & 0.2711 & 0.2452 & 0.8333 & 161.82 & 0.2664 & 0.2389 \\
\hline 1.0833 & 140. & 0.3496 & 0.3 & 1.0 & 161.87 & 0.2974 & 0.2667 \\
\hline 1.5833 & 140.75 & 0.4209 & 0.3 & & 162 & 0.3 & 556 \\
\hline $2.0 \varepsilon$ & 14 & 0 & & & & & 0 \\
\hline & & & & & & & 22 \\
\hline 3. & 140 & 0.5 & & & & 0.5 & 0.5222 \\
\hline 5.5000 & 141. & 0.7277 & 0.6 & 5.5 & 162.55 & 0.7 & 0.6444 \\
\hline 9.7500 & 141.29 & 0.8062 & 0.7 & 9.7 & 162.7 & 0.8117 & 0.7278 \\
\hline 3.7500 & 141.44 & 0.9132 & 0.8 & 23.7 & 162.92 & 0.9480 & 0.8500 \\
\hline 7.75 & 141.46 & 0.9275 & 0.8 & 27.7 & 162.94 & 0.9604 & 0.8611 \\
\hline 37 & 141.5 & 0.9561 & 0.8 & 33 & 162.97 & 0.9790 & 0.8778 \\
\hline .50 & 141.54 & 0.9846 & 0.8 & 0 & 163.04 & 224 & 0.9167 \\
\hline & 14 & & & & & & 0.9667 \\
\hline & & 1.0 & & & 163.18 & & 0.9944 \\
\hline 0.10 & 141.71 & 1.1059 & 1.0000 & 166.7500 & 163.19 & 1.1153 & 1.000 \\
\hline
\end{tabular}

Table 4.13a Water uptake data for $5.0 \mathrm{wt} \%$ Cloisite $10 \mathrm{~A}^{\circledR}$ nanocomposite samples:

\begin{tabular}{|c|c|c|c|c|c|c|c|}
\hline Time, h & $\begin{array}{c}\text { Weight, } \\
\text { mg }\end{array}$ & $\begin{array}{c}\text { Water } \\
\text { content, } \\
\text { wt } \% \\
0.2032\end{array}$ & $\mathrm{M}_{\mathrm{t}} / \mathrm{M}_{\mathrm{inf}}$ & Time, $\mathrm{h}$ & $\begin{array}{c}\text { Weight, } \\
\text { mg }\end{array}$ & $\begin{array}{c}\text { Water } \\
\text { content } \\
\text { wt } \% \\
0.18838\end{array}$ & $\mathrm{I}_{\mathrm{t}} / \mathrm{M}_{\mathrm{inf}}$ \\
\hline 0.0000 & 127.49 & 0.0000 & 0.0000 & 0.0000 & 107. & 0.00 & 0.0000 \\
\hline 0.1667 & 127. & 0.09 & 0.06 & 3 & 7 & 0.0 & 0.0313 \\
\hline 0.3333 & 127.7 & 0.1647 & 0.1105 & 0.2500 & 107.47 & 0.1398 & 0.0938 \\
\hline 0.5000 & 127.78 & 0.2275 & 0.1526 & 0.4167 & 107.57 & 0.2329 & 0.1562 \\
\hline 0.7500 & 127.87 & 0.2981 & 0.2000 & 0.6667 & 107.68 & 0.3354 & 0.2250 \\
\hline 1.0000 & 127.98 & 0.3843 & 0.25 & 0.9 & 107.76 & 0.4100 & 0.2750 \\
\hline 1.50 & 128.07 & 0.4 & 0.3 & & 107 & & 312 \\
\hline 2.0 & 12 & 0.5 & & & 99 & 0.6 & 0 \\
\hline 2.7 & 128.26 & & & & 10 & 0.6 & 0.4 \\
\hline 3.75 & 128.34 & 0.66 & 0.4 & 3.6 & $10 \varepsilon$ & 0.7 & 0.4750 \\
\hline 0.2500 & 128.64 & 0.9020 & 0.6053 & 10.2 & 108.37 & 0.9784 & 0.6562 \\
\hline 5.0000 & 128.88 & 1.0903 & 0.73 & 25.0 & 108.49 & 1.0902 & 0.7312 \\
\hline 37.00 & 128.96 & 1.1530 & 0.7737 & 37.0 & 108.62 & 1.2113 & 0.8125 \\
\hline 5000 & 129.16 & 1.3099 & 0.8789 & 49.5 & 108.75 & 1.3 & 0.8937 \\
\hline 78.2500 & 129.28 & 1 & 0.94 & 78.2 & 87 & & 687 \\
\hline & & & & & & & 000 \\
\hline & 129.39 & & 1.0 & & 108 & & 1.0000 \\
\hline 14 & 129.39 & 1.4903 & 1.0000 & 140.5000 & 108.92 & 1.4909 & 1.0000 \\
\hline
\end{tabular}


Table 4.13b Water uptake data for $5.0 \mathrm{wt} \%$ Cloisite $10 \mathrm{~A}^{\circledR}$ nanocomposite samples:

\begin{tabular}{cccc} 
Time, h & $\begin{array}{c}\text { Weight, } \\
\text { mg }\end{array}$ & $\begin{array}{c}\text { Water } \\
\text { content, } \\
\text { wt } \%\end{array}$ & $\mathrm{M}_{\mathrm{t}} / \mathrm{M}_{\text {inf }}$ \\
& \multicolumn{3}{c}{$2 \ell=0.14816 \mathrm{~mm}$} \\
0.0000 & 75.46 & 0.0000 & 0.0000 \\
0.0833 & 75.51 & 0.0663 & 0.0450 \\
0.2500 & 75.58 & 0.1590 & 0.1081 \\
0.4167 & 75.66 & 0.2650 & 0.1802 \\
0.6667 & 75.74 & 0.3711 & 0.2523 \\
0.9167 & 75.79 & 0.4373 & 0.2973 \\
1.4167 & 75.87 & 0.5433 & 0.3694 \\
1.9167 & 75.94 & 0.6361 & 0.4324 \\
2.6667 & 75.98 & 0.6891 & 0.4685 \\
3.6667 & 76.02 & 0.7421 & 0.5045 \\
10.2500 & 76.21 & 0.9939 & 0.6757 \\
25.0000 & 76.36 & 1.1927 & 0.8108 \\
37.0000 & 76.47 & 1.3385 & 0.9099 \\
49.5000 & 76.53 & 1.4180 & 0.9640 \\
78.2500 & 76.57 & 1.4710 & 1.0000 \\
96.0000 & 76.57 & 1.4710 & 1.0000
\end{tabular}

Table 4.14a Water uptake data for $0.66 \mathrm{wt} \%$ Cloisite $\mathrm{Na}^{\circledR}$ nanocomposite samples:

\begin{tabular}{|c|c|c|c|c|c|c|}
\hline Time, $\mathrm{h}$ & $\begin{array}{c}\text { Weight, } \\
\text { mg }\end{array}$ & $\begin{array}{c}\text { Water } \\
\text { content, } \\
\text { wt } \% \\
0.5080\end{array}$ & $\mathrm{M}_{\mathrm{t}} / \mathrm{M}_{\mathrm{inf}}$ & $\begin{array}{c}\text { Weight, } \\
\text { mg }\end{array}$ & $\begin{array}{c}\text { Water } \\
\text { content, } \\
\text { wt } \% \\
=0.5376\end{array}$ & $\mathrm{M}_{\mathrm{t}} / \mathrm{M}_{\mathrm{inf}}$ \\
\hline 0.0000 & 274.29 & 0.0000 & 0.0000 & 294.34 & 0.0000 & 0.0000 \\
\hline 0.0833 & 274.4 & 0.0401 & 0.0442 & 294.44 & 0.0340 & 0.0380 \\
\hline 0.2500 & 274.5 & 0.0766 & 0.0843 & 294.53 & 0.0646 & 0.0722 \\
\hline 0.5000 & 274.61 & 0.1167 & 0.1285 & 294.61 & 0.0917 & 0.1027 \\
\hline 0.7500 & 274.72 & 0.1568 & 0.1727 & 294.72 & 0.1291 & 0.1445 \\
\hline 1.2500 & 274.87 & 0.2115 & 0.2329 & 294.92 & 0.1971 & 0.2205 \\
\hline 2.2500 & 275.11 & 0.2990 & 0.3293 & 295.12 & 0.2650 & 0.2966 \\
\hline 3.2500 & 275.3 & 0.3682 & 0.4056 & 295.3 & 0.3262 & 0.3650 \\
\hline 4.4167 & 275.48 & 0.4338 & 0.4779 & 295.47 & 0.3839 & 0.4297 \\
\hline 6.2500 & 275.71 & 0.5177 & 0.5703 & 295.73 & 0.4722 & 0.5285 \\
\hline 10.2500 & 276 & 0.6234 & 0.6867 & 296.04 & 0.5776 & 0.6464 \\
\hline 23.5000 & 276.44 & 0.7838 & 0.8635 & 296.55 & 0.7508 & 0.8403 \\
\hline 30.7500 & 276.55 & 0.8239 & 0.9076 & 296.68 & 0.7950 & 0.8897 \\
\hline 55.7500 & 276.71 & 0.8823 & 0.9719 & 296.86 & 0.8562 & 0.9582 \\
\hline 78.0000 & 276.75 & 0.8969 & 0.9880 & 296.9 & 0.8697 & 0.9734 \\
\hline 100.0000 & 276.75 & 0.8969 & 0.9880 & 296.9 & 0.8697 & 0.9734 \\
\hline 146.2500 & 276.78 & 0.9078 & 1.0000 & 296.98 & 0.8969 & 1.0038 \\
\hline 217.2500 & 276.78 & 0.9078 & 1.0000 & 296.97 & 0.8935 & 1.0000 \\
\hline
\end{tabular}


Table 4.14b Water uptake data for $3.25 \mathrm{wt} \%$ Cloisite $\mathrm{Na}^{\circledR}$ nanocomposite samples:

\begin{tabular}{|c|c|c|c|c|c|c|c|}
\hline Time, h & $\begin{array}{c}\text { Weight, } \\
\text { mg }\end{array}$ & $\begin{array}{c}\text { Water } \\
\text { content, } \\
\text { wt } \% \\
0.41486\end{array}$ & $M_{t} / M_{i n f}$ & Time, $\mathrm{h}$ & $\begin{array}{l}\text { Weight, } \\
\text { mg }\end{array}$ & $\begin{array}{c}\text { Water } \\
\text { content } \\
\text { wt } \% \\
=0.3968\end{array}$ & $M_{t} / M_{\text {inf }}$ \\
\hline 0.0000 & 237.51 & 0.0000 & 0.0000 & 0.0000 & 203.65 & 0.0000 & 0.0000 \\
\hline 0.1667 & 237.63 & 0.0505 & 0.0456 & 0.0833 & 203.73 & 0.0393 & 0.0343 \\
\hline 0.3333 & 237.71 & 0.0842 & 0.0760 & 0.2500 & 203.81 & 0.0786 & 0.0687 \\
\hline 0.5833 & 237.88 & 0.1558 & 0.1407 & 0.5000 & 203.99 & 0.1670 & 0.1459 \\
\hline 0.8333 & 238 & 0.2063 & 0.1863 & 0.7500 & 204.11 & 0.2259 & 0.1974 \\
\hline 1.3333 & 238.25 & 0.3116 & 0.2814 & 1.2500 & 204.28 & 0.3094 & 0.2704 \\
\hline 1.7500 & 238.35 & 0.3537 & 0.3194 & 1.7500 & 204.44 & 0.3879 & 0.3391 \\
\hline 2.7500 & 238.62 & 0.4673 & 0.4221 & 2.7500 & 204.7 & 0.5156 & 0.4506 \\
\hline 4.9167 & 238.95 & 0.6063 & 0.5475 & 4.9167 & 205 & 0.6629 & 0.5794 \\
\hline 7.9167 & 239.28 & 0.7452 & 0.6730 & 7.9167 & 205.29 & 0.8053 & 0.7039 \\
\hline 22.1667 & 239.86 & 0.9894 & 0.8935 & 22.1667 & 205.79 & 1.0508 & 0.9185 \\
\hline 31.1667 & 240.12 & 1.0989 & 0.9924 & 31.1667 & 205.98 & 1.1441 & 1.0000 \\
\hline 53.6667 & 240.13 & 1.1031 & 0.9962 & 53.6667 & 206 & 1.1539 & 1.0086 \\
\hline 75.9167 & 240.13 & 1.1031 & 0.9962 & 75.9167 & 205.98 & 1.1441 & 1.0000 \\
\hline 120.4167 & 240.14 & 1.1073 & 1.0000 & 120.4167 & 205.98 & 1.1441 & 1.0000 \\
\hline 191.9167 & 240.14 & 1.1073 & 1.0000 & 191.9167 & 205.98 & 1.1441 & 1.0000 \\
\hline
\end{tabular}




\section{APPENDIX IV}

\section{Derivation of exact solution and short times solutions to Fick's Law}

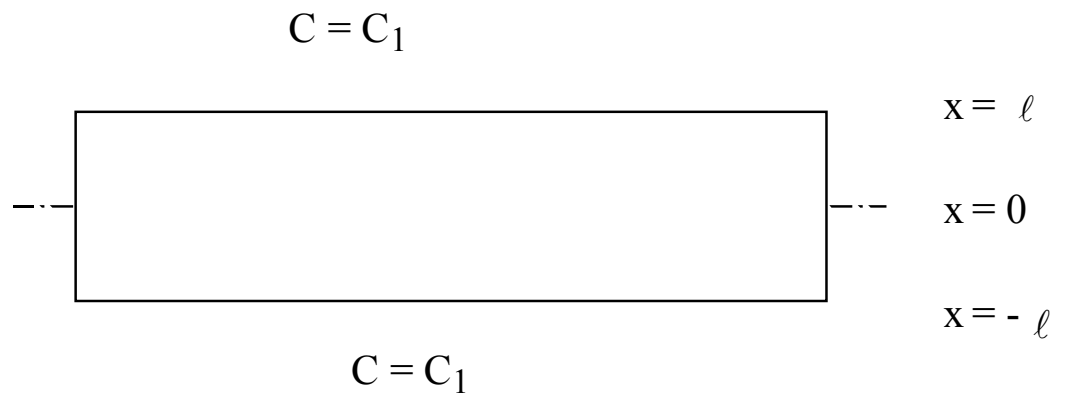

Figure A.6 Schematic of polymer film and boundary conditions.

Consider a sheet of polymer of thickness $2 \ell$ with initial solute concentration of $\mathrm{C}_{0}$. Let it be exposed to a constant solute concentration of $\mathrm{C}_{1}$ at time $\mathrm{t}=0$. Assuming the surface reaches the external concentration of $\mathrm{C}_{1}$ instantly. The diffusion of the solute into the polymer film can be obtained by solving the Fick's Second Law of Diffusion as follows,

$$
\frac{\partial C}{\partial t}=D \frac{\partial^{2} C}{\partial t^{2}}
$$

Boundary conditions,

$$
\begin{aligned}
& \mathrm{t}=0, \quad \mathrm{C}=\mathrm{C}_{0} \\
& \mathrm{t}>0, \quad \mathrm{x}= \pm \ell, \quad \mathrm{C}=\mathrm{C}_{1} \\
& t>0, \quad x=0, \quad \frac{\partial C}{\partial x}=0
\end{aligned}
$$


Consider,

$$
\theta=\frac{\mathrm{C}-\mathrm{C}_{0}}{\mathrm{C}_{1}-\mathrm{C}_{0}} ; \tau=\frac{\mathrm{Dt}}{\ell^{2}} ; \varepsilon=\frac{\mathrm{x}}{\ell}
$$

Then Equation A.18 becomes,

$$
\frac{\partial \theta}{\partial \tau}=\frac{\partial^{2} \theta}{\partial \varepsilon^{2}}
$$

with boundary conditions,

$$
\begin{array}{lll}
\tau=0, & \theta=0 & \ldots(\mathrm{iv}) \\
\varepsilon=1, & \theta=1 & \ldots(\mathrm{v}) \\
\varepsilon=0, & \frac{\partial \theta}{\partial \varepsilon}=0 & \ldots(\mathrm{vi})
\end{array}
$$

Taking Laplace Transform of equation A.19 and its boundary conditions, we have,

$$
\begin{array}{ll}
s \bar{\theta}-\theta(\varepsilon, 0)=\frac{\partial^{2} \bar{\theta}}{\partial \varepsilon^{2}}, & (\text { where } \bar{\theta}=\operatorname{LT}[\theta]) \\
\therefore s \bar{\theta}=\frac{\partial^{2} \bar{\theta}}{\partial \varepsilon^{2}}, & (\because \theta=0 \text { at } \tau=0)
\end{array}
$$


or $\frac{\partial^{2} \bar{\theta}}{\partial \varepsilon^{2}}=(\sqrt{\mathrm{s}})^{2} \bar{\theta}$

with boundary conditions,

$$
\begin{array}{ll}
\varepsilon=1, & \bar{\theta}=\frac{1}{\mathrm{~s}} \\
\varepsilon=0, & \frac{\partial \bar{\theta}}{\partial \varepsilon}=0
\end{array}
$$

Solving equation A.20 we get,

$$
\bar{\theta}=\operatorname{ACosh}(\sqrt{\mathrm{s} \varepsilon})+\operatorname{BSinh}(\sqrt{\mathrm{s} \varepsilon})
$$

On differentiating equation A.21, we get,

$$
\frac{\partial \bar{\theta}}{\partial \varepsilon}=\mathrm{A} \sqrt{\mathrm{s}} \operatorname{Sinh}(\sqrt{\mathrm{s} \varepsilon})+\mathrm{B} \sqrt{\mathrm{s}} \operatorname{Cosh}(\sqrt{\mathrm{s}} \varepsilon)
$$

Applying the boundary condition (vii) to equation (A.22),

$$
\begin{aligned}
& 0=\mathrm{A} \sqrt{\mathrm{s}}(0)+\mathrm{B} \sqrt{\mathrm{s}}(1) \\
& \Rightarrow \mathrm{B}=0 \\
& \therefore \bar{\theta}=\mathrm{ACOsh}(\sqrt{\mathrm{s}} \varepsilon)
\end{aligned}
$$


Applying boundary condition (vi) to equation (A.23),

$\frac{1}{\mathrm{~s}}=\mathrm{A} \operatorname{Cosh}(\sqrt{\mathrm{s}}) \Rightarrow \mathrm{A}=\frac{1}{\mathrm{~s} \operatorname{Cosh}(\sqrt{\mathrm{s}})}$

$\therefore \bar{\theta}=\frac{\operatorname{Cosh}(\sqrt{\mathrm{s} \varepsilon})}{\mathrm{s} \operatorname{Cosh}(\sqrt{\mathrm{s}})}$

Consider,

$\frac{\mathrm{N}(\mathrm{s})}{\mathrm{D}(\mathrm{s})}=\frac{\operatorname{Cosh}(\sqrt{\mathrm{s} \varepsilon})}{\mathrm{s} \operatorname{Cosh}(\sqrt{\mathrm{s}})}$

we have 2 poles, ie solutions of $\mathrm{D}(\mathrm{s})=0$,

$\mathrm{s}=0 \quad$ and $\quad \sqrt{\mathrm{s}}=\mathrm{i}\left[(2 \mathrm{n}+1) \frac{\pi}{2}\right], \quad \mathrm{n}=0,1,2 \ldots \ldots$

or $\quad \mathrm{s}_{\mathrm{n}}=0,-(2 \mathrm{n}+1)^{2} \frac{\pi^{2}}{4}, \quad \mathrm{n}=0,1,2 \ldots$ 
i.e. when $\mathrm{D}(\mathrm{s})=0$

$\mathrm{s}=0 \quad$ and $\quad \operatorname{Cosh}(\sqrt{\mathrm{s}})=0$

$\operatorname{Cosh}(\mathrm{x})=\operatorname{Cos}(\mathrm{x} / \mathrm{i})$

$\Rightarrow \operatorname{Cos}(\sqrt{\mathrm{s}} / \mathrm{i})=0$

$\Rightarrow \frac{\sqrt{\mathrm{s}}}{\mathrm{i}}=(2 \mathrm{n}+1) \frac{\pi}{2}$

or $\sqrt{\mathrm{s}}=\left[(2 \mathrm{n}+1) \frac{\pi}{2}\right] \mathrm{i}$

we have $\mathrm{F}(\tau)=\mathrm{L}^{-1}[\mathrm{~F}(\mathrm{~s})]=\sum_{0}^{\infty} \mathrm{a}_{\mathrm{n}}(\tau)$

where, $a_{n}=\frac{N\left(s_{n}\right)}{D^{\prime}\left(s_{n}\right)} e^{s_{n} \tau}$

Case (i), $s=0$

$a_{0}=\frac{N(0)}{D^{\prime}(0)} e^{0}$

$\mathrm{D}^{\prime}(\mathrm{s})=\operatorname{Cosh}(\sqrt{\mathrm{s}})+\frac{\sqrt{\mathrm{s}}}{2} \operatorname{Sinh}(\sqrt{\mathrm{s}})$

$\Rightarrow \mathrm{a}_{0}=\frac{\operatorname{Cosh}(0)}{\operatorname{Cosh}(0)+0}=\frac{1}{1}=1$ 
Case (ii),

$$
\begin{aligned}
& s=-(2 n+1)^{2} \frac{\pi^{2}}{4} \\
& a_{n}=\frac{\operatorname{Cosh}\left(i(2 n+1) \frac{\pi}{2}\right)}{\frac{\left[i(2 n+1) \frac{\pi}{2}\right]}{2} \operatorname{Sinh}\left(i(2 n+1) \frac{\pi}{2}\right)+\operatorname{Cosh}\left(i(2 n+1) \frac{\pi}{2}\right)} \exp \left[-(2 n+1)^{2} \frac{\pi^{2}}{4}\right], n=0,1,2 \ldots
\end{aligned}
$$

$\operatorname{Cosh}\left(i(2 n+1) \frac{\pi}{2}\right)=\operatorname{Cos}\left((2 n+1) \frac{\pi}{2}\right)=0$

$\operatorname{Sinh}(\mathrm{x})=\mathrm{i} \operatorname{Sin}(\mathrm{x} / \mathrm{i})$

$\therefore \operatorname{Sinh}\left(\mathrm{i}(2 \mathrm{n}+1) \frac{\pi}{2}\right)=\mathrm{iSin}\left((2 \mathrm{n}+1) \frac{\pi}{2}\right)=\mathrm{i}(-1)^{\mathrm{n}}$

$\therefore \mathrm{a}_{\mathrm{n}}=\frac{\operatorname{Cos}\left((2 \mathrm{n}+1) \frac{\pi}{2} \varepsilon\right)}{(2 \mathrm{n}+1) \frac{\pi}{4} \mathrm{i}^{2}(-1)^{\mathrm{n}}} \exp \left[-(2 \mathrm{n}+1)^{2} \frac{\pi^{2}}{4} \tau\right], \mathrm{n}=0,1,2 \ldots$

or, $\mathrm{a}_{\mathrm{n}}=-\frac{4}{\pi}\left(\frac{(-1)^{\mathrm{n}}}{(2 \mathrm{n}+1)} \exp \left[-(2 \mathrm{n}+1)^{2} \pi^{2} \frac{\mathrm{Dt}}{4 \ell^{2}}\right] \operatorname{Cos}\left((2 \mathrm{n}+1) \frac{\pi \varepsilon}{2}\right)\right), \mathrm{n}=0,1,2 \ldots$

$\therefore \theta=\frac{\mathrm{C}-\mathrm{C}_{0}}{\mathrm{C}_{1}-\mathrm{C}_{0}}=1-\frac{4}{\pi} \sum_{\mathrm{n}=0}^{\infty} \frac{(-1)^{\mathrm{n}}}{(2 \mathrm{n}+1)} \exp \left[-(2 \mathrm{n}+1)^{2} \pi^{2} \frac{\mathrm{Dt}}{4 \ell^{2}}\right] \operatorname{Cos}\left((2 \mathrm{n}+1) \pi \frac{\mathrm{x}}{2 \ell}\right)$ 
$\mathrm{M}_{\mathrm{t}}$, mass uptake in the sample at time $\mathrm{t}$ is given by,

$\mathrm{M}_{\mathrm{t}}=2 \int_{0}^{\mathrm{t}} \mathrm{D}\left(\frac{\partial \mathrm{C}}{\partial \mathrm{x}}\right)_{\mathrm{x}=\ell} \mathrm{dt}$

Assuming unit surface area.

From equation A.26, we have,

$\mathrm{C}=\mathrm{C}_{1}-\left(\mathrm{C}_{1}-\mathrm{C}_{0}\right) \frac{4}{\pi} \sum_{\mathrm{n}=0}^{\infty} \frac{(-1)^{\mathrm{n}}}{(2 \mathrm{n}+1)} \exp \left[-(2 \mathrm{n}+1)^{2} \frac{\pi^{2}}{4} \frac{\mathrm{Dt}}{4 \ell^{2}}\right] \operatorname{Cos}\left((2 \mathrm{n}+1) \pi \frac{\mathrm{x}}{2 \ell}\right)$

and,

$\frac{\partial \mathrm{C}}{\partial \mathrm{x}}=\left(\mathrm{C}_{1}-\mathrm{C}_{0}\right) \frac{4}{\pi} \sum_{\mathrm{n}=0}^{\infty} \frac{(-1)^{\mathrm{n}}}{(2 \mathrm{n}+1)} \exp \left[-(2 \mathrm{n}+1)^{2} \pi^{2} \frac{\mathrm{Dt}}{4 \ell^{2}}\right] \operatorname{Sin}\left((2 \mathrm{n}+1) \pi \frac{\mathrm{x}}{2 \ell}\right)\left((2 \mathrm{n}+1) \frac{\pi}{2 \ell}\right)$

$\left.\therefore \mathrm{D} \frac{\partial \mathrm{C}}{\partial \mathrm{x}}\right|_{\mathrm{x}=\ell}=\mathrm{D}\left(\mathrm{C}_{1}-\mathrm{C}_{0}\right) \frac{4}{\pi} \sum_{\mathrm{n}=0}^{\infty} \frac{(-1)^{\mathrm{n}}}{(2 \mathrm{n}+1)} \exp \left[-(2 \mathrm{n}+1)^{2} \pi^{2} \frac{\mathrm{Dt}}{4 \ell^{2}}\right](-1)^{\mathrm{n}}\left[(2 \mathrm{n}+1) \frac{\pi}{2 \ell}\right]$

$=2 \mathrm{D} \frac{\left(\mathrm{C}_{1}-\mathrm{C}_{0}\right)}{\ell} \sum_{\mathrm{n}=0}^{\infty} \exp \left[-(2 \mathrm{n}+1)^{2} \pi^{2} \frac{\mathrm{Dt}}{4 \ell^{2}}\right]$

$\therefore \mathrm{M}_{\mathrm{t}}=2 \int_{0}^{\mathrm{t}} 2 \mathrm{D} \frac{\left(\mathrm{C}_{1}-\mathrm{C}_{0}\right)}{\ell} \sum_{\mathrm{n}=0}^{\infty} \exp \left[-(2 \mathrm{n}+1)^{2} \pi^{2} \frac{\mathrm{Dt}}{4 \ell^{2}}\right] \mathrm{dt}$ 


$$
\begin{aligned}
& M_{t}=-\left.\frac{4 D}{\ell}\left(C_{1}-C_{0}\right) \sum_{n=0}^{\infty} \exp \left[-(2 n+1) \pi^{2} \frac{D t}{4 \ell^{2}}\right] \frac{4 \ell^{2}}{(2 n+1)^{2} \pi^{2} D}\right|_{0} ^{t} \\
& =\frac{4 \mathrm{D}}{\ell}\left(\mathrm{C}_{1}-\mathrm{C}_{0}\right)\left[-\left.\sum_{\mathrm{n}=0}^{\infty} \frac{4 \ell^{2}}{(2 \mathrm{n}+1)^{2} \pi^{2} \mathrm{D}} \exp \left[-(2 \mathrm{n}+1)^{2} \pi^{2} \frac{\mathrm{Dt}}{4 \ell^{2}}\right]\right|_{0} ^{\mathrm{t}}\right. \\
& =\frac{4 \mathrm{D}}{\ell}\left(\mathrm{C}_{1}-\mathrm{C}_{0}\right) \frac{4 \ell^{2}}{\mathrm{D}}\left[\sum_{\mathrm{n}=0}^{\infty} \frac{1}{(2 \mathrm{n}+1)^{2} \pi^{2}}-\sum_{\mathrm{n}=0}^{\infty} \frac{1}{(2 \mathrm{n}+1)^{2} \pi^{2}} \exp \left(-(2 \mathrm{n}+1)^{2} \pi^{2} \frac{\mathrm{Dt}}{4 \ell^{2}}\right)\right] \\
& \therefore \mathrm{M}_{\mathrm{t}}=16 \ell\left(\mathrm{C}_{1}-\mathrm{C}_{0}\right)\left[\frac{\pi^{2}}{8} \frac{1}{\pi^{2}}-\sum_{\mathrm{n}=0}^{\infty} \frac{1}{(2 \mathrm{n}+1)^{2} \pi^{2}} \exp \left(-(2 \mathrm{n}+1)^{2} \pi^{2} \frac{\mathrm{Dt}}{4 \ell^{2}}\right)\right] \\
& {\left[\because \sum_{\mathrm{n}=0}^{\infty} \frac{1}{(2 \mathrm{n}+1)^{2}}=\frac{\pi^{2}}{8}\right]} \\
& M_{t}=\frac{16 \ell}{8}\left(C_{1}-C_{0}\right)\left[1-\sum_{n=0}^{\infty} \frac{8}{(2 n+1)^{2} \pi^{2}} \exp \left(-(2 n+1)^{2} \pi^{2} \frac{D t}{4 \ell^{2}}\right)\right] \\
& \Rightarrow \frac{M_{t}}{M_{\infty}}=1-\sum_{n=0}^{\infty} \frac{8}{(2 n+1)^{2} \pi^{2}} \exp \left(-(2 n+1)^{2} \pi^{2} \frac{D t}{4 \ell^{2}}\right)
\end{aligned}
$$

where $2 \ell\left(C_{1}-C_{0}\right)=M_{\infty}$ 


\section{Derivation for short time}

From equation A.24, we have,

$\bar{\theta}=\frac{\operatorname{Cosh}(\sqrt{\mathrm{s} \varepsilon})}{\operatorname{s} \operatorname{Cosh}(\sqrt{\mathrm{s}})}$

expanding,

$\bar{\theta}=\frac{\mathrm{e}^{\sqrt{\mathrm{s} \varepsilon}}+\mathrm{e}^{-\sqrt{\mathrm{s} \varepsilon}}}{\mathrm{s}\left(\mathrm{e}^{\sqrt{\mathrm{s}}}-\mathrm{e}^{-\sqrt{\mathrm{s}}}\right)}$

$=\frac{\mathrm{e}^{\sqrt{\mathrm{s} \varepsilon}}+\mathrm{e}^{-\sqrt{\mathrm{s} \varepsilon}}}{\mathrm{S} \cdot \mathrm{e}^{\sqrt{\mathrm{s}}}\left(1+\mathrm{e}^{-2 \sqrt{\mathrm{s}}}\right)}$

or, $\frac{\mathrm{e}^{-\sqrt{\mathrm{s}}(1-\varepsilon)}+\mathrm{e}^{-\sqrt{\mathrm{s}}(1+\varepsilon)}}{\mathrm{s}} \cdot\left(1+\mathrm{e}^{-2 \sqrt{\mathrm{s}}}\right)^{-1}$

expanding $\left(1+\mathrm{e}^{-2 \sqrt{\mathrm{s}}}\right)^{-1}$ as a binomial expansion,

$\bar{\theta}=\frac{\mathrm{e}^{-\sqrt{\mathrm{s}}(1-\varepsilon)}+\mathrm{e}^{-\sqrt{\mathrm{s}}(1+\varepsilon)}}{\mathrm{s}} \cdot \sum_{\mathrm{n}=0}^{\infty}(-1)^{\mathrm{n}} \mathrm{e}^{-2 \mathrm{n} \sqrt{\mathrm{s}}}$ 


$$
\begin{aligned}
& {\left[\begin{array}{l}
(1+x)^{-1}=1-x+x^{2}+\ldots . \\
\therefore(1+x)^{-1}=\sum_{n=0}^{\infty}(-1)^{n} x^{n}
\end{array}\right]} \\
& \therefore \bar{\theta}=\sum_{\mathrm{n}=0}^{\infty}(-1)^{\mathrm{n}} \frac{\mathrm{e}^{-\sqrt{s}(1-\varepsilon+2 \mathrm{n})}}{\mathrm{s}}+\sum_{\mathrm{n}=0}^{\infty}(-1)^{\mathrm{n}} \frac{\mathrm{e}^{-\sqrt{\mathrm{s}}(1+\varepsilon+2 \mathrm{n})}}{\mathrm{s}} \\
& \theta=\mathrm{L}^{-1}[\bar{\theta}]=\sum_{\mathrm{n}=0}^{\infty}(-1)^{\mathrm{n}} \operatorname{erfc}\left(\frac{(1-\varepsilon+2 \mathrm{n})}{2 \sqrt{\tau}}\right)+\sum_{\mathrm{n}=0}^{\infty}(-1)^{\mathrm{n}} \operatorname{erfc}\left(\frac{(1+\varepsilon+2 \mathrm{n})}{2 \sqrt{\tau}}\right) \\
& \because \mathrm{L}^{-1}\left[\frac{1}{\mathrm{~s}} \mathrm{e}^{-\mathrm{k} \sqrt{\mathrm{s}}}\right]=\operatorname{erfc}\left(\frac{\mathrm{k}}{2 \sqrt{\mathrm{t}}}\right) \\
& \therefore \frac{\mathrm{C}-\mathrm{C}_{0}}{\mathrm{C}_{1}-\mathrm{C}_{0}}=\sum_{\mathrm{n}=0}^{\infty}(-1)^{\mathrm{n}} \operatorname{erfc}\left(\frac{(2 \mathrm{n}+1) \ell-\mathrm{x}}{2 \sqrt{\mathrm{Dt}}}\right)+\sum_{\mathrm{n}=0}^{\infty}(-1)^{\mathrm{n}} \operatorname{erfc}\left(\frac{(2 \mathrm{n}+1) \ell+\mathrm{x}}{2 \sqrt{\mathrm{Dt}}}\right) \\
& \text { or, } \frac{\mathrm{C}-\mathrm{C}_{0}}{\mathrm{C}_{1}-\mathrm{C}_{0}}=\sum_{\mathrm{n}=0}^{\infty}(-1)^{\mathrm{n}} \operatorname{erfc}\left(\frac{(2 \mathrm{n}+1)-\frac{\mathrm{x}}{\ell}}{2 \frac{\sqrt{\mathrm{Dt}}}{\ell}}\right)+\sum_{\mathrm{n}=0}^{\infty}(-1)^{\mathrm{n}} \operatorname{erfc}\left(\frac{(2 \mathrm{n}+1)+\frac{\mathrm{x}}{\ell}}{2 \frac{\sqrt{\mathrm{Dt}}}{\ell}}\right)
\end{aligned}
$$

From equation A.27 we have,

$$
\mathrm{M}_{\mathrm{t}}=2 \int_{0}^{\mathrm{t}} \mathrm{D}\left(\frac{\partial \mathrm{C}}{\partial \mathrm{x}}\right)_{\mathrm{x}=\ell} \mathrm{dt}
$$




$$
\begin{array}{r}
\mathrm{C}=\mathrm{C}_{0}+\left(\mathrm{C}_{1}-\mathrm{C}_{0}\right) \sum_{\mathrm{n}=0}^{\infty}(-1)^{\mathrm{n}} \operatorname{erfc}\left(\frac{(2 \mathrm{n}+1) \ell-\mathrm{x}}{2 \sqrt{\mathrm{Dt}}}\right)+\sum_{\mathrm{n}=0}^{\infty}(-1)^{\mathrm{n}} \operatorname{erfc}\left(\frac{(2 \mathrm{n}+1) \ell+\mathrm{x}}{2 \sqrt{\mathrm{Dt}}}\right) \\
\begin{aligned}
\frac{\partial C}{\partial x}=\left(C_{1}-C_{0}\right)\left[\sum_{n=0}^{\infty}(-1)^{\mathrm{n}}\left(\frac{-2}{\sqrt{\pi}}\right) \exp \left[\left(\frac{(2 \mathrm{n}+1) \ell-\mathrm{x}}{2 \sqrt{\mathrm{Dt}}}\right)^{2}\right]\left(-\frac{1}{2 \sqrt{\mathrm{Dt}}}\right)\right. \\
\left.+\sum_{\mathrm{n}=0}^{\infty}(-1)^{\mathrm{n}}\left(\frac{-2}{\sqrt{\pi}}\right) \exp \left[\left(\frac{(2 \mathrm{n}+1) \ell+\mathrm{x}}{2 \sqrt{\mathrm{Dt}}}\right)^{2}\right]\left(\frac{1}{2 \sqrt{\mathrm{Dt}}}\right)\right]
\end{aligned}
\end{array}
$$$$
\left.\frac{\partial \mathrm{C}}{\partial \mathrm{x}}\right|_{\mathrm{x}=\ell}=\left(\mathrm{C}_{1-} \mathrm{C}_{0}\right)\left[\sum_{\mathrm{n}=0}^{\infty}(-1)^{\mathrm{n}} \frac{\exp \left[\left(\frac{2 \mathrm{n} \ell+\ell-\ell}{2 \sqrt{\mathrm{Dt}}}\right)^{2}\right]}{\sqrt{\pi \mathrm{Dt}}}-\sum_{\mathrm{n}=0}^{\infty}(-1)^{\mathrm{n}} \frac{\exp \left[\left(\frac{2 \mathrm{n} \ell+\ell+\ell}{2 \sqrt{\mathrm{Dt}}}\right)^{2}\right]}{\sqrt{\pi \mathrm{Dt}}}\right]
$$$$
\left.\therefore \frac{\partial \mathrm{C}}{\partial \mathrm{x}}\right|_{\mathrm{x}=\ell}=\left(\mathrm{C}_{1}-\mathrm{C}_{0}\right)\left[\sum_{\mathrm{n}=0}^{\infty}(-1)^{\mathrm{n}} \frac{\exp \left(-\frac{\mathrm{n}^{2} \ell^{2}}{\mathrm{Dt}}\right)}{\sqrt{\pi \mathrm{Dt}}}-\sum_{\mathrm{n}=0}^{\infty}(-1)^{\mathrm{n}} \frac{\exp \left(-\frac{(\mathrm{n}+1)^{2} \ell^{2}}{\mathrm{Dt}}\right)}{\sqrt{\pi \mathrm{Dt}}}\right]
$$$$
M_{t}=2 \int_{0}^{t} D\left(C_{1}-C_{0}\right)\left[\sum_{n=0}^{\infty}(-1)^{n} \frac{\exp \left(-\frac{n^{2} \ell^{2}}{D t}\right)}{\sqrt{\pi \mathrm{Dt}}}-\sum_{n=0}^{\infty}(-1)^{\mathrm{n}} \frac{\exp \left(-\frac{(\mathrm{n}+1)^{2} \ell^{2}}{\mathrm{Dt}}\right)}{\sqrt{\pi \mathrm{Dt}}}\right] \mathrm{dt}
$$ 
Let, $I=\int_{0}^{\mathrm{t}} \sum_{0}^{\infty}(-1)^{\mathrm{n}} \frac{\exp \left(-\frac{\mathrm{n}^{2} \ell^{2}}{\mathrm{Dt}}\right)}{\sqrt{\pi \mathrm{Dt}}} \mathrm{dt}-\int_{0}^{\mathrm{t}} \sum_{0}^{\infty}(-1)^{\mathrm{n}} \sum_{\mathrm{n}=0}^{\infty}(-1)^{\mathrm{n}} \frac{\exp \left(-\frac{(\mathrm{n}+1)^{2} \ell^{2}}{\mathrm{Dt}}\right)}{\sqrt{\pi \mathrm{Dt}}} \mathrm{dt}$

Upon integration,

$$
\begin{aligned}
\mathrm{I}=\sum_{0}^{\infty}(-1)^{\mathrm{n}} 2\left[\frac{\sqrt{\pi \mathrm{Dt}}}{\pi \mathrm{D}} \exp \left(-\frac{\mathrm{n}^{2} \ell^{2}}{\mathrm{Dt}}\right)+\frac{\mathrm{n} \ell \pi}{\pi \mathrm{D}} \operatorname{erf}\left(\frac{\mathrm{n} \ell}{\sqrt{\mathrm{Dt}}}\right)\right]_{0}^{\mathrm{t}} \\
\quad-\sum_{\mathrm{n}=0}^{\infty}(-1)^{\mathrm{n}} 2\left[\frac{\sqrt{\pi \mathrm{Dt}}}{\pi \mathrm{D}} \exp \left(-\frac{(\mathrm{n}+1)^{2} \ell^{2}}{\mathrm{Dt}}\right)+\frac{(\mathrm{n}+1) \ell \pi}{\pi \mathrm{D}} \operatorname{erf}\left(\frac{(\mathrm{n}+1) \ell}{\sqrt{\mathrm{Dt}}}\right)\right]_{0}^{t}
\end{aligned}
$$

$$
\begin{aligned}
=\sum_{\mathrm{n}=0}^{\infty}(-1)^{\mathrm{n}} 2[( & {\left.\left[\sqrt{\frac{\mathrm{t}}{\pi \mathrm{D}}} \exp \left(-\frac{\mathrm{n}^{2} \ell^{2}}{\mathrm{Dt}}\right)+\frac{\mathrm{n} \ell}{\mathrm{D}} \operatorname{erf}\left(\frac{\mathrm{n} \ell}{\sqrt{\mathrm{Dt}}}\right)\right)-\left(\frac{\mathrm{n} \ell}{\mathrm{D}} \operatorname{erf}(\infty)+0\right)\right] } \\
& -\left[\sum_{\mathrm{n}=0}^{\infty}(-1)^{\mathrm{n}} 2\left[\left(\sqrt{\frac{\mathrm{t}}{\pi \mathrm{D}}} \exp \left(-\frac{(\mathrm{n}+1)^{2} \ell^{2}}{\mathrm{Dt}}\right)+\frac{(\mathrm{n}+1) \ell}{\mathrm{D}} \operatorname{erf}\left(\frac{(\mathrm{n}+1) \ell}{\sqrt{\mathrm{Dt}}}\right)\right)-\left(\frac{(\mathrm{n}+1) \ell}{\mathrm{D}} \operatorname{erf}(\infty)+0\right)\right]\right]
\end{aligned}
$$

$=\sum_{0}^{\infty}(-1)^{\mathrm{n}} 2\left[\sqrt{\frac{\mathrm{t}}{\pi \mathrm{D}}} \exp \left(-\frac{\mathrm{n}^{2} \ell^{2}}{\mathrm{Dt}}\right)-\frac{\mathrm{n} \ell}{\mathrm{D}}\left(1-\operatorname{erf}\left(\frac{\mathrm{n} \ell}{\sqrt{\mathrm{Dt}}}\right)\right)\right]$

$$
-\sum_{0}^{\infty}(-1)^{\mathrm{n}} 2\left[\sqrt{\frac{\mathrm{t}}{\pi \mathrm{D}}} \exp \left(-\frac{(\mathrm{n}+1)^{2} \ell^{2}}{\mathrm{Dt}}\right)-\frac{(\mathrm{n}+1) \ell}{\mathrm{D}}\left(1-\operatorname{erf}\left(\frac{(\mathrm{n}+1) \ell}{\sqrt{\mathrm{Dt}}}\right)\right)\right]
$$

$(1-\operatorname{erf}(\mathrm{x})=\operatorname{erfc}(\mathrm{x}))$ 


$$
\begin{aligned}
& =\sum_{\mathrm{n}=0}^{\infty}(-1)^{\mathrm{n}} 2\left[\sqrt{\frac{\mathrm{t}}{\pi \mathrm{D}}} \exp \left(-\frac{\mathrm{n}^{2} \ell^{2}}{\mathrm{Dt}}\right)-\frac{\mathrm{n} \ell}{\mathrm{D}} \operatorname{erfc}\left(\frac{\mathrm{n} \ell}{\sqrt{\mathrm{Dt}}}\right)\right] \\
& -\sum_{\mathrm{n}=0}^{\infty}(-1)^{\mathrm{n}} 2\left[\sqrt{\frac{\mathrm{t}}{\pi \mathrm{D}}} \exp \left(-\frac{(\mathrm{n}+1)^{2} \ell^{2}}{\mathrm{Dt}}\right)-\frac{(\mathrm{n}+1) \ell}{\mathrm{D}} \operatorname{erfc}\left(\frac{(\mathrm{n}+1) \ell}{\sqrt{\mathrm{Dt}}}\right)\right] \\
& =2 \sqrt{\frac{\mathrm{t}}{\mathrm{D}}}\left[\sum_{\mathrm{n}=0}^{\infty}(-1)^{\mathrm{n}}\left[\frac{1}{\sqrt{\pi}} \exp \left(-\frac{\mathrm{n}^{2} \ell^{2}}{\mathrm{Dt}}\right)-\frac{\mathrm{n} \ell}{\sqrt{\mathrm{Dt}}} \operatorname{erfc}\left(\frac{\mathrm{n} \ell}{\sqrt{\mathrm{Dt}}}\right)\right]\right. \\
& \left.-\sum_{\mathrm{n}=0}^{\infty}(-1)^{\mathrm{n}}\left[\frac{1}{\sqrt{\pi}} \exp \left(-\frac{(\mathrm{n}+1)^{2} \ell^{2}}{\mathrm{Dt}}\right)-\frac{(\mathrm{n}+1) \ell}{\sqrt{\mathrm{Dt}}} \operatorname{erfc}\left(\frac{(\mathrm{n}+1) \ell}{\sqrt{\mathrm{Dt}}}\right)\right]\right] \\
& \left(\operatorname{ierfc}(x)=\frac{1}{\sqrt{\pi}} e^{-x^{2}}-x \cdot \operatorname{erfc}(x)\right)
\end{aligned}
$$

Therefore we have,

$\Rightarrow \mathrm{I}=2 \sqrt{\frac{\mathrm{t}}{\mathrm{D}}}\left[\sum_{\mathrm{n}=0}^{\infty}(-1)^{\mathrm{n}} \operatorname{ierfc}\left(\frac{\mathrm{n} \ell}{\sqrt{\mathrm{Dt}}}\right)-\sum_{\mathrm{n}=0}^{\infty}(-1)^{\mathrm{n}} \operatorname{ierfc}\left(\frac{(\mathrm{n}+1) \ell}{\sqrt{\mathrm{Dt}}}\right)\right]$

\section{Expanding each term,}




$$
\begin{aligned}
=2 \sqrt{\frac{\mathrm{t}}{\mathrm{D}}}\left[\operatorname{ierfc}(0)-\operatorname{ierfc}\left(\frac{\ell}{\sqrt{\mathrm{Dt}}}\right)+\operatorname{ierfc}\left(\frac{2 \ell}{\sqrt{\mathrm{Dt}}}\right)+\ldots \ldots+(-1)^{\mathrm{n}} \operatorname{ierfc}\left(\frac{\mathrm{n} \ell}{\sqrt{\mathrm{Dt}}}\right)\right. \\
\left.\quad-\operatorname{ierfc}\left(\frac{\ell}{\sqrt{\mathrm{Dt}}}\right)+\operatorname{ierfc}\left(\frac{2 \ell}{\sqrt{\mathrm{Dt}}}\right)+\ldots \ldots-(-1)^{\mathrm{n}-1} \operatorname{ierfc}\left(\frac{\mathrm{n} \ell}{\sqrt{\mathrm{Dt}}}\right)-(-1)^{\mathrm{n}} \operatorname{ierfc}\left(\frac{(\mathrm{n}+1) \ell}{\sqrt{\mathrm{Dt}}}\right)\right]
\end{aligned}
$$

or,

$$
\mathrm{I}=2 \sqrt{\frac{\mathrm{t}}{\mathrm{D}}}\left[\frac{1}{\sqrt{\pi}}-2 \cdot \operatorname{ierfc}\left(\frac{\ell}{\sqrt{\mathrm{Dt}}}\right)+2 \cdot \operatorname{ierfc}\left(\frac{2 \ell}{\sqrt{\mathrm{Dt}}}\right)+\ldots \ldots+(-1)^{\mathrm{n}} 2 \cdot \operatorname{ierfc}\left(\frac{\mathrm{n} \ell}{\sqrt{\mathrm{Dt}}}\right)-\left.(-1)^{\mathrm{n}} \operatorname{ierfc}\left(\frac{(\mathrm{n}+1) \ell}{\sqrt{\mathrm{Dt}}}\right)\right|_{\mathrm{n} \rightarrow \infty}\right]
$$

$\operatorname{ierfc}(\infty)=0$

$\Rightarrow \mathrm{I}=2 \sqrt{\frac{\mathrm{t}}{\mathrm{D}}}\left[\frac{1}{\sqrt{\pi}}+2 \sum_{\mathrm{n}=1}^{\infty}(-1)^{\mathrm{n}} \operatorname{ierfc}\left(\frac{\mathrm{n} \ell}{\sqrt{\mathrm{Dt}}}\right)\right]$

$\therefore \mathrm{M}_{\mathrm{t}}=2 \mathrm{D}\left(\mathrm{C}_{1}-\mathrm{C}_{0}\right)\left[2 \sqrt{\frac{\mathrm{t}}{\mathrm{D}}}\left(\frac{1}{\sqrt{\pi}}+2 \sum_{\mathrm{n}=1}^{\infty}(-1)^{\mathrm{n}} \operatorname{ierfc}\left(\frac{\mathrm{n} \ell}{\sqrt{\mathrm{Dt}}}\right)\right)\right]$

$\mathrm{M}_{\mathrm{t}}=4\left(\mathrm{C}_{1}-\mathrm{C}_{0}\right) \sqrt{\mathrm{Dt}}\left[\left(\frac{1}{\sqrt{\pi}}+2 \sum_{\mathrm{n}=0}^{\infty}(-1)^{\mathrm{n}} \operatorname{ierfc}\left(\frac{\mathrm{n} \ell}{\sqrt{\mathrm{Dt}}}\right)\right)\right]$

$\mathrm{M}_{\mathrm{t}}=4 \ell\left(\mathrm{C}_{1}-\mathrm{C}_{0}\right) \sqrt{\frac{\mathrm{Dt}}{\ell^{2}}}\left[\left(\frac{1}{\sqrt{\pi}}+2 \sum_{\mathrm{n}=0}^{\infty}(-1)^{\mathrm{n}} \operatorname{ierfc}\left(\frac{\mathrm{n} \ell}{\sqrt{\mathrm{Dt}}}\right)\right)\right]$ 
$\therefore \frac{\mathrm{M}_{\mathrm{t}}}{\mathrm{M}_{\infty}}=2 \sqrt{\frac{\mathrm{Dt}}{\ell^{2}}}\left[\left(\frac{1}{\sqrt{\pi}}+2 \sum_{\mathrm{n}=0}^{\infty}(-1)^{\mathrm{n}} \operatorname{ierfc}\left(\frac{\mathrm{n} \ell}{\sqrt{\mathrm{Dt}}}\right)\right)\right]$

where, $2 \ell\left(\mathrm{C}_{1}-\mathrm{C}_{0}\right)=\mathrm{M}_{\infty}$

Equation A.3.11 can be reduced to a simpler form when considering initial slope of the sorption curve.

When $\mathrm{x}=2.2, \operatorname{ierfc}(\mathrm{x})=0.00035$

Therefore, considering the smallest case when $\mathrm{n}=1$, for $\frac{\ell}{\sqrt{\mathrm{Dt}}}>2.2$, i.e. $\frac{\mathrm{Dt}}{4 \ell^{2}}<0.05$, the ierfc term can be neglected, and equation A.3.10 reduces to,

$$
\frac{\mathrm{M}_{\mathrm{t}}}{\mathrm{M}_{\infty}}=\frac{4}{\sqrt{\pi}} \sqrt{\frac{\mathrm{Dt}}{4 \ell^{2}}}
$$

Using equation A.3.1, the diffusion coefficient can be determined from the initial slope of the $\frac{\mathrm{M}_{\mathrm{t}}}{\mathrm{M}_{\infty}}$ versus $\mathrm{t}^{1 / 2} / 2 \ell$, considering points upto $\frac{\mathrm{M}_{\mathrm{t}}}{\mathrm{M}_{\infty}}=0.5 . \because \frac{\ell}{\sqrt{\mathrm{Dt}}}=2.2$ corresponds to $\frac{\mathrm{M}_{\mathrm{t}}}{\mathrm{M}_{\infty}}=0.5$ 


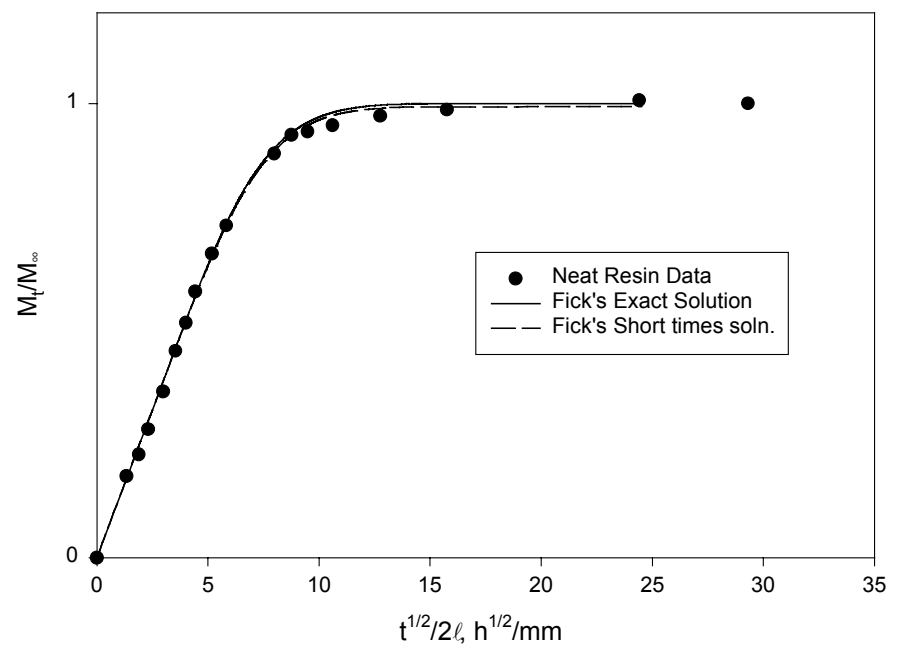

Figure A.7 Comparison between Fick's Law Exact solution and Fick's Law solution for short times. Data are for neat vinyl ester resins. 


\section{Derivation of Tortuosity in Polymer Nanocomposites}

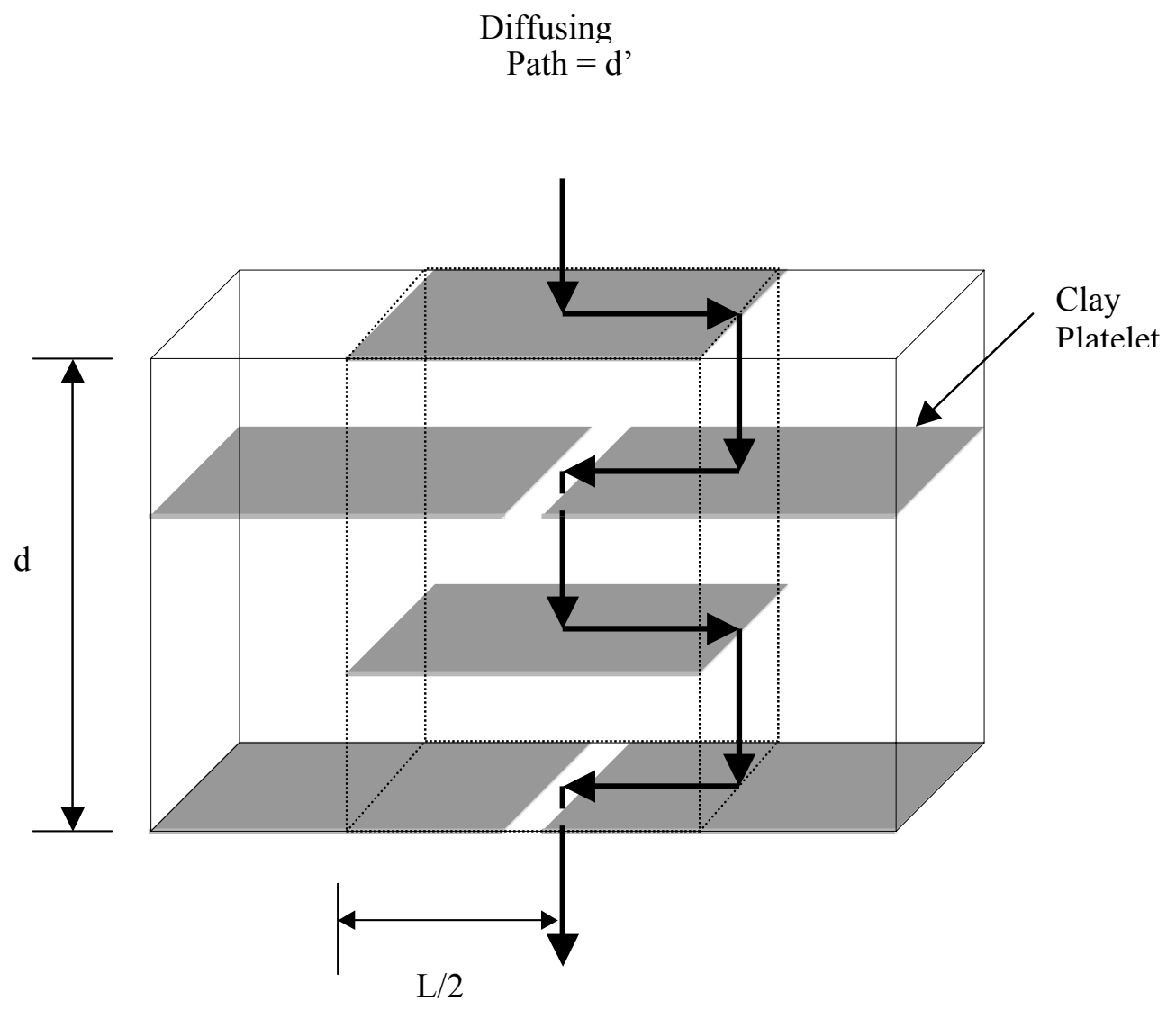

Figure A8. Volume element of a polymer nanocomposite film.

Consider a portion of the polymer nanocomposite film (shown by the dotted cube) of surface area equal to that of a clay platelet. The thickness of the film, or the distance a diffusing molecule has to traverse in the absence of clay is, $d$. Due to tortuousity, the new path length of the diffusing molecule will be longer than d, and is referred to as d'. This 
path will be longer than $\mathrm{d}$, by a distance equal to $n \frac{L}{2}$, where $\mathrm{n}$ is the effective number of clay platelets encountered during dffusion, and $\mathrm{L}$ is the length of each plate.

Volume fraction of clay platelets in the volume of interest,

$\mathrm{V}_{\mathrm{f}}=\frac{\mathrm{n} \cdot \mathrm{A} \cdot \mathrm{W}}{\mathrm{A} \cdot \mathrm{d}}$

where $\mathrm{A}$ is the surface area of the volume element.

$\therefore \mathrm{V}_{\mathrm{f}}=\frac{\mathrm{n} \cdot \mathrm{W}}{\mathrm{d}}$

or, $\mathrm{n}=\mathrm{V}_{\mathrm{f}} \frac{\mathrm{d}}{\mathrm{W}}$

New path length, $d^{\prime}=d+n \frac{L}{2}$

$\therefore \mathrm{d}^{\prime}=\mathrm{d}+\mathrm{d} \frac{\mathrm{L}}{2 \mathrm{~W}} \mathrm{~V}_{\mathrm{f}}$

or,

Tortuosity, $\tau=\frac{\mathrm{d}}{\mathrm{d}^{\prime}}=\frac{1}{\left[1+\left(\frac{\mathrm{L}}{2 \mathrm{~W}}\right) \mathrm{V}_{\mathrm{f}}\right]}$

Hence, realtive permaebility is given by the expression,

$$
\frac{\mathrm{P}_{\mathrm{c}}}{\mathrm{P}_{\mathrm{p}}}=\frac{1}{1+\left(\frac{\mathrm{L}}{2 \mathrm{~W}}\right) \mathrm{V}_{\mathrm{f}}}
$$

